\title{
Kinetics of Tap Water Dechlorination and Aquatic Health Impacts of Selected Dechlorination Chemicals
}

\author{
Submitted by \\ Bhagya N. Weerasinghe \\ Hon. B.Sc., University of Toronto, Canada \\ A thesis submitted to the Faculty of Graduate Studies and Research in partial fulfillment \\ of the requirements for the degree of \\ Master of Applied Science*
}

Ottawa-Carleton Institute for Environmental Engineering

Carleton University

Ottawa, Ontario, Canada

Copyright (C) 2008 B.N. Weerasinghe

*The Master of Applied Science in Environmental Engineering Program is a joint program with the University of Ottawa, administered by the Ottawa-Carleton Institute for Environmental Engineering 


$\begin{array}{ll}\begin{array}{l}\text { Library and } \\ \text { Archives Canada }\end{array} & \begin{array}{l}\text { Bibliothèque et } \\ \text { Archives Canada }\end{array} \\ \begin{array}{l}\text { Published Heritage } \\ \text { Branch }\end{array} & \begin{array}{l}\text { Direction du } \\ \text { Patrimoine de l'édition }\end{array} \\ \begin{array}{l}\text { 395 Wellington Street } \\ \text { Ottawa ON K1A 0N4 } \\ \text { Canada }\end{array} & \begin{array}{l}\text { 395, rue Wellington } \\ \text { Ottawa ON K1A 0N4 } \\ \text { Canada }\end{array}\end{array}$

Your file Votre référence ISBN: 978-0-494-44060-5 Our file Notre référence ISBN: 978-0-494-44060-5

NOTICE:

The author has granted a nonexclusive license allowing Library and Archives Canada to reproduce, publish, archive, preserve, conserve, communicate to the public by telecommunication or on the Internet, loan, distribute and sell theses worldwide, for commercial or noncommercial purposes, in microform, paper, electronic and/or any other formats.

The author retains copyright ownership and moral rights in this thesis. Neither the thesis nor substantial extracts from it may be printed or otherwise reproduced without the author's permission.
AVIS:

L'auteur a accordé une licence non exclusive permettant à la Bibliothèque et Archives Canada de reproduire, publier, archiver, sauvegarder, conserver, transmettre au public par télécommunication ou par l'Internet, prêter, distribuer et vendre des thèses partout dans le monde, à des fins commerciales ou autres, sur support microforme, papier, électronique et/ou autres formats.

L'auteur conserve la propriété du droit d'auteur et des droits moraux qui protège cette thèse. $\mathrm{Ni}$ la thèse ni des extraits substantiels de celle-ci ne doivent être imprimés ou autrement reproduits sans son autorisation.
In compliance with the Canadian Privacy Act some supporting forms may have been removed from this thesis.

While these forms may be included in the document page count, their removal does not represent any loss of content from the thesis.
Conformément à la loi canadienne sur la protection de la vie privée, quelques formulaires secondaires ont été enlevés de cette thèse.

Bien que ces formulaires aient inclus dans la pagination, il n'y aura aucun contenu manquant.

\section{Canada}




\begin{abstract}
The kinetics of seven dechlorination agents (DA) was studied to identify the efficacy of dechlorination under variable dosage, mixing (periodic/continuous), and $\mathrm{pH}$ conditions $(6.5-8.6$ and/or $>9)$. Dechlorination reactions at $1 \mathrm{x}$ stoichiometric dosage $(\mathrm{mg} \mathrm{DA} / \mathrm{mg}$ $\mathrm{Cl}_{2}$ ) of the DAs are rapid in most cases, but not instantaneous and in some cases needed more than stoichiometric dosage to ensure a near zero residual level $(0.02 \mathrm{mg} / \mathrm{L}$ total residual chlorine, as required by CEPA (1999)). Dechlorination kinetic analysis revealed reactions were either pseudo-first or zero order with respect to total chlorine concentration in solution at the $10 \mathrm{x}$ stoichiometric dosage and second order overall at $2-$ 4x stoichiometric dosages. 48-hour aquatic toxicity tests were conducted using Daphnia magna to identify the acute (short-term) toxicity affects of the dechlorination chemicals over a range of concentrations $(0-200 \mathrm{mg} / \mathrm{L})$. Sodium sulfite and thiosulfate were found to have the least aquatic mortality effects while hydrogen peroxide and calcium thiosulfate had the most deleterious effects.
\end{abstract}

Key words: dechlorination kinetics, dechlorination, aquatic toxicity, sulfur salts, thiosulfates 


\section{Acknowledgements}

I would like to take this opportunity to thank everyone who helped me in various ways to make this thesis project possible.

I would like to extend my greatest gratitude to my research supervisor, Dr. Onita Basu. Without your guidance, advice and encouragements this thesis project would not have been possible.

I would also like to thank Professor Susan Logie for keeping me motivated to write and providing me with valuable feedback on my draft reports. Thank you, Dr. Deniz Karman for your advice on the data analysis and helping me improve the quality of my research.

I also would like to acknowledge the Region of Niagara for funding the analytical equipment used in this project and Canada Colors Limited for providing me with cost information for the chemicals.

I would like to acknowledge Dr. Marie Tudoret-Chow, Environmental Engineering Laboratory Technologist, for your assistance in providing laboratory space, ordering supplies and always lending me a helping hand when assistance was needed. Thank you, Mr. Peter Mosher, Manager of Science Stores and Chemistry at Carleton University, for providing me with the initial stock of chemicals for the aquatic toxicity testing.

Also, a special thank you goes to Dr Bernard Vigneault, Program Manager at the Metals and the Environment at Natural Resources Canada, and Ms. Maureen McKeague for providing the initial Daphnia magna stock cultures and necessary procedures to maintain the cultures.

I am really grateful to Nigel De Souza for all the assistance you provided me with the dechlorination experiments.

Last but not least, I want to thank my family and those most dear to me, especially Thaminda Perera, for their support, patience and understanding throughout this project. 


\section{Table of Contents}

ABSTRACT

ACKNOWLEDGEMENTS.................................................................................... III

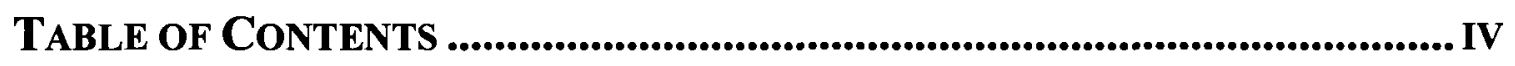

LIST OF NOMENCLATURE.............................................................. VI

LIST OF TABLES.................................................................................. VII

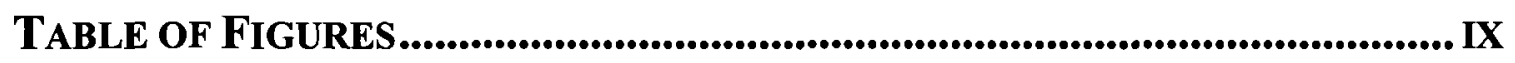

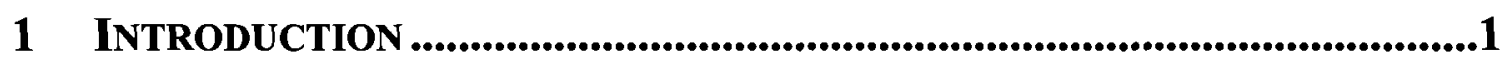

1.1 Rationale for this Study .................................................................................................. 4

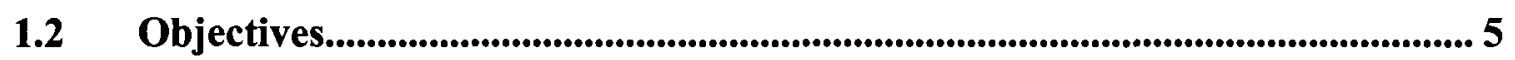

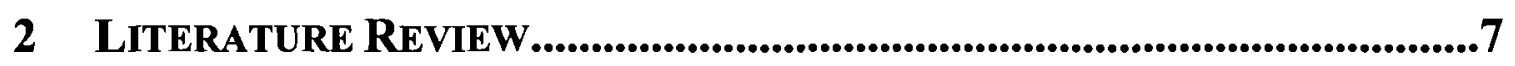

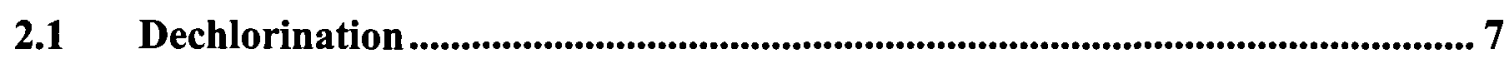

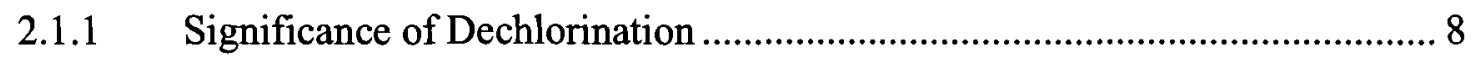

2.1.2 Introduction to Selected Dechlorination Chemicals .................................... 10

2.2 Selection Criteria for Dechlorination Agents in Wastewater Applications... 22

2.2.1 Chemical Dosage and Cost ..................................................................... 22

2.2.2 Contact Time for Reaction Completion and Mixing Requirements ............. 26

2.3 Health Impacts of Dechlorination Chemicals.................................................... 29

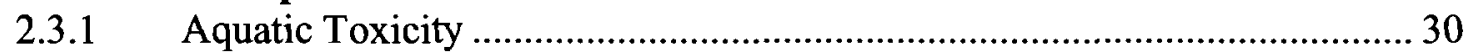

2.3.2 Human Health Effects........................................................................ 38

3 METHODOLOGY ............................................................................44

3.1 Dechlorination Experiments: Materials and Methods ....................................... 44

3.1.1 Dechlorination Agents Tested..................................................................5

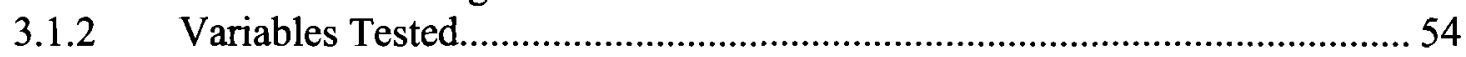

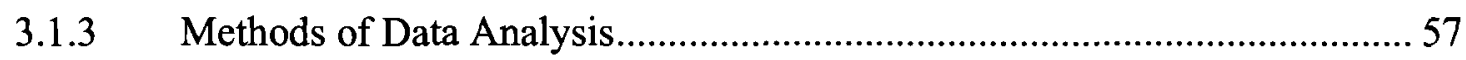

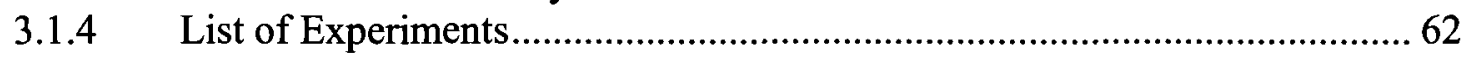

3.2 Aquatic Toxicity Testing: Daphnia Experiments............................................... 63

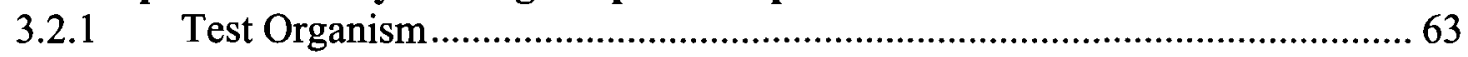

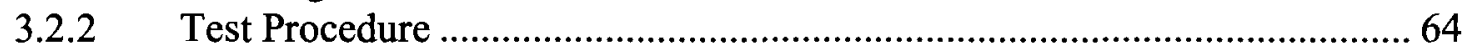

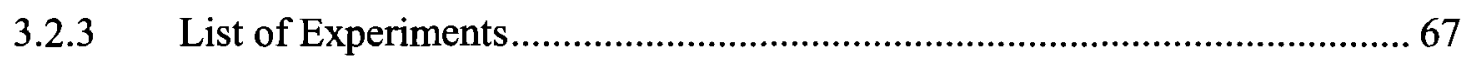

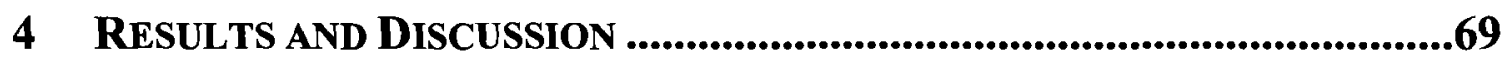

4.1 Dechlorination Experiments ............................................................................ 70

4.1.1 Order of Dechlorination Reactions ........................................................ 71

4.1.2 Impact of Tested Variables on the Dechlorination Rate ................................ 83

4.1.3 Summary of Dechlorination Results............................................................ 106

4.2 Acute Toxicity Tests: Daphnia magna Experiments......................................... 109 


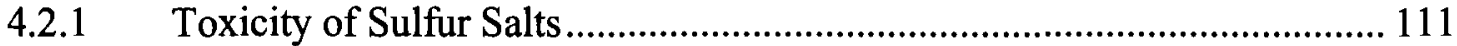

4.2.2 Toxicity of Thiosulfates................................................................... 115

4.2.3 Toxicity of Hydrogen Peroxide and Ascorbic Acid .................................. 117

4.2.4 Comparison of the Acute Toxicity of the Dechlorination Agents .............. 119

4.3 Applications in Wastewater Treatment Plant Design .................................. 125

5 CONCLUSIONS AND FUTURE WORK............................................... 133

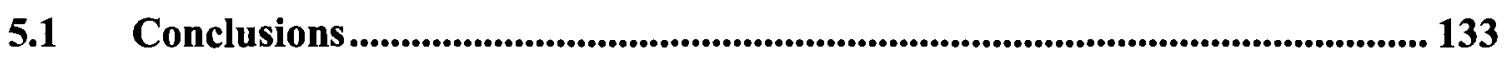

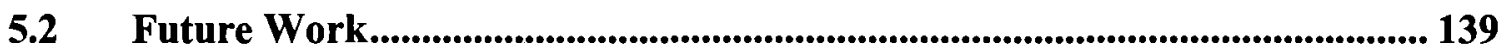

REFERENCES................................................................................................... 141

Appendices................................................................................................................................. 147

Appendix 1: NFPA Hazard Chart.............................................................................. 147

Appendix 2: Dechlorination Agent Dosage and Cost Calculations .......................... 148

Appendix 3: Plots for Reaction Order Determination .......................................... 151

Appendix 4: Plots for LC50 Determination........................................................ 157 


\section{List of Nomenclature}

\begin{tabular}{|l|l|}
\hline AA & Ascorbic Acid \\
\hline CEPA & Canadian Environmental Protection Act, 1999 \\
\hline CTS & Calcium Thiosulfate \\
\hline DA & Dechlorination Agent \\
\hline DI water & De-ionized water \\
\hline DO & Dissolved Oxygen \\
\hline EC & Environment Canada \\
\hline EC 50 & $\begin{array}{l}\text { Effective Concentration: DA concentration which induces a } \\
50 \% \text { effect to the response compared to the control or response } \\
\text { halfway between the baseline and maximum }\end{array}$ \\
\hline FC & Free Chlorine \\
\hline HP & Hydrogen Peroxide \\
\hline LC 50 & $\begin{array}{l}\text { Lethal Concentration: the concentration that reduces the } \\
\text { survival by 50\% }\end{array}$ \\
\hline NOEC & $\begin{array}{l}\text { No Observed Effect Concentration: the highest concentration of } \\
\text { material in a toxicity test that has no statistically significant } \\
\text { adverse effects on the exposed organisms as compared to the } \\
\text { controls }\end{array}$ \\
\hline MSDS & Material Safety Data Sheet \\
\hline MWWE & Municipal Wastewater Effluent \\
\hline NFPA & National Fire Protection Association (United States) \\
\hline OEL & Occupational Exposure Limit \\
\hline RPM & Revolutions Per Minute \\
\hline SBS & Sodium Bisulfite \\
\hline SMBS & Sodium Metabisulfite \\
\hline SS & Sodium Sulfite \\
\hline STS & Sodium Thiosulfate \\
\hline TC & Total Chlorine \\
\hline &
\end{tabular}




\section{List of Tables}

Table 1: Comparison of various wastewater disinfection options.................................3

Table 2: Advantages and disadvantages of selected dechlorination chemicals...............21

Table 3: Stoichiometric dosages and cost of various dechlorination chemicals...............24

Table 4: Potential human health effects of dechlorination chemicals ...............................39

Table 5: Comparison of the composition of municipal wastewater effluent and the test water of this experimental study.

Table 6: Preparation of hard water with hardness between $160-180 \mathrm{mg} / \mathrm{L}$ as $\mathrm{CaCO}_{3} \ldots . .51$

Table 7: List of experiments undertaken for each of the seven dechlorination chemicals. 62

Table 8: Concentrations of DA used in 48 hours Daphnia magna mortality testing

Table 9: Apparent reaction orders (with respect to total chlorine concentration) and rate constants for the seven dechlorination chemicals tested at $10 \mathrm{x}$ stoichiometric ratio. ........76

Table 10: Second order reaction rate constants $(\mathrm{L} / \mathrm{mol} . \mathrm{s})$ for the dechlorination reactions of sodium bisulfite and ascorbic acid at $2 \mathrm{x}$ and $3 \mathrm{x}$ stoichiometric dosage.

Table 11: Second order reaction rate constants (L/mol.s) for the dechlorination reactions of sodium sulfite, metabisulfite, and sodium thiosulfate at $2-4 \mathrm{x}$ stoichiometric dosage 80

Table 12: Dechlorination reaction rate constants obtained at various dosages of the dechlorination chemicals.

Table 13: Calculated reaction rate constants for the various mixing regimes of sodium sulfite and ascorbic acid.

Table 14: Calculated reaction rate constants for the various mixing regimes of sodium bisulfite, metabisulfite, and sodium thiosulfate.

Table 15: Calculated reaction rate constants for calcium thiosulfate under various mixing regimes 100

Table 16: Calculated reaction rate constants for calcium thiosulfate under various mixing regimes.

Table 17: Impact of mixing and solution $\mathrm{pH}$ on the dechlorination rate 106

Table 18: Results summary for dechlorination experiments 106

Table 19: The average dissolved oxygen (\%) and $\mathrm{pH}$ values for the three replicates with various concentrations of sodium sulfite, bisulfite and metabisulfite. 
Table 20: The average dissolved oxygen (\%) and $\mathrm{pH}$ values for the three replicates with various concentrations of sodium and calcium thiosulfate.

Table 21: The average dissolved oxygen (\%) and $\mathrm{pH}$ values for the three replicates with various concentrations of ascorbic acid and hydrogen peroxide.

Table 22: Type of aquatic toxicity caused by the dechlorination chemicals. ................120

Table 23: 48 hour $\mathrm{LC}_{50}$ values derived using the Graphical Method (USEPA, 2002)...122

Table 24: Acute toxicity test results summary 123

Table 25: Calculated required reaction times for $10 \mathrm{x}$ stoichiometric dosages of DAs to achieve $0.02 \mathrm{mg} / \mathrm{L}$ residual with a 1,2 and $3 \mathrm{mg} / \mathrm{L}$ initial concentration of chlorine.....128 


\section{Table of Figures}

Figure 1: Distribution diagram for the chlorine species $\mathrm{HOCl}$ and $\mathrm{OCl}^{-}$in water at various $\mathrm{pH}$ levels.

Figure 2: Daphnia magna

Figure 3: Experimental setup

Figure 4: Detailed schematic of the experimental setup. Not drawn to scale.

Figure 5: Three-blade propeller used to mix the experimental solution.

Figure 6: DULCOMETER ${ }^{\circledR}$ D1C online continuous $\mathrm{pH}$ and chlorine residual analyzer..49

Figure 7: Hach® DR2800 spectrophotometer and free/total chlorine powder pillows.....49

Figure 8: Culture jars in the incubator with the timed "cool-white" fluorescent light $\sim 30$

$\mathrm{cm}$ above the water surface.

Figure 9: Measured total chlorine concentrations overtime following the addition of sodium metabisulfite to the experimental solution.

Figure 10 (a), (b), (c): Unimolecular pseudo first order tests for sodium. Data for the $10 \mathrm{x}$ stoichiometric dosage at continuous low intensity mixing and $\mathrm{pH} 6.5-8.5$ was used in the analysis.

Figure 11: Second order tests undertaken for the $2-3 \mathrm{x}$ stoichiometric dosages of sodium bisulfite, calcium thiosulfate and ascorbic acid.

Figure 12: Second order tests for the $2-3 x$ stoichiometric dosages of sodium sulfite, sodium metabisulfite, sodium thiosulfate and calcium thiosulfate.

Figure 13: Second order test for the 1x stoichiometric dosages of Sodium bisulfite, sodium metabisulfite, calcium thiosulfate, and hydrogen peroxide.

Figure 14: Kinetic results for sodium sulfite, sodium thiosulfate and ascorbic acid under 1x stoichiometric dosage. .84

Figure 15: Kinetic data for sodium sulfite, thiosulfate and ascorbic acid under various dosages $(2-4 \mathrm{x})$. The solution $\mathrm{pH}$ was between $6.5-8.5$ and the samples were continuously mixed at 130 RPM.

Figure 16: Kinetic results for sodium bisulfite, metabisulfite, calcium thiosulfate and hydrogen peroxide at the $1 \mathrm{x}$ stoichiometric dosage.

Figure 17(a), (b): Kinetic results for the sodium bisulfite, metabisulfite and calcium thiosulfate under varying dosages $(2-4 x)$. 
Figure 18: Reaction kinetics for sodium sulfite at various mixing regimes tested. .95

Figure 19: Reaction kinetics for ascorbic acid at various mixing regimes tested. .95

Figure 20: Reaction kinetics for sodium bisulfite at various mixing regimes tested 97

Figure 21(a), (b) \& (c): Reaction kinetics for sodium thiosulfate, hydrogen peroxide and sodium metabisulfite at various mixing regimes tested.

Figure 22: Reaction kinetics for 10x stoichiometric dosage of sodium metabisulfite at various mixing regimes tested.

Figure 23(a) \& (b): Reaction rate constants for sodium metabisulfite and calcium thiosulfate at various mixing regimes tested. 100

Figure 24: Reaction rate constants for sodium metabisulfite and sodium thiosulfate at the two $\mathrm{pH}$ regimes tested.

Figure 25: Reaction rate constants for ascorbic acid at the two $\mathrm{pH}$ regimes tested.........104

Figure 26: Reaction rate constants for sodium sulfite at the two $\mathrm{pH}$ regimes tested.......105

Figure 27: Reaction rate constants for calcium thiosulfate at the two $\mathrm{pH}$ regimes. 105

Figure 28: Percentage survival of Daphnia magna for various concentrations of sodium sulfite, bisulfite and metabisulfite.

Figure 29: Percentage survival of Daphnia magna for various concentrations of the sodium thiosulfate and calcium thiosulfate.

Figure 30: Percentage survival of Daphnia magna for various concentrations of hydrogen peroxide and ascorbic acid.

Figure 31: Percentage survival for the control, sodium bisulfite, metabisulfite, ascorbic acid, calcium thiosulfate and hydrogen peroxide. Sodium sulfite and sodium thiosulfate were omitted as these chemicals did not cause any significant changes to the percentage survival.

Figure 32: Percentage survival data for Daphnia magna for the $2 \mathrm{mg} / \mathrm{L}$ concentration of the seven dechlorination agents.

Figure 33: Percentage survival data for Daphnia magna for the $20 \mathrm{mg} / \mathrm{L}$ concentration of the seven dechlorination agents.

Figure 34 : Percentage survival data for Daphnia magna for the $200 \mathrm{mg} / \mathrm{L}$ concentration of the seven dechlorination agents. 


\section{Chapter 1}

\section{Introduction}

Municipal wastewater effluents (MWWEs), one of the largest single effluent discharges (by volume) in Canada (Environment Canada (EC), 2001), was estimated to be 14.4 million $\mathrm{m}^{3} /$ day of treated wastewater in 1999 (EC, 2001b). Prior to treatment, MWWE contains a noxious mix of human waste, suspended solids, debris, and a variety of chemicals from residential, commercial and industrial processes (EC, 2001b). MWWE not only contains toxic compounds and material that will lead to a high dissolved oxygen demand in receiving waters, but it also contains disease-causing microorganisms (eg $E$. Coli) that could potentially be harmful to humans. Consequently, the wastewater effluent is treated and disinfected to minimize its impact on the aquatic environment. The purpose of disinfection is to remove pathogenic microorganisms, using a variety of chemical and physical disinfectants, prior to discharging the water into natural water bodies. Disinfection of the effluent is an essential step in maintaining good water quality of fresh water bodies that support aquatic species, contact and non-contact recreation, or 
serve as a source of potable water. Chlorine is the most popular disinfectant for wastewater treatment facilities across North America, because of its effectiveness in achieving the desired microbial inactivation at a low cost and due to its wide availability.

The Canadian Environmental Protection Act, 1999 (CEPA 1999), declared chlorinated municipal wastewater effluents as toxic to aquatic biota, and identified the effluent as a priority for risk management action. As a result, chlorine in the disinfected wastewater effluent is required to be less than $0.02 \mathrm{mg} / \mathrm{L}$ as $\mathrm{Cl}_{2}$ by 2010 . In order to meet this regulatory requirement, there are two main options available for the wastewater treatment facilities: neutralize or remove the chlorine in disinfected wastewater using common dechlorination chemicals or carbon adsorption (USEPA, 2000), or switch to another disinfectant method such as ultraviolet (UV) treatment or ozonation. However, the UV treatment could be costly due to high energy consumption as a result of high absorbance of UV light by wastewater (Macauley et al., 2006), and suspended particles in wastewater could reduce the effectiveness of UV disinfection and increase the required dosage (Loge et al., 1999; Parker \& Darby, 1995). Ozonation is currently not a preferred option by wastewater treatment facilities because ozone is expensive to produce, requires on-site generation and immediate use, and has high operational and maintenance costs (EPA Victoria, 2002). The advantages and disadvantages of various available wastewater disinfection options are tabulated in Table 1. Thus many of the treatment facilities still use chlorine as the disinfectant and neutralize the toxic chlorine using dechlorination chemicals prior to discharge. 
Table 1: Comparison of various wastewater disinfection options.

\begin{tabular}{|c|c|c|c|}
\hline \multicolumn{4}{|l|}{ Effectiveness Against } \\
\hline Bacteria & High & High & High \\
\hline Viruses & Low to medium & High & High \\
\hline Parasites & Low & High & Not fully assessed \\
\hline \multicolumn{4}{|l|}{ Practicality } \\
\hline Process Control & Well Developed & Developing & Developing \\
\hline Complexity Maintenance and & Simple to moderate & Complex & Simple to moderate \\
\hline Cleaning & Low to moderate & $\begin{array}{l}\text { Moderate to } \\
\text { intensive }\end{array}$ & Intensive \\
\hline \multicolumn{4}{|l|}{ Reliability } \\
\hline & High & High & Medium \\
\hline \multicolumn{4}{|c|}{ Costs (depending on size of plant) } \\
\hline Operation & Medium 1 & Medium $^{1}$ & Medium $^{1}$ \\
\hline Capital (small to medium plant) & Medium & High & Low to Medium \\
\hline Capital (medium to large plant) & Low to Medium & High & Medium to high \\
\hline \multicolumn{4}{|l|}{ Adverse Effects } \\
\hline Safety Risk: Transportation & Yes & No & No \\
\hline Safety Risk: on-site & Substantial & Moderate & Minimal \\
\hline $\begin{array}{l}\text { Fish and macro-invertebrate } \\
\text { toxicity }\end{array}$ & Toxic $^{3}$ & Unlikely & No \\
\hline Formation of toxic by-products & Potential & Unknown & Unknown \\
\hline Disposal of cleaning products & No & No & Yes \\
\hline High Energy consumption & No & Yes & Yes \\
\hline
\end{tabular}

Adapted from EPA Vicotoria (2002) modified from USEPA (1992)

${ }^{1}$ The ranking of the three methods varies with the size of the system design

${ }^{2}$ The toxic residual chlorine can be reduced by dechlorination

The process of removing residual chlorine from disinfected wastewater prior to its discharge into the natural environment is known as dechlorination. The objective of dechlorination is to reduce all chlorine-produced oxidants to a non-reactive halide form (Helz \& Nweke, 1995) via chemical reactions. Since stringent regulations governing effluent chlorine levels are in place in Quebec and in the United States for some time (Tikkanen et al., 2001), kinetics of dechlorination reactions should be well studied. However, there is a lack of published research studies on the kinetics of the reactions between the dechlorination chemicals and chlorine under varying dosages of the dechlorination agent, mixing and $\mathrm{pH}$ conditions. 
Dechlorination agents (DAs) are added to the municipal wastewater effluent to reduce the deleterious effects of chlorine on aquatic species. Water that has been chlorinated and then dechlorinated is reported to be far less toxic to aquatic organisms than either unchlorinated or chlorinated effluent (EC, 2003). Nevertheless, the dechlorination agents, known to be less harmful than chlorine, might also pose a threat to the aquatic species in receiving streams. Thus, it is important to investigate the aquatic toxicity of common dechlorination chemicals. Even though the environmental benefits to the dechlorination of wastewater effluent prior to discharge has been the focus of research for many years, potential aquatic and human health impacts of DAs have not been well studied (Ryon et al., 2002). When choosing a dechlorination agent to treat the wastewater effluent, knowing the aquatic and human health impacts of the chemical exposure becomes important, because the receiving natural rivers and lakes support contact and non-contact recreation, aquatic life and serve as a portable source of water.

\subsection{Rationale for this Study}

In order to ensure that the effluent is completely neutralized and the dechlorination reactions are optimized, it is important to have a better understanding of the kinetics of dechlorination reactions. This research into the kinetics of dechlorination reactions should help wastewater engineers and operations staff in selecting the appropriate dechlorination agent, applying the proper dosage, allowing for sufficient contact time and adequate mixing, as well as understanding the influence of $\mathrm{pH}$ regimes and identifying economical constraints. The study of the aquatic and human health impacts associated with the use of dechlorination chemicals at various concentrations will help the wastewater facility managers and policy makers to make accurate decisions regarding the 
most suitable dechlorination chemical based on minimum human and aquatic health impacts. Thus, this research study will investigate the dechlorination kinetics and aquatic toxicity of selected dechlorination chemicals.

\subsection{Objectives}

The main objectives of this experimental study are as follows:

1. Investigate and compare:

- the reaction kinetics of several dechlorination agents with chlorine

- the efficacy (in terms of the reaction time) of dechlorination under a range of conditions stoichiometric dosages, mixing, $\mathrm{pH}$

2. Assess and identify:

- the acute (short-term) toxicity affects of dechlorination chemicals to Daphnia magna

- the least harmful dechlorination chemical to be used in practice
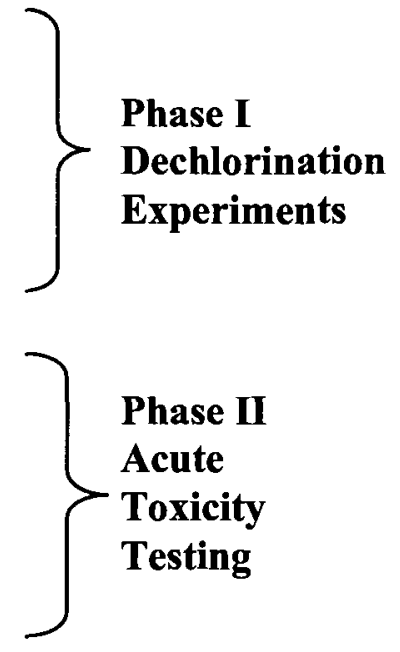

This research study was conducted in two separate phases to fulfill the above objectives.

The first phase of the study focused on investigating and comparing the reaction kinetics of several dechlorination agents with chlorine in municipal wastewater through laboratory experiments. The objectives of these experiments were to investigate the rate and the efficacy of dechlorination, with respect to reaction time, under a range of dosages, $\mathrm{pH}$ and mixing conditions in chlorinated tap water to assess for changes on the dechlorination rate. In the second phase of the study, the objective was on identifying and assessing the acute (short-term) toxicity of selected dechlorination chemicals to dominant aquatic herbivore Daphnia magna through the use of acute toxicity tests conducted in the laboratory according to the Environment Canada method for acute 
toxicity testing $(\mathrm{EC}, 1990)$. Percentage mortality of Daphnia magna was investigated under various concentrations of the dechlorination chemicals to identify the least harmful dechlorination chemical to be used in practice.

The remaining chapters will present the necessary background on dechlorination chemicals and their health impacts, a detailed description of the experimental methodology, the results of the dechlorination experiments and the aquatic toxicity testing and a discussion of the significance of the experimental data as well as conclusions and recommendations of the study. Chapter 2 is a review of literature pertaining to the significance of dechlorination, selected dechlorination chemicals, selection criteria for dechlorination chemicals, and the impacts of these chemicals on aquatic and human health. Chapter 3 includes a description of the detailed experimental methodology of the dechlorination experiments and aquatic toxicity testing undertaken in the laboratory. Chapter 4 presents the results that were obtained in the experimental studies and discusses the significance of these results. Chapter 5 summarizes the main findings and recommendations for future research. 


\section{Chapter 2}

\section{Literature Review}

This chapter includes a review of the literature related to the significance of dechlorination, chemistry of the selected dechlorination chemicals, selection criteria for dechlorination chemicals, and the impacts of these chemicals on aquatic and human health.

\subsection{Dechlorination}

The following sections present the significance of the dechlorination of disinfected municipal wastewater effluent, and introduce the physical and chemical properties of selected dechlorination chemicals, and their chemistry with chlorine. The selection criteria for dechlorination chemicals in municipal wastewater applications are also discussed. 


\subsubsection{Significance of Dechlorination}

Dechlorination is the process of partially or completely removing residual chlorine from disinfected wastewater by chemical or physical treatment prior to discharge into the natural environment or into the drinking water system (i.e. for superchorinated waters) ( Helz \& Nweke, 1995; US Army, 1988; USEPA, 2000). In 1999, an estimated 14.4 million $\mathrm{m}^{3} /$ day of treated wastewater was discharged into Canadian fresh water bodies, making municipal wastewater effluents (MWWEs) one of the largest single effluent discharges in the country (Environment Canada (EC), 2001b). Since MWWE contains toxic compounds, and material and disease-causing microorganisms (fecal-coliforms), it is disinfected before being discharged into natural freshwater bodies (using a variety of chemical and physical disinfectants). The most commonly used chemical disinfectants are chlorine-based disinfectants (chlorine gas, chloramines and chlorine dioxide) and ozone. Chlorine and chloramines have become an attractive disinfectant for wastewater treatment facilities across North America, because of their effectiveness in achieving desired microbial inactivation, low cost and wide availability. (EC, 2001b) A brief description of chlorination chemistry is included below.

\section{Chlorination Chemistry}

Chlorine is added to wastewater either in the form of gas $\left(\mathrm{Cl}_{2}\right)$ or as hypochlorite salts (e.g sodium hypochlorite, $\mathrm{NaOCl}$ ). When chlorine (gas) is dispersed in water it rapidly hydrolyses as can be seen in the following reaction:

$$
\mathrm{Cl}_{2}+\mathrm{H}_{2} \mathrm{O} \rightarrow \mathrm{HOCl}+\mathrm{H}^{+}+\mathrm{Cl}
$$


At $25^{\circ} \mathrm{C}$, the equilibrium constant $\left(\mathrm{K}_{\mathrm{eq}}\right)$ for this reaction is reported to be $4.5 \times 10^{4} \mathrm{M}^{-1}$. In dilute solutions with $\mathrm{pH}$ values of 3 or greater, this forward reaction is essentially complete (USEPA, 2007b). Depending on the $\mathrm{pH}$ of the solution, at $20^{\circ} \mathrm{C}$, hypochlorous acid ( $\mathrm{HOCl})$ dissociates (see Figure 1) into hypochlorite ion $\left(\mathrm{OCl}^{-}\right)$as follows:

$$
\mathrm{HOCl} \leftrightarrow \mathrm{OCl}^{-}+H^{+} \quad p K_{a}=7.6
$$

In addition, the $\mathrm{HOCl}$ and $\mathrm{OCl}^{-}$ions, also known as free chlorine, are powerful oxidants and readily react with millimole (mmol) concentrations of reduced nitrogen (in the form of ammonia, organic amines, and amides) present in wastewater, resulting in the formation of chloramines (Helz \& Nweke, 1995). Chloramines, also known as combined chlorine, exist in three forms: monochloramine, dichloramine, and

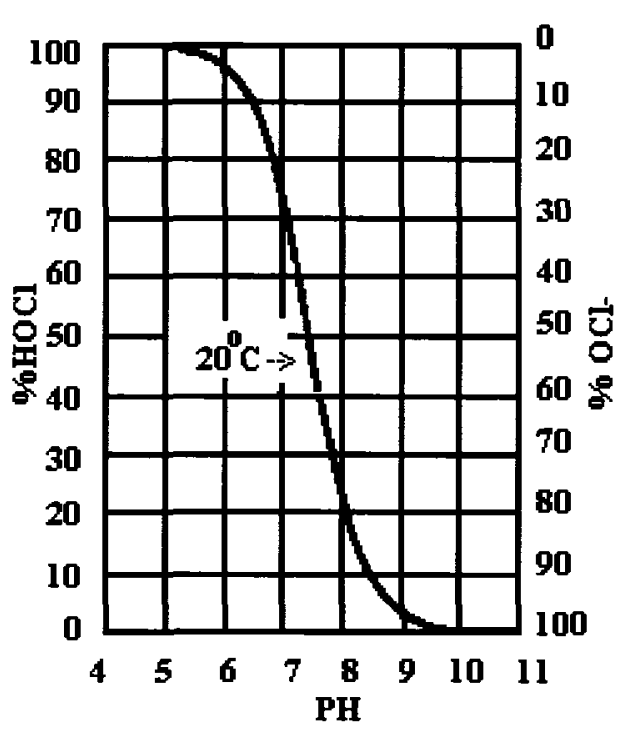

Figure 1: Distribution diagram for the chlorine species $\mathrm{HOCl}$ and $\mathrm{OCl}^{-}$in water at various $\mathrm{pH}$ levels.

Adapted From: www.uq.edu.au

trichloramine. Thus, chlorine being a powerful oxidant is an effective disinfectant for the purpose of wastewater treatment.

Although chlorinated wastewater has been directly discharged into Canadian freshwater bodies in the past, there have been increasing concerns about the impact of chlorine residuals and chlorination byproducts on aquatic biota (EC, 2001b). Consequently, under the Canadian Environmental Protection Act, 1999 (CEPA, 1999), chlorinated municipal wastewater effluents were recognized to be toxic and were identified as a priority for risk 
management action. After recognizing the potential negative effects of chlorine on the aquatic life of the receiving water bodies, Environment Canada published a Proposed Notice in the Canada Gazette (June $7^{\text {th }}, 2003$ ) requiring certain owners of wastewater systems to prepare and implement pollution prevention plans for inorganic chloramines and chlorinated wastewater effluents (chlorine) under the Canadian Environmental Protection Act, 1999 (CEPA, 1999). All wastewater facilities with an effluent release to surface water greater than or equal to $5000 \mathrm{~m}^{3} /$ day, were required to have total residual chlorine concentrations no more than $0.02 \mathrm{mg} / \mathrm{L}$.

Although the use of dechlorination chemicals has been the main dechlorination strategy utilized by treatment facilities for many years (USEPA, 2000; EC, 2003), there is a lack of published research on the reaction kinetics between these dechlorination chemicals and chlorine. Having an understanding of reaction kinetics and the associated aquatic and human health impacts of these chemicals should help wastewater facility managers and policy makers to choose the most suitable dechlorination chemical. Section 2.1.2 includes a discussion of seven dechlorination agents that are currently in use for various applications including wastewater treatment. These seven dechlorination compounds include three sulfur compounds, two thiosulfates, ascorbic acid, and hydrogen peroxide.

\subsubsection{Introduction to Selected Dechlorination Chemicals}

Many dechlorination strategies are currently used in practice, including injection of sulfur compounds, thiosulfates, ascorbic acid, and hydrogen peroxide and carbon adsorption (USEPA, 2000). Injection of sulfur compounds (e.g. sulfur dioxide $\left(\mathrm{SO}_{2}\right)$, sodium sulfite ( $\mathrm{SS}-\mathrm{Na}_{2} \mathrm{SO}_{3}$ ), sodium bisulfite ( $\mathrm{SBS}-\mathrm{NaHSO}_{3}$ ), sodium metabisulfite (SMBS - 
$\left.\mathrm{Na}_{2} \mathrm{~S}_{2} \mathrm{O}_{5}\right)$ ) and carbon adsorption are amongst the most commonly used strategies for dechlorination (USEPA, 2000). Due to ease of handling, sulfur dioxide gas is primarily used in large facilities (EC, 2003), while small facilities prefer sodium sulfite and bisulfite due to the ease of control and handling of these chemicals (USEPA, 2000). SMBS hydrolyzes to SBS when added to water, which is a method utilized by many researchers as a source of bisulfite for experimental purposes (Yonkos et al., 2001). As a result of the high costs associated with carbon adsorption, it is not a widely used dechlorination method in the wastewater industry. Alternatively, dechlorination agents such as sodium thiosulfate ( $\mathrm{STS}-\mathrm{Na}_{2} \mathrm{~S}_{2} \mathrm{O}_{3}$ ), calcium thiosulfate (CTS $-\mathrm{CaS}_{2} \mathrm{O}_{3}$ ), hydrogen peroxide $\left(\mathrm{HP}-\mathrm{H}_{2} \mathrm{O}_{2}\right)$ and ascorbic acid $\left(\mathrm{AA}-\mathrm{C}_{5} \mathrm{H}_{5} \mathrm{O}_{5} \mathrm{CH}_{2} \mathrm{OH}\right)$ are used for many dechlorination applications, including wastewater treatment, due to their effectiveness in neutralizing chlorine. The following subsections further discuss seven dechlorination agents that are of interest in the subsequent experimental studies of this research project.

\subsubsection{Sodium Sulfite (SS)}

Sodium sulfite $\left(\mathrm{Na}_{2} \mathrm{SO}_{3}\right)$, available in powder/crystalline and tablet form, undergoes the following reaction with free chlorine:

$$
\underset{\text { Sodium sulfite }}{\mathrm{Na}_{2} \mathrm{SO}_{3}}+\underset{\text { Hypochlorous acid }}{\mathrm{HOCl}} \rightarrow \underset{\text { Sodium sulfate }}{\mathrm{Na}_{2} \mathrm{SO}_{4}}+\underset{\text { Hydrochloric acid }}{\mathrm{HCl}}
$$

SS is available in tablet form, making it easier to store, handle and apply, compared to solutions or powders. SS may reduce the solution $\mathrm{pH}$ because it produces hydrochloric acid as a product of the reaction with chlorine, and $1.78 \mathrm{mg}$ of SS is required to remove 1 $\mathrm{mg}$ of chlorine. Reducing the $\mathrm{pH}$ of the water may pose a threat to the aquatic biota. SS, 
like other sulfur compounds (Ryon et al., 2002), is a reducing agent and is reported to scavenge oxygen (Tikkanen et al., 2001) by the following reaction:

$$
\underset{\text { Sodium sulfite }}{2 \mathrm{Na}_{2} \mathrm{SO}_{3}}+\mathrm{O}_{2} \rightarrow \underset{\text { Sodium sulfate }}{2 \mathrm{Na}_{2} \mathrm{SO}_{4}}
$$

Theoretically, $1 \mathrm{mg}$ of SS is calculated to scavenge $0.127 \mathrm{mg}$ of oxygen (See Appendix 2).

\subsubsection{Sodium Bisulfite (SBS)}

Available as a white powder, granules or clear liquid solution, sodium bisulfite $\left(\mathrm{NaHSO}_{3}\right)$ is highly soluble in water. It undergoes the following reactions with free chlorine:

$$
\underset{\text { Sodium bisulfite }}{\mathrm{NaHSO}_{3}}+\underset{\text { Hypochlorous acid }}{\mathrm{HOCl}} \rightarrow \underset{\text { Sodium bisulfate }}{\mathrm{NaHSO}_{4}}+\underset{\text { Hydrochloric acid }}{\mathrm{HCl}}
$$

To remove $1 \mathrm{mg}$ of chlorine, $1.47 \mathrm{mg}$ of SBS is required and 1.38 parts of alkalinity (as $\mathrm{CaCO}_{3}$ ) is consumed per 1 part of chlorine removed (EC, 2003). SBS is also an oxygen scavenger (Ryon et al., 2002) according to the following reaction:

$$
\underset{\text { Sodium bisulfite }}{2 \mathrm{NaHSO}_{3}}+\mathrm{O}_{2} \rightarrow 2 \mathrm{Na}^{+}+2 \mathrm{H}^{+}+2 \mathrm{SO}_{4}^{-2}
$$

SBS may crystallize at room temperature. Also, because of its high viscosity of 3.64 $\mathrm{mPa}$.s compared to $1.00 \mathrm{mPa} . \mathrm{s}$ for water at $20^{\circ} \mathrm{C}$, this dechlorination agent is difficult to handle. Also, SBS is a highly acidic solution ( $\mathrm{pH}$ of $1 \% \mathrm{w} / \mathrm{v}$ SBS solution $=4.3$ ), which in combination with the production of hydrochloric acid during the reaction may lower the $\mathrm{pH}$ of the receiving water (Tikkanen et al., 2001). 


\subsubsection{Sodium Metabisulfite (SMBS)}

Similar to sodium bisulfite, sodium metabisulfite $\left(\mathrm{Na}_{2} \mathrm{~S}_{2} \mathrm{O}_{5}\right)$ is preferred by small treatment facilities due to its availability as a liquid in various concentrations (EC, 2003), as well as white crystals or powder form (USEPA, 2007a). SMBS reacts with free chlorine as follows:

$$
\underset{\text { Sodium metabisulfite }}{\mathrm{Na}_{2} \mathrm{~S}_{2} \mathrm{O}_{5}}+2 \mathrm{Cl}_{2}+3 \mathrm{H}_{2} \mathrm{O} \rightarrow \underset{\text { Sodium bisulfite }}{2 \mathrm{NaHSO}_{4}}+\underset{\text { Hydrochloric acid }}{4 \mathrm{HCl}}
$$

SMBS hydrolyzes to SBS when added to water, which is a method utilized by researchers to produce bisulfite for experimental purposes (Yonkos et al., 2001). To remove $1 \mathrm{mg}$ of chlorine residual $1.34 \mathrm{mg}$ of SMBS is required, and similar to bisulfite, 1.38 parts of alkalinity $\left(\mathrm{as}_{\mathrm{CaCO}}\right.$ ) is consumed per each part of chlorine removed (Worley, 2000). Since the above chlorine neutralization reaction produced hydrochloric acid, it may lower the $\mathrm{pH}$ of the solution. Similar to SBS, even a solution of $1 \%$ SMBS is very acidic and has a $\mathrm{pH}$ of 4.3. In addition, the reaction between SMBS and chlorine results in the production of hydrochloric acid, which may further reduce the $\mathrm{pH}$ of the receiving water.

\subsubsection{Sodium Thiosulfate (STS)}

In the United States, sodium thiosulfate $\left(\mathrm{Na}_{2} \mathrm{~S}_{2} \mathrm{O}_{3}\right)$ has been widely used in the wastewater industry (Tikkanen et al., 2001), however, in Canada its main applications have been in aquarium dechlorination (EC, 2003), the pulp and paper industry and in bench-scale chlorination/dechlorination studies (White, 1999). STS is an odorless, colorless, transparent, monoclinic crystal, which undergoes multiple reactions with free and combined chlorine. 
The STS dosage required for dechlorination is $\mathrm{pH}$ dependent. At low $\mathrm{pH}$ values, the acidity in the solution causes the thiosulfate ion to be unstable and disproportionate into sulfite and elemental sulfur as shown below.

$$
\mathrm{S}_{2} \mathrm{O}_{3}^{2-}+\mathrm{H}^{+} \rightarrow \mathrm{HSO}_{3}^{-}+\mathrm{S}
$$

For instance at a $\mathrm{pH}$ of 11 the stoichiometric dosage is $0.56 \mathrm{mg} \mathrm{STS} / \mathrm{mg} \mathrm{Cl}$, while at a $\mathrm{pH}$ of 8 the dosage increases to $1.86 \mathrm{mg} \mathrm{STS} / \mathrm{mg} \mathrm{Cl}_{2}$ (Tchobanoglous, 2003; Worley, 2000). The following reaction is only stoichiometric at $\mathrm{pH} 2$ and yields sodium bisulfate (Tchobanoglous, 2003; Worley, 2000).

$$
\underset{\text { Sodium thiosulfate }}{\mathrm{Na}_{2} \mathrm{~S}_{2} \mathrm{O}_{3}}+\mathrm{Cl}_{2}+5 \mathrm{H}_{2} \mathrm{O} \rightarrow \underset{\text { Sodium bisulfate }}{2 \mathrm{NaHSO}_{4}}+8 \mathrm{HCl}
$$

If excess thiosulfate is present with chlorine in the solution, sulfur dioxide (which smells like a rotten egg) is produced according to the following reaction. Elemental sulfur is also produced in this reaction.

$$
\underset{\text { Sodium thiosulfate }}{\mathrm{Na}_{2} \mathrm{~S}_{2} \mathrm{O}_{3}}+\underset{\text { Hydrochloric Acid }}{2 \mathrm{HCl}} \rightarrow \underset{\text { Sodium chloride }}{2 \mathrm{NaCl}}+\mathrm{H}_{2} \mathrm{O}+\mathrm{S}+\underset{\text { Sulfur dioxide }}{\mathrm{SO}_{2}}
$$

STS is available in anhydrous $\left(\mathrm{Na}_{2} \mathrm{~S}_{2} \mathrm{O}_{3}\right)$ as well as pentahydrate $\left(\mathrm{Na}_{2} \mathrm{~S}_{2} \mathrm{O}_{3} .5 \mathrm{H}_{2} \mathrm{O}\right)$ form. The anhydrous form has a lower solubility in water compared to the pentahydrate form that is readily soluble. Although STS is a reducing agent, it scavenges comparably less oxygen than sodium sulfite, bisulfite or metabisulfite. The required contact time for STS to react with chlorine is higher than for most other dechlorination agents (Ryon et al., 2002). Also, excess thiosulfate released into rivers and streams may promote thiobacillus bacterial growth, especially during low flow conditions (Tikkanen et al., 2001). In the presence of oxygen, thiobacillus bacteria have the unique ability to convert hydrogen 
sulfide gas into sulfuric acid as follows (EPA,1998), reducing the $\mathrm{pH}$ of the receiving waters (Ryon et al., 2002; Tikkanen et al., 2001).

$$
\underset{\text { hydrogen sulffide }}{\mathrm{H}_{2} \mathrm{~S}_{(\mathrm{g})}}+\underset{\text { atmospheric oxygen }}{2 \mathrm{O}_{2}} \stackrel{\text { thiobacillus bacteria }}{\longrightarrow} \underset{\text { Sulfuric acid }}{\mathrm{H}_{2} \mathrm{SO}_{4}}
$$

\subsubsection{Calcium Thiosulfate (CTS)}

Available as a clear crystalline substance, calcium thiosulfate $\left(\mathrm{CaS}_{2} \mathrm{O}_{3}\right)$ has a faintly sulfurous odor (Wang et al., 2006). It reacts with free as well as combined chlorine. CTS undergoes the following reaction with free chlorine (Tikkanen et al., 2001) producing calcium sulfate in the process.

$$
\underset{\text { Calcium thiosulfate }}{\mathrm{CaS}_{2} \mathrm{O}_{3}}+\underset{\text { Hypochlorous acid }}{4 \mathrm{HOCl}}+\mathrm{H}_{2} \mathrm{O} \underset{\text { Calcium sulfate }}{\mathrm{CaSO}_{4}}+\underset{\text { Hydrochloric acid }}{4 \mathrm{HCl}}+\underset{\text { Sulfuric acid }}{\mathrm{H}_{2} \mathrm{SO}_{4}}
$$

At pH 7.35, $0.99 \mathrm{mg}$ of CTS is required to neutralize $1 \mathrm{mg}$ of residual chlorine; however at $\mathrm{pH} 11$, only $0.45 \mathrm{mg} \mathrm{CTS}$ is required for the reaction. This variation in the required dosage of CTS with variable $\mathrm{pH}$ is because at $\mathrm{pH} 7.35$, the chlorine species (e.g. $\mathrm{HOCl}$ to $\mathrm{OCl}^{-}$) are in $\sim 1: 1$ ratio but at $\mathrm{pH} 11$, all of the chlorine in solution is in the $\mathrm{OCl}^{-}$form (see Figure 1).

Although, CTS is found to be non-toxic to aquatic species, one disadvantage to the usage of CTS is that the reactions using stoichiometric concentrations are rather slow and require nearly five minutes for complete neutralization (Wang et al., 2006). CTS is not an oxygen scavenger and does not produce sulfur dioxide gas as a reaction by-product like the other sodium-based dechlorination agents (Wang et al., 2006). If the wastewater effluent is over-dosed with CTS, milky-colored suspended solids are produced, which add to the turbidity of the water. CTS also promotes the growth of thiobacillus bacteria if 
released in excess into receiving water bodies (Tikkanen et al., 2001), which might result in the case of cooling water and disinfected wastewater dechlorination operations (Wang et al., 2006). Another concern with using CTS is that it produces both hydrochloric and sulfuric acid in the dechlorination reaction, which could substantially lower the $\mathrm{pH}$ of the solution.

\subsubsection{Hydrogen Peroxide (HP)}

Both municipalities and industries use hydrogen peroxide $\left(\mathrm{H}_{2} \mathrm{O}_{2}\right)$ for dechlorination purposes (Worley, 2000). HP reacts with free chlorine according to the following reaction when the $\mathrm{pH}$ is above 7 :

$$
\mathrm{Cl}_{2}+\mathrm{H}_{2} \mathrm{O}_{2} \rightarrow 2 \mathrm{HCl}+\mathrm{O}_{2}
$$

The reaction is instantaneous and complete at the $\mathrm{pH}$ value of 8.5. (EC, 2003) To neutralize $1 \mathrm{mg}$ of chlorine, $0.48 \mathrm{mg}$ of $\mathrm{HP}$ is required. Also, the oxygen produced in the above reaction can increase the dissolved oxygen (DO) level in the receiving streams. Therefore, a major advantage of using HP in wastewater application is that it has no negative impact on receiving water bodies, and it may boost the DO levels in the receiving water bodies (EC, 2003). However, if excess HP is present in the effluent as a result of overdose, HP could be quenched with a quenching agent such as catalase. These quenching agents have been reported to be unstable for HP quenching because of the complexity and the length of time required for the measurements (Liu et al., 2003).

In addition, HP reacts with hypochlorite ion as follows:

$$
\mathrm{ClO}^{-}+\mathrm{H}_{2} \mathrm{O}_{2} \rightarrow \mathrm{Cl}^{-}+\mathrm{H}_{2} \mathrm{O}+\mathrm{O}_{2}
$$


From a kinetic analysis of the above reaction in the temperature range $15-35^{\circ} \mathrm{C}$, Shams El Din \& Mohammed (1998) found that the reaction was complete in 10-15 minutes, both in portable and sea water. They also concluded that the reaction is second order with respect both reactants. However, in the presence of one reactant in excess, the reaction was determined to be first order with respect to the other reactant (i.e. pseudo-first order). In other words, the dechlorination reaction involving hydrogen peroxide is pseudo-first order with respect to hypochlorite ion $\left(\mathrm{ClO}^{-}\right)$. (Shams El Din \& Mohammed, 1998)

The reaction between HP and combined chlorine species such as chloramine has been reported to be considerably slower than its reaction with free chlorine (Shams El Din \& Mohammed, 1998). Therefore, in terms of the required reaction time, sulfur compounds are preferred for dechlorination of wastewater with high concentrations of reduced nitrogen. HP is ideal for wastewater facilities with either long contact times for dechlorination, or mechanical mixing, or if wastewater is denitrified before chlorination. Due to these operational constraints, and the difficulties in chemical handling, it is unlikely that HP will be used in small treatment facilities (EC, 2003).

\subsubsection{Ascorbic Acid (AA)}

Commonly known as vitamin $\mathrm{C}$, L-ascorbic acid $\left(\mathrm{C}_{5} \mathrm{H}_{5} \mathrm{O}_{5} \mathrm{CH}_{2} \mathrm{OH}\right)$ is widely used to dechlorinate water for medical (e.g. kidney dialysis units) (Wiseman, 1997) and analytical purposes (Bedner et al., 2004). To neutralize $1 \mathrm{mg}$ of chlorine (as $\left.\mathrm{Cl}_{2}\right) 2.48$ mg of $\mathrm{AA}$ is required (see Appendix 2 for calculation). Available as colourless, odourless, white crystals, AA reacts with chlorine as follows: 


$$
\mathrm{C}_{5} \mathrm{H}_{5} \mathrm{O}_{5} \mathrm{CH}_{2} \mathrm{OH} \mathrm{OH}+\underset{\text { Hypochloric Acid Acid }}{\mathrm{HOCl}} \rightarrow \underset{\text { Dehydroascorbic Acid }}{\mathrm{C}_{5} \mathrm{H}_{3} \mathrm{O}_{5} \mathrm{CH}_{2} \mathrm{OH}}+\underset{\text { Hydrochloric Acid }}{\mathrm{HCl}}+\mathrm{H}_{2} \mathrm{O}
$$

During the above reaction, hydrochloric acid is produced reducing the solution $\mathrm{pH}$. The AA solution itself has a $\mathrm{pH}$ of 2 , which is highly corrosive (EC, 2003). Together, the above factors could substantially reduce the $\mathrm{pH}$ of the $\mathrm{AA}$ reaction solution. $\mathrm{AA}$ is effective in reducing both hypochlorite and chloramine (Paterka, 1998), but Bedner et al. (2004) found the reaction rate of AA with chlorine to be much slower than that of sodium sulfite and thiosulfate. Although EC (2003) claims that AA is not a DO scavenger, Bedner et al. (2004) found that it exerts a Biological Oxygen Demand (BOD) of $3.1 \mathrm{mg}$ $\mathrm{O}_{2} / \mathrm{L}$ when reducing $1 \mathrm{mg} \mathrm{Cl}_{2} / \mathrm{L}$ with a $50 \%$ molar excess of AA. However, considering the health benefits and low risks associated with $\mathrm{AA}$, it has been drawing attention as a potential dechlorination chemical for natural water streams (Paterka, 1998). Other advantages of using AA are that it is safe to handle, and has no inherent odor (Paterka, 1998).

\subsubsection{Summary of Dechlorination Chemicals}

A number of dechlorination chemicals are currently used to remove free and/or combined chlorine from the water in the wastewater industry, medical field, pulp and paper industry and in bench-scale laboratory studies. The following section summarizes the reaction chemistry, the advantages and the disadvantages of selected dechlorination chemicals in wastewater application.

Sulfur salts such as sodium sulfite (SS), sodium bisulfite (SBS), and sodium metabisulfite (SMBS) are amongst the most commonly used chemicals for wastewater applications 
(USEPA, 2000). SS and SBS are also known as sulfur (IV) compounds, since they contain sulfur in the +4 oxidation state (Helz \& Nweke, 1995) and, when dissolved in water, they produce sulfur (IV) compounds, such as the sulfite ion $\left(\mathrm{SO}_{3}^{-2}\right)$ and sulfur dioxide gas. However, compared to sulfur dioxide gas itself, the salts have less dechlorination efficiency per amount of product added. Nevertheless, small facilities prefer SS and SBS over sulfur dioxide gas due to ease of storage, chemical feeding (into the reactor), control and handling. Amongst all the available sulfur salts, SMBS has been reported to require the lowest addition rate (USEPA, 2000). In addition, sulfur containing dechlorination agents are known to deplete $\mathrm{DO}$ and suppress $\mathrm{pH}$ levels of the water, which may negatively impact the aquatic organisms in the receiving streams (Tikkanen et al., 2001; Yonkos et al., 2001). Also, it has been found that the S (IV) compounds are more effective in reducing total residual chlorine and the resulting toxicity in waters with chlorine present in the free chlorine form compared to the combined chlorine from. Sulfur salts are less efficient in neutralizing combined chlorine, which is the predominant chlorinated species in wastewater with high organic loads (Helz \& Nweke, 1995).

STS and CTS have also become popular dechlorination agents, especially in bench-scale laboratory studies and aquarium applications. Even though commonly used for dechlorination in the United States (Ryon et al., 2002), there seems to be no evidence for the use of these chemicals in wastewater dechlorination in Canada. Thiosulfates are reported to be more effective than sulfites in reducing both residual chlorine fractions in wastewater (Bedner et al., 2004). The reaction involving STS is sensitive to the solution 
$\mathrm{pH}$, thus the stoichiometric dosage required varies depending on the $\mathrm{pH}$ (Worley, 2000). CTS, on the other hand, reacts very rapidly with free chlorine reducing the required contact time for dechlorination. This reduction in contact time is a great advantage in wastewater applications with short contact times available for the dechlorination reactions. However, using CTS in excess may cause an increase in the effluent turbidity and promote the growth of thiobacillus bacteria in the receiving water bodies (Tikkanen et al., 2001).

Hydrogen peroxide (HP) and ascorbic acid (AA) are also two emerging dechlorination chemicals. HP, however, is not used in large scale applications because its highly corrosive nature makes it dangerous to handle (Worley, 2000). Also, it requires long reaction times for the reaction with chloramines, thus may only be suitable for large facilities with denitrification processes in place to reduce the formation of chloramines during chlorination. Thus, HP is ideal for wastewater facilities either with long contact times or if high levels of mechanical mixing are present following dechlorination, and it is unlikely to be used in the wastewater treatment at the municipal level (EC, 2003).

L-ascorbic acid $\left(\mathrm{C}_{5} \mathrm{H}_{5} \mathrm{O}_{5} \mathrm{CH}_{2} \mathrm{OH}\right)$ is becoming a popular dechlorination chemical due to its ease of handling, short reaction times and because it is safe to the user and the aquatic environment. Also, it is able to completely remove residual chlorine. However, the $\mathrm{pH}$ impacts, and the high cost associated with its use (see Table 3) prohibits the application of $\mathrm{AA}$ in the wastewater industry $(\mathrm{EC}, 2003)$. 
Table 2 summarizes the advantages and disadvantages of the seven dechlorination agents

\section{from an operational point of view.}

Table 2: Advantages and disadvantages of selected dechlorination chemicals.

\begin{tabular}{|c|c|c|}
\hline $\begin{array}{l}\text { Dechlorination } \\
\text { Agent (DA) }\end{array}$ & Advontagest & Disadvantages \\
\hline $\begin{array}{l}\text { Sodium Sulfite } \\
\text { (SS) }\end{array}$ & $\begin{array}{l}\text { - Significant use history } \\
\text { - Non-toxic, non-corrosive, } \\
\text { easy to use }\end{array}$ & $\begin{array}{l}\text { - High use ratio } \\
\text { - Solutions subject to freezing in cold } \\
\text { weather } \\
\text {-Difficult to handle }\end{array}$ \\
\hline $\begin{array}{l}\text { Sodium Bisulfite } \\
\text { (SBS) }\end{array}$ & $\begin{array}{l}\text { - Significant use history } \\
\text { - Easy to inject } \\
\text { - Low use ratio }\end{array}$ & $\begin{array}{l}\text { - Expensive chemical } \\
\text { - Highly Corrosive } 1 \\
\text { - Solutions subject to freezing in cold } \\
\text { temperatures }\end{array}$ \\
\hline $\begin{array}{l}\text { Sodium } \\
\text { Metabisulfite } \\
\text { (SMBS) }\end{array}$ & $\begin{array}{l}\text { - Significant use history } \\
\text { - Easy to inject } \\
\text { - Amongst all sulfur salts, lowest } \\
\text { addition rate required }^{5}\end{array}$ & $\begin{array}{l}\text { - Solutions subject to freezing in } \\
\text { temperatures }\end{array}$ \\
\hline $\begin{array}{l}\text { Sodium } \\
\text { Thiosulfate (STS) }\end{array}$ & $\begin{array}{l}\text { - Significant use history } \\
\text { - Non-toxic, non-corrosive, } \\
\text { easy to use } \\
\text { - Low initial capital costs } \\
\text { - Easy to inject } \\
\text { - Scavenges less oxygen than sodium } \\
\text { sulfite, bisulfite or metabisulfite }^{1}\end{array}$ & $\begin{array}{l}\text { - Solutions subject to freezing in cold } \\
\text { weather } \\
\text {-Required stoichiometric dosage varies } \\
\text { depending on the solution } \mathrm{pH}^{3} \\
\text {-Excess thiosulfate release may produce } \\
\text { turbidity violations }{ }^{1} \\
\text { - Excess thiosulfate release into } \\
\text { receiving streams promote thiobacillus } \\
\text { bacterial growth }\end{array}$ \\
\hline $\begin{array}{l}\text { Calcium } \\
\text { Thiosulfate } \\
\text { (CTS) }\end{array}$ & 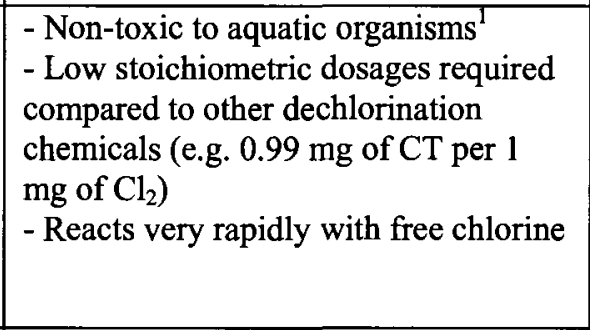 & $\begin{array}{l}\text { - Reactions using stoichiometric } \\
\text { concentrations require long contact } \\
\text { times }(\sim 5 \text { mins }) \\
\text { - Overdosing may cause turbidity } \\
\text { violations }{ }^{1} \\
\text { - Excess thiosulfate release into } \\
\text { receiving streams promote thiobacillus } \\
\text { bacterial growth }^{1}\end{array}$ \\
\hline $\begin{array}{l}\text { Hydrogen } \\
\text { Peroxide (HP) }\end{array}$ & $\begin{array}{l}\text { - Easy to inject } \\
\text { - Inexpensive chemical cost } \\
\text { - Release oxygen during the } \\
\text { neutralization reaction }^{3} \\
\end{array}$ & $\begin{array}{l}\text { - Does not remove chloramines at a } \\
\text { useful rate } \\
\text { - Highly unstable and subject to } \\
\text { deterioration }\end{array}$ \\
\hline $\begin{array}{l}\text { Ascorbic Acid } \\
\text { (AA) }\end{array}$ & $\begin{array}{l}\text { - Safe to handle } \\
\text { - Do not scavenge oxygen } \\
\text { - No inherent odor } \\
\text { - Reaction rate of AA is much slower } \\
\text { than that of sulfite and thiosulfate }\end{array}$ & $\begin{array}{l}\text { - High chemical cost } \\
\text { - When dissolved in water, it is } \\
\text { corrosive due to the low pH }\end{array}$ \\
\hline
\end{tabular}

Table adapted from Environment Canada (2003), Tikkanen et al., 2001; ${ }^{2}$ Paterka, 1998; ${ }^{3}$ Worley, $2000 ;{ }^{4}$ Bedner et al., 2004; ${ }^{5}$ USEPA, 2000 
Comparing the above-mentioned DAs from an operational point of view, it is evident that using sulfur compounds - SS, SBS and SMBS - is a logical choice for dechlorination of wastewater effluent. However, there are other selection criteria (Section 2.2) that need to be considered when selecting a dechlorination agent to achieve optimum results.

\subsection{Selection Criteria for Dechlorination Agents in}

\section{Wastewater Applications}

Various dechlorination facilities use different dechlorination chemicals depending on several factors such as required chemical dosage and cost, contact time for complete neutralization, and mixing requirements (operational conditions). Other important criteria that need to be considered when choosing a DA are safety and ease of handling (NMED, 2003; EC, 2003), which were previously discussed in the Table 2.

\subsubsection{Chemical Dosage and Cost}

Adding the sufficient dosage of the dechlorination chemical is a critical factor in producing non-detectable chlorine residual in the effluent. Theoretically required stoichiometric dosages calculated from the balanced chemical reaction equation of each of the dechlorination agents are tabulated in Table 3. Typically, the weight ratio of the dechlorination agent added to chlorine is $1: 1\left(\mathrm{mg} \mathrm{DA} / \mathrm{mg} \mathrm{Cl}_{2}\right.$ ), and USEPA (2000) is highlighting the importance of using proper amounts of chemicals to avoid over-dosing. Over-dosing may have negative consequences on the receiving waters. For example, excess sulfur salts have the potential to react with DO (4 parts of sulfite will consume 1 
part of oxygen on weight-to-weight basis) in the wastewater, producing sulfates (USEPA, 2000; NMED, 2003) according to the following reaction (Bedner et al.,2004):

$$
\underset{\text { Sulfite }}{2 \mathrm{SO}_{3}^{-2}}+\mathrm{O}_{2} \rightarrow \underset{\text { Sulfate }}{2 \mathrm{SO}_{4}^{-2}}
$$

This reaction not only reduces the DO levels in the water, but it also lowers the effluent $\mathrm{pH}$ (USEPA, 2000). NMED (2003) on the other hand claims that an excess of $10 \%$ above theoretical values of the dechlorination agent is necessary to achieve complete dechlorination. GVRD (1997) also claims that "over-dosing is the best approach." Helz $\&$ Nweke (1995) claim that approximately $50 \%$ molar excess of sodium sulfite (relative to the initial total residual chlorine) is currently used by wastewater treatment facilities in the United States. Dechlorination Design Standards for Maine Wastewater Facilities recommends the use of approximately the stoichiometric ratios of $1.8,1.5$ and 1.5 sodium sulfite (SS), bisulfite (SBS) and metabisulfite (SMBS) to chlorine on a weight basis (mg $\mathrm{DA} / \mathrm{mg} \mathrm{Cl}$ ), respectively (DEP, 2005). Thus, it is apparent that there are conflicting practices regarding the appropriate dosage of dechlorination agents to be used to achieve complete neutralization. Further studies are needed, using varying dosages of chemicals to evaluate the minimum dosage necessary to achieve complete dechlorination over a reasonable reaction time (less than 1-3 minutes).

Worley (2000) conducted similar dechlorination experiments with ascorbic acid (AA), sodium thiosulfate (STS) and hydrogen peroxide (HP) and determined the effective dose for the dechlorination of chlorine for the three chemicals to be $3.0,2.2$ and $0.6 \mathrm{mg} / \mathrm{mg} \mathrm{Cl}_{2}$ respectively. It was also found that after 5 minutes of reaction with a $1 \mathrm{x}$ stoichiometric dosage (henceforth " $x$ " will be used to designate the stoichiometric weight ratio of DA to 
$\mathrm{Cl}_{2}$ ) of each of those 3 chemicals, there was $\sim 7.5 \%, 2.5 \%$ and $65 \%$ of the residual chlorine left in the effluent for AA, HP and STS, respectively. This research further supports the idea that the dechlorination reactions at $1 \mathrm{x}$ stoichiometric dosages are not instantaneous and are incomplete.

The cost of the dechlorination chemicals is directly proportional to the required dosage. Thus, the amount of chemical dosage required for complete dechlorination is a main determinant of the type of dechlorination agent that is used. The required dosage is directly related to the incoming effluent chlorine concentration, desired residual concentration, and the type of dechlorination chemical that is being used (NMED, 2003). Table 3 tabulates the stoichiometric dosages of each dechlorination chemical required to neutralize $1 \mathrm{mg}$ of chlorine (as $\mathrm{Cl}_{2}$ ) and the associated costs per $\mathrm{kg}$ of residual neutralized. The sample calculations are included in Appendix 2.

Table 3: Stoichiometric dosages and cost of various dechlorination chemicals

\begin{tabular}{|c|c|c|c|c|}
\hline 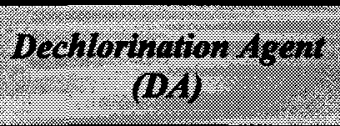 & 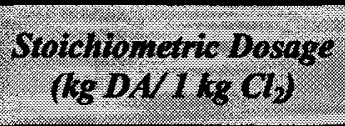 & $\begin{array}{l}\text { Weriwery } \\
\text { concentratom }\end{array}$ & $\begin{array}{l}\text { Morikg of } \\
\text { chemical }\end{array}$ & $\begin{array}{l}\text { Costikg of } \\
\text { residual }\end{array}$ \\
\hline Ascorbic acid (AA) & 2.5 & $99 \%$ (solid) & $\$ 9.95$ & $\$ 25.13$ \\
\hline \multirow{2}{*}{$\begin{array}{l}\text { Sodium Bisulfite } \\
\text { (SBS) }\end{array}$} & \multirow{2}{*}{1.47} & $97 \%$ (solid) & $\$ 2.40$ & $\$ 3.64$ \\
\hline & & $38 \%$ (liquid) & $\$ 0.45^{1}$ & $\$ 1.74^{2}$ \\
\hline \multirow{3}{*}{$\begin{array}{l}\text { Sodium Thiosulfate } \\
\text { (STS) }\end{array}$} & $0.56 @ \mathrm{pH} 11$ & \multirow{3}{*}{$97 \%$ (solid) } & $\$ 1.70$ & $\$ 0.97$ \\
\hline & $1.86 @ \mathrm{pH} 8$ & & $\$ 1.70$ & $\$ 3.26$ \\
\hline & 2.23@pH 6.5 & & $\$ 1.70$ & $\$ 3.90$ \\
\hline Sodium Sulfite (SS) & 1.78 & $96 \%$ (Solid) & $\$ 1.22$ & $\$ 2.26$ \\
\hline \multirow{2}{*}{$\begin{array}{l}\text { Hydrogen peroxide } \\
\text { (HP) }\end{array}$} & \multirow{2}{*}{0.48} & $35 \%$ (liquid) & $\$ 1.37$ & $\$ 1.88$ \\
\hline & & $50 \%$ (liquid) & $\$ 0.96$ & $\$ 0.90$ \\
\hline $\begin{array}{l}\text { Sodium Metabisulfite } \\
\text { (SMBS) }\end{array}$ & 1.34 & $97 \%$ (solid) & $\$ 0.94$ & $\$ 1.30$ \\
\hline \multirow{2}{*}{$\begin{array}{l}\text { Calcium Thiosulfate } \\
\text { (CTS) }\end{array}$} & $0.45 @ \mathrm{pH} 11$ & \multirow{2}{*}{$30 \%$ (liquid) } & $\$ 1.95^{1}$ & $\$ 2.93$ \\
\hline & $0.99 @ \mathrm{pH} 7.35$ & & $\$ 1.95^{1}$ & $\$ 6.44$ \\
\hline
\end{tabular}

Adopted from EC, 2003.

${ }^{1}$ Email communication with Canada Colors Limited, May $20^{\text {th }}, 2008$.

${ }^{2}$ See calculation in appendix 2 
From Table 3 it can be seen that the dechlorination costs are directly proportional to the dosage of chemical required. For example, $\mathrm{AA}$ requires the largest dosage per $\mathrm{mg} \mathrm{of} \mathrm{Cl}_{2}$, and has the highest cost per unit of chemical. Therefore, it has the highest cost per $\mathrm{kg}$ of residual neutralized. CTS is also costly; however, it only costs $25 \%$ of the cost of AA per unit of residual neutralized The neutralizing costs (per $\mathrm{kg}$ residual) of the rest of the chemicals are significantly less (an order of magnitude) than that of AA. Cost of dechlorination using HP is also claimed to be much less than methods based on treatment with sulfur dioxide (Shams El Din \& Mohammed, 1998). . From a cost point of view, for large facilities using large quantities of the dechlorination chemicals, it is impractical to use AA or CTS.

The choice of dechlorination chemical will not only influence the costs for the chemicals, but it will also have an impact on the cost of dosing equipment, installation, labour, operation and maintenance of the treatment facility. Also, there might be other costs that would have to be considered depending on the location and the size of the treatment plant. For example, according to EC (2003), the use of sulfur salts by wastewater facilities is largely dependent on the availability of the chemicals and associated transportation costs. Therefore, the cost of the chemical is directly proportional to transportation costs and each facility will require a thorough cost analysis before adopting the use of sulfur salts (USEPA, 2000). When choosing the most effective dechlorination chemical to be used, the cost savings should be weighed against other design requirements (mixing and contact time), safe handling and storage issues. 


\subsubsection{Contact Time for Reaction Completion and Mixing Requirements}

Generally, wastewater facilities are designed to allow for a minimum of 30 seconds of mixing and contact time following dechlorination during peak hourly flow (NMED, 2003; Utilities Kingston, 2004). Thus, it is essential that the dechlorination agent of choice be able to neutralize the free and combined chlorine rapidly within a short period of time. Many dechlorination agents are unable to achieve complete dechlorination in less than 30 seconds. In some cases during peak hourly flow, after the addition of the dechlorination agent, the effluent is directed into a holding tank to allow for additional mixing and reaction time (NMED, 2003). Typically the residence time of water in these holding tanks is a few minutes, which may or may not be sufficient to achieve the desired residual chlorine levels in the residual $(<0.02 \mathrm{mg} / \mathrm{L})($ GVRD, 1997). Thus, it is important to have a clear idea of the required contact time during the design of the wastewater treatment facility to assess the requirements of a holding tank and/or adequate mixing to ensure complete neutralization.

Sulfur salts (as discussed in Section 2.1.2.8) produce sulfur (IV) compounds that readily react with free and combined chlorine species (Ekkad \& Huber, 1996). The required contact times for these reactions are between one to five minutes, which is considerably shorter when compared to other chemicals such as the thiosulfates (EC, 2003; US Army, 1988). On the other hand, NMED (2003) claims that the reaction between free or combined chlorine and the sulfur (IV) compounds will occur within a much shorter time period of 15-20 seconds. Ekkad and Huber (1996) claim that all the dechlorination reactions are rapid at low $\mathrm{pH}$, but at neutral $\mathrm{pH}$ the reaction of sulfite with free chlorine 
and inorganic chloramines is completed in a few seconds while the reaction with organic chloramines is much slower. Although not explicitly stated in their reports, this inconsistency in the required contact time reported by each of the above agencies could be due to the differences in the dosage that was used. Thus, it is evident that a small variation in the dose may result in an order of magnitude change in the contact time.

Although dechlorination using sulfur (IV) compounds is assumed to be rapid and complete (USEPA, 2000; Ekkad \& Huber, 1996), many researchers (Bedner et al., 2004; Helz \& Nweke, 1995; Jensen \& Helz, 1998; MacCrehan et al., 1998; Worley, 2000) challenge this notion. Through pilot-scale testing at two wastewater treatment facilities, the authors claim that dechlorination only removes $87-98 \%$ of free chlorine in the effluent rapidly, and the rest is reduced at a much slower rate. Approximately $90 \%$ of the initial residual chlorine was reduced by sulfite within the first 2 minutes of the reaction, however, the remaining $10 \%$ reacted more slowly with a first-order rate constant of 0.026 $\min ^{-1}$. Even doubling of the initial sulfite concentration did not eliminate all the residual chlorine from the sample within 1 hour (Helz \& Nweke, 1995). In agreement with Helz \& Nweke (1995), Bedner et al. (2004) also found that sulfite only reduces $67 \%$ of residual chlorine within the first 2 minutes of the reaction, and that chlorine reduction remains incomplete after 2 hours. This incomplete dechlorination occurs because the hydrophilic residual chlorine components of wastewater are readily reduced by dechlorination agents compared to the hydrophobic components that are more resistant to dechlorination. 
Although highly effective in rapidly reducing inorganic form of chlorine species (e.g. $\mathrm{HOCl}, \mathrm{OCl}^{-}, \mathrm{NHCl}_{2}, \mathrm{NCl}_{3}$ ), studies have shown that sulfite is not as effective in reducing organic chloramines, especially $\mathrm{N}$-chloropeptides (macromolecular chloramine), that are resistant to dechlorination by sulfite (Bedner et al., 2004; Helz \& Nweke, 1995; Jensen \& Helz, 1998; Jameel \& Helz, 1999; MacCrehan et al., 1998). N-chloropeptides are peptides that have been monochlorinated at the terminal $\mathrm{N}$, and the majority of the residual chlorine species found in the dechlorinated effluent after several minutes are $\mathrm{N}$ chloropepties (Jensen \& Helz, 1998). Chlorine disinfected municipal wastewater can be high in inorganic $\mathrm{N}$-chloropeptides that would not be completely neutralized in less than 1 hour (Jensen \& Helz, 1998). Thus, the required contact time for complete dechlorination is not only is dependent on the dosage, but it is also dependent on the composition of the wastewater and the possibility of other chloramine compound formation.

Minimal, and often conflicting information, on required contact times is available on other dechlorination chemicals such as HP, AA, CTS and STS as well. HP rapidly reacts with free chlorine, yet the reaction with combined chlorine is slow, and would require longer contact times of between 10 to 15 minutes (Shams El Din \& Mohammed, 1998) to achieve complete dechlorination (EC, 2003). Although AA is claimed to react with chlorine rapidly (EC, 2003), others report that it is comparatively less effective than sulfites (Bedner et al., 2004). Thiosulfates on the other hand have been found to be more effective than sulfites in reducing both hydrophilic and hydrophobic residual chlorine fractions (Bedner et al., 2004). Thus in terms of the contact time and mixing 
requirements, sulfur salts seem to have an advantage over the other dechlorination agents of choice.

Even though the required contact time is a critical criterion that needs primary consideration when selecting a dechlorination agent, it seems that minimal information is available regarding the required reaction times of the commonly used dechlorination chemicals. Also, the existing reaction time data with varying dechlorination chemical dosages appear conflicting. Therefore, more research is needed to investigate the required contact time for complete dechlorination under various dosages of the dechlorination agents.

\subsection{Health Impacts of Dechlorination Chemicals}

Wastewaters are usually disinfected with chlorine, as one of a number of measures to control waterborne diseases. A drawback of this public health strategy is that the dechlorination agents added to neutralize the toxic chlorine prior to discharge may harm aquatic organisms living in waters receiving treatment plant effluents, and humans who use this water for drinking and/or for recreational activities. Even though the dechlorination agents are known to be less harmful than chlorine, they might also pose a threat to the aquatic species in receiving streams, especially in the case where "overdosing" of dechlorination agents is required. Thus, it is important to investigate the aquatic toxicity of common dechlorination chemicals. Even though the environmental benefits associated with the dechlorination of wastewater effluent prior to discharge has been the focus of research for many years, the aquatic and human health impacts of DAs have not been very well studied (Ryon et al., 2002). When choosing a dechlorination 
agent to treat wastewater effluent that would be released into natural rivers and lakes that support contact and non-contact recreation, aquatic life and serve as a source of drinking water, the aquatic and human health impacts related to exposure to these chemicals become important. The following two sections review the aquatic and health impacts of selected dechlorination chemicals.

\subsubsection{Aquatic Toxicity}

There are several chemical, physical and biological factors that can independently or jointly contribute to the toxicity of wastewater effluent to aquatic species. In the case of wastewater effluent, it is the chemical components (e.g. ammonia, chlorine and heavy metals) that are found in or added to wastewaters that cause toxicity to the aquatic organisms in the receiving waters (SETAC, 2004).

In order to evaluate the aquatic toxicity of a given substance (e.g. dechlorination chemicals) various tests can be conducted such as acute or chronic lethality tests. Tests conducted in this research were acute lethality tests. Generally, acute lethality tests are carried out using indicator aquatic species such as Daphnia magna (D. magna), Daphnia carinata, Daphnia pulex, and Ceriodaphnia quadrangular (Wu et al., 2007), and some fish species such as the rainbow trout, stripped bass, and fathead minnow. An acute lethality test is defined as a test method used to determine the effect of a given material on a group of selected organisms under specific conditions (EC, 1990). An acute lethality test "measures the proportion of organisms affected by the exposure to different 
concentrations of chemicals, effluent, elutriate, leachate and receiving waters" (EC, 1990).

The species of choice for North American toxicity studies is Daphnia magna (Figure 2) (EC, 1990; USEPA, 2002), because it is a dominant herbivore present in the freshwater lakes and rivers of North America (Mitchell et al., 2004), where the water hardness is greater than $150 \mathrm{mg} / \mathrm{L}$ (EC, 1990). In addition, D. magna is an important link in the aquatic food chain, has

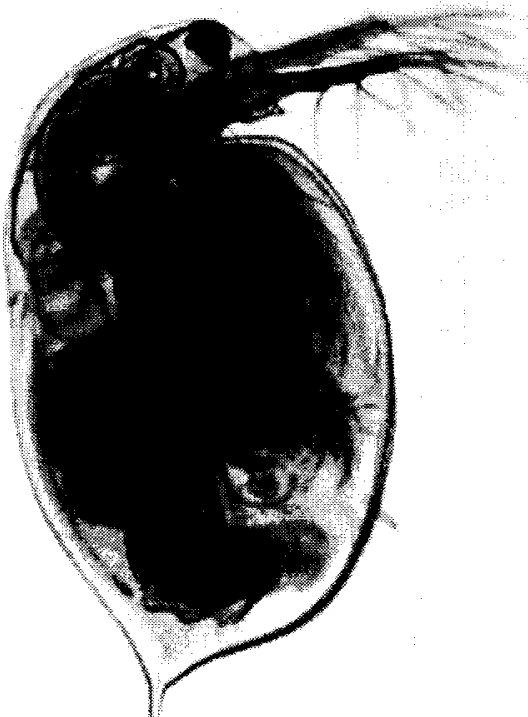

Figure 2: Daphnia magna

Adapted from www.mblaquaculture.com a short lifespan, can be "easily" cultured in the laboratory, is sensitive to a wide range of aquatic contaminants, and is a manageable size requiring only small volumes of test water. D. magna has the ability to produce genetically identical organisms via cyclical parthenogenesis (Wu et al., 2007), which makes them ideal for toxicity testing. Cyclical parthenogenesis is where female neonates emerge from sexual resting eggs and undergo cycles of asexual reproduction (Mitchell et al., 2004).

Lethality and toxicity field tests have been undertaken by researchers to identify the least harmful dechlorination chemical to be used in practice (EC, 2003; Oh et al., 2008; Ryon et al., 2002; Yonkos et al., 2001). For example, to investigate the effects of sulfur compounds used for the dechlorination of wastewater effluent, Ryon et al. (2002) 
conducted laboratory toxicity testing with Ceriodaphnia Dubia using sodium thiosulfate (STS) and bisulfite (SBS). From acute toxicity tests conducted with SBS, Ryon et al. (2002) concluded that the 24 hour Median Lethal Concentration $\left(\mathrm{LC}_{50}\right)$, the concentration that reduces the survival by $50 \%$, for Ceriodaphnia Dubia was $245 \mathrm{mg} / \mathrm{L}$.

The authors found that although overdosing with STS and SBS does not have any direct aquatic impacts as a result of the inherent toxicity of these chemicals, they have the indirect impact of suppressing the $\mathrm{pH}$ and consuming the $\mathrm{DO}$ of the receiving waters, potentially resulting in fish kill (Ryon et al., 2002). They discussed two examples to illustrate how the use of sulfur-containing compounds can influence the fish populations in receiving streams. The concentration of SBS necessary to cause a fish kill event in receiving waters was found to be $39 \mathrm{mg} / \mathrm{L}$, which can reduce the DO level in the receiving waters by $\sim 6 \mathrm{mg} / \mathrm{L}$. In agreement with the claims by EC (2003), Ryon et al. (2002) also found that these impacts require a unique set of circumstances to produce effects. The following is a list of receiving stream conditions (adopted from Ryon et al., 2002) indicative of sulfur compound over-dosing:

- Low levels of $\mathrm{pH}$ and DO

- In-stream sulfur precipitation

- Increased in-stream bacterial growth

- Changes in the color or appearance of the stream bed

- Changes in the concentrations of dissolved metals 
Although, the sulfite ion itself is not lethal, at higher dosages it can suppress the DO and $\mathrm{pH}$ level in the receiving water, thus inducing stress on the aquatic species (EC, 2003; Ryon et al., 2002). Also, it has been found that sulfite ion $\left(\mathrm{SO}_{3}^{-2}\right)$ concentrations of less than $10 \mathrm{mg} / \mathrm{L}$ have no significant effect on the aquatic environment (White, 1999).

STS is also thought to be non-toxic to aquatic species even at high concentrations (Ryon et al., 2002; Tikkanen et al., 2001). Oh et al. (2008) found the Median Effect Concentration $\left(\mathrm{EC}_{50}\right)$ of Daphnia magna, to be as high as $1334 \mathrm{mg} / \mathrm{L}$. In general, the $\mathrm{EC}_{50}$ is the DA concentration which induces a $50 \%$ effect to the response compared to the control or response halfway between the baseline and maximum and $\mathrm{LC}_{50}$ is concentration that produces a lethality effect in $50 \%$ of test organisms in a given population. In animal studies, however, $\mathrm{LC}_{50}$ and $\mathrm{EC}_{50}$ are used interchangeably to refer to the concentration that produces a lethality effect in $50 \%$ of test organisms in a given population (IUPAC, 1997). This $\mathrm{EC}_{50}$ in the case of STS is much higher than the expected concentration of STS in the wastewater effluent following dechlorination. Generally, the residual chlorine concentration in wastewater is approximately $0.95 \mathrm{mg} / \mathrm{L}$ (EC, 2007), which would require $~ 2.12 \mathrm{mg} / \mathrm{L}$ (@ pH 6.5) of STS to neutralize if STS is used at a 1:1 stoichiometric ratio. Therefore, it is safe to conclude that at concentrations presently being used for dechlorination of wastewater effluent, STS is non-toxic to aquatic organisms. 
However, Ryon et al., (2002) discovered that a STS concentration of $34-40 \mathrm{mg} / \mathrm{L}$ in a creek in Kentucky caused by overdosing was able to cause a fish kill of over 24,000 , given the following set of conditions. When the effluent was over-dosed $(34-40 \mathrm{mg} / \mathrm{L})$ with STS, a light-colored floc formation was observed in the receiving stream (Big Bayou Creek, Kentucky). This floc is a form of non-toxic elemental sulfur produced as a metabolic waste of the naturally-occurring bacteria that utilizes thiosulfate as an energy source in oxygenated waters. Besides causing sulfur accumulation, this process does not pose a problem under low $\left(<10^{\circ} \mathrm{C}\right)$ water temperatures. However, if the input rate of sulfur is reduced, these bacteria begin to metabolize the precipitated sulfur, producing sulfuric acid as a product. This acid production can reduce the water $\mathrm{pH}$ to approximately 4, causing fish kills. Other factors such as increasing temperature can further accelerate the metabolic rate of these bacteria, further reducing the water $\mathrm{pH}$ (Ryon et al., 2002).

Also, precaution should be taken when interpreting STS aquatic toxicity test results (Oh et al., 2008). Excess STS has the ability to form biologically unavailable forms of metal complexes with several cationic metals (such as copper - $\mathrm{Cu}(\mathrm{II})$, cadmium - $\mathrm{Cd}(\mathrm{II})$, nickel - Ni(II)) commonly present in wastewater (Oh et al., 2008). This complex formation could lead to over or underestimation of the sample toxicity. For example, the presence of zinc ( $\mathrm{Zn}(\mathrm{II}))$ in the dechlorinated water could increase the toxicity of the sample, while $\mathrm{Cu}(\mathrm{II}), \mathrm{Cd}(\mathrm{II})$ and $\mathrm{Ni}(\mathrm{II})$ can suppress the toxicity. Thus the aquatic toxicity effects of STS can vary largely depending on the composition of the effluent that is dechlorinated (Oh et al., 2008). 
Other dechlorination agents such as SMBS, SS, CTS, AA and HP have not been very well studied in terms of their aquatic impacts. For SMBS, USEPA (2007) reports the 96 hour $\mathrm{LC}_{50}$ value of $100 \mathrm{mg} / \mathrm{L}$ for fish, 72 hour $\mathrm{EC}_{50}$ of $48.1 \mathrm{mg} / \mathrm{L}$ for algae, an acute 48 hour $\mathrm{EC}_{50}$ and a No Observed Effect Concentration (NOEC) of $88.76 \mathrm{mg} / \mathrm{L}$ and $>10$ $\mathrm{mg} / \mathrm{L}$ for daphnids, respectively. Moreover, since SS and SMBS belong to the family of sulfur compounds, they could potentially have similar impacts on aquatic biota such as pH and DO suppression (Tikkanen et al., 2001). SS is also classified as non-hazardous for aquatic species, with a 48 hour $\mathrm{LC}_{50}$ value of $440 \mathrm{mg} / \mathrm{L}$ for Daphnia magna, and a 96 hour $\mathrm{LC}_{50}$ value of $460 \mathrm{mg} / \mathrm{L}$ for Western Mosquitofish (Mallinckrodt Chemicals, 2007). It is unlikely that these high concentrations of dechlorination agents will be present in the effluent or in the receiving water bodies, thus at lower concentrations these chemicals can be declared safe for aquatic species.

Nonetheless, the indirect aquatic impacts of these dechlorination chemicals, such as DO and $\mathrm{pH}$ suppression, can be deleterious to aquatic species thus need further investigation. Through an experimental study, Tikkanen et al. (2001) found that the use of stoichiometric concentrations of SMBS, SS, STS and CTS can suppress the DO in the water stream by $1.18,0.30,0.55,0.50 \mathrm{mg} / \mathrm{L}$, respectively after 250 seconds of reaction time. With twice the stoichiometric concentrations of the above chemicals, the DO concentration decreased by $1.0,0.90,0.90,0.70 \mathrm{mg} / \mathrm{L}$, respectively. In conclusion, the authors found SMBS to have the greatest impact on DO (Tikkanen et al., 2001). The implications of such DO suppression on aquatic species are well known (Alberta Environment, 1996). For example, extremely low levels (less than $6 \mathrm{mg} / \mathrm{L}$ ) of DO in the 
water can cause cellular breakdown and rapid death while sub-optimal levels of DO affect the ability of fish to survive and reproduce. In addition, an indirect effect of low DO levels is the reduction in survival of organisms that the fish prey on (Alberta Environment, 1996).

Ascorbic acid is a naturally occurring substance in the aquatic environment and has the least amount of information published on it in terms of aquatic toxicity (Science Lab Inc., 2005a). Available toxicity studies suggest that AA is non-toxic at high concentrations (200 mg/L) (NICNAS, 2003). The 48 hour $\mathrm{EC}_{50}$ value for $D$. Magna based on measured concentrations is given as $>190 \mathrm{mg} / \mathrm{L}$ by NICNAS (2003). The 96 hour $\mathrm{LC}_{50}$ value for fish was found to be $>80 \mathrm{mg} / \mathrm{L}$, and thus, AA is declared non-toxic to fish.

The addition of HP on the other hand, is thought to increase the DO concentration in the receiving water, since the reaction between chlorine and hydrogen peroxide is known to release oxygen (see Section 2.1.2.6) (EC, 2003). For example, addition of the stoichiometric concentration of hydrogen peroxide is known to increase the DO concentration in the water by $0.3 \mathrm{mg} / \mathrm{L}$ after 4 minutes and 10 seconds (Tikkanen $e t$ al., 2001). On the other hand, when twice the stoichiometric concentrations were added, the DO level was found to decrease by $0.2 \mathrm{mg} / \mathrm{L}$, and the authors failed to discuss the possible reasons behind such a DO decrease. HP moreover, is subjected to oxidation and reduction processes in the receiving waters and undergoes decomposition into water and oxygen. The highly reactive and corrosive nature of HP can cause adverse effects in the aquatic environment. Studies (Advanced Sterilization Products, 2005) have shown the $\mathrm{EC}_{50}$ value for Daphnia magna to be $7.7 \mathrm{mg} / \mathrm{L}, 48$ hour $\mathrm{LC}_{50}$ for Daphnia pulex to be 2.4 
$\mathrm{mg} / \mathrm{L}$, while fish species such as the fathead minnow and catfish have 96 hour $\mathrm{LC}_{50}$ values of 16.4 and $37.4 \mathrm{mg} / \mathrm{L}$ respectively. In addition, the half life of HP in the aquatic environment is 8 to 20 days, which is long enough to cause adverse effects on the aquatic species. Compared to other dechlorination chemicals mentioned above, hydrogen peroxide seems to pose a threat to the aquatic species at much smaller concentrations (Advanced Sterilization Products, 2005).

Tikkanen et al. (2001) have also found that treatment with AA can deplete water $\mathrm{pH}$, which can result in deleterious effects to the aquatic species. The addition of stoichiometric and twice the stoichiometric amounts of the dechlorination chemicals can reduce the $\mathrm{pH}$ of the water by 0.3 and $0.6 \mathrm{pH}$ units, respectively (Tikkanen et al., 2001). Thus, even though ascorbic acid does not have a direct impact on the aquatic species, it could have an indirect impact by reducing the $\mathrm{pH}$ of the water. These indirect impacts need further consideration and research.

The aquatic health impacts of dechlorination chemicals can be directly studied through aquatic toxicity testing, however, human health effects are not as easily studied. Nevertheless, knowing the human health effects of primary and secondary exposure to these dechlorination chemicals will help identify the least harmful chemical to be used in wastewater practice. Section 2.3.2 provides a brief review of the literature of the human health effects of the seven dechlorination agents under consideration. 


\subsubsection{Human Health Effects}

There are two main ways in which these dechlorination agents could come into contact with humans and cause health impacts. Typically, these chemicals may pose an occupational health hazard to their handlers at wastewater treatment facilities, especially because they are exposed to high concentrations over a long period of time. The general population may be exposed to much lower concentrations because typically, treated wastewater is discharged into freshwater lakes, rivers, or oceans that support contact and non-contact recreation or serve as a source of potable water. Thus it is important to get an understanding of the human health effects resulting from primary and secondary contact with these dechlorination chemicals. Table 4 summarizes short-term (acute) and long-term (choric) human health effects of exposure to the selected dechlorination chemicals.

Sulfur salts, SS, SBS and SMBS, all have National Fire Protection Association (NFPA) health hazard ratings $(0-4)$ (see Appendix 1 for details) of 2, 1 and 3, respectively. SMBS is declared by NFPA as the most hazardous of the three sulfur salts considered. Nonetheless, all the sulfur salts have health effects on the human skin, cardiovascular and central nervous systems. Ingestion of sulfite compounds may cause severe allergic reactions (anaphylactoid symptoms) in sensitive individuals and some asthmatics. Exposure to larges doses of sulfur compounds over a short period of time could cause circulatory disturbances, diarrhea, and depression of the central nervous system. 
Table 4: Potential human health effects of dechlorination chemicals

\begin{tabular}{|c|c|c|c|}
\hline \multirow{2}{*}{ mentical } & \multirow{2}{*}{ Wrat herlh } & \multicolumn{2}{|c|}{ 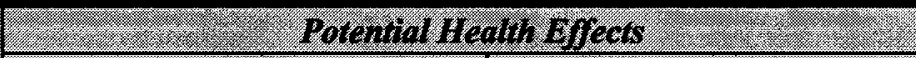 } \\
\hline & & 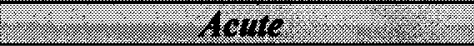 & Ghoule \\
\hline Sodium sulfite ${ }^{3,1}$ & $\begin{array}{l}2 \text { - may be } \\
\text { harmful if } \\
\text { inhaled or } \\
\text { absorbed }\end{array}$ & \multirow{3}{*}{$\begin{array}{l}\text { - only moderately toxic in large } \\
\text { amounts } \\
\text { - produce central nervous } \\
\text { system depression, bronchio- } \\
\text { constriction and anaphylaxis in } \\
\text { asthmatics } \\
\text { - gastric irritation } \\
\text { - large doses: circulatory } \\
\text { disturbances, diarrhea, and } \\
\text { central nervous system } \\
\text { depression } \\
\text { - skin, eye, respiratory tract } \\
\text { irritation with coughing and } \\
\text { wheezing } \\
\text { - harmful if swallowed }\end{array}$} & \multirow{3}{*}{$\begin{array}{l}\text { - eye and respiratory tract } \\
\text { irritation. } \\
\text { - harmful if swallowed or } \\
\text { inhaled } \\
\text { - highly corrosive } \\
\text { - allergic dermatitis } \\
\text { - skin sensitization } \\
\text { - target organs damage } \\
\text { - affect the liver, urinary } \\
\text { system, and metabolism } \\
\text { (weight loss) } \\
\text { - irritate lungs, cause } \\
\text { bronchitis }\end{array}$} \\
\hline $\begin{array}{l}\text { Sodium } \\
\text { bisulfite }\end{array}$ & $\begin{array}{l}1 \text { - may be } \\
\text { irritating }\end{array}$ & & \\
\hline $\begin{array}{l}\text { Sodium } \\
\text { metabisulfite }\end{array}$ & $\begin{array}{l}3 \text { - corrosive or } \\
\text { toxic- avoid } \\
\text { skin contact or } \\
\text { inhalation }\end{array}$ & & \\
\hline $\begin{array}{l}\text { Sodium } \\
\text { thiosulfate }^{5}\end{array}$ & $\begin{array}{l}1 \text { - may be } \\
\text { irritating }\end{array}$ & $\begin{array}{l}\text { - cause skin and eye irritation } \\
\text { - ingestion of large amounts } \\
\text { may cause diarrhea } \\
\text { - probable lethal dose for } \\
\text { humans is } 0.5-5.0 \mathrm{~g} / \mathrm{kg} \text {. }\end{array}$ & $\begin{array}{l}\text { - may cause bluish skin color } \\
\text { - human exposure to } 300 \\
\text { mg/kg of the pentahydrate, } \\
\text { for } \\
7 \text { days, resulted in cyanosis } \\
\text { - used for therapeutic } \\
\text { purposes in small ( } 15-20 \\
\text { mmol/day) concentrations } \\
\text { - large doses: affects } \\
\text { unknown }\end{array}$ \\
\hline $\begin{array}{l}\text { Calcium } \\
\text { thiosulfate }^{6} \\
(30 \% \mathrm{w} / \mathrm{v})\end{array}$ & $\begin{array}{l}0 \text { - no direct } \\
\text { health hazard }\end{array}$ & $\begin{array}{l}\text { - ingestion of large amounts } \\
\text { may cause diarrhea }\end{array}$ & $\begin{array}{l}\text { - large doses: affects } \\
\text { unknown }\end{array}$ \\
\hline Ascorbic acid & $\begin{array}{l}1 \text { - may be } \\
\text { irritating }\end{array}$ & $\begin{array}{l}\text { - eye, skin irritation and } \\
\text { respiratory tract irritation if } \\
\text { inhaled }^{7} \\
\text {-ingestion of large amounts } \\
\text { may cause gastrointestinal tract } \\
\text { irritation, urinary stones, and } \\
\text { renal failure } \\
\text { - large doses cause nausea }^{9} \text {, } \\
\text { diarrhea }^{9}\end{array}$ & $\begin{array}{l}\text { - may affect the blood/bone } \\
\text { marrow and metabolism }{ }^{7} \\
\text { - may also affect behavior } \\
\text { - mutagenic effects }\end{array}$ \\
\hline $\begin{array}{l}\text { Hydrogen } \\
\text { peroxide }(30 \% \\
w / v)^{7}\end{array}$ & $\begin{array}{l}3 \text { - corrosive or } \\
\text { toxic - avoid } \\
\text { skin contact or } \\
\text { inhalation }\end{array}$ & $\begin{array}{l}\text { - toxic and corrosive can cause } \\
\text { serious burns } \\
\text { - eye contact cause serious } \\
\text { injury such as blindness } \\
\text { - lowest published lethal dose } \\
\text { for humans is } 1429 \mathrm{mg} \mathrm{kg}^{-1}\end{array}$ & - mutagenic effects ${ }^{9}$ \\
\hline
\end{tabular}

Science Lab Inc., 2005b; ${ }^{2}$ Tikkanen et al., 2001; ${ }^{3}$ Mallinckrodt Chemicals, 2005; ${ }^{4}$ ESSECO USA, 2001; MDL Information Systems, Inc, 2002; ${ }^{6}$ Tramfloc Inc., 2002; ${ }^{7}$ Oxford University, 2005; ${ }^{8}$ See Section 2.1.2.8 above for details of the NFPA Hazard Rating system; ${ }^{9}$ Science Lab Inc., $2005 \mathrm{a}$. 
Short-term exposure to sulfur compounds can cause eye and respiratory tract irritation. Since these salts are highly corrosive, contact with the skin can result an allergic dermatitis, which is an allergic reaction. In addition, sulfur salts can cause skin sensitization, which is also an allergic reaction that becomes evident upon re-exposure to this chemical. Ingestion of sodium sulfite, bisulfite or metabisulfite, could cause damage to the liver and the urinary system and effect metabolism, causing weight loss. Prolonged inhalation of sulfur compounds may irritate the lungs and cause bronchitis to develop with cough, phlegm and/or shortness of breath. (Science Lab Inc., 2005b; Tikkanen et al., 2001; Mallinckrodt Chemicals, 2005; ESSECO USA, 2007)

Short-term exposure to STS can cause skin, eye and respiratory system irritation and STS is declared to be non-carcinogenic (MDL Information Systems, Inc., 2002). With a NFPA health rating of 1 , STS is categorized as an irritant, similar to SBS and AA. STS is neither a genotoxic nor a reproductive/developmental toxicant, and up to 5 times molar concentration (M) of STS was found to have no effect on human cells (USEPA, 2003). In addition, once ingested, thiosulfates are utilized by mitochondrial enzymes in humans and the excess is rapidly hydrolyzed into sodium chloride, water, sulfur and sulfate, all of which are harmless common constituents of the human body. Due to the rapid breakdown by mitochondria, STS does not have any negative cumulative effects on the human body (USEPA, 2003). However, if ingested in large doses, STS can cause diarrhea and the chronic effect of bluish skin (MDL Information Systems, Inc., 2002). Health effects resulting from the long-term exposure to large doses of STS are unknown (MDL Information Systems, Inc., 2002). However, chronic exposure to smaller doses of 
STS (15 $-20 \mathrm{mmol} /$ day orally) is a common therapeutic practice for patients with renal failure, and has been shown to have no adverse effects on patients with renal failure. Give that STS is a strong diuretic (USEPA, 2003), it is not very well absorbed by the human gastrointestinal tract, thus ingestion may result in cathartic effects (act as a laxative) (MDL Information Systems, Inc., 2002).

CTS has a NFPA health hazard rating of zero, meaning it produces no direct health hazard. Of all of the seven dechlorination chemicals considered, CTS is the only chemical declared as non-hazardous by the NFPA (Tramfloc Inc., 2002). However, similar to STS, short-term CTS exposure can cause diarrhea and nausea. Compared to the other chemicals under consideration, there is a minimal amount of literature published in the effects of CTS on human health (Tramfloc Inc., 2002).

AA with a NPFA health hazard rating of 1 is declared to be an irritant. Short-term exposure to large amounts of ascorbic acid may cause skin, eye and respiratory tract irritation. Ingestion of small amounts of AA during industrial handling is declared to pose a low health hazard. However, ingestion of large amounts can cause gastrointestinal tract irritation, hypermotility, diarrhea, acidification of the urine, which may cause stones in the urinary tract, and renal failure. (Science Lab Inc., 2005a) There is a scarcity of information available on the carcinogenicity of AA; however long-term exposure is known to cause mutagenic effects on mammalian somatic cells (Oxford University, 2005). Chronic AA exposure could potentially effect blood/bone marrow and 
metabolism and may effect behavior (psychomotor) in humans as well (Science Lab Inc., 2005a).

With an NFPA rating of 3 (corrosive or toxic - avoid skin contact or inhalation), HP $(30 \% \mathrm{w} / \mathrm{v})$ is a highly corrosive dechlorination chemical that readily decomposes to oxygen and water, and it may also produce hydroxyl radicals that can cause DNA damage if ingested by humans (CSTEE, 2001). Short-term exposure to HP can result in serious burns, and eye contact can lead to blindness (Oxford University, 2005). Therefore, the occupational exposure limits in the UK (OEL) are set to $1 \mathrm{ppm}$. The lowest published lethal dose for humans is $1429 \mathrm{mg} \mathrm{kg}^{-1}$ (Oxford University, 2005), which is much higher than the concentrations that may present in receiving waters as a result of wastewater treatment plant discharge. In addition, HP is found to be genotoxic and induce mutations in human mammalian cells (CSTEE, 2001; Oxford University, 2005).

Although there are no direct human health impacts resulting from the exposure to the dechlorination chemicals in consideration, the indirect human health effects of these dechlorination chemicals need consideration before the use of these chemicals can be deemed safe. Francy et al, (1996) found that dechlorination of disinfected wastewater can enhance the repair of injuries and survival of chlorine-injured fecal coliforms compared to chlorination alone. This repair mechanism that occur as a result of dechlorination was observed only in lake water but not in river water, yet the reason for this discrepancy in the case of lake and river water was not investigated by Fancy et al. 
(1996). However, from the work of these researchers it is evident that repair mechanisms exist for injured fecal coliforms to recover, which can defy the purpose of disinfecting with chlorine. Coliform injury repair and survival can have a negative impact on the receiving water quality, and might exceed the allowable fecal coliform levels effecting recreational potential of lakes and rivers. Thus, the implications of dechlorination on the recovery of fecal coliforms need further assessment.

Considering the human health effect resulting from acute and chronic exposure to the seven dechlorination chemicals discussed above, it is safe to conclude that the majority of the chemicals at low concentrations do not pose a serious direct threat to human health. Nonetheless, it is important that additional care be taken when handlings large quantities of these chemicals to avoid accidents that could result in exposure to harmful levels of these chemicals. 


\section{Chapter 3}

This chapter provides a detailed description of the methodology used for both the dechlorination, and the aquatic toxicity experiments, respectively. For the dechlorination experiments, the materials and methods used, dechlorination agents and the variables tested, and a list of experiments undertaken is included. Information regarding the Daphnia magna experiments undertaken as a part of the aquatic toxicity tests, also includes a description of the culturing of the test organisms, test procedures and a list of experiments.

\subsection{Dechlorination Experiments: Materials and Methods}

Dechlorination experiments were conducted to investigate and compare the reaction kinetics of the seven dechlorination agents with chlorine. The objectives of these experiments were to investigate the efficacy of dechlorination under a range of 
conditions. The rate of dechlorination was investigated under various dosage conditions, solution $\mathrm{pH}$ and mixing conditions.

\section{Experimental Apparatus}

The experimental setup and a flow diagram is shown in Figure 3 and Figure 4. The $8 \mathrm{~L}$ experimental container was used as the reactor, which was connected to $1.8 \mathrm{~m}$ of $1 / 4 "$ ID x 3/8" OD 70F non-toxic PVC NSF-51 tubing, coupled to $0.28 \mathrm{~m}$ of Microflex® 06486-24 tubing running through the peristaltic pump (mode 7024-20). The peristaltic pump was used to continuously pump the test solution from the experimental container through the Dulcometer ${ }^{\circledR}$ Continuous $\mathrm{pH}$ and Chlorine analyzer. The Microflex® tube running through the pump was connected to the flow stabilizer with $0.25 \mathrm{~m}$ of Tygon ${ }^{\circledR}$ R-3603 tubing using plastic coupling that was attached

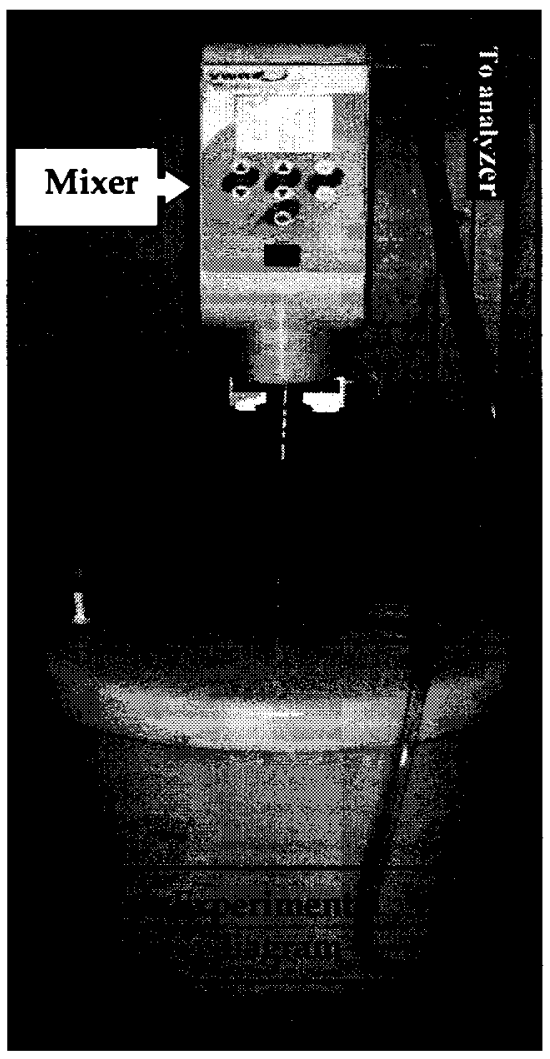

Figure 3: Experimental setup to the chlorine residual analyzer with $0.18 \mathrm{~m}$ of the same type of Tygon ${ }^{\circledR}$ tubing. A flow diagram of the experimental setup is shown in Figure 4. 


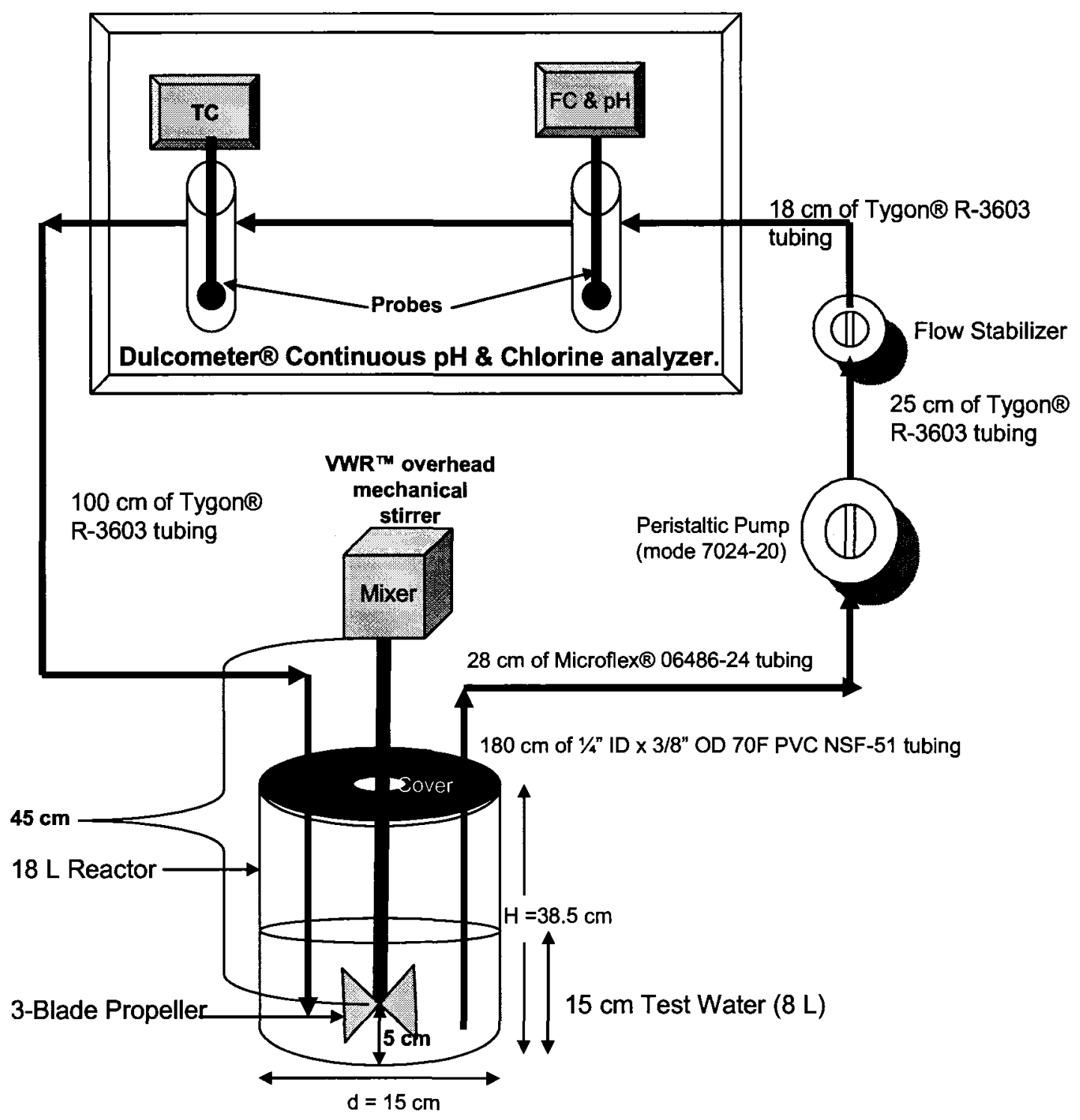

Figure 4: Detailed schematic of the experimental setup. Not drawn to scale.

A VWR ${ }^{\mathrm{TM}}$ overhead mechanical stirrer (Power Max Elite Dual Speed Meter) with a simple on/off switch was used to mix the sample. A 3-blade propeller (Figure 5) with a radius of $8.5 \mathrm{~cm}$ was attached to the mixer with a $45 \mathrm{~cm}$ iron rod. 


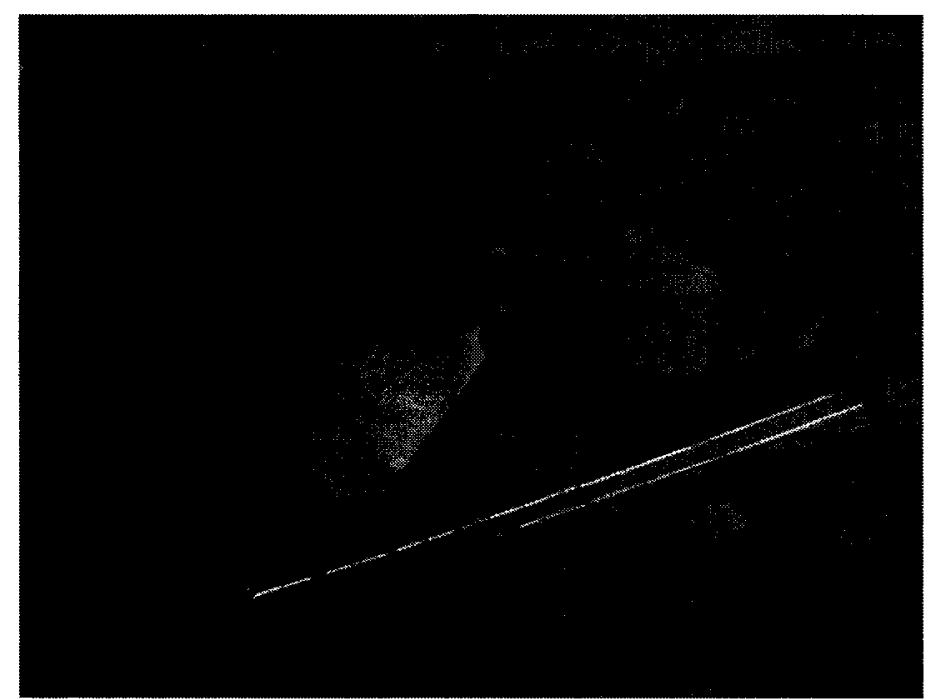

Figure 5: Three-blade propeller used to mix the experimental solution.

Dechlorination experiments were conducted using an online continuous $\mathrm{pH}$ and chlorine residual analyzer, DULCOMETER ${ }^{\circledR}$ D1C (Figure 6). The total chlorine (TC), free chlorine (FC), temperature, and the $\mathrm{pH}$ of the experimental solutions were continuously monitored and recorded over time until the reaction reached completion and for those that did not reach completion, until 720 seconds have elapsed.

Complete dechlorination was considered to be achieved once the total chlorine levels reached below $0.02 \mathrm{mg} / \mathrm{L}$ as $\mathrm{Cl}_{2}$. However, only the residual analyzer measurements above $0.10 \mathrm{mg} / \mathrm{L}$ were considered. Once the chlorine values reached below $0.10 \mathrm{mg} / \mathrm{L}$, a DPD test was conducted to measure and verify the chlorine levels in the solution. If the reaction was complete at the stoichiometric dosage shown in Table 3 , over a reasonable amount of time (less than 180 seconds), less than stoichiometric dosages were tested to investigate the minimum dosage required. On the other hand, if the reactions did not reach completion within 720 seconds with the stoichiometric dosage, higher dosages (1, 
2, 3 and $4 \mathrm{x}$ stoichiometric dosages on a weight-basis, $\mathrm{mg} \mathrm{DA} / \mathrm{mg} \mathrm{Cl}_{2}$ ) were tested until complete dechlorination was achieved.

The DULCOMETER ${ }^{\circledR}$ CTE 1-mA type total chlorine probe and a CLE-3 mA type free chlorine probe with measuring ranges of $0.05-5 \mathrm{mg} / \mathrm{L}$ were used to monitor the total and free chlorine concentration in solution. Even though the resolution of the probes were specified as $0.01 \mathrm{mg} / \mathrm{L}$, during the experiments it was found that the probe was only reliable down to about $0.10 \mathrm{mg} / \mathrm{L}$. The $\mathrm{D} 1 \mathrm{C}$ analyzer was able to measure $\mathrm{pH}$ ranging from $0-14 \mathrm{pH}$ units. However, the sensors that were used in these experiments were most effective in the $\mathrm{pH}$ range of $5.5-9.5$. The sensors were designed with an amperometric membrane that allowed specific ions to pass through, and in time react with an electrolyte. The current measured by the sensor was proportional to the concentration of TC and FC in solution in parts per million by volume (ppm). Since $1 \mathrm{~L}$ of pure water at $4^{\circ} \mathrm{C}$ and 1 standard atmosphere pressure weighs exactly $1 \mathrm{~kg}, 1 \mathrm{ppm}$ of water is equivalent to $1 \mathrm{mg} / \mathrm{L}$ (Satterfield, 2004), thus the readings were directly recorded in $\mathrm{mg} / \mathrm{L}$. The FC sensor measured hypochlorous acid concentration $(\mathrm{HOCl})$ in the experimental solution, while the TC sensor measured the free and combined chlorine concentration together. 


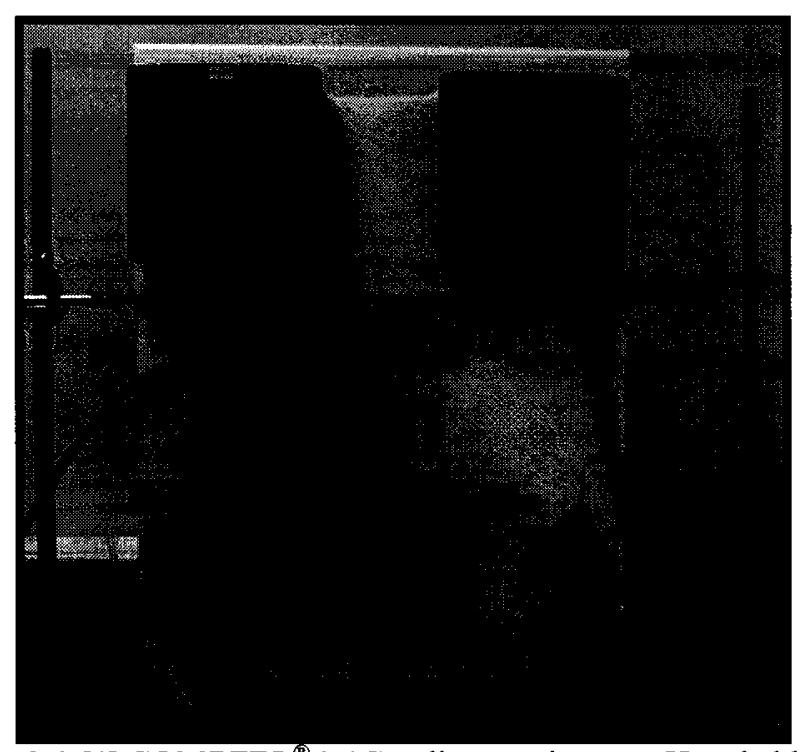

Figure 6: DULCOMETER ${ }^{\circledR}$ D1C online continuous $\mathrm{pH}$ and chlorine residual analyzer

Obtained chlorine values from the continuous chlorine analyzer were periodically checked and recalibrated against DPD chlorine measurements using the Hach $\circledast$ DR2800 spectrophotometer (Figure 7), Total Chlorine (DPD Method 8167) and Free Chlorine (DPD Method 8021) powder pillows, respectively.
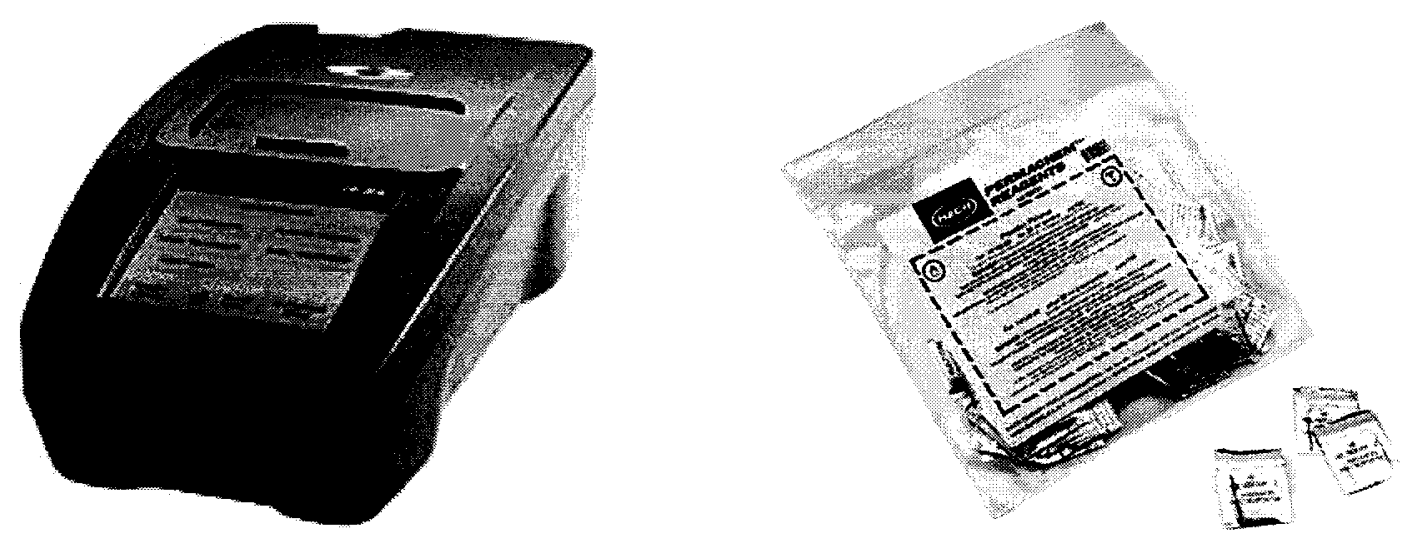

Figure 7: Hach® DR2800 spectrophotometer and free/total chlorine powder pillows.

There was a lag time for the test solution to travel from the experimental container to the $\mathrm{pH}, \mathrm{FC}$, and TC sensors of the analyzer as it had to travel through the tubes. These lag times were determined to be 15,17 and 20 seconds from the experimental container to 
the $\mathrm{pH}, \mathrm{FC}$ and $\mathrm{TC}$ sensors, respectively. In order to compensate for the delay in traveling from the container to the sensors, data analysis was modified by omitting the first 20 seconds of the obtained $\mathrm{TC}$ and $\mathrm{FC}$ values in the analysis. In some cases where the 20 second reading was not obtained, up to 25 seconds of the initial readings were omitted, which will be further discussed in Chapter 3. Also, once the FC and TC values reached below $0.10 \mathrm{mg} / \mathrm{L}$, the sensitivity of the chlorine analyzer deteriorated. Therefore, the TC and FC values below $0.10 \mathrm{mg} / \mathrm{L}$ were also omitted from the data analysis.

\section{Test Solution Preparation}

The experiments were undertaken using tap water to minimize other variables, such as nitrogen content in wastewater, that can interfere with the D1C analyzer measurements to obtain the kinetics of these experiments under 'ideal' conditions with minimum or no interferences. A comparison between the composition of typical wastewater effluent and the test water used in this study is provided in Table 5. Since this experimental study was conducted using chlorinated tap water to prevent the formation of chloramines, one could argue the usefulness of these results in application at actual wastewater facilities with high levels of inorganic and organic chloramines (e.g. $\mathrm{NH}_{2} \mathrm{Cl}, \mathrm{NHCl}_{2}, \mathrm{RNHCl}$ ) in the wastewater. Many of the dechlorination chemicals, especially sulfites, are known to be highly effective in rapidly reducing inorganic forms of chlorine species (e.g. $\mathrm{HOCl}, \mathrm{OCl}^{-}$, $\left.\mathrm{NHCl}_{2}, \mathrm{NCl}_{3}\right)(\mathrm{EC}, 2001 \mathrm{~b})$, yet slow in reducing organic forms of chlorine species. Thus, this experimental study of the reduction of inorganic forms of chlorine species (e.g. $\mathrm{HOCl}$ ) is very useful in determining the minimum dose, contact time, $\mathrm{pH}$ and mixing requirements necessary to achieve dechlorination of the wastewater effluent. Knowing 
that the rest of the effluent constituents are slow reducing, the dosage and the contact time can be increased accordingly to achieve complete dechlorination of the effluent with varying water quality.

Table 5: Comparison of the composition of municipal wastewater effluent and the test water of this experimental study.

\begin{tabular}{|c|c|c|}
\hline Parancier & $\begin{array}{l}\text { Mromichal } \\
\text { Wastewner }\end{array}$ & Tesil Matert \\
\hline $\begin{array}{l}\text { Total Residual Chlorine, mg } \\
\mathrm{Cl}_{2} / \mathrm{L}\end{array}$ & $0.95^{*}$ & $1.5-2$ \\
\hline Total suspended solids (TSS) & $20-80 \mathrm{mg} / \mathrm{L}$ & Not measured \\
\hline $\begin{array}{l}\text { Nutrients } \\
\text { - total phosphorus } \\
\text { - nitrogen-based compounds } \\
\text { / total nitrogen (nitrate, nitrite, } \\
\text { ammonia, and ammonium) }\end{array}$ & $\begin{array}{l}10-16 \mathrm{~g} \mathrm{P} / \mathrm{m}^{3} \\
10-35 \mathrm{~g} \mathrm{~N} / \mathrm{m}^{3}\end{array}$ & $\begin{array}{c}\text { Not measured } \\
0.15-0.30 \mathrm{NH}_{3}-\mathrm{N} \\
\mathrm{mg} / \mathrm{L}\end{array}$ \\
\hline $\begin{array}{l}\text { Microorganisms (e.g. fecal } \\
\text { coliforms) }\end{array}$ & $10^{8}$ per $100 \mathrm{~mL}$ & Not detectable \\
\hline Sulphides & $0.100 \mathrm{~S} \mathrm{~g} / \mathrm{m}^{3}$ & Not measured \\
\hline $\mathrm{pH}$ & $6.5-8.5$ & $6.5-8.5$ \\
\hline Turbidity, NTU & $1.8-9$ & $0.15-0.20$ \\
\hline Monochloramine, $\mathrm{mg} \mathrm{Cl}_{2} / \mathrm{L}$ & -- & $2-3$ \\
\hline Free Chlorine, & -- & $0.05-0.20$ \\
\hline Temperature, ${ }^{\circ} \mathrm{C}$ & $20 \pm 2$ & $20 \pm 2{ }^{\circ} \mathrm{C}$ \\
\hline Total hardness, $\mathrm{mg} \mathrm{CaCO}_{3} / \mathrm{L}$ & $324-668$ & $160-180$ \\
\hline
\end{tabular}

-- unknown

* EC, $2003 \mathrm{~b}$

In addition, chemicals (see Table 6) were added to increase the hardness of the test solution to $160-180 \mathrm{mg} / \mathrm{L}$ as $\mathrm{CaCO}_{3}$ to simulate the typical hardness of river and lake water in Ontario, and to reflect that wastewater is expected to be fairly well buffered. Another purpose of using the hardened water was to stabilize the $\mathrm{pH}$ values of the solution and to mimic the composition of water used in the Daphnia Magna toxicity testing. The composition of the prepared hard water is shown in Table 6 .

Table 6: Preparation of hard water with hardness between $160-180 \mathrm{mg} / \mathrm{L}$ as $\mathrm{CaCO}_{3}$

\begin{tabular}{|c|c|c|c|c|}
\hline Chamical & ontint & 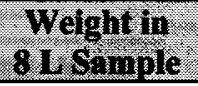 & Stodr Concentrition & $\begin{array}{l}\text { Stogk volime } \\
\qquad 8 \mathrm{~L}\end{array}$ \\
\hline $\mathrm{NaHCO}_{3}$ & $192 \mathrm{mg} / \mathrm{L}$ & $1536 \mathrm{mg}$ & $15.36 \mathrm{~g} / 100 \mathrm{ml}=153.6 \mathrm{~g} / \mathrm{L}$ & $10 \mathrm{ml}$ \\
\hline $\mathrm{CaSO}_{4}$ & $120 \mathrm{mg} / \mathrm{L}$ & $960 \mathrm{mg}$ & \multicolumn{2}{|c|}{ Added directly as a solid } \\
\hline $\mathrm{Mg} \mathrm{SO}_{4}$ & $120 \mathrm{mg} / \mathrm{L}$ & $960 \mathrm{mg}$ & $19.2 \mathrm{~g} / 200 \mathrm{ml}=96 \mathrm{~g} / \mathrm{L}$ & $10 \mathrm{ml}$ \\
\hline $\mathrm{KCl}$ & $8 \mathrm{mg} / \mathrm{L}$ & $64 \mathrm{mg}$ & $6.4 \mathrm{~g} / 100 \mathrm{ml}=64 \mathrm{~g} / \mathrm{L}$ & $1 \mathrm{ml}$ \\
\hline
\end{tabular}


The stock solutions of $\mathrm{NaHCO}_{3}, \mathrm{MgSO}_{4}$, and $\mathrm{KCl}$ were prepared by dissolving $15.36 \mathrm{~g}$, $19.2 \mathrm{~g}$, and $6.4 \mathrm{~g}$ of the solid in 100,200 and $100 \mathrm{ml}$ of DI water, respectively, in a volumetric flask of the appropriate volume. They were labelled and stored in amber bottles in a dark, cool place. Since the solubility of $\mathrm{CaSO}_{4}$ in water is appreciably low, stock solutions were not prepared. Instead, $0.96 \mathrm{mg}$ of $\mathrm{CaSO}_{4}$ was weighed separately, dissolved with $100 \mathrm{ml}$ of the experimental water and then added to the bucket to ensure homogenous mixing.

\section{Experimental Procedure}

The experimental reactor was filled with $8 \mathrm{~L}$ of hardened (Table 6) tap water, and the tubes leading to and leaving the chlorine analyzer were connected to the container. The container was covered with the lid and the peristaltic pump was turned on. The flow rate was set to $60 \mathrm{~L} / \mathrm{hr}$ using the flow control unit attached to the $\mathrm{DlC}$ analyzer. The mechanical mixer was turned on and set to the appropriate rate (130 RPM for periodic and continuous low mixing and 275 RPM for continuous high mixing). The flow meter was run for approximately 15 to 20 minutes and a set amount of Javex (usually $600 \mathrm{uL}-$ corresponding to $4-5 \mathrm{mg} / \mathrm{L}$ of $\mathrm{TC}$ in solution) was injected into the container to increase the chlorine concentration in solution. Then the D1C analyzer was run until the displayed total and free chlorine values stabilized. When the reading stablized, the total and the free chlorine of the water was measured using the DR 2800 spectrophotometer Total Chlorine DPD Method 8167 and the Free Chlorine DPD Method 8021, respectively. If the displayed values of $\mathrm{FC}$ and $\mathrm{TC}$ of the analyzer and the $\mathrm{HACH}$ 
measurement were not in agreement, the analyzer was calibrated according to the HACH analyzer values.

The volume of the dechlorination agent (DA) to be added was calculated using the following equation:

$$
\text { Vol. of } D A \text { req'd }=\frac{T C(m g / L) x \text { vol.of test solution }(L) x \text { stoich.ratio }(\text { unitless })}{\text { Concentration of } D A \text { stock solution }(m g / L)}
$$

For SS, SBS, SMBS, CTS, and STS the prepared stock solution concentration was 10 $\mathrm{g} / \mathrm{L}$. The stock solutions were prepared by dissolving $5 \mathrm{~g}$ of the respective chemical in $500 \mathrm{~mL}$ of DI water. Once the required volume of DA was determined, a pipette was used to add the determined volume of DA into the experimental container, and the timer was turned on simultaneously. The total and free chlorine values as well as the $\mathrm{pH}$ values displayed on the analyzer was noted starting at $\mathrm{t}=0$ until the reaction was complete or until 720 seconds (12 minutes) has elapsed.

\subsubsection{Dechlorination Agents Tested}

Seven dechlorination agents were studied: sodium sulfite (SS), sodium bisulfite (SBS), sodium metabisulfite (SMBS), sodium thiosulfate (STS), calcium thiosulfate (CTS), ascorbic acid (AA), and hydrogen peroxide (HP). Since the injection of sulfur salts is the most commonly used strategy for dechlorination in practice (USEPA, 2000), three of the sulfur salts - SS, SBS and SMBS were tested. Although, SMBS hydrolyzes to SBS when added to water, which is a method utilized by researchers to produce bisulfite (Yonkos et al., 2001), it was tested as a separate chemical for comparison purposes. STS was chosen because it is being used widely in the United States, and AA and CTS were 
considered because they are reported to be non-toxic to aquatic species (Tikkanen et al., 2001). HP was tested for the same reasons; its use in wastewater application has no negative impact on receiving water bodies, and it boosts the DO levels in the water bodies (EC, 2003).

\subsubsection{Variables Tested}

Three variables were tested for each dechlorination agent: DA concentration, mixing regimes and the solution $\mathrm{pH}$. The following sections further discuss these variables tested.

\subsubsection{Dechlorination Agent Concentration}

Stoichiometric as well as higher dosages $(1,2,2.5,3,4,10 \mathrm{x}$ stoichiometric on a weightbasis, $\mathrm{mg} \mathrm{DA} / \mathrm{mg} \mathrm{Cl}_{2}$ ) of dechlorination agents were tested to determine dechlorination rates of the seven dechlorination chemicals. The required stoichiometric dosages for each chemical were calculated according to the chemical reaction equations as shown in Appendix 2. For example, the calculation for SS was as follows:

$$
\begin{gathered}
\underset{\text { Sodium sulfite }}{\mathrm{Na}_{2} \mathrm{SO}_{3}}+\underset{\text { Hypochlorous acid }}{\mathrm{HOCl}} \rightarrow \underset{\text { Sodium sulfate }}{\mathrm{Na}_{2} \mathrm{SO}_{4}}+\underset{\text { Hydrochloric acid }}{\mathrm{HCl}} \\
\mathrm{Cl}_{2}+\mathrm{H}_{2} \mathrm{O} \rightarrow \mathrm{HOCl}+\mathrm{H}^{+}+\mathrm{Cl}^{-}
\end{gathered}
$$

Stoich. dosage for $\mathrm{SS}=$

$$
\frac{126 \mathrm{mg} \mathrm{Na}_{2} \mathrm{SO}_{3}}{1 \mathrm{~mol} \mathrm{Na}_{2} \mathrm{SO}_{3}} \times \frac{1 \mathrm{~mol} \mathrm{Na}_{2} \mathrm{SO}_{3}}{1 \mathrm{~mol} \mathrm{HOCl}} \times \frac{1 \mathrm{~mol} \mathrm{HOCl}}{70.9 \mathrm{mgCl}}=1.78 \mathrm{mg} \mathrm{SS} / \mathrm{mgCl} l_{2}
$$

For the two thiosulfates that were tested - STS and CTS - the stoichiometric dosage required is reported to be $\mathrm{pH}$ dependent (Tikkanen et al., 2001). For STS and CTS at a $\mathrm{pH}$ of 11 the stoichiometric dosage is 0.56 and $0.45 \mathrm{mg} / \mathrm{mg} \mathrm{Cl}_{2}$, respectively. However, 
at a $\mathrm{pH}$ of 8 and 7.35 the dosage increases to $1.86 \mathrm{mg} / \mathrm{mg} \mathrm{Cl}_{2}$ for STS and $0.99 \mathrm{mg} / \mathrm{mg}$ $\mathrm{Cl}_{2}$ for CTS, respectively. In these experiments the $\mathrm{pH}$ of the experimental water ranged from 7.5 to 8.5 , Therefore the later concentration were used as the stoichiometric basis. The Table 3 summarizes the required stoichiometric dosage of each dechlorination chemical to neutralize $1 \mathrm{mg}$ of $\mathrm{Cl}_{2}$ residual in solution.

\subsubsection{Mixing Regimes}

Three different mixing regimes were tested for each dechlorination agent to investigate the affects of variable mixing conditions on the reaction rate, and thus the required reaction time. Samples were either periodically mixed or continuously mixed at two different intensities (275 or $130 \mathrm{RPM}$ ). In the case of the continuous mixing, the mechanical mixer was continuously operated at 130 and 275 RPM for the full length of the experiments, from the point of dechlorination agent addition until the reaction was fully complete. For the periodic mixing case, the samples were mixed at 130 RPM for only the first 10 seconds following the addition of the dechlorination agent.

Typically, in wastewater applications, the mixing intensity is measured represented by the G-value, and the RPM values used in this study can be converted to G-values using the following formula:

$$
\begin{aligned}
& G=\left(\frac{P}{\mu V}\right)^{1 / 2} \\
& \mathrm{G}=\text { mean velocity gradient } \\
& \mathrm{P}=\text { power input }(\mathrm{Nm} / \mathrm{s} \text { or } \mathrm{W}) \\
& \mu=\text { viscosity of water at a given temperature }\left(\mathrm{N} . \mathrm{s} / \mathrm{m}^{2}\right)
\end{aligned}
$$




$$
\begin{aligned}
& \mathrm{V}=\text { volume of the reactor }(\mathrm{L}) \\
& 1 H P=745 W=\frac{2 \pi(T)(R P M)}{33000 f t . l b}
\end{aligned}
$$

$\mathrm{G}$ value is a function of tank volume, water temperature, and mixer shape, size, and horsepower (HP). Based on the toque value of 90 in.oz as indicated on the display unit of the mixer with a $9.5 \mathrm{~cm}$ impeller, equation 3 was used to calculate the power input $(\mathrm{P})$. For example, for the 130 RPM mixing intensity the G-value was calculated as follows:

$$
\begin{aligned}
& G=\left(\frac{P}{\mu V}\right)^{1 / 2} \\
& T=90 \text { in.oz } x \frac{1 f t . l b}{12 \times 16 \text { in.oz }}=0.469 \mathrm{ft} . \mathrm{lb} \\
& \text { Power }=\frac{2 \pi(0.469 \mathrm{ft} . \mathrm{lb})(130 \mathrm{RPM})}{33000 \mathrm{ft} . \mathrm{lb}}=0.0116 \mathrm{HP} x \frac{745.7 \mathrm{~W}}{1 \mathrm{HP}}=8.65 \mathrm{~W} \\
& \mu=0.0089 \mathrm{~N} / \mathrm{s} . \mathrm{m}^{2} \\
& V=8 L=0.008 \mathrm{~m}^{3} \\
& G=\left(\frac{8.65 \mathrm{Nm} / \mathrm{s}}{\left.0.0089 \mathrm{~N} / \mathrm{s.m^{2 } ( 0 . 0 0 8 \mathrm { m } ^ { 3 } )}\right)^{1 / 2}=349 \mathrm{~s}^{-1}}\right.
\end{aligned}
$$

Similarly, the G-value for the 275 RPM mixing regime was calculated to be $507 \mathrm{~s}^{-1}$.

The dosage tested for the effect of mixing conditions varied for each dechlorination chemical. Since the $10 \mathrm{x}$ stoichiometric dosage reactions were very fast, the next highest dosages that reached complete dechlorination in less than 180 seconds were tested for the 275 RPM and the periodic mixing cases, due to time constraints. 


\subsubsection{3 pH}

Two different $\mathrm{pH}$ ranges were tested: $\mathrm{pH} 6.5-8.5$ and $>9$. The former is the typical $\mathrm{pH}$ range of municipal wastewater (WEF \& ASCE, 1998), whereas the $\mathrm{pH}$ range $>9$ was chosen to simulate the scenario where the $\mathrm{pH}$ is slightly over the higher margin of the typical $\mathrm{pH}$ range of wastewater. Sulfuric acid $\left(\mathrm{H}_{2} \mathrm{SO}_{4}\right)$ was used to lower the $\mathrm{pH}$ and sodium hydroxide was $(\mathrm{NaOH})$ used to increase the $\mathrm{pH}$ of the test solutions.

\subsubsection{Methods of Data Analysis}

There are two types of analysis of kinetic data; the differential rate law shows how the rate of the reaction depends on concentrations, while the integrated rate law shows how the concentrations of the species in the reaction depend on time. Since the concentration of the reactants were measured as a function of time in these experiments, this data is useful in determining the integrated (concentration/time) rate law for the seven dechlorination chemicals. However, the form of the integrated rate law used for any reaction is dependent on the type of the reaction in consideration. The data was analyzed using the integral method because this method is useful when fitting simple reaction types corresponding to elementary reactions, and depending on the kinetic form of the reaction, integration yields different results. (Levenspiel, 1999; Zumdahl, 1998) Also, the integral method is easy to use, and is recommended when testing relatively simple rate expressions. The differential method was not used as it requires larger amounts of data. (Levenspiel, 1999) The following presents the way in which the order of the dechlorination reactions was determined. 
A particular rate equation was put to the test by comparing the predicted concentration versus the time curve with the experimental concentration versus time data (Levenspiel, 1999). Two different methods of analysis were used depending on the form of the reaction equation.

- Primary Method: When DA is well in excess (10x) of the stoichiometric requirement

- Irreversible Unimolecular-Type Reactions: A $\rightarrow$ products

- Zero order

- Pseudo-first order

- Pseudo-second order

- Secondary Method: When DA is close to the stoichiometric requirement.

- Irreversible bimolecular-type second-order reactions:

- Stoichiometric ratio of DA to $\mathrm{Cl}: 2 \mathrm{~A} \rightarrow$ products

- Greater than stoichiometric ratio $(2-4 \mathrm{x}): \mathrm{A}+\mathrm{B} \rightarrow$ products

Initially, the $10 \mathrm{x}$ stoichiometric data for all the chemicals were analyzed using the primary method and categorized into four different categories depending on the deduced reaction order. The four categories are: zero order kinetics and pseudo-first order. The kinetic data obtained for 1-4x stoichiometric dosages was analyzed using the secondary method. The following sections discuss the two methods of reaction order analysis used in this study. 


\subsubsection{Determination of the Reaction Order with Respect to Total}

\section{Chlorine Concentration: Irreversible Unimolecular-Type}

\section{Reactions}

Even though the dechlorination reaction is in the form of $\mathrm{DA}+\mathrm{Cl}_{2} \rightarrow$ Product, when the DA is well in excess of the stoichiometric requirement, this reaction form reduces to a unimolecular reaction in terms of total chlorine. The assumption in unimolecular reactions is that if the initial concentration of the dechlorination agent (henceforth represented by $\left.[D A]_{0}\right)$ is much higher than the initial concentration of total chlorine in solution (henceforth represented by $[\mathrm{TC}]_{0}$ ) the DA concentration will not change appreciably over the course of the reaction (Levenspiel, 1999). Thus, in order to investigate the order and the rate constants of the reactions in terms of the total chlorine concentration in solution, $10 \mathrm{x}$ stoichiometric dosages was tested.

The data obtained were subjected to three order tests, and plots were constructed for each of the seven dechlorination chemicals to investigate the order of the reaction:

1. Zero order kinetics: $-r=k$

$$
C_{A}=-k t+C_{0} \rightarrow \text { Thus, } t=\frac{1}{k}\left(C_{0}-C_{A}\right)
$$

Total chlorine (C) concentration versus time was plotted and if it yields a straight line, the slope $(\mathrm{k})$ represents the rate constant. For zero order reactions, the rate is constant, and it does not change with concentrations as it does for first-order or second-order reactions (Zumdahl, 1998).

2. First order kinetics: $-\mathrm{r}_{\mathrm{A}}=\mathrm{kC}_{\mathrm{A}}$ 


$$
-\ln \frac{C_{A}}{C_{A 0}}=k t \rightarrow \text { Thus, } t=\left(\frac{1}{k}\right) \ln \frac{C}{C_{0}}
$$

In this case the plot of $\ln (\mathrm{C} / \mathrm{Co})$ versus time gives a straight line, where the slope (-k) represents the rate constant. The derivation of the rate equation for a pseudo first order reaction is included in Appendix 3.

3. Second order kinetics: $-r_{A}=k C_{A}^{2}$

$$
\frac{1}{C_{A}}=k t+\frac{1}{C_{A 0}} \rightarrow \text { Thus, } t=\frac{1}{k}\left(\frac{1}{C_{A}}-\frac{1}{C_{A 0}}\right)
$$

In this case the plot of $1 / \mathrm{C}$ versus time gives a straight line where the slope $(\mathrm{k})$ represents the rate constant.

The $\mathrm{R}^{2}$ values for the line of best fit for all the data points were compared among the plots to deduce the order of the reaction for each of the dechlorination agents. The plots were also visually investigated to assess the best fit. The plot with the highest $R^{2}$ value was chosen as the plot that produced the best fit, and the reaction order was assigned accordingly.

\subsubsection{Determination of Overall Reaction Order of Dechlorination \\ Reactions: Irreversible Bimolecular-Type Second-order}

\section{Reactions}

\section{$\underline{\text { Reaction form } \mathrm{A}+\mathrm{B} \rightarrow \text { Products }}$}

When analyzing an irreversible bimolecular-type (e.g. A $+\mathrm{B} \rightarrow \mathrm{R}$ ) second-order reaction with $C_{A o} \neq C_{B o}$, the following rate expression can be tested:

$$
\ln \frac{M-X_{A}}{M\left(1-X_{A}\right)}=C_{A 0}(M-1) k t \quad \text { where } X_{A}=1-\frac{C_{A}}{C_{A 0}} \text { and } M=\frac{C_{B O}}{C_{A O}} \neq 1
$$


$C_{A o}=$ initial concentration of chlorine in experimental solution $(\mathrm{mg} / \mathrm{L})$

$C_{B o}=$ initial concentration of dechlorination agent added $(\mathrm{mg} / \mathrm{L})$

$X_{A}=$ the fraction of chlorine converted to products

$C_{A}=$ concentration of chlorine in the experimental solution $(\mathrm{mg} / \mathrm{L})$

In order to test the second order kinetics, plots of $\ln \frac{M-X_{A}}{M\left(1-X_{A}\right)}$ versus time were constructed and the obtained slope of the line was divided by $C_{A 0}(M-1)$ to obtain the $k$ value, which represented the second order reaction rate constant. If the plot yields a straight line then the reaction is determined to be second order.

If $C_{B 0}$ is much larger than $C_{A 0}$ (e.g. $10 \times$ stoichiometric dosages of the $D A$ ), $C_{B}$ remains approximately constant at all times, and as suggested by Levenspiel (1999), at this point the second order reaction equation presented above becomes the following pseudo firstorder reaction:

$$
-\ln \frac{C_{A}}{C_{A 0}}=k t
$$

\section{$\underline{\text { Reaction form } 2 \mathrm{~A} \rightarrow \text { Products }}$}

For the reaction between the stoichiometric dosage of the dechlorination agent and chlorine, since the initial concentration of chlorine and DA are equal, the second order reaction test was undertaken as the reaction is in the form of $2 \mathrm{~A} \rightarrow$ products. The reaction rate constant, $k$, was then determined by testing this rate expression by plotting $\frac{1}{C_{A}}$ versus time. This method failed to yield plots of straight lines, and the predicted $\mathrm{C}$ versus $t$ plots were not in agreement with the experimental results. Thus, this method was deemed unacceptable for the data analysis in this study. 


\subsubsection{List of Experiments}

Table 7 lists the experiments undertaken for each of the dechlorination agents.

Table 7: List of experiments undertaken for each of the seven dechlorination chemicals.

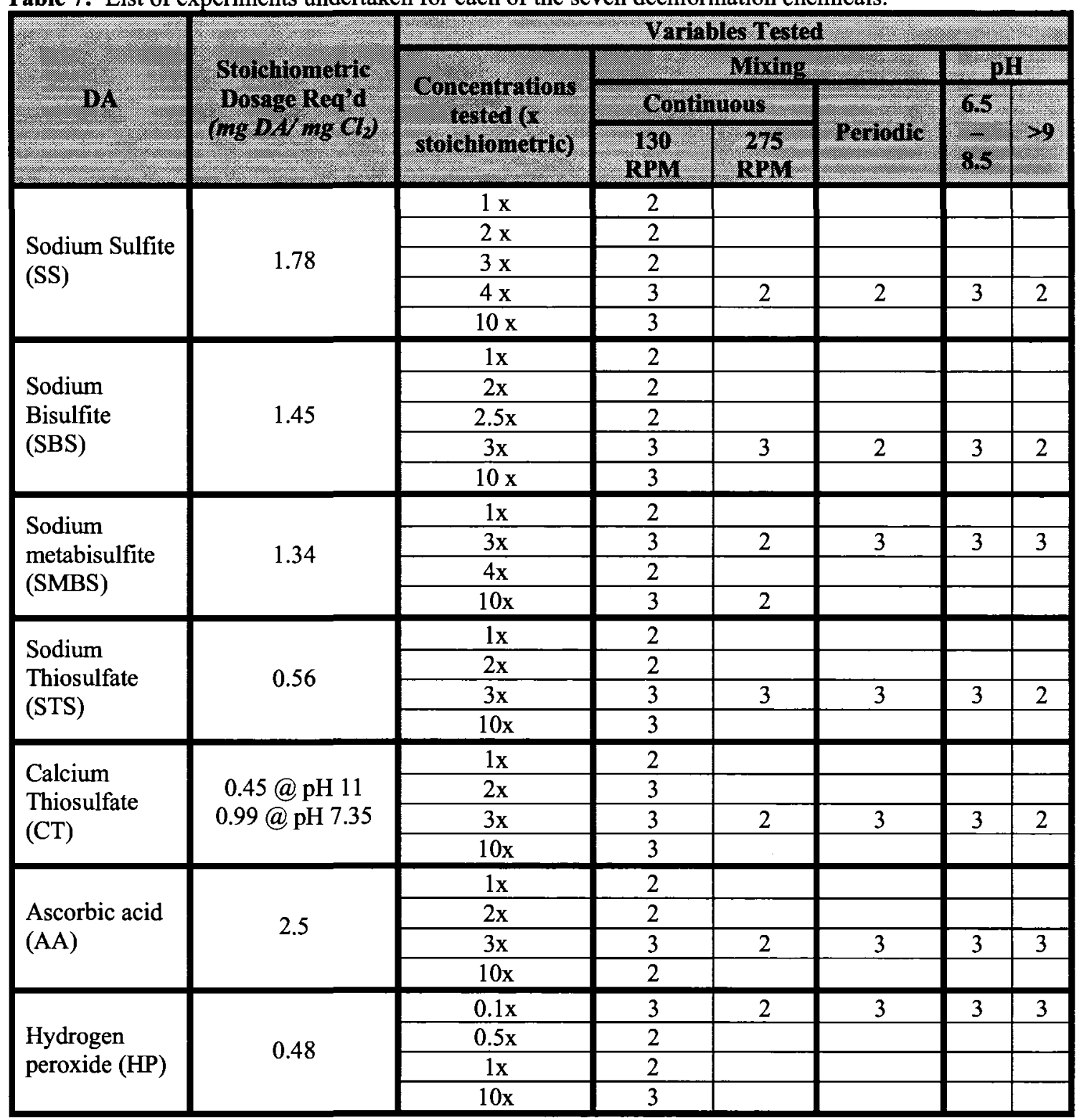

Minimum 2 or maximum 3 replicate experiments were undertaken for each dechlorination chemical. Mixing and $\mathrm{pH}$ were varied only for a selected concentration. 


\subsection{Aquatic Toxicity Testing: Daphnia Experiments}

The purpose of the daphnia experiments was to identify and assess the acute (short-term) toxicity of selected dechlorination chemicals to the dominant aquatic herbivore Daphnia magna through laboratory acute toxicity tests conducted according to the Environment Canada method for acute toxicity testing (EC,1990). Percentage mortality of Daphnia magna was investigated under various concentrations of the dechlorination chemicals to identify the least harmful dechlorination chemical to be used in practice.

\subsubsection{Test Organism}

The cultured organisms were maintained in DI water as required by the standard procedure, with hardness added according to Table 6, to simulate the hardness of water in North American rivers and lakes. The temperature of the culture solution was maintained at $20 \pm 1{ }^{\circ} \mathrm{C}$ by placing them in an incubator with a photo-period of $16 \mathrm{~h}$ light: $8 \mathrm{~h}$ dark of "cool-white" fluorescent light of $400-800$ lux. Dissolved Oxygen (DO) levels in the culture media were maintained at $>80 \%$ by aerating if necessary. The $\mathrm{pH}$ of the culture medium was adjusted to between $6-8.5$, using hydrochloric acid $(\mathrm{HCl})$ and sodium hydroxide $(\mathrm{NaOH})$, if necessary. Monthly 48 hour reference toxicity tests were conducted using zinc sulfate $\left(\mathrm{ZnSO}_{4}\right)$ as the reference toxicant to investigate the general health of the cultures. Stock cultures received daily water changes, and laboratory cultured algae feed of $12 \mathrm{~mL} / \mathrm{L}$ of dilution water, consisting of a mixture of Selenastrum capricornutum and Chlorella pyrenoidosa and $4 \mathrm{~mL} / \mathrm{L}$ of dilution water of laboratory prepared Yeast-cerophyl-trout chow (YCT) (USEPA, 2002). YCT was prepared according to the method outlined by USEPA (2002) using FLEISCHMANN'S® Yeast, 
TETRAMIN® fish flakes, and rabbit pellets made of alfa alfa leaves. Algal culture medium was also prepared according to the method outlined in the USEPA method 13 (2002).

The freshwater cladoceran Daphnia magna was used for all the toxicity tests. The initial batch of the Daphnia magna was obtained from CANMET Mining and Mineral Sciences Laboratories of Natural Resources Canada, Ottawa, Ontario. Two batches of culture organisms consisting of 40 daphnia each were initiated from the initial cultures in the laboratory. The test organisms were obtained from these in-house cultures, which were maintained according to the standard methods outlined by Environment Canada (1990) in the "Test Biological Test Method: Acute Lethality Test Using Daphnia spp."

\subsubsection{Test Procedure}

The tests were carried out in $250 \mathrm{~mL}$ Pyrex ${ }^{\circledR}$ beakers using $100 \mathrm{~mL}$ of dilution water with 5 neonates (daphnia $<24$ hours old, i.e. daphnids) per beaker, or $150 \mathrm{ml}$ of dilution water with 10 neonates per beaker. Additional care was taken by renewing the culture media 24 hours prior to the tests to ensure that the neonates were $<24$ hours old at the beginning of the tests. DI water with a hardness between $160-180 \mathrm{mg} / \mathrm{L}$ as $\mathrm{CaCO}_{3}$

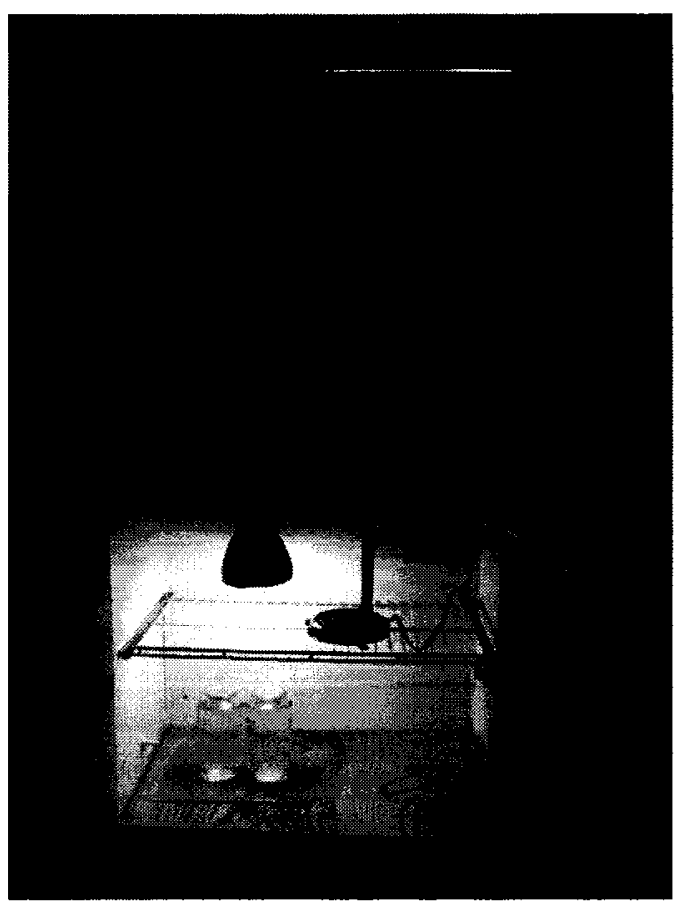

Figure 8: Culture jars in the incubator with the timed "cool-white" fluorescent light $\sim 30 \mathrm{~cm}$ above the water surface 
was used as the dilution water. Temperature, $\mathrm{DO}, \mathrm{pH}$ and conductivity of the test solutions were measured at least once at the beginning, or at the end of the tests as recommended by EC (1990). The temperature of the test solution was maintained in the incubator at $20 \pm 1{ }^{\circ} \mathrm{C}$ with a photoperiod of $16 \mathrm{~h}$ light: $8 \mathrm{~h}$ dark of "cool-white" fluorescent light of $400-800$ lux (Figure 8). The $\mathrm{pH}$ and the DO of the test solutions were not adjusted after the addition of the DA during the test setup, since suppression of $\mathrm{pH}$ and $\mathrm{DO}$ was one of the indirect effects of some DA on the aquatic environment (EC, 2003; Ryon et al., 2002). Thus, test solution $\mathrm{pH}$ and DO was measured before and after the addition of the DA for comparison purposes. The daphnids were not fed during the tests that lasted 48 hours and were visually observed in terms of mortality and movement at the beginning ( $0-1$ hours) and at the end of the test ( $48 \pm 2$ hours). Three replicates for each of the tests were used and the beakers were clearly labeled to indicate the concentration of DA. A control group was also tested (dilution water only) for comparison purposes.

\section{Stock Solution Prepared from Solids:}

Stock solutions with a concentration of $10 \mathrm{~g} / \mathrm{L}$ were prepared for SS, SMBS, SBS, AA, and STS by weighing and dissolving $1 \mathrm{~g}$ of the reagent grade chemical in the solid (crystal or powder) form in $100 \mathrm{~mL}$ of $\mathrm{DI}$ water. The stock solutions were prepared the day of the test in $100 \mathrm{~mL}$ volumetric flasks and stored in amber bottles (to prevent photoreactions) in a cool and dry place. Fresh stock solutions were prepared at the beginning of each test since previous studies reported a drop in S(IV) levels in stock solutions of SMBS over 48 hours (Yonkos et al., 2001). 


\section{Stock Solution Prepared from Solids:}

For HP and CTS the $30 \% \mathrm{w} / \mathrm{v}$ stock solution was diluted by adding $1 \mathrm{~mL}$ of stock into 10 $\mathrm{mL}$ of DI water, and appropriate volumes were added to each test solution to achieve the desired concentration below $20 \mathrm{mg} / \mathrm{L}$.

\section{Sample Calculations:}

Concentrations of DA ranging from $0-200 \mathrm{mg} / \mathrm{L}$ were tested and the volume of DA stock solution needed to achieve a given concentration of DA (e.g $200 \mathrm{mg} / \mathrm{L})$ in the 100 $\mathrm{mL}$ test beaker was calculated as follows:

Calculation 1 - For SS, SBS, SMBS, STS, and AA with $10 \mathrm{~g} / \mathrm{L}(=10 \mathrm{mg} / \mathrm{mL})$ stock solution concentration:

Desired DA concentration in $100 \mathrm{~mL}$ test solution $=200 \mathrm{mg} / \mathrm{L}$

Mass of DA needed for $100 \mathrm{~mL}=\frac{200 \mathrm{mg}}{1000 \mathrm{~mL}} \times 100 \mathrm{~mL}=20 \mathrm{mg}$

DA stock volume $=\frac{1 \mathrm{~mL}}{10 \mathrm{mg}} \times 20 \mathrm{mg}=2 \mathrm{~mL}$

Calculation 2 - For CTS and HP with $30 \%$ w/v $(=30 \mathrm{mg} / \mathrm{mL})$ stock solution concentration:

Desired DA concentration in $100 \mathrm{~mL}$ test solution $=200 \mathrm{mg} / \mathrm{L}$

Mass of DA needed in $100 \mathrm{~mL}=\frac{200 \mathrm{mg}}{1000 \mathrm{~mL}} \times 100 \mathrm{~mL}=20 \mathrm{mg}$

DA stock volume $=\frac{1 \mathrm{~mL}}{30 \mathrm{mg}} \times 20 \mathrm{mg}=0.667 \mathrm{~mL}=666 \mu \mathrm{L}$ 


\subsubsection{List of Experiments}

The concentrations of dechlorination chemicals tested for acute toxicity varied from 0 to $200 \mathrm{mg} / \mathrm{L}$. The maximum limit was conservatively set to $200 \mathrm{mg} / \mathrm{L}$, because such high concentrations of dechlorination chemicals are not expected in the wastewater effluent on a regular operation basis, although $200 \mathrm{mg} / \mathrm{L}$ could potentially represent an accidental spill into the aquatic environmental. Table 8 outlines the concentrations tested for each of the dechlorination chemicals, each of the concentrations was tested in replicates of 3 .

Table 8: Concentrations of DA used in 48 hours Daphnia magna mortality testing

\begin{tabular}{|l|l|}
\hline \multicolumn{1}{|c|}{$\boldsymbol{D A}$} & \multicolumn{1}{c|}{ Concentrations Tested $(\mathbf{m g} \boldsymbol{L})^{*}$} \\
\hline SS & $0,4.6,20,200$ \\
\hline SBS & $0,4.6,10,20,22,50,100,200$ \\
\hline SMBS & $0,20,50,80,100,200$ \\
\hline STS & $0,4.6,10,20,22,46,100,150,200$ \\
\hline CTS & $0,1,5,10,20,80,100,200$ \\
\hline AA & $0,1,10,20,100,200$ \\
\hline HP & $0,1,5,10,200$ \\
\hline Chlorine & $0,0.1,1,5,10$ \\
\hline
\end{tabular}

* For all of the dechlorination agents, a control solution was tested with dilution water and no dechlorination agent $(0 \mathrm{mg} / \mathrm{L})$

No chlorine was added to the test solution prior to the addition of the dechlorination agent, because the purpose of these acute toxicity tests was to identify the toxicity affects of the dechlorination agents themselves. Since the toxicity of chlorine itself to aquatic biota is well known, and as such is regulated by the amendment to CEPA (1999), the main focus of the aquatic toxicity tests was to identify the toxicity of the dechlorination agents. However, a separate 48 -hour toxicity test was undertaken using just chlorine to substantiate the toxic effects of chlorine on Daphnia magna. Concentrations of $0.1,1,2$, and $5 \mathrm{mg} / \mathrm{L} \mathrm{Cl}_{2}$ were tested without adjusting the $\mathrm{pH}$ and the $\mathrm{DO}$ of the test solutions. 
All the percentage mortality data obtained were plotted against the concentration of each of the dechlorination chemicals to investigate the critical concentrations of each DA that is needed to cause an appreciable mortality of daphnia. Also, for all the chemicals tested, obtained mortality results were used to calculate the 48 -hour $\mathrm{LC}_{50}$ values using the Graphical Method suggested by the USEPA (2002). The $\mathrm{LC}_{50}$ value is the dechlorination agent concentration at which $50 \%$ of the population died over the 48 hours. However, for STS and SS, LC50 values could not be calculated using this method because these chemicals did not cause any mortality at very high concentrations (e.g. $200 \mathrm{mg} / \mathrm{L}$ ); the obtained mortality rate did not bracket the $50 \%$ mortality mark for the concentrations tested, and more tests could not be conducted at higher concentrations due to time constraints. 


\section{Results and Discussion}

This chapter presents the results and conclusions for the two phases of the experiments undertaken as a part of this research project. Section 4.1 presents the results for the dechlorination experiments and analyzes these results in terms of their application in the wastewater treatment plant design. Section 4.2 includes a discussion of the acute toxicity test results used to identify the toxicity of these chemicals to the common fresh water herbivore Daphnia magna. Section 4.3 summarizes the application of the dechlorination kinetics and the acute toxicity test results to the wastewater treatment plant design process and explains how the results could be used to make decisions related to dechlorination agent application point, appropriate dosage and the contact time of the dechlorination agent needed to achieve complete dechlorination, and the best dechlorination chemical to be used in practice considering the chemical costs and the aquatic toxicity. 


\subsection{Dechlorination Experiments}

The following sections discuss the results of the dechlorination experiments undertaken to identify and compare the dechlorination kinetics of seven dechlorination chemicals that are currently used in practice. The seven dechlorination agents studied were: sodium sulfite (SS), sodium bisulfite (SBS), sodium metabisulfite (SMBS), sodium thiosulfate (STS), calcium thiosulfate (CTS), ascorbic acid (AA), and hydrogen peroxide (HP). The efficacy of these seven chemicals was evaluated under variable dosages, mixing regimes and $\mathrm{pH}$ conditions. Section 4.1.1 presents the way in which the reaction order of the dechlorination reactions was determined. In section 4.1.2 the affects of the three tested variables on the dechlorination rate is discussed.

As discussed in the experimental methodology section, there was a $20-25$ second lag time for the reaction solution to travel from the experimental container to the analyzer. Figure 9 shows the total chlorine data obtained for sodium metabisulfite, which mirrors the other six dechlorination agents tested. Although the reactants were in contact at $t=0$ seconds, changes in analyzer readings were not observed until 20 seconds had elapsed. In the case where the 20 second data were not available, up to 25 seconds of the initial data was omitted in the data analysis. 


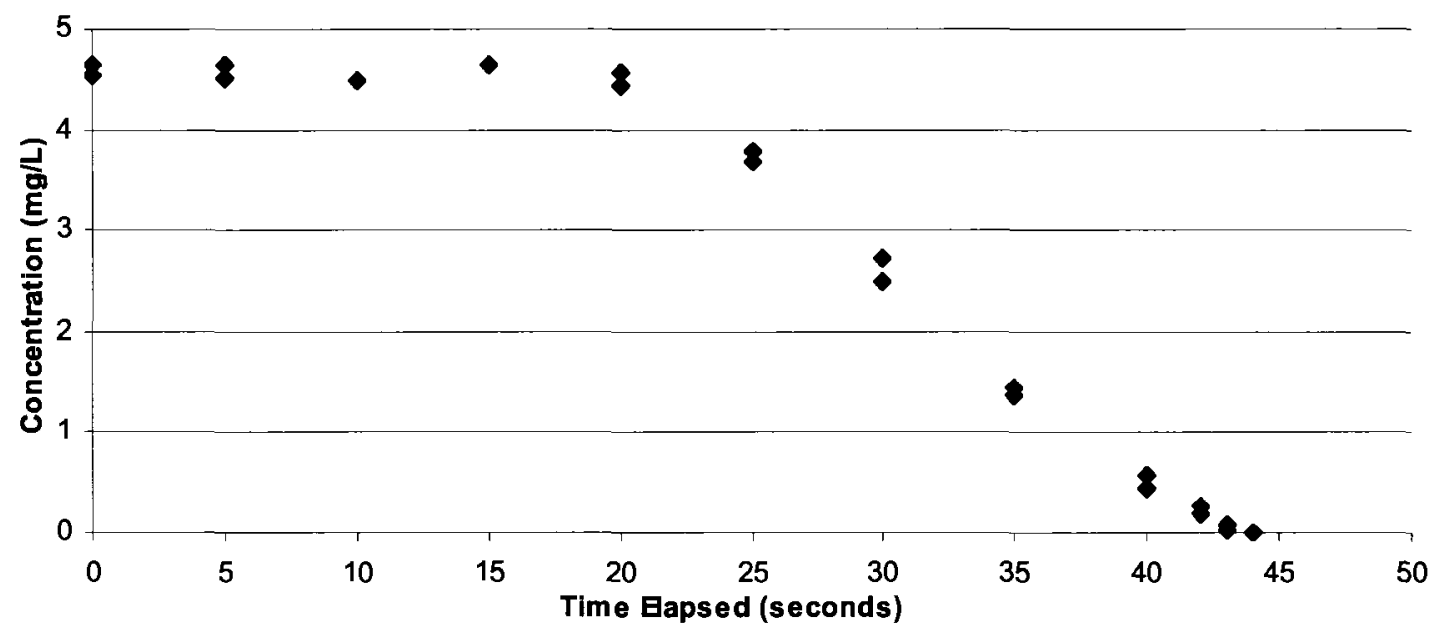

Figure 9: Measured total chlorine concentrations overtime following the addition of sodium metabisulfite to the experimental solution.

Also, once the FC and TC values reached a level below $0.10 \mathrm{mg} / \mathrm{L}$, the sensitivity of the chlorine analyzer deteriorated and the Hach DPD method has also been reported to be inaccurate (EC, 2003). Therefore, the $\mathrm{TC}$ and $\mathrm{FC}$ values below $0.10 \mathrm{mg} / \mathrm{L}$ were also omitted from the data analysis.

\subsubsection{Order of Dechlorination Reactions}

The following sections present the way in which the order of the dechlorination reactions were determined. Initially, $10 \mathrm{x}$ stoichiometric dosage of the dechlorination chemicals were analyzed to determine the reaction order with respect to TC. Tests were conducted for zero, first, and second order. For the dosages $<10 \mathrm{x}$ and $>1 \mathrm{x}$ stoichiometric dosages, the data were tested for first order kinetics with respect to both TC and DA concentrations, to determine if the overall order of the reaction is second order. For the $1 \mathrm{x}$ stoichiometric dosage of the dechlorination agent, the data was not subjected to any kinetic analysis as many of the chemicals failed to achieve complete dechlorination over 
the 180 second time period. The following sections discuss the primary and the secondary methods of reaction order analyses that were used in this study.

\subsubsection{Determination of the Reaction Order with Respect to Total \\ Chlorine Concentration at 10x stoichiometric ration of dechlorination agents}

In order to investigate the pseudo-zero, -first and -second order kinetics for the seven dechlorination chemicals tested with respect to the total chlorine concentration in solution, total chlorine concentration $(\mathrm{C}), \ln (\mathrm{C} / \mathrm{Co})$, and $1 / \mathrm{C}$ versus time graphs were constructed for the $10 \mathrm{x}$ stoichiometric dosage, respectively. A linear trendline was fitted to the data, and the $\mathrm{R}^{2}$ values for each of these plots were compared to see the goodness of fit (see Figure 10). The plot with the highest $\mathrm{R}^{2}$ value was chosen and the rate of the reaction was determined to be the slope of the linear trendline fitted to all the data. The following (see Figure 10) example demonstrates the method by which the order of the dechlorination reaction was deduced for the $10 \mathrm{x}$ stoichiometric dosage of sodium thiosulfate.

From Figure 10, the average $\mathrm{R}^{2}$ value for the zero, first and second order STS tests were $0.854,0.923,0.657$, respectively. Even though the $R^{2}$ value for the zero and the first order plots are similar, visual examination of the plots reveal that the zero order plots are closer to a curve than to a straight-line fit. Thus, since the $\ln (\mathrm{C} / \mathrm{Co})$ versus time plot produces the highest $\mathrm{R}^{2}$ value and the best visible straight-line fit of the data, the order of the STS reaction was determined to be pseudo first-order with respect to the total chlorine 
concentration in solution. From the slope of the trendline, the pseudo-first order rate constant is determined to be $0.108 \mathrm{~s}^{-1}$.

Free chlorine concentration of the experimental solution was also analyzed as shown in Figure 10. If the initial water sample was pure, the chlorine demand would be zero and also there would be no ammonia and other organic matter, and thus when sodium hypochlorite is added to the solution, combined chlorine will not be formed. If ammonia is present in the water sample however, some free chlorine will be consumed, and combined chlorine will be formed.

In pure water: Total residual chlorine $(\mathrm{TRC})=$ Free Chlorine $(\mathrm{FC})$

In the presence of ammonia or other impurities:

Ammonia/organic matter $+\mathrm{FC}=$ Combined Chlorine;

$\mathrm{TRC}=\mathrm{FC}+$ Combined Chlorine; and thus TRC $>$ FC 


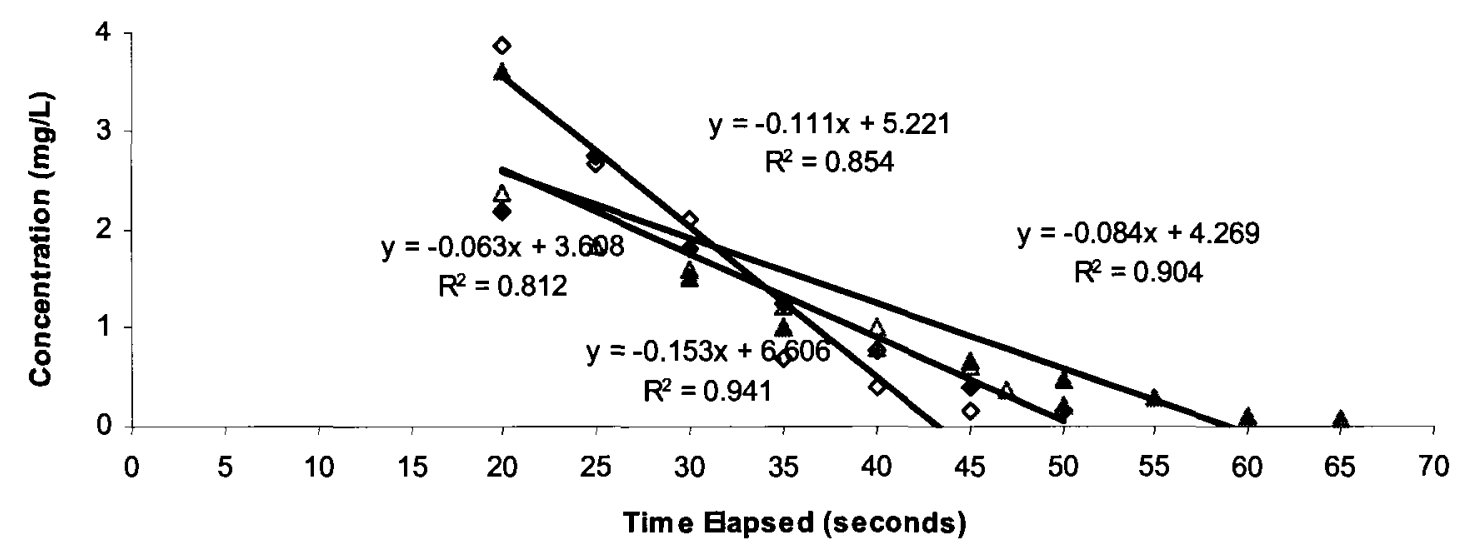

- Total C2 run1 $\diamond$ Total C2 run2 $\Delta$ Free C2 run1 $\Delta$ Freel C2 run2

(a) Zero order test

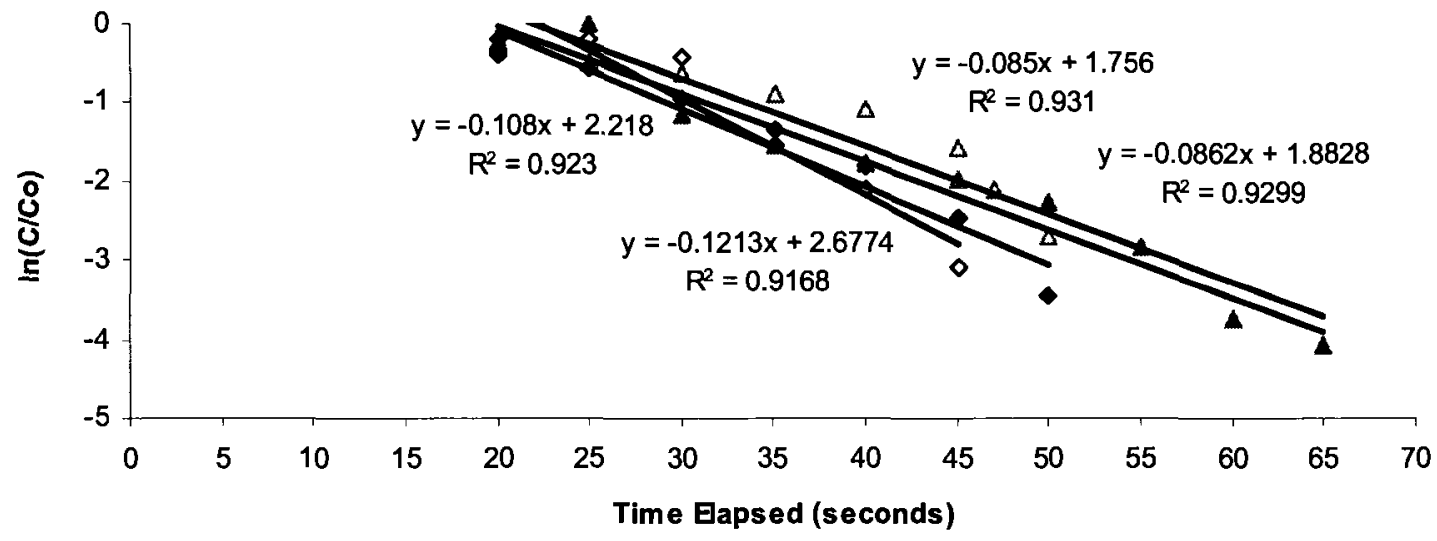

- Total C2 run1 $\diamond$ Total C2 run2 $\Delta$ Free C12 run1 $\Delta$ Free C2 run2

(b) Pseudo-first order test

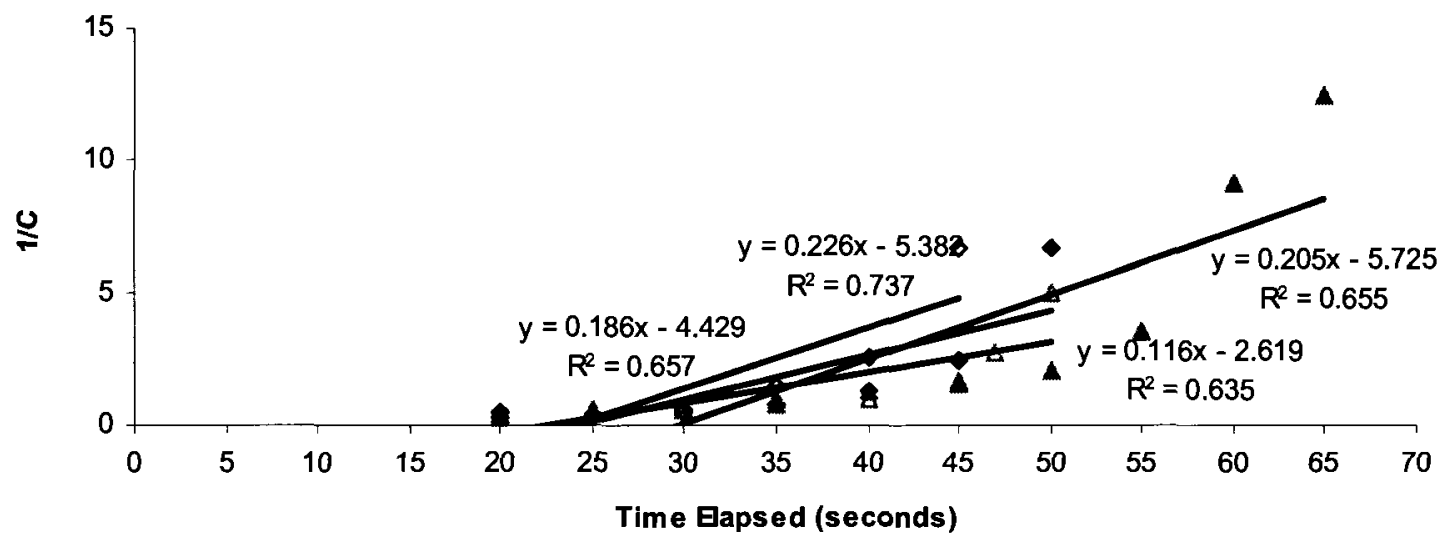

- Total C2 run1 $\diamond$ Total C12 run2 $\wedge$ Free C12 run1 $\Delta$ Free C12 run2

(c) Second order test

Figure 10 (a), (b), (c): Unimolecular pseudo first order tests for sodium. Data for the $10 \mathrm{x}$ stoichiometric dosage at continuous low intensity mixing and $\mathrm{pH} 6.5-8.5$ was used in the analysis. 
The CEPA (1999) regulation requires that the total residual chlorine (TRC) in solution be less than $0.02 \mathrm{mg} / \mathrm{L}$. Thus, the reaction order was analyzed in terms of the total residual chlorine concentration instead of the free chlorine concentration. The reason for using TC is because the total and the free chlorine concentrations were not equal as expected, which indicated the formation of combined chlorine species. The initial free chlorine concentration was lower than the total chlorine concentration in solution possibly because of the impurities of the water sample. For the free chlorine values below $\sim 0.30 \mathrm{mg} / \mathrm{L}$, the measured free chlorine value exceeded the total chlorine value in solution because the measuring equipment was not sensitive enough at such low values.

In addition, free chlorine values obtained were a lot more scattered compared to the total chlorine values due to sensitivity issues in the measuring equipment. Also, the agreement between the D1C residual analyzer measurements and the DPD measurements deteriorated for values of free chlorine below $1.0 \mathrm{mg} / \mathrm{L}$. For example, there were instances where the DPD measurements were $0 \mathrm{mg} / \mathrm{L}$ while the analyzer had a reading of $0.12 \mathrm{mg} / \mathrm{L}$. Therefore, the reaction kinetics were analyzed in terms of the total chlorine in solution and not the free chlorine concentration.

A similar analysis was undertaken for the runs with rest of the six dechlorination chemicals at 10x stoichiometric ratio (plots are shown in Appendix 3). For sodium sulfite, metabisulfite, thiosulfate and hydrogen peroxide, the dechlorination reaction with respect to the total chlorine concentration in solution was determined to be pseudo-first order. The plot of $\ln (\mathrm{C} / \mathrm{Co})$ versus time had the highest $\mathrm{R}^{2}$ value and the best visible fit, 
thus the reaction order was concluded to be pseudo-first order. However, in order to be certain that the reaction order and the rate found is the intrinsic reaction order, and the reactions are not affected by other variables such as the dosage, mixing and $\mathrm{pH}$, further analysis was conducted under those variable conditions. This analysis is discussed in the following sections.

Reaction with sodium bisulfite (SBS), calcium thiosulfate (CTS) and ascorbic acid (AA) were identified to have zero order kinetics with respect to $\mathrm{TC}$ at the $10 \mathrm{x}$ stoichiometric dosage, with the plot of total chlorine concentration versus time giving the best visible straightline fit and the highest $\mathrm{R}^{2}$ value indicating that the reactions were zero order with respect to $\mathrm{TC}$.

The orders of the reactions obtained from the above analyses, as well as the determined reaction rate constants $(k)$, are reported in Table 9.

Table 9: Apparent reaction orders (with respect to total chlorine concentration) and rate constants for the seven dechlorination chemicals tested at $10 \mathrm{x}$ stoichiometric ratio.

\begin{tabular}{|c|c|c|c|c|}
\hline Pechlowingiron & Pate Equation & 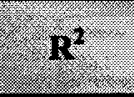 & $\begin{array}{l}\text { Prendo Rate } \\
\text { Constant (W) }\end{array}$ & Reaction Orider \\
\hline Sodium Sulfite & $\mathrm{r}_{\mathrm{TC}}=0.142[\mathrm{TC}]$ & 0.874 & 0.142 & Pseudo-first \\
\hline Sodium Bisulfite & $\mathrm{r}_{\mathrm{TC}}=0.626$ & 0.966 & 0.626 & Zero \\
\hline Sodium Metabisulfite & $\mathrm{r}_{\mathrm{TC}}=0.172[\mathrm{TC}]$ & 0.969 & 0.172 & Pseudo-first \\
\hline Sodium Thiosulfate & $\mathrm{r}_{\mathrm{TC}}=0.108[\mathrm{TC}]$ & 0.923 & 0.108 & Pseudo-first \\
\hline Calcium Thiosulfate & $\mathrm{r}_{\mathrm{TC}}=0.280[\mathrm{TC}]$ & 0.993 & 0.280 & Zero \\
\hline Ascorbic Acid & $\mathrm{r}_{\mathrm{TC}}=0.395$ & 0.788 & 0.395 & Zero \\
\hline Hydrogen Peroxide & $\mathrm{r}_{\mathrm{TC}}=0.502[\mathrm{TC}]$ & 0.851 & 0.502 & Pseudo-first \\
\hline
\end{tabular}

* The pseudo rate constants are $k[\mathrm{DA}]^{\mathrm{x}}$, where $\mathrm{x}$ is the undetermined order w.r.t [DA]. Units would depend on the value of $x$.

[TC] denotes the concentration of total chlorine 
For the 10x stoichiometric dosage of the DAs the data was possible to be analyzed as irreversible unimolecular type reactions because the DA was well in excess of the $\mathrm{Cl}_{2}$ concentration in solution. For $2-4 \mathrm{x}$ dosages however the DA concentration was concluded to be not sufficiently in excess to assume that the DA concentration remained constant from the beginning to the end of the experiment. Thus, the order of the $2-4 x$ dosages were analyzed assuming that the reactions were irreversible bimolecular-type second order reactions, and the pseudo-order (determined at 10x dosage) of the reaction with respect to the TC concentration in solution (determined at 10x dosage) was assumed to be the same at lower dosages (Table 9).

\subsubsection{Test for First Order Reaction Order with respect to both Reagents at near Stoichiometric Ratios of [DA]/[TC]}

\section{$\underline{2-4 x \text { Stoichiometric Dosages }}$}

The tests at 10x stoichiometric above suggested zero order kinetics with respect to [TC] in some cases and first order in others. The dependance on DA concentration cannot be determined with the current experimental procedure lacking concentration measurement capability for all the dechclorination agents. In order to investigate if the dechlorination reactions can be tested for first order kinetics with respect to both reagents (second order overall), the $2 \mathrm{x}, 3 \mathrm{x}$ and $4 \mathrm{x}$ stoichiometric dosage data was tested for second order using the irreversible bimolecular second-order test for the reaction form $\mathrm{A}+\mathrm{B} \rightarrow$ products. Thus, the reaction rate equation will be as follows:

$$
-r_{\text {overall }}=k_{\text {overall }} C_{T C} C_{D A}
$$


If the reaction between DA and chlorine is second order at $2 \mathrm{x}-4 \mathrm{x}$ stoichiometric concentrations of the DAs, the plots of $\ln \frac{M-X_{A}}{M\left(1-X_{A}\right)}$ versus time are expected to produce straight lines. Each run for the $2 \mathrm{x}-4 \mathrm{x}$ stoichiometric dosage experiments were analyzed separately and determined to have a straighline fit, which indicated that the dechlorination reactions were second order overall. The obtained slopes of the trendlines were then divided by the respective $C_{A 0}(M-1)$ values for each of the runs and the reaction rate constants $(\mathrm{k})$ were calculated for each run. The average of the reaction rate constants of all the runs for each test condition was calculated to be the overall $\mathrm{k}\left(\mathrm{k}_{\text {overall }}\right)$ value of each reaction.

The second order tests conducted for SBS, CTS and AA are shown in Figure 11. For the 2x stoichiometric dosage of SBS, CTS and AA the obtained $\mathrm{k}_{\text {overall }}$ was $0.952,1.193$ and $0.877 \mathrm{~L} / \mathrm{mol} . \mathrm{s}$, respectively. Similar $\mathrm{k}_{\text {overall }}$ values of $0.1 .059,0.713$ and $0.989 \mathrm{~L} / \mathrm{mol} . \mathrm{s}$ were obtained for the $3 \mathrm{x}$ stoichiometric dosage of SBS and AA, respectively. These results indicate that the second order rate constant for the reaction involving SBS, CTS and $\mathrm{AA}$ is between $0.877-1.193 \mathrm{~L} / \mathrm{mol} . \mathrm{s}$ and that the overall reaction involving SBS, CTS, AA and chlorine is second order. 


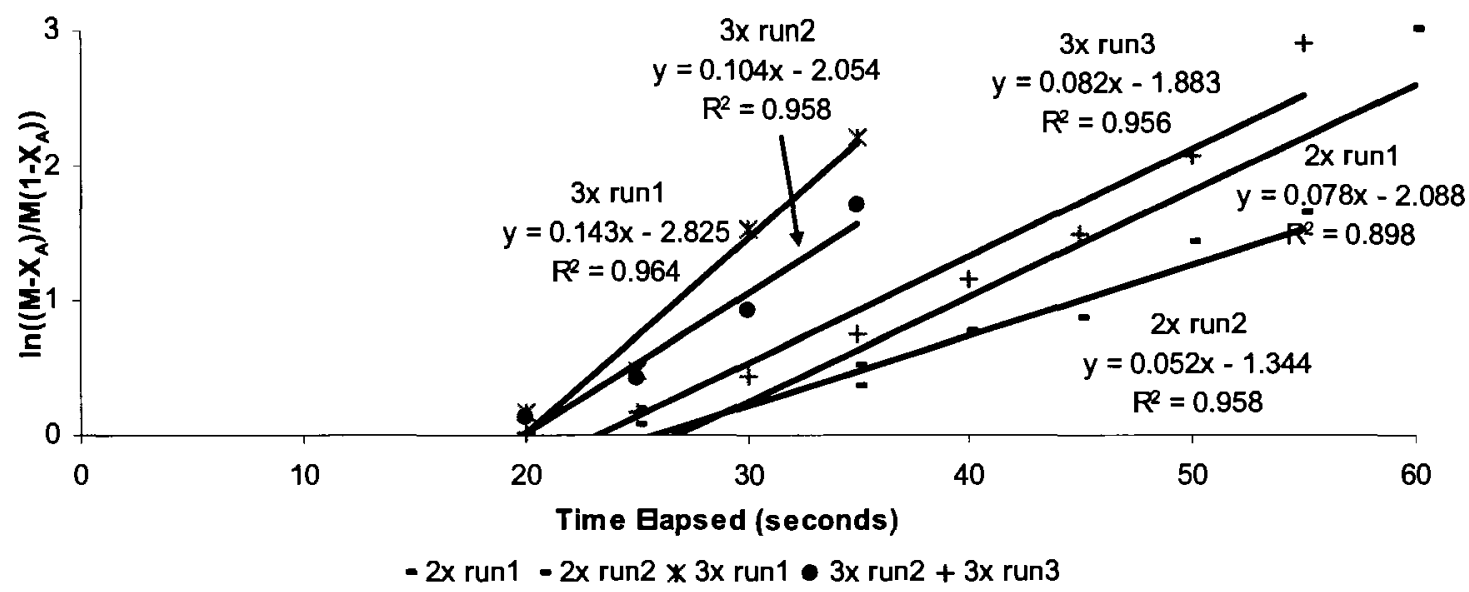

(a) Sodium bisulfite

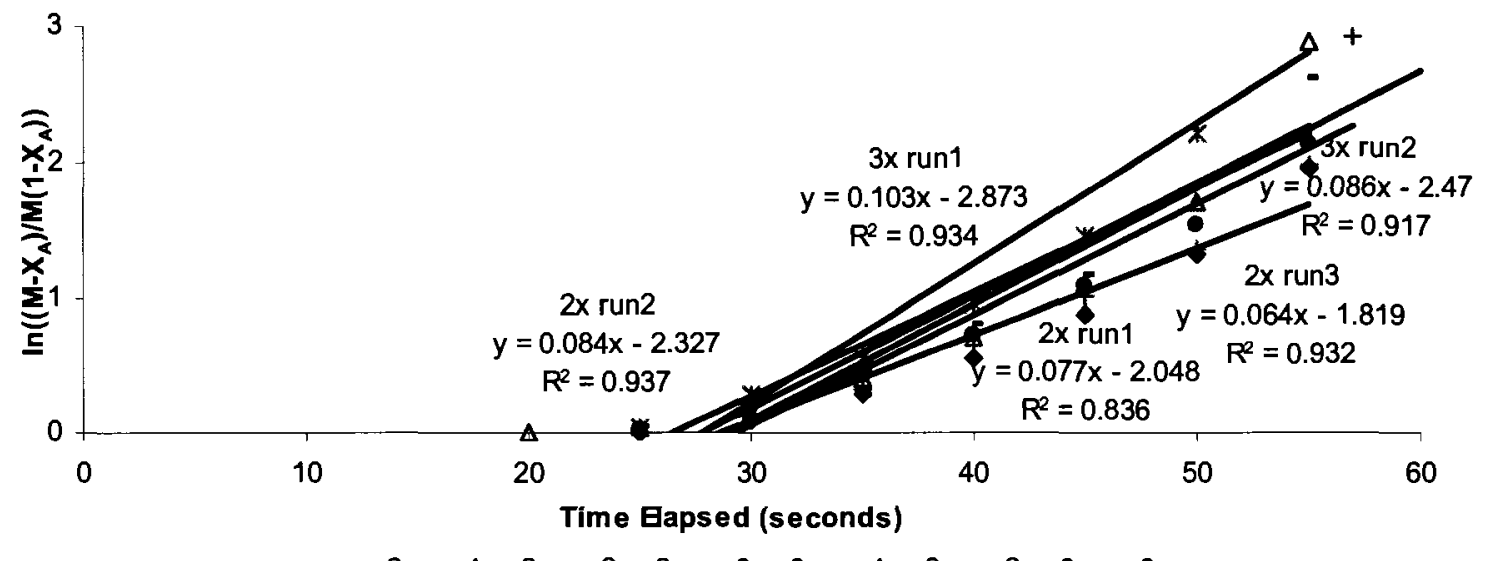

$\Delta 2 x$ run1 $-2 x$ run $2 \bullet 2 x$ run $3 * 3 x$ run $1 \bullet 3 x$ run $2+3 x$ run 3

(b) Calcium thiosulfate

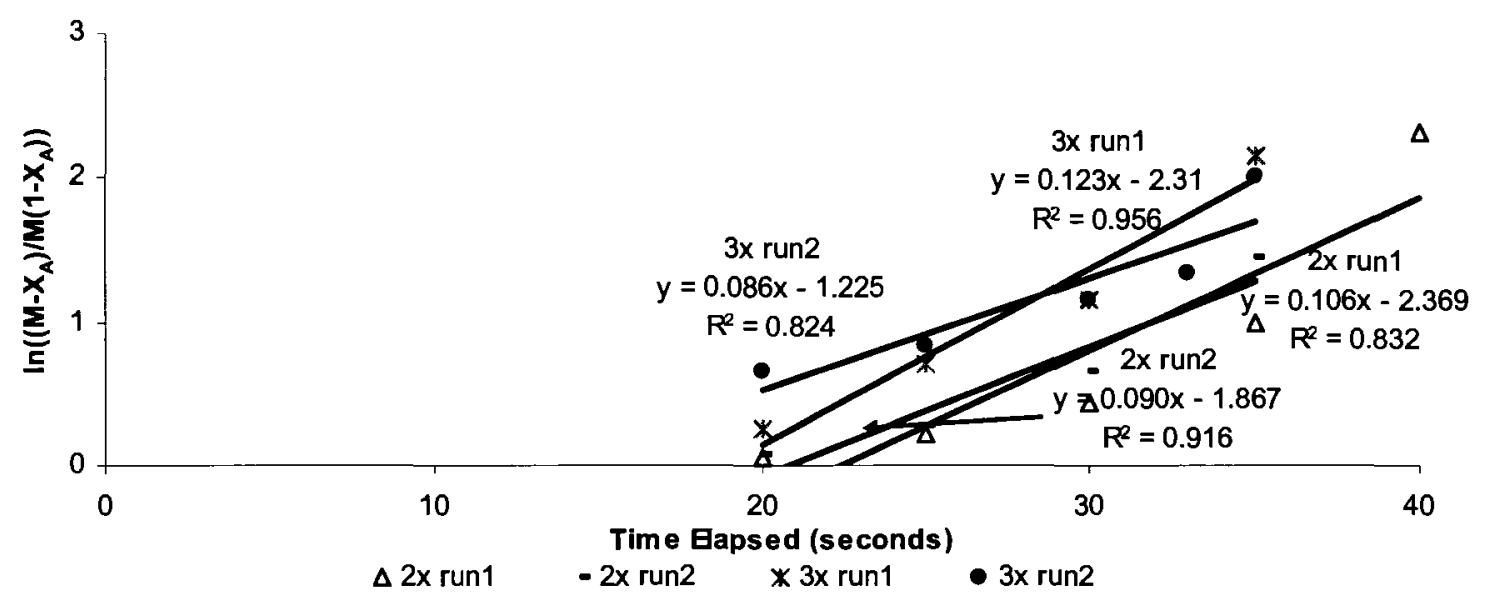

(c) Ascorbic acid

Figure 11: Second order tests undertaken for the $2-3 \mathrm{x}$ stoichiometric dosages of sodium bisulfite, calcium thiosulfate and ascorbic acid. 
Table 10: Second order reaction rate constants $(\mathrm{L} / \mathrm{mol} . \mathrm{s})$ for the dechlorination reactions of sodium bisulfite and ascorbic acid at $2 \mathrm{x}$ and $3 \mathrm{x}$ stoichiometric dosage.

\begin{tabular}{|c|c|c|c|c|c|c|c|c|c|c|}
\hline & 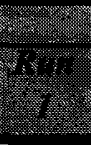 & & & 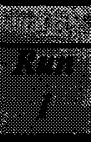 & 9 & & 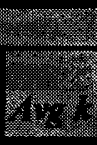 & 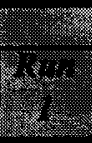 & $\frac{4}{4}$ & 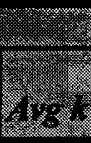 \\
\hline 2x stoich & 1.009 & 0.894 & 0.952 & 1.207 & 1.411 & 0.974 & 1.193 & 0.822 & 0.932 & 0.877 \\
\hline 3xstoich & 1.251 & 0.867 & 1.059 & 0.789 & 0.729 & 0.697 & 0.713 & 1.268 & 0.709 & 0.989 \\
\hline
\end{tabular}

*solution pH was between 6.5-8.5 and reactions were continuously mixed at 130 RPM

Reactions involving SMBS and STS which had pseudo-first order reaction kinetics with respect to the total chlorine concentration at 10x stoichiometric dosage, had good fits for the first order test with respect to each of the reactants (second order overall) at $2 \mathrm{x}-4 \mathrm{x}$ stoichiometric dosages (Figure 12).

The calculated reaction rate constant values are tabulated in Table 11.

Table 11: Second order reaction rate constants ( $\mathrm{L} / \mathrm{mol} . \mathrm{s})$ for the dechlorination reactions of sodium sulfite, metabisulfite, and sodium thiosulfate at $2-4 \mathrm{x}$ stoichiometric dosage.

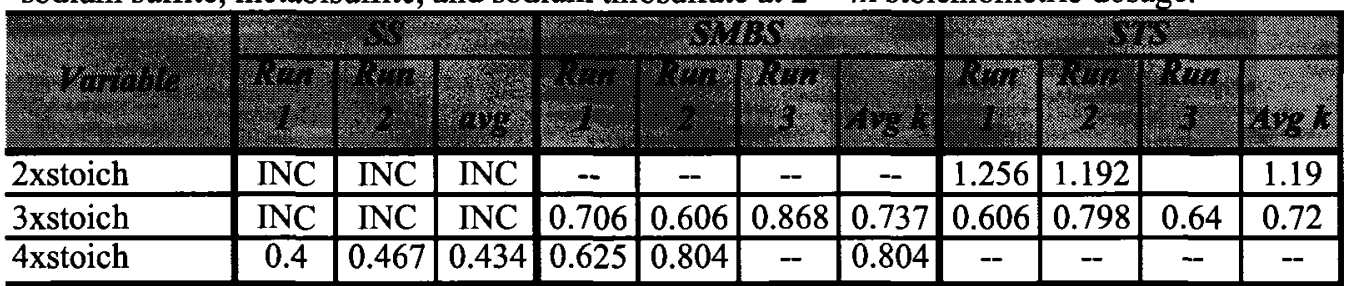

solution pH was between 6.5-8.5 and reactions were continuously mixed at $130 \mathrm{RPM}$ $\mathrm{INC}$ - denotes that the reaction did not reach completion within 180 seconds.

-- denotes concentrations that were not tested 


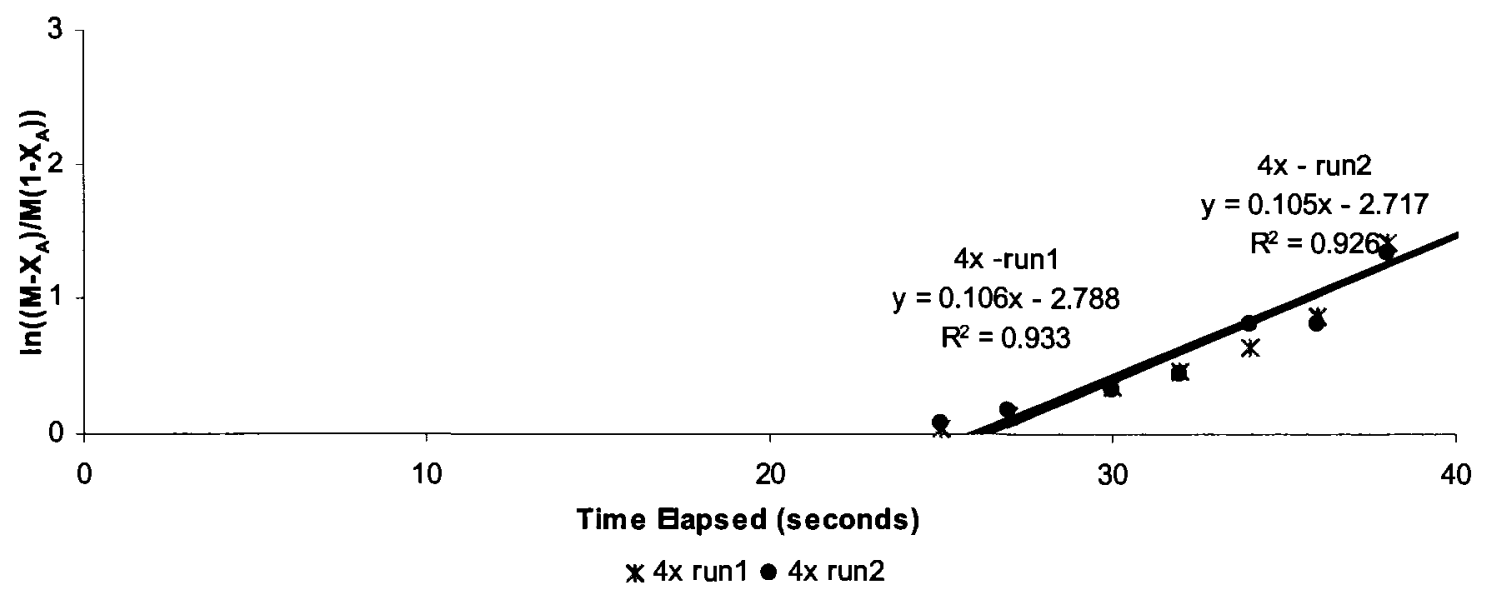

(a) Sodium sulfite

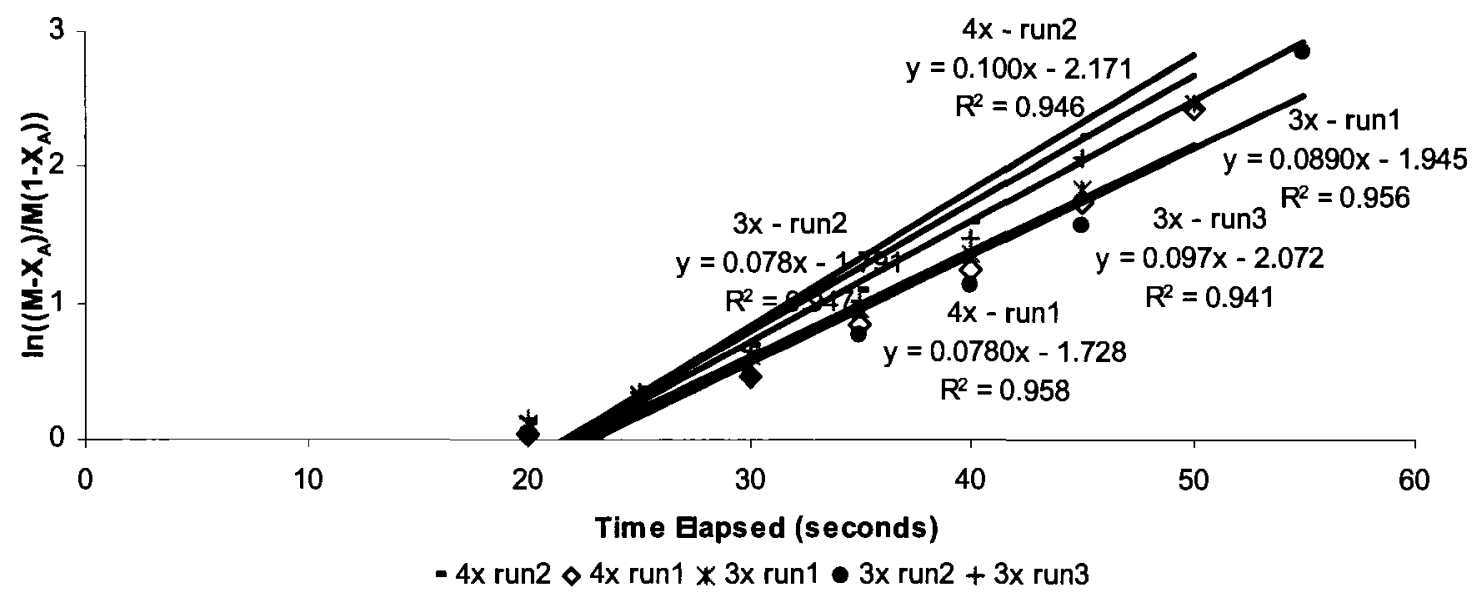

(b) Sodium metabisulfite

Figure 12: Second order tests for the $2-3 x$ stoichiometric dosages of sodium sulfite, sodium metabisulfite, sodium thiosulfate and calcium thiosulfate.

\section{Special Case}

HP was a special case because it achieved complete dechlorination with less than $1 \mathrm{x}$ stoichiometric dosages (e.g. $0.1 \mathrm{x}$ stoichiometric dosage) of the dechlorination agent. Interferences with the analytical unit and other possible side reactions, which may have either catalyzed the reaction or reduced chlorine via an alternate reaction mechanism, are suspected to be a few possible reasons for this finding. Consequently, only $10 \mathrm{x}$ and the $1 \mathrm{x}$ stoichiometric data of HP was analyzed for the reaction kinetics. 


\section{$\underline{1 x \text { Stoichiometric Dosage }}$}

For SS, STS and AA the reactions involving the $1 \mathrm{x}$ stoichiometric dosage were not analyzed for the reaction order because those reactions did not reach completion within the 180 second reaction time. For the rest of the four chemicals (SBS, SMBS, CTS, HP), the $1 \mathrm{x}$ stoichiometric dosage data was analyzed using the second order reaction tests for the reactions in the form of $2 \mathrm{~A} \rightarrow$ Products as shown in Section 3.1.3.2. Plots of $\frac{1}{C_{A}}$ versus time were constructed to investigate a straight line fit as shown in Figure 13.

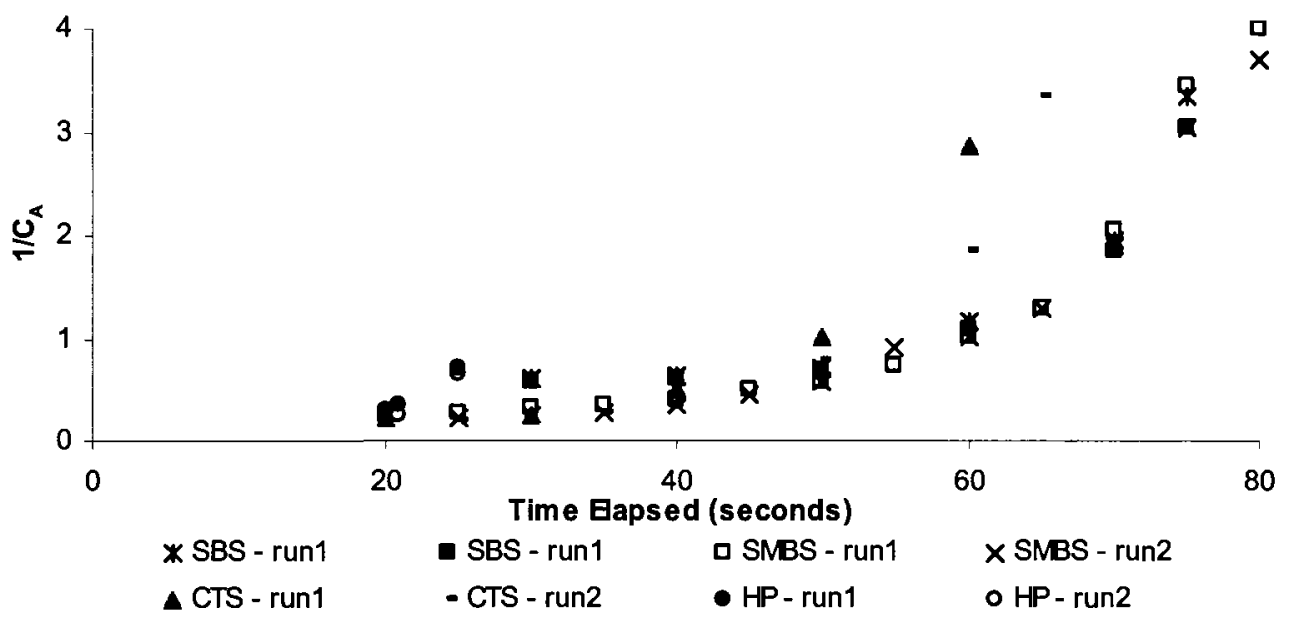

Figure 13: Second order test for the 1x stoichiometric dosages of Sodium bisulfite, sodium metabisulfite, calcium thiosulfate, and hydrogen peroxide.

The plots failed to produce a straight line fit and were better described by a curve, which confirmed that at $1 \mathrm{x}$ stoichiometric dosage the reaction between the above DAs and chlorine is not second order. Further analysis to determine the order at $1 \mathrm{x}$ stoichiometric dosage was not conducted due to time constraints and analyzing the kinetic data to check for fractional order or mixed order. 


\subsubsection{Impact of Tested Variables on the Dechlorination Rate}

Three variables were tested to investigate their effects on the dechlorination reaction rate. Stoichiometric dosage of the DA was varied from 1- 10x stoichiometric to investigate the affects of variable dosage on the dechlorination rate and the results are reported in section 4.1.2.1. Section 4.1.2.2 presents the kinetic results obtained under variable mixing conditions. The effect of varying $\mathrm{pH}$ on the dechlorination rate of these chemicals is discussed in section 4.1.2.3.

\subsubsection{Impact of DA Dosage on Dechlorination}

Typically, the recommended DA dosage for municipal wastewater applications is $10 \%$ in excess of the stoichiometric requirement. For sulfur (IV) compounds, the recommended dosage is 1:1 (WEF \& ASCE, 1998). However, the kinetic data obtained through experiments in this study indicated that most dechlorination agents were unable to achieve complete dechlorination within a reasonable amount of time $(<180$ seconds $)$ with a $1 \mathrm{x}$ stoichiometric dosage. The following sections present the reaction rates deduced for the different dechlorination chemicals under varying dosages.

\section{Reactions Incomplete at 1x Stoichiometric Dosage}

At $1 \mathrm{x}$ stoichiometric dosage of SS, STS and AA, the dechlorination reactions did not reach completion in 180 seconds (Figure 14). 


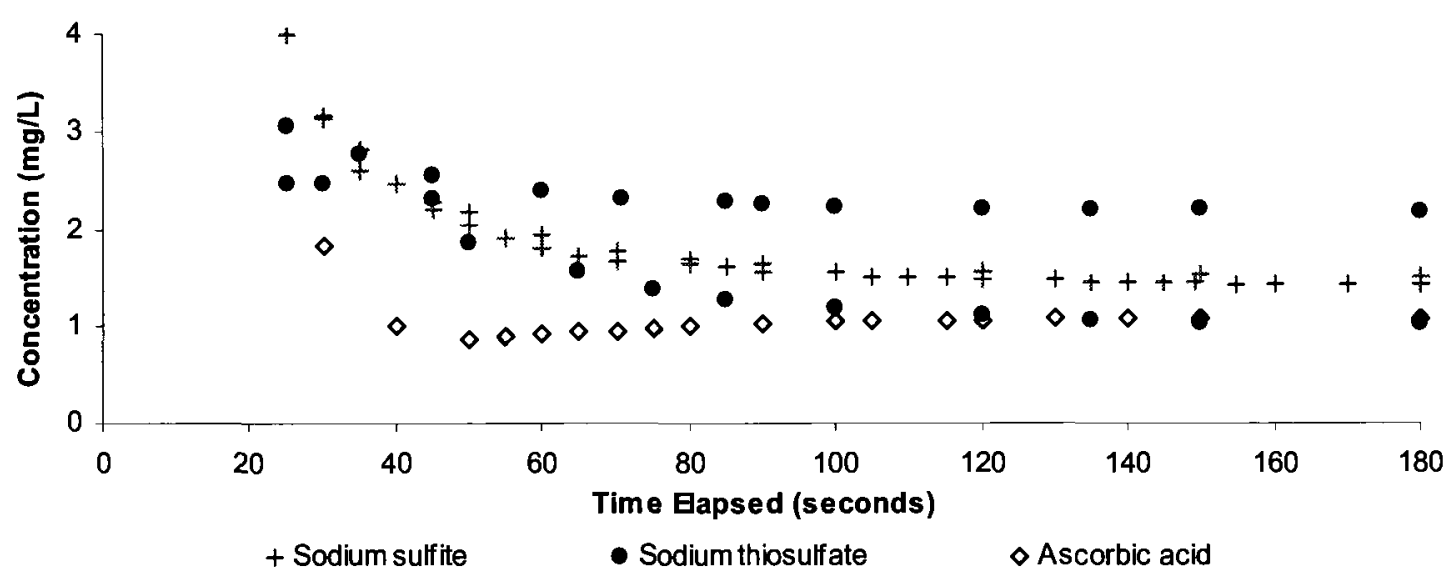

Figure 14: Kinetic results for sodium sulfite, sodium thiosulfate and ascorbic acid under 1x stoichiometric dosage.

For SS, not only the $1 \mathrm{x}$ stoichiometric reaction was incomplete, but the $2 \mathrm{x}$ and the $3 \mathrm{x}$ stoichiometric reactions were also incomplete. At the $4 \mathrm{x}$ dosage the SS reaction reached completion (Figure 15) and the overall reaction rate constant was $0.434 \mathrm{~L} / \mathrm{mol} . \mathrm{s}$. When the dosage was increased to 10x stoichiometric, the SS reaction rate constant was $0.142 \mathrm{~s}$ ${ }^{1}$ with respect to total chlorine concentration. These experimental results show that 1,2 and even $3 \mathrm{x}$ dosages of SS were insufficient to achieve complete dechlorination within 180 seconds. Dosages greater than $3 \mathrm{x}$ stoichiometric of SS were required to achieve complete neutralization within a reasonable amount of time. Further experimental investigations are needed at dosages between $3 \mathrm{x}$ and $4 \mathrm{x}$ stoichiometric (e.g. 3.5x) to definitively deduce the minimum dosage needed to achieve complete dechlorination with SS. 


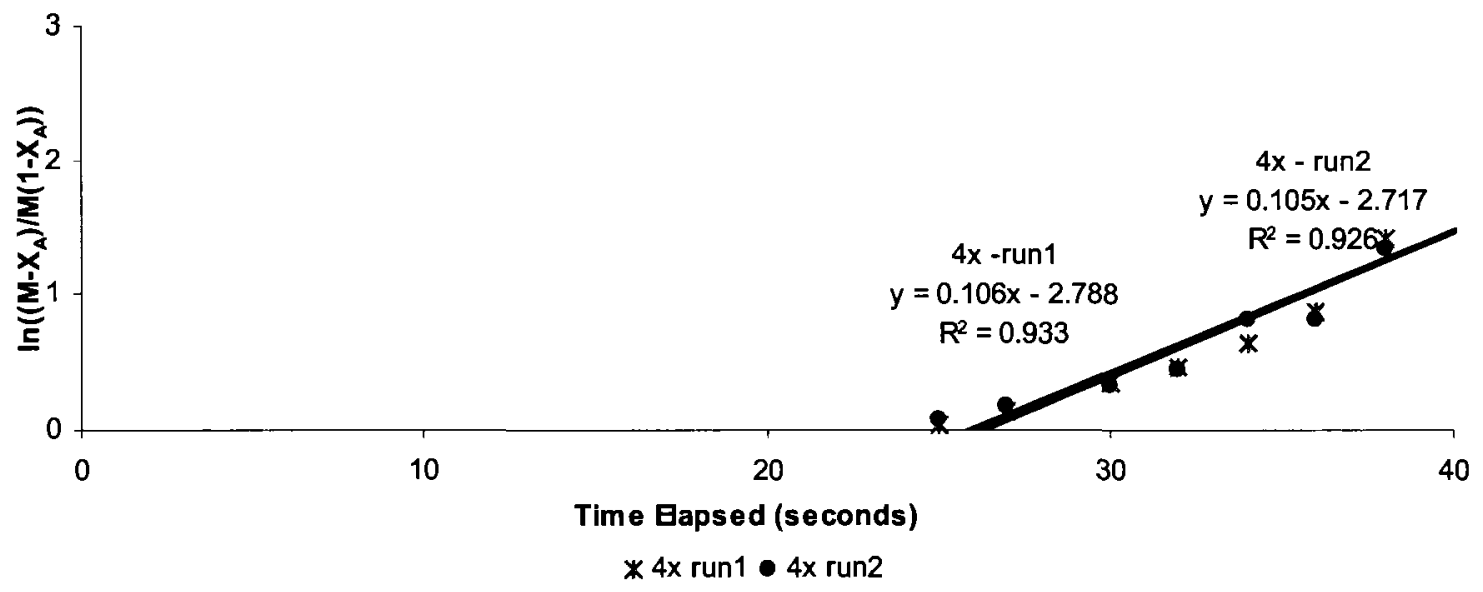

(a) Sodium sulfite

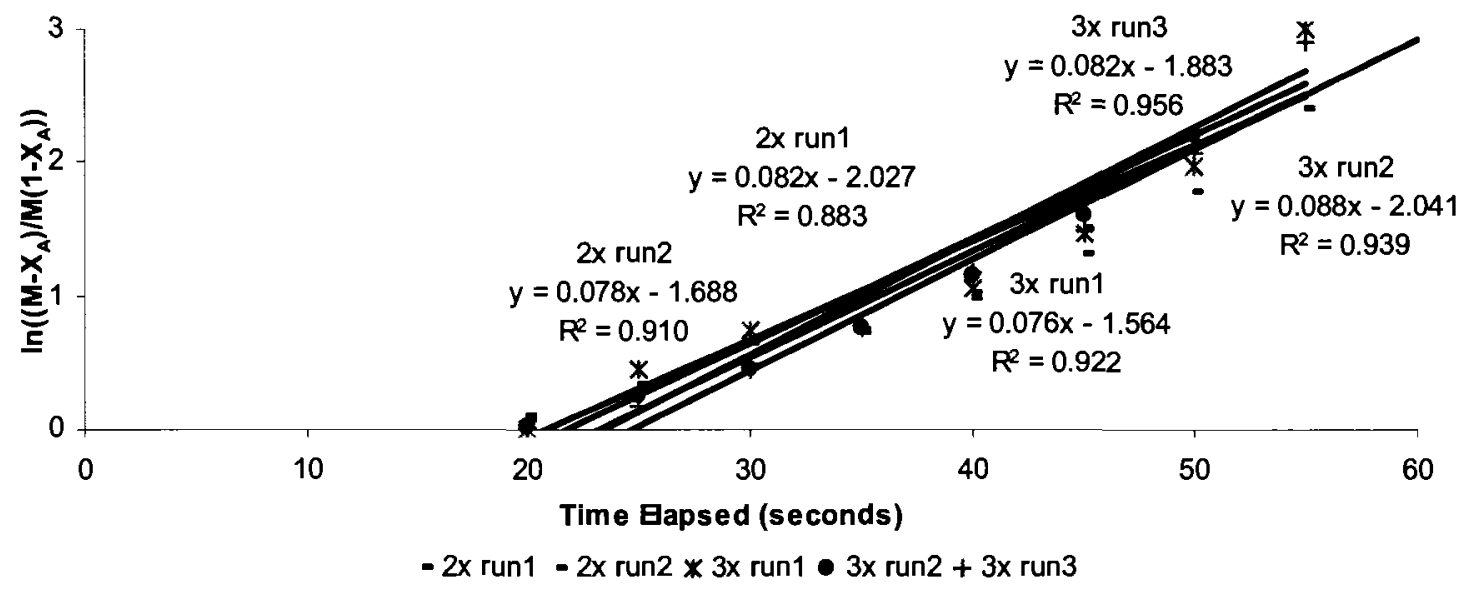

(b) Sodium thiosulfate

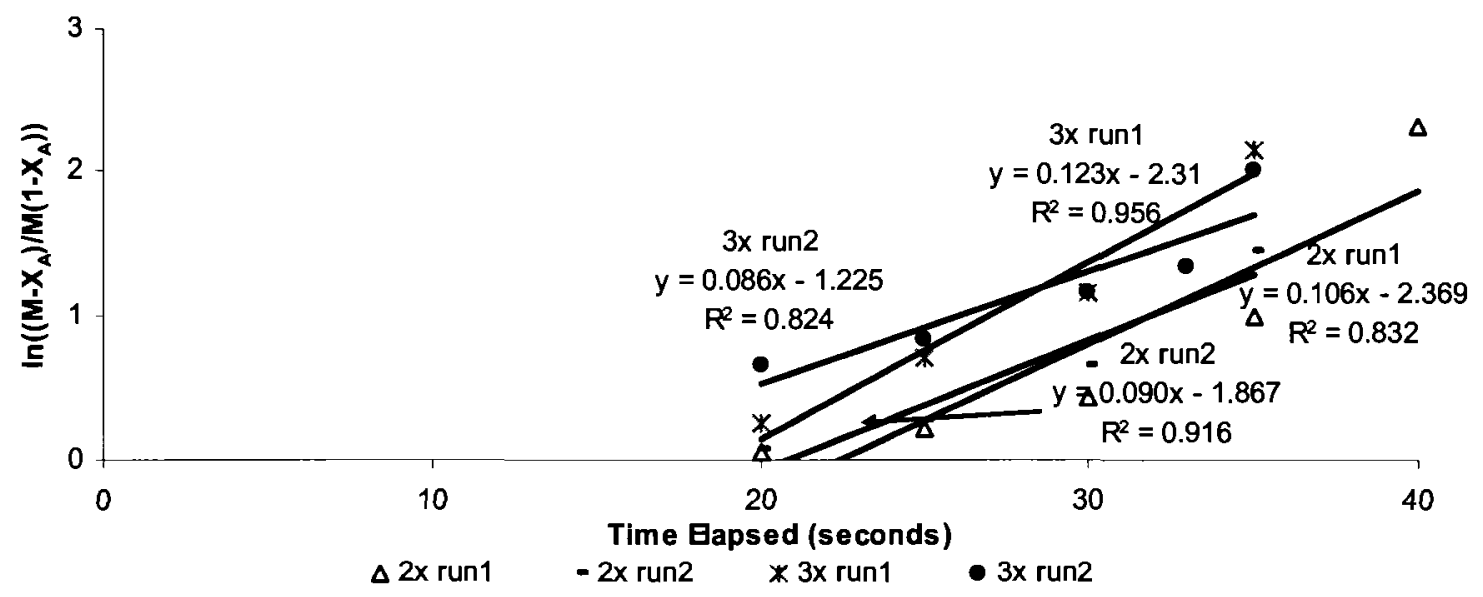

(c) Ascorbic acid

Figure 15: Kinetic data for sodium sulfite, thiosulfate and ascorbic acid under various dosages (2-4x). The solution $\mathrm{pH}$ was between $6.5-8.5$ and the samples were continuously mixed at $130 \mathrm{RPM}$. 
Kinetic data obtained for STS is plotted in Figure 15. Even though the reactions with $1 \mathrm{x}$ stoichiometric dosage of STS were incomplete, when the dosage was doubled to $2 \mathrm{x}$ the stoichiometric requirement the reaction reached completion with a overall second order reaction rate constant of $1.19 \mathrm{~L} / \mathrm{mol} . \mathrm{s}$. When the dosage was tripled to $3 \mathrm{x}$ stoichiometric, the overall reaction rate constant for STS decreased to $0.720 \mathrm{~L} / \mathrm{mol} . \mathrm{s}$, which is a 1.7 fold decrease from the $2 \mathrm{x}$ dosage. This decrease in reaction rate could also be attributed to experimental error, and further studies are needed at both the $2 \mathrm{x}$ and $3 \mathrm{x}$ dosages to investigate the reaction rates at these dosages. When the dosage was increased to $10 \mathrm{x}$ stoichiometric, the STS reaction rate constant was $0.108 \mathrm{~s}^{-1}$ (Figure 10b). Thus, for STS, it is apparent that a stoichiometric dosage of $1 \mathrm{x}$ is insufficient to achieve $0.02 \mathrm{mg} / \mathrm{L}$ of $\mathrm{Cl}_{2}$ residual levels. Using STS dosages greater than $1 \mathrm{x}$ stoichiometric is necessary to ensure complete dechlorination within a reasonable amount of time $(<180$ seconds). Also, the decrease in required reaction time that occurred as a result of the increased reaction rate at the $2 \mathrm{x}$ stoichiometric dosage was not much higher than at the $3 \mathrm{x}$ stoichiometric dosage. Also, for both SS and STS, using 10x stoichiometric dosages did not increase the reaction rate substantially compared to the lower dosages, probably because the rate was limited by the concentration of residual chlorine in solution at such high DA levels.

For AA also, the dechlorination reactions did not reach completion in 180 seconds at the 1x stoichiometric dosage (Figure 14). But for the $2 \mathrm{x}$ stoichiometric dosage, the reaction reached completion in $<180$ seconds (Figure 15) with a reaction rate constant of 0.877 $\mathrm{L} /$ mol.s. When the dosage was increased to $3 \mathrm{x}$ stoichiometric the reaction rate slightly 
increased to $0.989 \mathrm{~L} / \mathrm{mol} . \mathrm{s}$. For $10 \mathrm{x}$ stoichiometric dosage of AA on the other hand, the reaction was zero order with respect to TC with a pseudo reaction rate constant of 0.396 $\mathrm{mg} / \mathrm{L} . \mathrm{s}$ as shown in Figure A 6a.

Dechlorination results obtained for AA and STS in this experimental study are in agreement with what was found in the literature (Worley, 2000). Worley (2000) undertook similar dechlorination studies with AA and STS and found that AA could eliminate chlorine at twice the stoichiometric dosage. Experiments were performed on solutions with $2-4 \mathrm{mg} / \mathrm{L}$ as $\mathrm{Cl}_{2}$, at $\mathrm{pH} 6.5-7$, and the reactants were allowed to react approximately 5 minutes at room temperature. The stoichiometric dose of $0.56 \mathrm{mg} / \mathrm{mg}$ of STS was used, even though this value is only accurate at $\mathrm{pH} 2$ (White, 1999). STS on the other hand was reported to require dosages several times the stoichiometric dosage (minimum $1.5 \mathrm{x}$ ) to achieve complete dechlorination. (Worley, 2000)

\section{Reactions Complete at $1 x$ Stoichiometric Dosage}

For SBS and SMBS, the trends in reaction rate observed were similar to those of SS and STS. However, one of the major differences observed is that the $1 \mathrm{x}$ dosage in the case of SBS and SMBS did reach completion in $<180$ seconds following the addition of the DA (see Figure 16). 


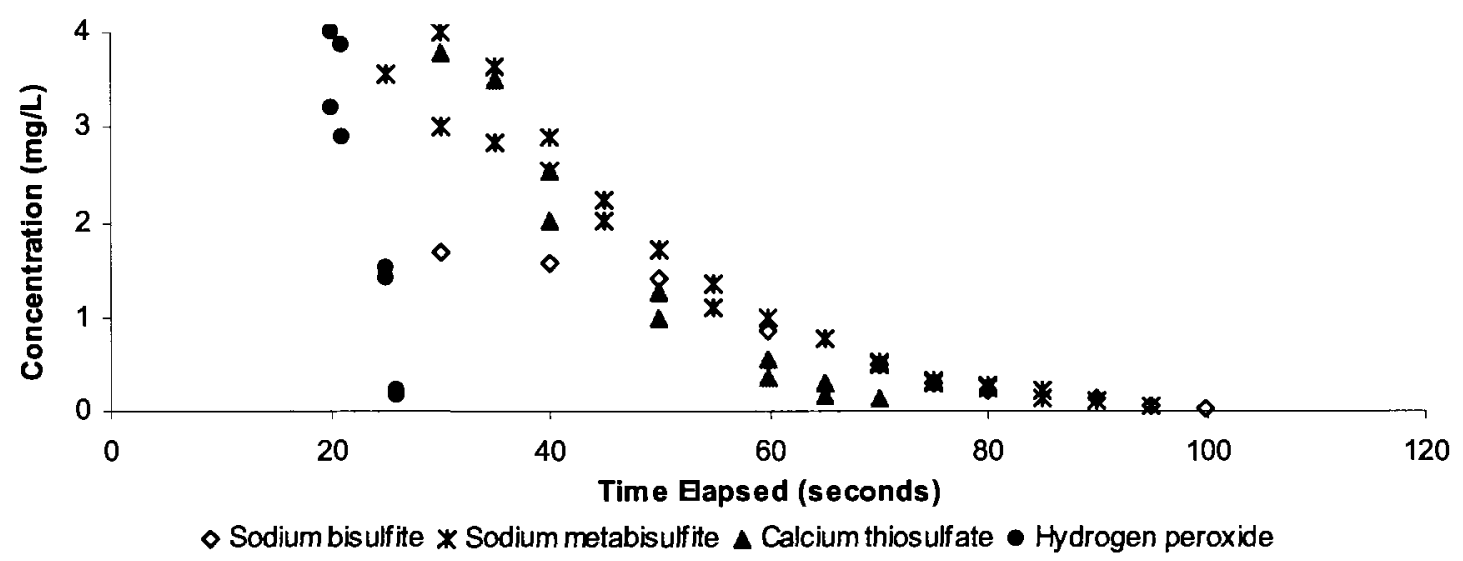

Figure 16: Kinetic results for sodium bisulfite, metabisulfite, calcium thiosulfate and hydrogen peroxide at the $1 \mathrm{x}$ stoichiometric dosage.

Both SBS and SMBS reactions at the 1x stoichiometric dosage required between $60-90$ seconds for completion (Figure 17), which might not be suitable in wastewater applications since typically only $30-60$ seconds is available for dechlorination. The rate constant for the 1x stoichiometric dosages of SBS and SMBS could not be determined from the kinetic analysis because the obtained data did not fit into the second order model that was tested. At the $2 \mathrm{x}$ stoichiometric dosage of SBS, k-value was $0.952 \mathrm{~L} / \mathrm{mol} . \mathrm{s}$, which slightly increased to $1.059 \mathrm{~L} / \mathrm{mol} . \mathrm{s}$ for the $3 \mathrm{x}$ dosage. For the $10 \mathrm{x}$ stoichiometric dosage, the zero order rate constant with respect to the total chlorine concentration in solution was determined to be $0.626 \mathrm{mg} / \mathrm{L} . \mathrm{s}$. For the $3 \mathrm{x}$ and the $4 \mathrm{x}$ stoichiometric dosages of SMBS, the obtained $\mathrm{k}$ values were 0.737 and $0.804 \mathrm{~L} / \mathrm{mol} . \mathrm{s}$, respectively (see Table 10 and Table 11). For the $4 \mathrm{x}$ dosage of SMBS, the reaction rate did not substantially increase compared to the $1 \mathrm{x}$ stoichiometric concentration. Moreover, at the 10x stoichiometric dosage of SMBS, the pseudo-first order reaction rate constant with respect to the total chlorine concentration in solution was determined to be $0.172 \mathrm{~s}^{-1}$. 


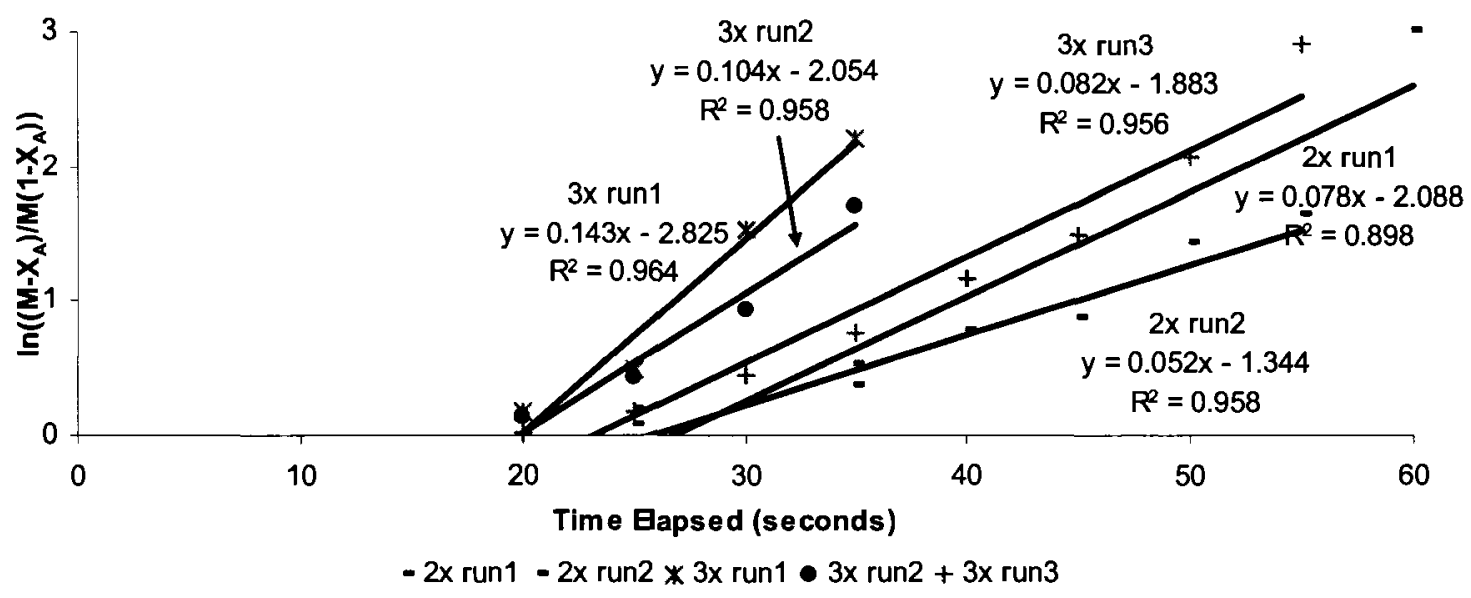

(a) Sodium bisulfite

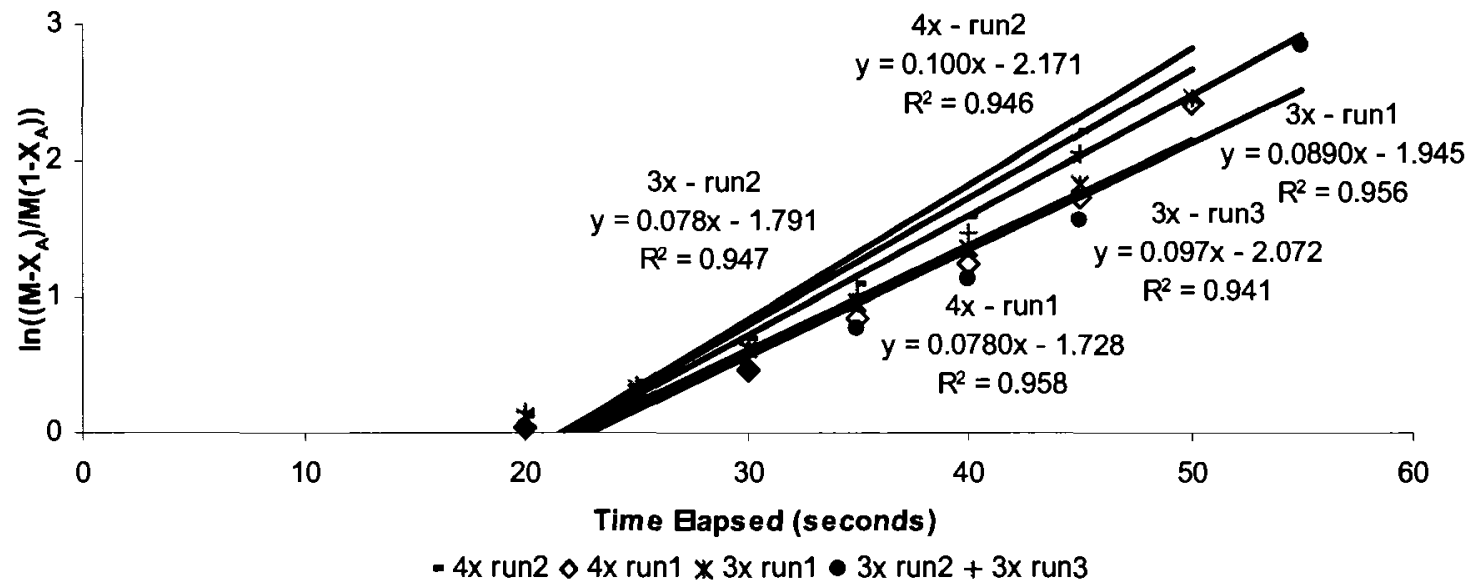

(b) Sodium Metabisulfite

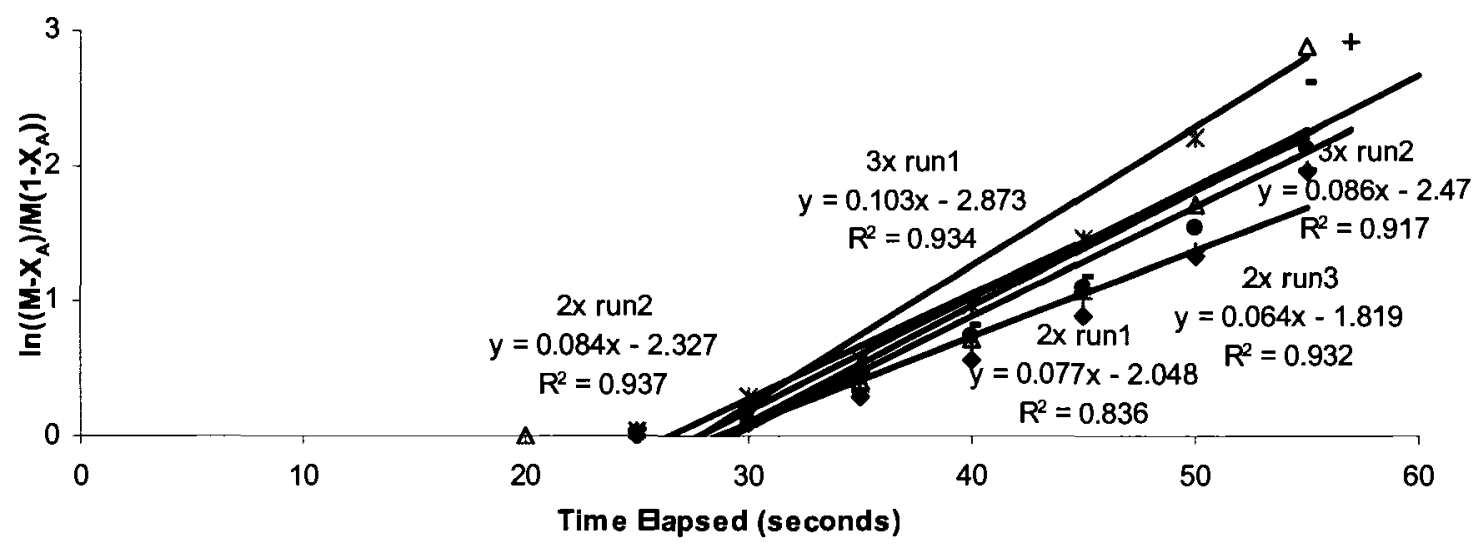

$\Delta 2 x$ run $1-2 x$ run $2 \bullet 2 x$ run $3 * 3 x$ run $1 \bullet 3 x$ run $2+3 x$ run 3

(c) Calcium thiosulfate

Figure 17(a), (b): Kinetic results for the sodium bisulfite, metabisulfite and calcium thiosulfate under varying dosages $(2-4 x)$. 
Results obtained for SBS and SMBS also substantiate the claim that dechlorination reactions are not instantaneous (Bedner et al., 2004; Helz \& Nweke, 1995; Jensen \& Helz, 1998; MacCrehan et al., 1998). Rather, depending on the initial chlorine levels in the solution, the dechlorination time required for completion may vary. The initial chlorine concentration for the SBS and SMBS reactions was $4-5 \mathrm{mg} / \mathrm{L}$ as $\mathrm{Cl}_{2}$, which required $60-90$ seconds to be completely neutralized at $1 \mathrm{x}$ stoichiometric dosages of SBS and SMBS. However, the chlorine level in the wastewater effluent is unlikely to be as high as $4-5 \mathrm{mg} / \mathrm{L}$. Thus, depending on the initial concentration of chlorine in the effluent, 1x stoichiometric dosage of SBS and SMBS may be sufficient to achieve complete neutralization within $<60$ seconds. Dosage required to achieve complete dechlorination of the wastewater effluent is site specific, depending on the flow rate, available contact time, and the chlorine concentration in the effluent.

Kinetic data obtained for CTS is shown in Figure 17, which had similar trends to STS in that the overall reaction rate constant decreased with increasing dosage of CTS. At $2 x$ stoichiometric dosage, CTS had a $\mathrm{k}_{\text {overall }}$ value of $1.193 \mathrm{~L} / \mathrm{mol} . \mathrm{s}$, but at the $3 \mathrm{x}$ dosage the calculated $\mathrm{k}_{\text {overall }}$ values was $0.713 \mathrm{~L} / \mathrm{mol} . \mathrm{s}$, which is a 1.7 fold decrease. This decrease in observed reaction rate constant is identical to the decrease in rate observed for STS going from $2 \mathrm{x}$ to $3 \mathrm{x}$ dosage. Possible reasons for this similarity is unknown, but it could indicate that both sodium and calcium thiosulfate have similar kinetic behavior when reacting with chlorine. 
HP was a special case because it was able to achieve complete dechlorination with concentrations less than the stoichiometric requirement (e.g. $0.1 \mathrm{x}$ ), which is practically impossible. Possible reasons for such an observation could be that there are other simultaneous and/or catalytic reactions that occur in the reaction solution reducing chlorine levels or possible interferences of HP and reaction products with the chlorine analyzer probes. Consequently, only $10 \mathrm{x}$ and the $1 \mathrm{x}$ stoichiometric data was analyzed for HP. At the $1 \mathrm{x}$ stoichiometric dosage, the HP kinetic data failed to fit into the second order model that was tested, but at the $10 \mathrm{x}$ dosage the pseudo-first order reaction rate constant with respect to chlorine was determined to be $0.502 \mathrm{~s}^{-1}$. HP results also show that the dechlorination reactions with HP are not instantaneous. Although the $10 \mathrm{x}$ stoichiometric dosage was able to reduce the residual chlorine levels to below $0.02 \mathrm{mg} / \mathrm{L}$ within 30 - 40 seconds, using dechlorination chemicals in excess of the stoichiometric dosage is not recommended for wastewater applications (USEPA, 2002) because presence of high DA concentrations in natural waters may lead to deleterious human and aquatic health impacts. Similar findings have been previously reported in the literature (Worley, 2000), where a $1 \times$ stoichiometric dosage of HP was only able to reduce residual chlorine values to $0.1 \%$ of the initial values. The experiments were performed on solutions of $2-4 \mathrm{mg} / \mathrm{L}$ as $\mathrm{Cl}_{2}$, at $\mathrm{pH} 6.5-7$, and reactants were allowed to react approximately 5 minutes at room temperature.

The reaction rates for each of the seven dechlorination chemicals under varying dosages are shown in Table 12. 
Table 12: Dechlorination reaction rate constants obtained at various dosages of the dechlorination chemicals.

\begin{tabular}{|l|c|c|c|c|c|}
\hline \multirow{2}{*}{ Dechlorination Agent } & \multicolumn{5}{|c|}{ Dosage (x stoichiometric) } \\
\cline { 2 - 6 } & $\mathbf{1}$ & $\mathbf{2}$ & $\mathbf{3}$ & $\mathbf{4}$ & $\mathbf{1 0}$ \\
\hline Sodium Sulfite & $\mathrm{INC}^{\dagger}$ & $\mathrm{INC}$ & $\mathrm{INC}$ & 0.434 & 0.142 \\
\hline Sodium Bisulfite & $\mathrm{ND}^{\gamma}$ & 0.952 & 1.059 & -- & $0.626^{*}$ \\
\hline Sodium Metabisulfite & ND & -- & 0.737 & 0.804 & 0.172 \\
\hline Sodium Thiosulfate & INC & 1.192 & 0.719 & -- & 0.108 \\
\hline Calcium Thiosulfate & ND & 1.193 & 0.713 & -- & $0.280^{*}$ \\
\hline Ascorbic Acid & INC & 0.877 & 0.989 & -- & $0.399^{*}$ \\
\hline Hydrogen Peroxide & ND & ND & ND & ND & 0.502 \\
\hline
\end{tabular}

Results are for the reaction conducted under continuous, low intensity (130 RPM) mixing and $\mathrm{pH} 6.5-8.5$ condition

For 2, 3 and $4 \mathrm{x}$ dosage the indicated $\mathrm{k}$ values are for the overall second order reaction rate constants $(\mathrm{L} / \mathrm{mol} . \mathrm{s})$

For the 10x dosage the pseudo-first/zero order rate constants with respect to the total chlorine concentration are indicated

* for SBS, CTS and AA the reactions were determined to be zero order for all the dosages, thus the unit for the reaction rate is $\mathrm{mg} / \mathrm{L} . \mathrm{s}$

${ }^{\dagger}$ INC - denotes that the reaction did not reach completion within 180 seconds.

${ }^{\top} \mathrm{ND}$ - denotes that the reaction rate constant could not be determined from the undertaken analysis

-- denotes concentrations that were not tested

Generally, the overall reaction rate constant increased with increasing dosage for all the dechlorination chemicals except for the $2-3 \mathrm{x}$ stoichiometric dosage of STS and CTS as shown in Table 12. With the $1 \mathrm{x}$ stoichiometric dosage, SS, STS and AA did not achieve complete neutralization for over 180 seconds. SBS, SMBS, and CTS reached completion within 60 to 90 seconds, while HP reached completion in $<60$ seconds. Thus, these results show that the dechlorination with the $1 \mathrm{x}$ stoichiometric dosage is not instantaneous for all of the chemicals and incomplete in some cases. In real life applications, the time required for complete dechlorination is expected to be much less than what was observed during the experiments, because the initial chlorine levels in the test solutions were between $4-5 \mathrm{mg} / \mathrm{L}$, which is much higher than the expected concentrations of chlorine in the disinfected municipal effluent. In addition, there was a time lag of 25 seconds for the experimental solution to travel from the experimental 
container to the free and total chlorine probes of the residual analyzer. For the purpose of this analysis, the beginning of the reaction $(t=0)$ was taken as the time that the dechlorination chemical was added to the experimental bucket and not the time that it reached the analyzer.

Given that the contact time of MWWE with the dechlorination agent is in the order of minutes and possibly less (NMED, 2003; Utilities Kingston, 2004), the dosage of the dechlorination chemicals needed to achieve regulated effluent chlorine levels seems to be site-specific. If SS, STS or AA is the DA of choice, using the DA $2 x-3 x$ in excess of the stoichiometric requirement is a feasible and necessary strategy to lower the effluent chlorine levels. If the stoichiometric concentrations are used, the required residence time is over 180 seconds, which is impractical in the case of municipal wastewater treatment. For stoichiometric dosages between $2 \mathrm{x}-4 \mathrm{x}$, which is a 2 -fold or more increase in dosage compared to the initial value, the required reaction time was higher compared to the $10 \mathrm{x}$ stoichiometric dosage. However, such a high dosage as $10 \mathrm{x}$ stoichiometric is not recommended in wastewater applications as it may cause deleterious effects in the aquatic environment. If SBS or SMBS is the DA of choice, a $1 \mathrm{x}$ stoichiometric dosage may be sufficient depending on the initial chlorine levels in the effluent and the available contact time. For HP the reactions were very fast and the $1 \mathrm{x}$ stoichiometric dosage was found to be sufficient to achieve complete dechlorination.

\subsubsection{Impact of Mixing on Dechlorination}

Commonly in practice, assuming that the dechlorination is instantaneous and complete, 20-30 seconds of mixing time is allowed for the chlorinated wastewater effluent and the 
dechlorination agent to mix after disinfection (NMED, 2003; Utilities Kingston, 2004). Having a homogeneous reactant mixture may increase the efficiency of the reactions and reduce the required contact time. Thus, the affect of periodic and continuous mixing on the reaction rate was investigated at 130 RPM, and the effect of using different mixing intensities was investigated by comparing the reaction rates obtained at 130 and 275 RPM.

\section{Impact of mixing intensity on the reaction rate - High}

For SS and AA, the experimental results revealed that the mixing intensity had a stronger impact on the reaction rate than mixing frequency. Both SS and AA had very similar rate constants at the periodic and the continuous low mixing cases as shown in Table 13.

Table 13: Calculated reaction rate constants for the various mixing regimes of sodium sulfite and ascorbic acid.

\begin{tabular}{|c|c|c|c|c|c|c|}
\hline Herres & & 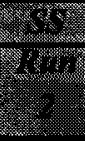 & & 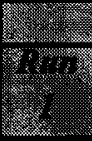 & 89 & 28 \\
\hline \multirow{3}{*}{\begin{tabular}{l|l} 
& periodic \\
low Intensity \\
high
\end{tabular}} & 0.612 & 0.561 & 0.587 & 0.814 & 1.554 & 1.184 \\
\hline & 0.4 & 0.467 & 0.434 & 1.268 & 0.709 & 0.989 \\
\hline & 0.935 & 0.728 & 0.832 & 2.459 & 0.957 & 1.708 \\
\hline
\end{tabular}

However, the overall reaction rate constant for the continuous high mixing condition of SS was approximately 2 times that of the continuous low case (Figure 19a). Doubling of the reaction rate of SS at high intensity mixing implies that increasing the intensity of mixing can increase the rate of the reaction, which would allow the reaction to be completed within a shorter contact time. Although, being able to increase the reaction rate by increasing the intensity of mixing could be advantageous and would lead to chemical cost savings, the downside is that high intensity mixing may be energy intensive, which would add to the operating costs. 


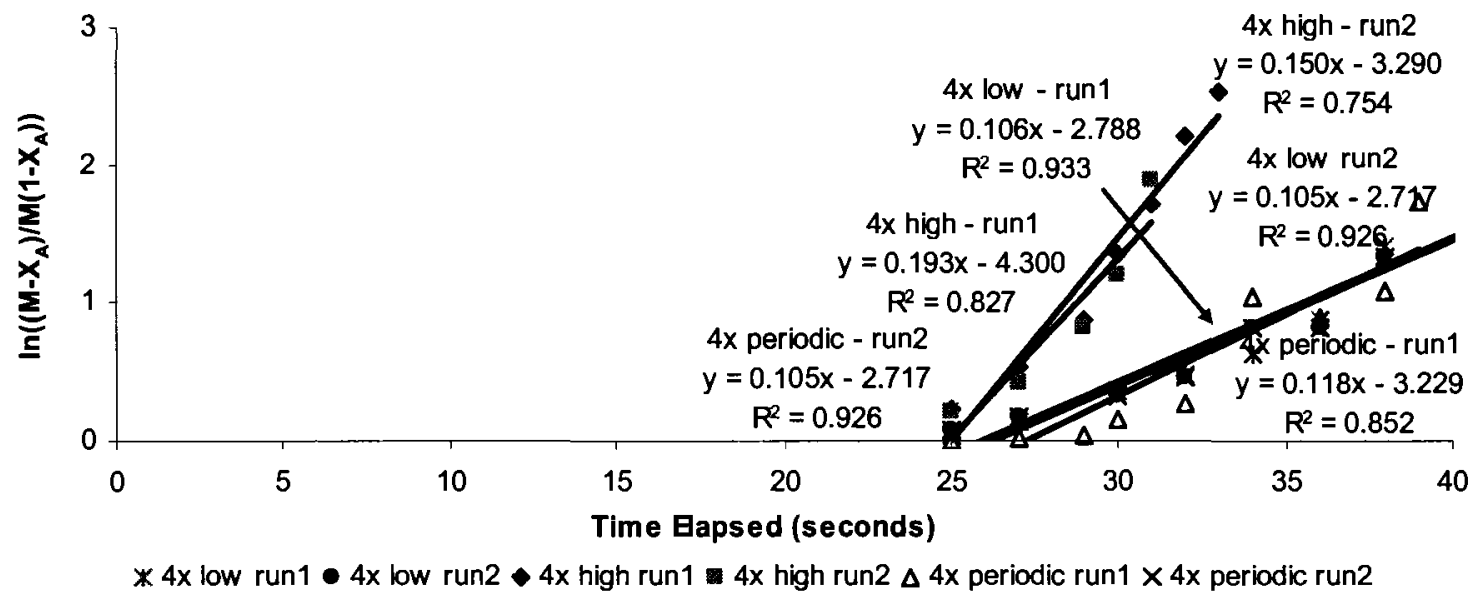

\section{Sodium Sulfite}

Figure 18: Reaction kinetics for sodium sulfite at various mixing regimes tested.

The kinetic results of AA were also similar to that of SS in that the reaction rate decreased when the frequency of mixing was increased from periodic to continuous mixing (Figure 19). For AA, the reaction rate constant at the periodic mixing case was $1.184 \mathrm{~L} / \mathrm{mol} . \mathrm{s}$ which decreased to $0.989 \mathrm{~L} / \mathrm{mol} . \mathrm{s}$ for the continuous low mixing scenario.

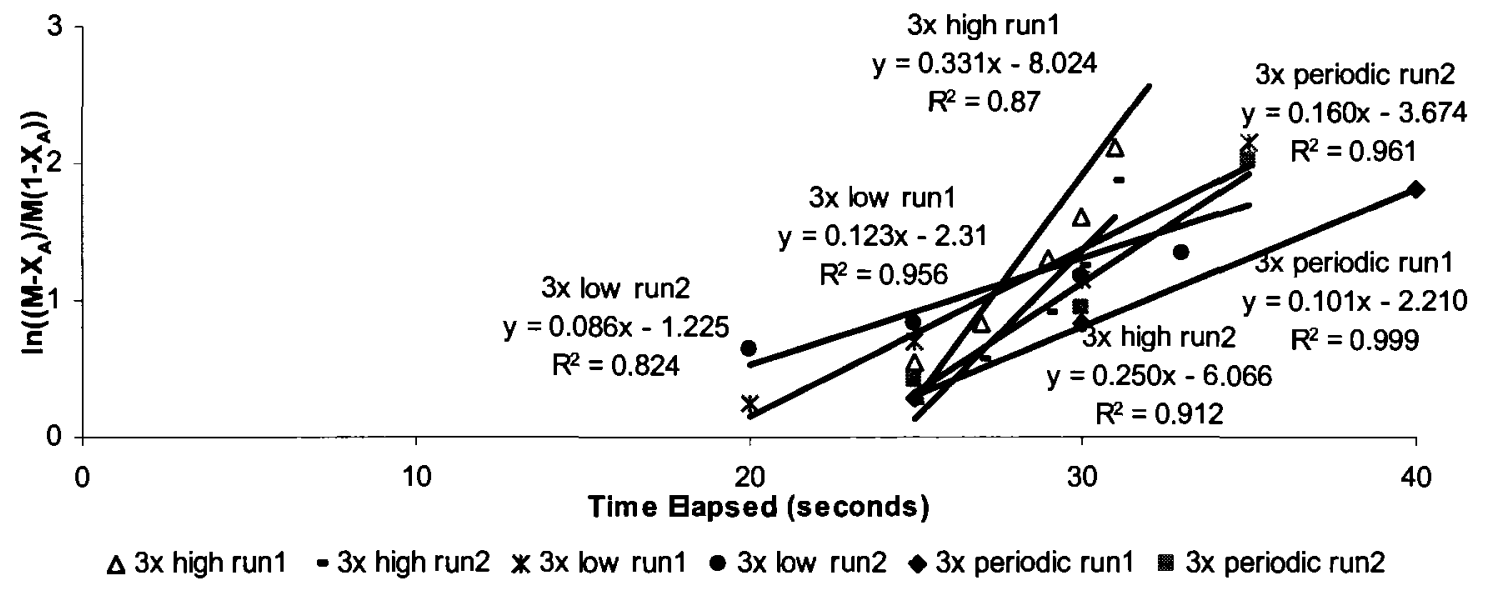

(b) Ascorbic Acid

Figure 19: Reaction kinetics for ascorbic acid at various mixing regimes tested. 
The reason for this decrease could be because at the $3 \mathrm{x}$ stoichiometric dosage, the reaction is limited by chlorine, and therefore increasing the frequency of mixing cannot increase the reaction rate any further. When the reaction intensity was further increased to $275 \mathrm{RPM}$ the reaction rate increased nearly 2 -fold compared to the low intensity case. This increase in reaction rate could mean that the reaction order of AA could be affected by mixing conditions, which is important to know since it was previously determined that the reaction order was independent of the concentration. However, further studies with more replicates are needed to substantiate this claim.

\section{Impact of mixing frequency and intensity on the reaction rate - Minimal}

As shown in Table 14, for SBS, SMBS and STS the reaction rates for the periodic, continuous low, and continuous high case were very similar.

Table 14: Calculated reaction rate constants for the various mixing regimes of sodium bisulfite, metabisulfite, and sodium thiosulfate.

\begin{tabular}{|c|c|c|c|c|c|c|c|c|c|c|c|c|}
\hline & & $\frac{5}{6}$ & $\begin{array}{l}34 \\
314\end{array}$ & 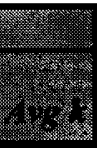 & 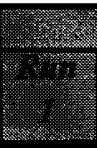 & 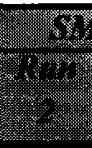 & Pro & & $\frac{1}{2}$ & 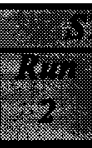 & $\frac{1}{430}$ & b j \\
\hline \multirow{3}{*}{$\underbrace{\infty}$} & periodic & 0.935 & 1.124 & 1.03 & 0.669 & 0.671 & - & 0.671 & 0.653 & 0.504 & -- & 0.50 \\
\hline & low Intensity & 1.251 & 0.867 & 1.059 & 0.706 & 0.606 & 0.868 & 0.737 & 0.606 & 0.798 & 0.64 & 0.72 \\
\hline & high & 0.765 & 1.11 & 0.938 & 0.747 & $\overline{0.546}$ & -- & 0.546 & 0.573 & 0.707 & 0.899 & 0.80 \\
\hline
\end{tabular}

For SBS (Figure 20), the overall second order rate constants were 1.03, 1.059 and 0.938 L/mol.s for the periodic, continuous low and continuous high case, respectively. Although the lowest reaction rate was observed with the high intensity mixing, the difference in rate is not considered significant. Thus, having adequate mixing within the first 10 seconds of the reaction (periodic), or for the first $1 / 3^{\text {rd }}-1 / 4^{\text {th }}$ of the total length of the reaction, is sufficient for the reaction to achieve a very high reaction rate; increasing 
the mixing time and the intensity any further do not increase the reaction rate significantly. This result also means that the mixing frequency and the intensity did not have a significant impact on the reaction rate of these chemicals.

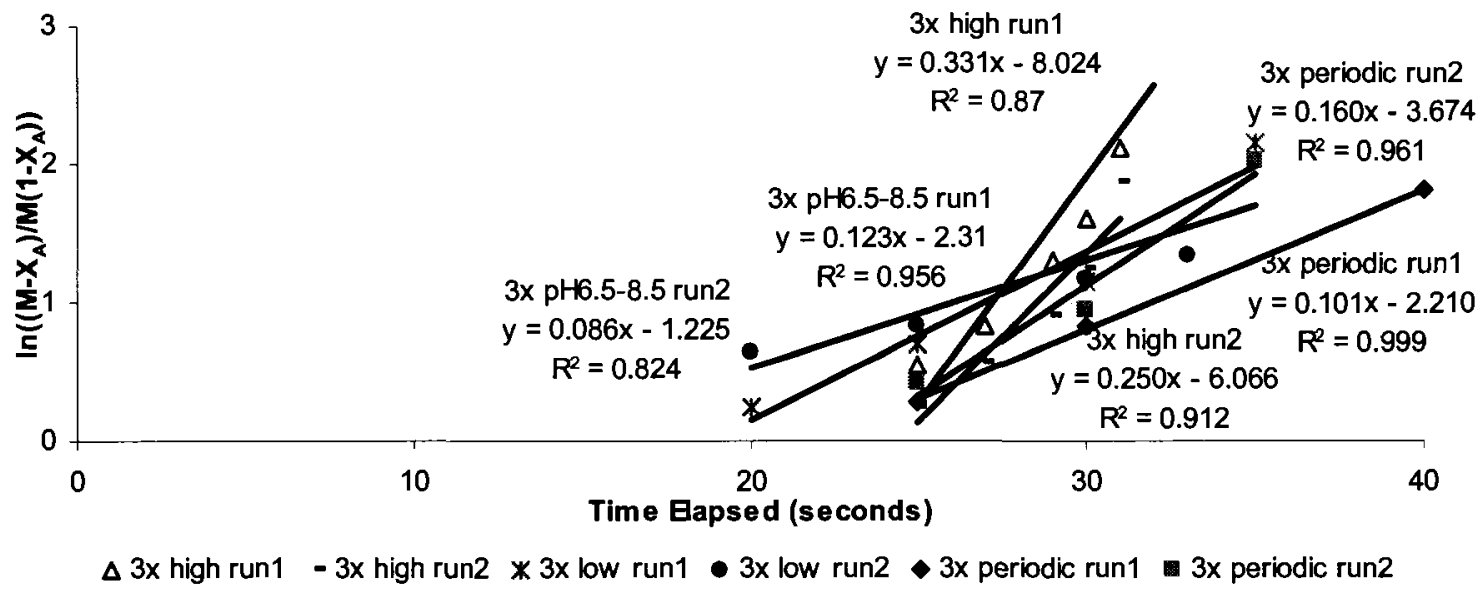

(a) Sodium bisulfite

Figure 20: Reaction kinetics for sodium bisulfite at various mixing regimes tested.

As shown in Table 14, for STS and SMBS also, the reaction rates for the periodic, continuous low, and continuous high case were very similar. For STS the dechlorination reaction rate constants were $0.500,0.720$ and $0.800 \mathrm{~L} / \mathrm{mol} . \mathrm{s}$ and for SMBS the rate constants were $0.671,0.737$ and $0.546 \mathrm{~L} / \mathrm{mol} . \mathrm{s}$ for the periodic, continuous low and continuous high case, respectively. In the case of STS, the reaction rates were almost identical for all the three mixing regimes tested, thus shows that mixing conditions and the intensity did not have an effect on the reaction rate. For SMBS, when the solution was continuously mixed at low intensity, the reaction rate slightly decreased, compared to the periodic mixing (see Figure 21). A slight reduction $(25 \%)$ in reaction rate was observed (see Table 14) for the SMBS at high intensity mixing condition compared to the low intensity condition for the same reasons described above. 


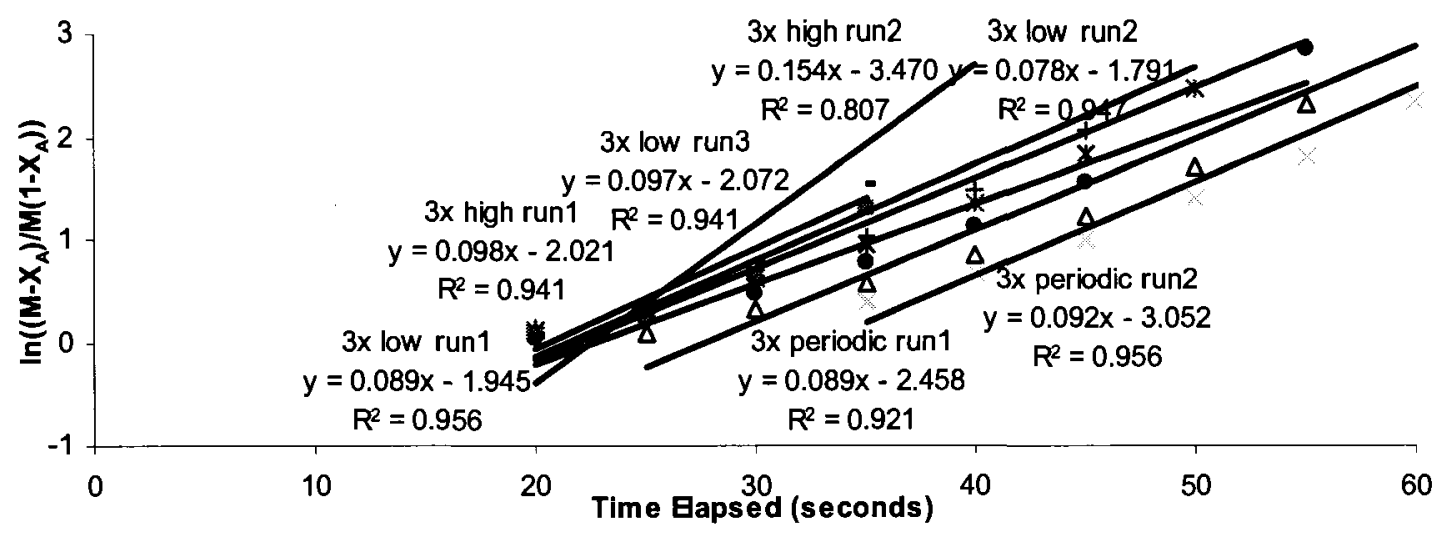

$x 3 x$ low run $1 \bullet 3 x$ low run $2+3 x$ low run $3-3 x$ high run $1=3 x$ high run2 $\Delta 3 x$ periodic run $1 \times 3 x$ periodic run 2

(b) Sodium Metabisulfite

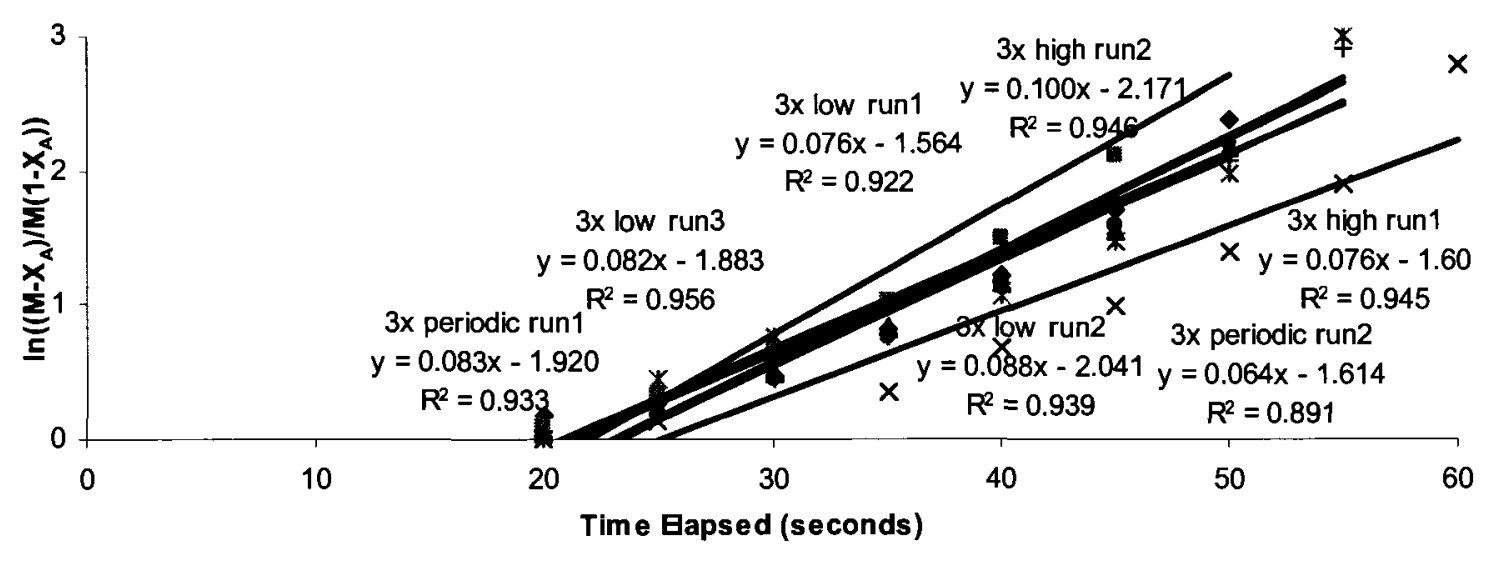

$* 3 x$ low run $1 \bullet 3 x$ low run $2+3 x$ low run $3 \bullet 3 x$ high run $1=3 x$ high run $2 \Delta 3 x$ periodic run $1 \times 3 x$ periodic run 2

(c) Sodium thiosulfate

Figure 21(a), (b) \& (c): Reaction kinetics for sodium thiosulfate, hydrogen peroxide and sodium metabisulfite at various mixing regimes tested.

In order to further substantiate this claim, an additional set of experiments were undertaken for SMBS using 10x stoichiometric dosages to investigate the effects of low and high intensity mixing on the rate of the dechlorination reaction. This result (Figure 22) indicates that at lower stoichiometric dosages (e.g. $4 \mathrm{x}$ stoichiometric) of SMBS, the increase in mixing intensity does not strongly influence the reaction rate, but at higher dosages (e.g. $10 \mathrm{x}$ stoichiometric) the mixing rate can have a greater influence on the reaction rate. 


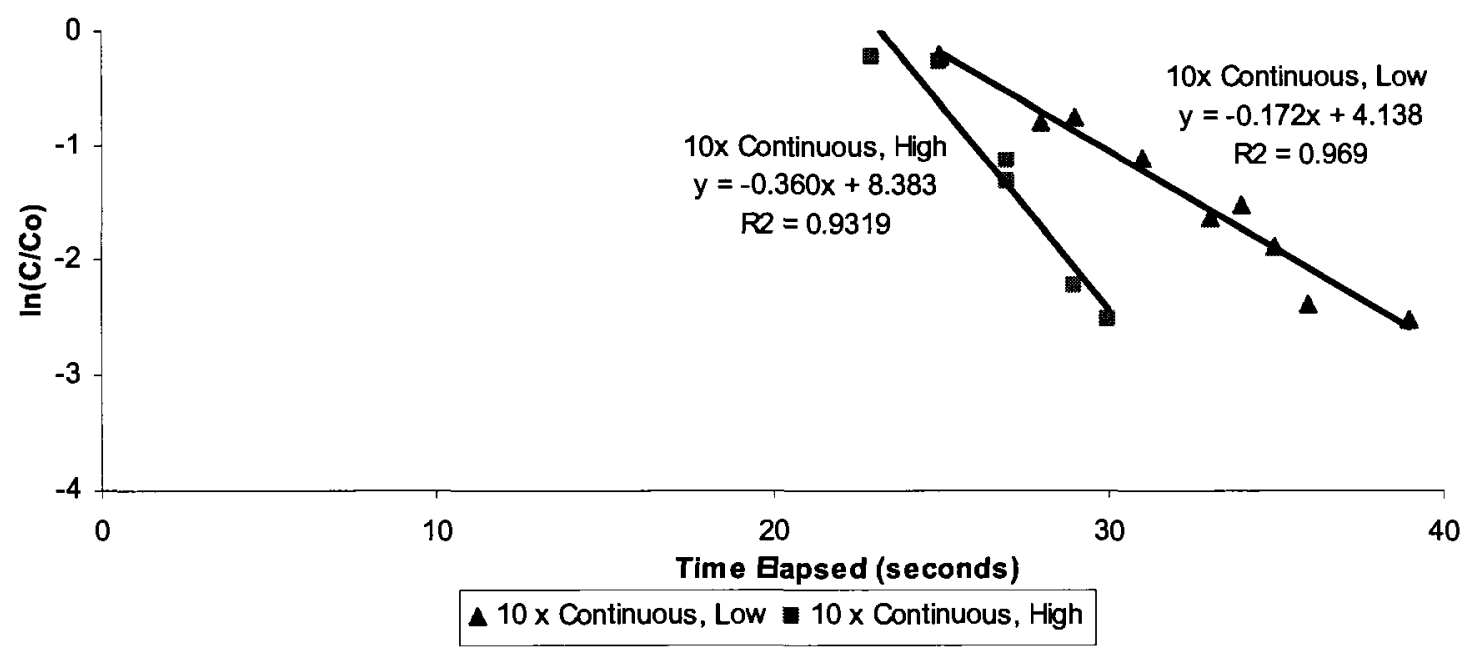

Figure 22: Reaction kinetics for $10 \mathrm{x}$ stoichiometric dosage of sodium metabisulfite at various mixing regimes tested.

This observed difference in the reaction rate may be because when the DA is present in $10 \mathrm{x}$ excess of the stoichiometric requirement, total chlorine becomes the limiting reagent, and having high intensity mixing can increase the likelihood of the two reactants coming into contact with each other. When the dosages of the DA are slightly in excess (3x) of the stoichiometric requirement, or the competition amongst the dechlorination agent molecules to make contact with a residual chlorine is not as high, the mixing does not substantially increase the reaction rate.

Impact of both the mixing intensity and frequency on the reaction rate - High For calcium thiosulfate both mixing intensity and frequency of mixing had an impact on the reaction rates as shown in Figure 23. 


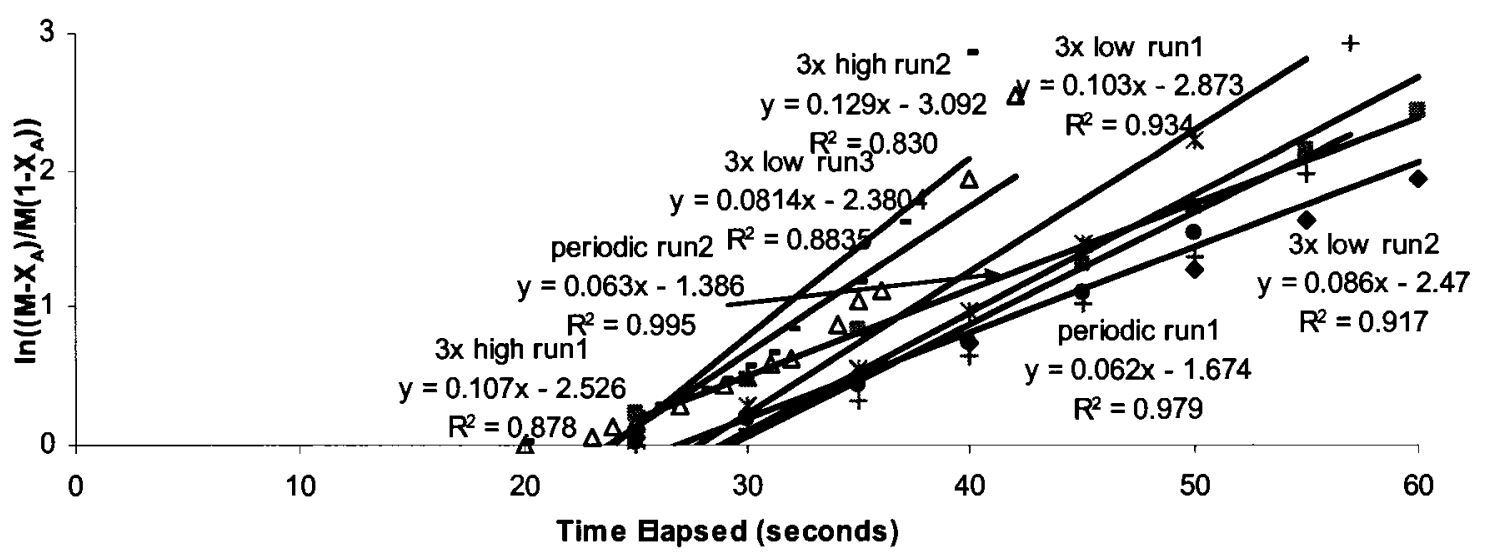

$\Delta 3 x$ high run1 $-3 x$ high run2 $* 3 x$ low run1 $\bullet 3 x$ low run2 $+3 x$ low run3 $\bullet 3 x$ periodic run1 $=3 x$ periodic run2

(b) Calcium Thiosulfate

Figure 23(a) \& (b): Reaction rate constants for sodium metabisulfite and calcium thiosulfate at various mixing regimes tested.

When the experimental solution was continuously mixed at low intensity, the reaction rate for CTS increased by approximately 1.3 -fold compared to the periodic mixing scenario (Table 15).

Table 15: Calculated reaction rate constants for calcium thiosulfate under various mixing regimes

\begin{tabular}{|c|c|c|c|c|}
\hline 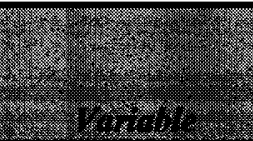 & 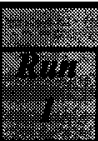 & $\frac{x}{10}$ & 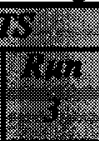 & 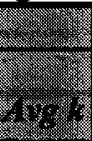 \\
\hline$\$ 0$ periodic & 0.475 & 0.561 & - & 0.561 \\
\hline$\cdot \frac{\Xi}{x}$ low Intensity & 0.789 & 0.729 & 0.697 & 0.713 \\
\hline$\sum \overline{\text { high }}$ & 0.973 & 1.126 & -- & 1.12 \\
\hline
\end{tabular}

-- denotes concentrations that were not tested

When the mixing intensity was increased from 130 RPM to 275 RPM, the reaction rate constant increased from 0.713 to $1.126 \mathrm{~L}$ /mol.s, which is also approximately a 1.6 -fold increase. This increase in reaction rate could be because the CTS reaction required $60-$ 80 seconds to achieve complete neutralization when the sample was periodically mixed, where the 10 second initial mixing accounts for only for $1 / 6^{\text {th }}-1 / 8^{\text {th }}$ of the total reaction time. Having 10 second initial mixing may be insufficient to ensure complete homogeneity of the reaction mixture. Thus, for CTS reactions that take approximately 60 
- 80 seconds to reach completion, both the intensity and the frequency of mixing can have a direct impact on the reaction rate compared to the 10 second initial mixing.

From the analysis of the effects of mixing on the reaction rate of the dechlorination chemicals, it is evident that for SS and AA the reaction rates for the periodic and continuous low mixing condition are similar. However, when the solution was mixed at high intensity, the reaction rate of SS and AA almost doubled compared to the low intensity mixing and these reactions required approximately $30-45$ seconds to reach completion. The SBS, STS and HP reactions required $45-80$ seconds to achieve completion, and the reaction rate was not influenced by the intensity or the frequency of mixing. On the other hand, for SMBS, which also required 50-80 seconds for reaction completion, continuous mixing was important, while the intensity of mixing did not impact the reaction rate. For CTS, mixing intensity was important while the frequency of mixing did not impact the reaction rate. The results obtained for the dechlorination agents under variable mixing conditions are tabulated in Table 17.

\subsubsection{Impact of pH on Dechlorination Rate}

Typically, the $\mathrm{pH}$ range of municipal wastewater (WEF \& ASCE, 1998) is $6.5-8.0$, and two different $\mathrm{pH}$ ranges were tested to investigate the effects of variable $\mathrm{pH}$ on the dechlorination reaction rate of the seven dechlorination chemicals. Two $\mathrm{pH}$ ranges tested were $\mathrm{pH} 6.5-8.5$ and $\mathrm{pH}>9$. For the majority of the chemicals tested there was no or minimal impact on the dechlorination rate with changing $\mathrm{pH}$. 


\section{Impact of solution $\mathrm{pH}$ on the dechlorination reaction rate - Minimal}

For SBS, SMBS and STS the dechlorination rate remained the same when the reaction solution $\mathrm{pH}$ was raised to $\mathrm{pH}>9$ from the $6.5-8.5$ as shown in Figure 24. For SBS and STS the reaction rate showed a slight increase from the $\mathrm{pH} 6.5-8.5$ to $\mathrm{pH}>9$ range as shown in Table 16. For SMBS however the reaction rate constant slightly decreased going from $\mathrm{pH} 6.5-8.5$ to $\mathrm{pH}>9$ case.

\begin{tabular}{|c|c|c|c|c|c|c|c|c|c|c|c|}
\hline & & $\frac{5}{5 x}$ & & & 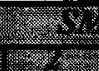 & 63 & 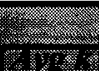 & 27 & $=0$ & $78=2$ & 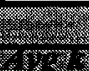 \\
\hline pH6.5-8.5 & 1.251 & 0.867 & 1.059 & 0.706 & 0.606 & 0.868 & 0.737 & 0.606 & 0.798 & 0.64 & 0.72 \\
\hline 志觢H9 & 1.25 & 1.474 & 1.362 & 0.665 & 0.712 & -- & 0.712 & 0.767 & 0.692 & 0.868 & 0.78 \\
\hline
\end{tabular}

-- denotes concentrations that were not tested

These slight changes (increase/decrease) in the reaction rate with increasing $\mathrm{pH}$ will not reduce or increase the required reaction time in practice by an appreciable amount, and neither will it appreciably effect the dechlorination ability of these chemicals, thus it is not considered to be a major advantage or disadvantage. Also, the finding that the solution $\mathrm{pH}$ has minimal or no impact on the dechlorination reaction rate of these chemicals confirms that the reaction orders calculated for the dechlorination reactions in section 4.1.1 are independent of the $\mathrm{pH}$ conditions. 


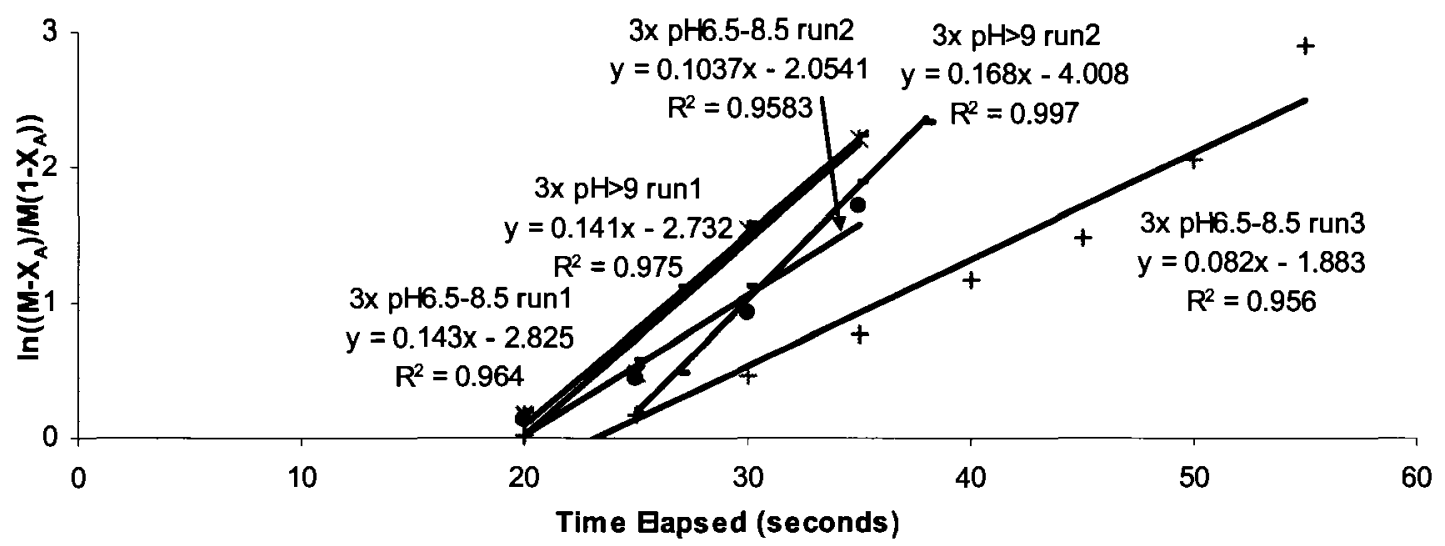

* $3 x$ run1 $-3 x$ run2 $+3 x$ run $3-3 x$ pH>9 run1 $-3 x$ pH>9 run2

(a) Sodium bisulfite

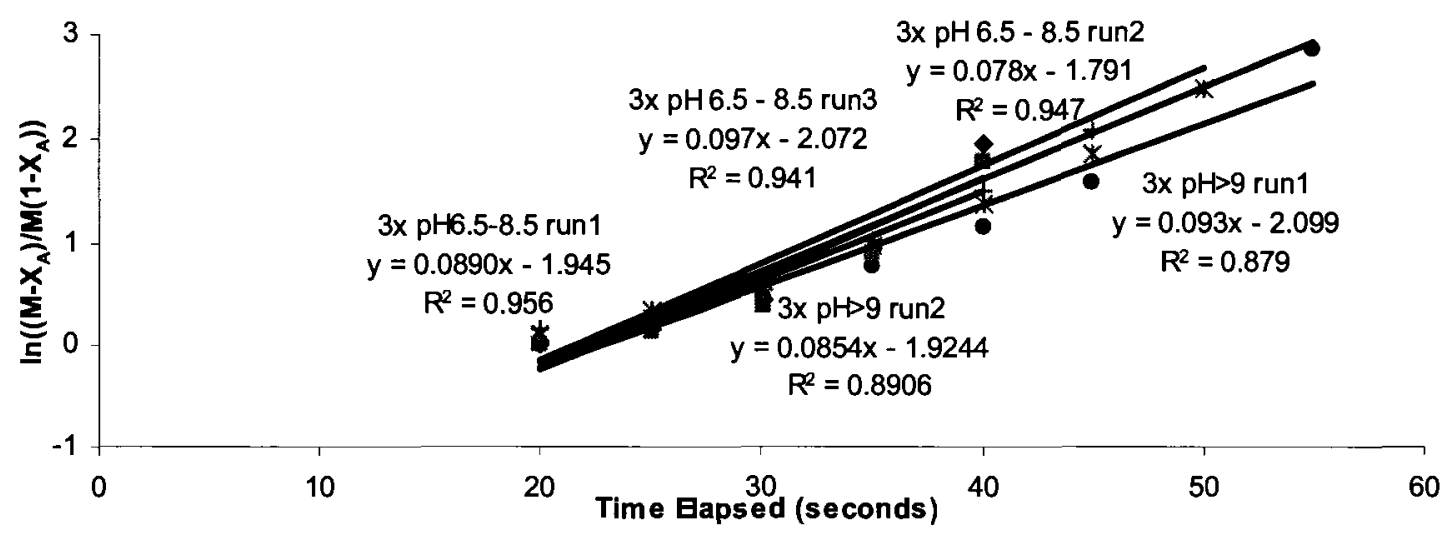

* 3x pH6.5-8.5 run1 $\bullet 3 x \mathrm{pH} 6.5-8.5$ run2 $+3 x \mathrm{pH} 6.5-8.5$ run3 $\bullet 3 x \mathrm{pH} \gg 9$ run1 $=3 x \mathrm{pH} \gg 9$ run2

(a) Sodium metabisulfite

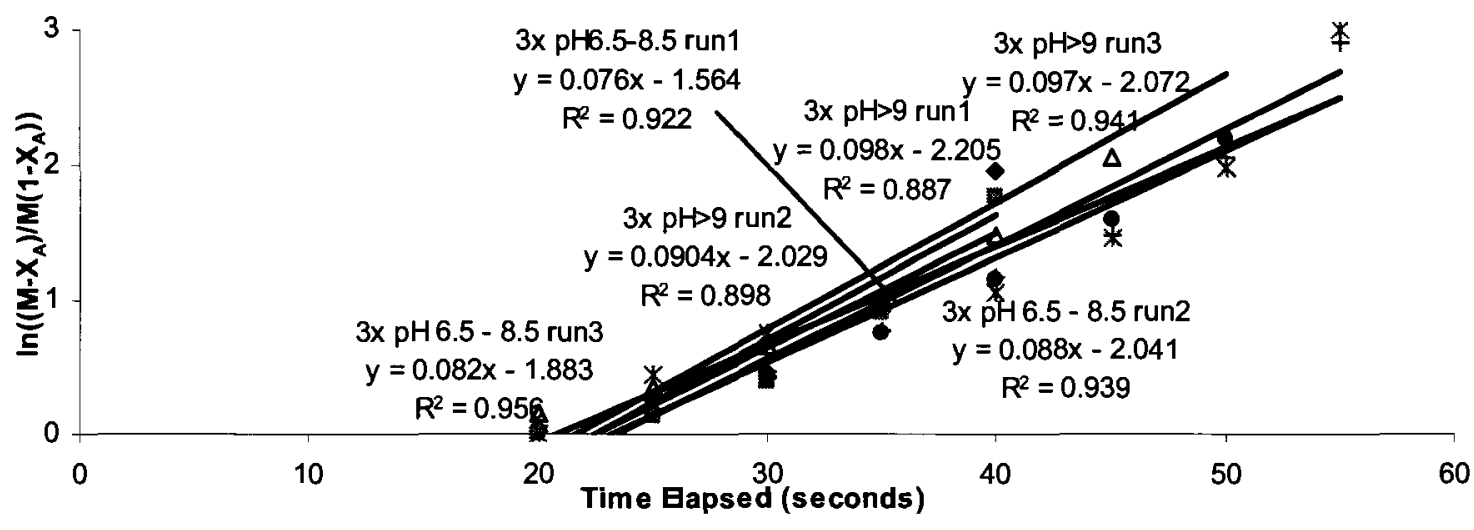

$* 3 x \mathrm{pH} 6.5-8.5$ run1 $\bullet 3 x$ pH6.5-8.5 run2 $+3 x$ pH6.5-8.5 run3 $\diamond 3 x \mathrm{pH}>9$ run1 $3 x$ pH>9 run2 $\Delta 3 x$ pH>9 run3

(a) Sodium thiosulfate

Figure 24: Reaction rate constants for sodium metabisulfite and sodium thiosulfate at the two $\mathrm{pH}$ regimes tested. 


\section{Impact of solution pH on the dechlorination reaction rate - High}

$\mathrm{AA}$ is a special case where the reaction rate for the $\mathrm{pH}>9$ case was 2.3 times the reaction rate of the $\mathrm{pH} 6.5-8.5$ condition (see Figure 25 ). The calculated reaction rates for the $\mathrm{pH} 6.5-8.5$ and $\mathrm{pH}>9$ case were 0.989 and $2.317 \mathrm{~L} / \mathrm{mol} . \mathrm{s}$, respectively. This could mean that the order of the reaction is impacted not by the concentration of the reaction (thus zero order) but by the $\mathrm{pH}$ of the solution.

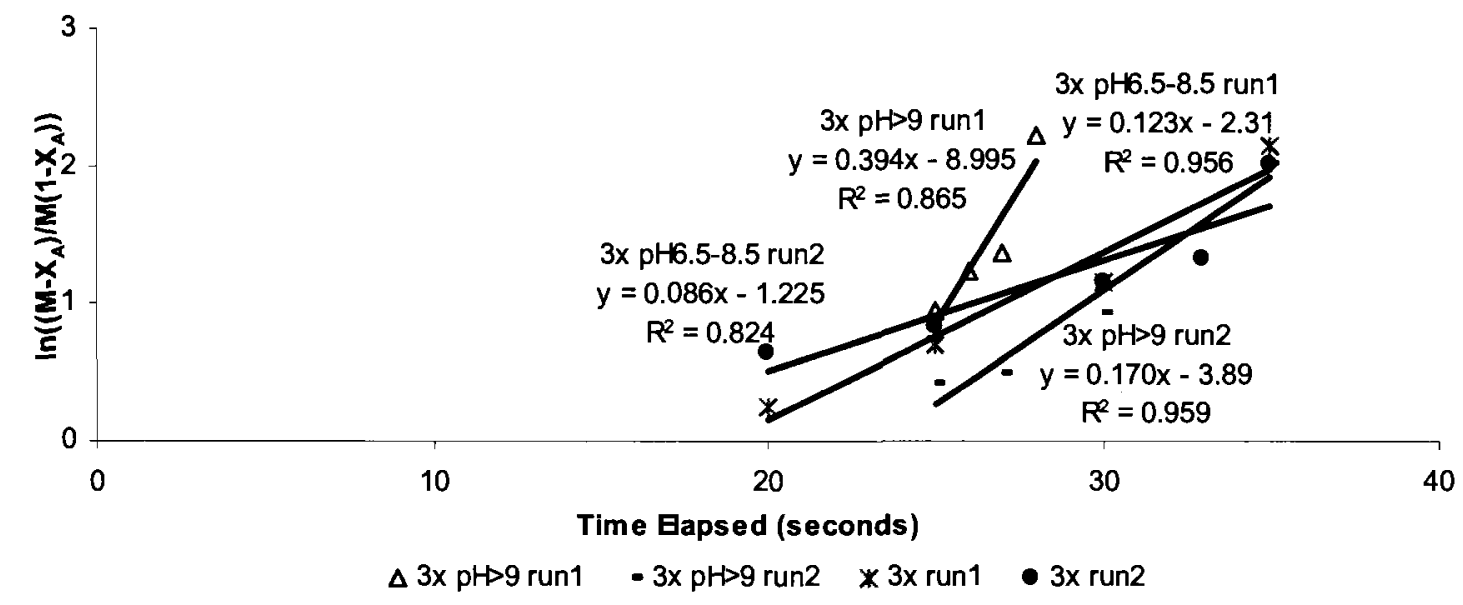

Figure 25: Reaction rate constants for ascorbic acid at the two $\mathrm{pH}$ regimes tested.

However, further testing will be required at the variable $\mathrm{pH}$ of the $10 \mathrm{x}$ dosage to substantiate this claim because the reaction order analysis was conducted at the $10 \mathrm{x}$ stoichiometric dosage.

The reaction rate constant of SS was also effected by the increase in $\mathrm{pH}$ from $6.5-8.5$ to $>9$ as shown in Figure 26. For the $\mathrm{pH} 6.5-8.5$ case the average $\mathrm{k}_{\text {overall }}$ was calculated to be $0.434 \mathrm{~L} / \mathrm{mol} . \mathrm{s}$, which increased by 1.5 -fold to $0.650 \mathrm{~L} / \mathrm{mol} . \mathrm{s}$ for the $\mathrm{pH}>9$ case. This increase in reaction rate constant observed for the higher $\mathrm{pH}$ range could reduce the required reaction time for dechlorination using SS, which might be an advantage in wastewater applications. 


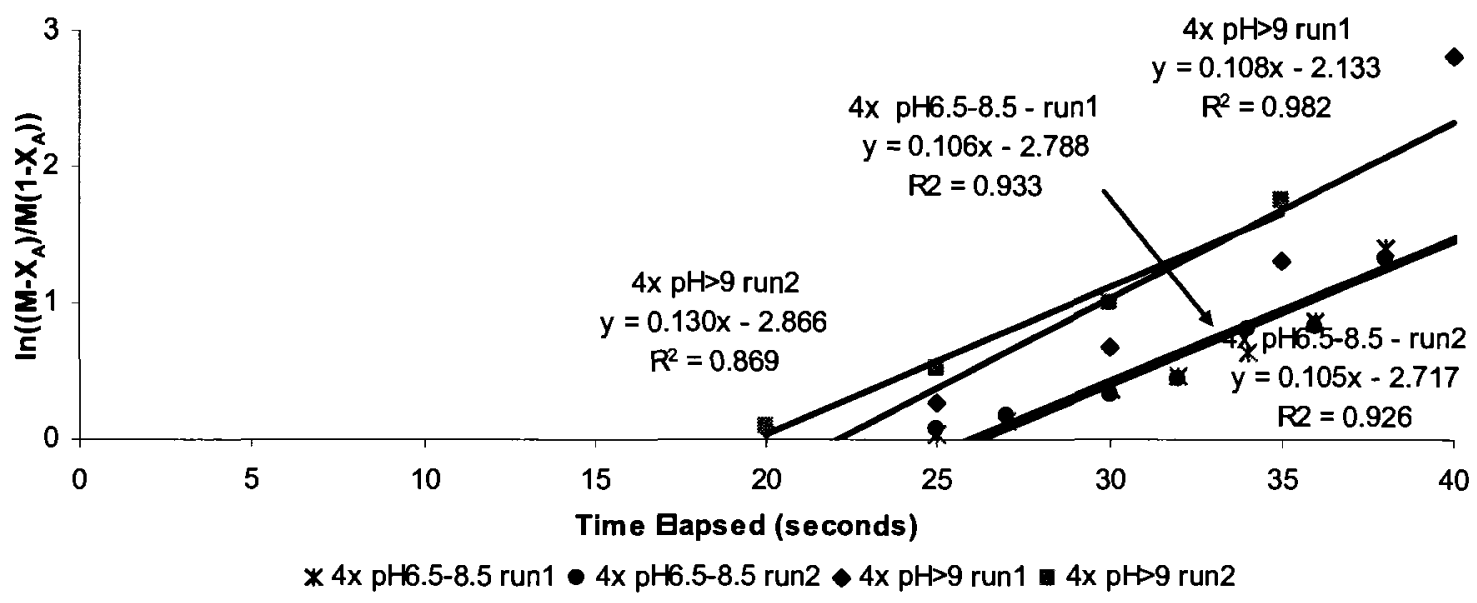

Figure 26: Reaction rate constants for sodium sulfite at the two $\mathrm{pH}$ regimes tested.

\section{Increasing $\mathrm{pH}$ caused a reduction in reaction rate}

For CTS, caution should be taken to maintain the $\mathrm{pH}$ between $6.5-8.5$, because a slight increase in $\mathrm{pH}$ could cause a reduction in the dechlorination rate (see Figure 27), which could result levels of residual chlorine in the effluent above regulated levels. The reaction rate constant for the CTS reaction at $\mathrm{pH} 6.5-8.5$ was $0.713 \mathrm{~L} / \mathrm{mol} . \mathrm{s}$, which decreased by 1.5-fold to $0.463 \mathrm{~L} / \mathrm{mol} . \mathrm{s}$ for the $\mathrm{pH}>9$ case. However, the difference in reaction rate between the two $\mathrm{pH}$ ranges tested for CTS was found to be insignificant, which also implies that the reaction orders calculated in section 4.1.1 are the intrinsic reaction orders.

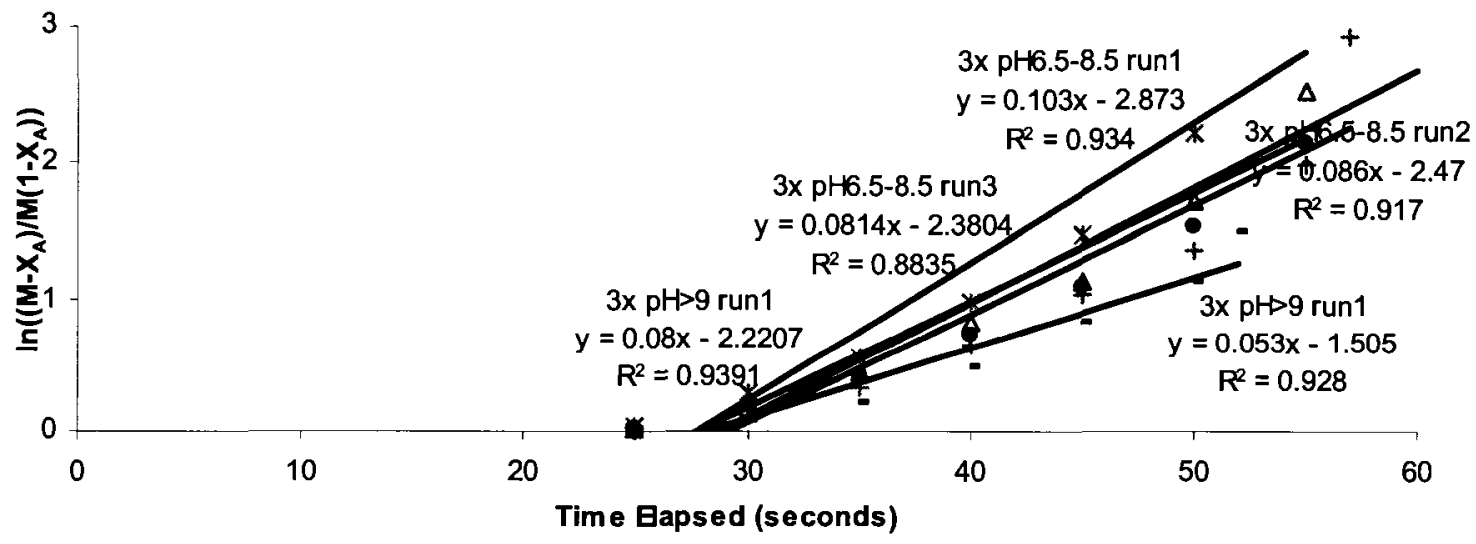

$\Delta 3 \times \mathrm{pH}>9$ run1 $-3 x \mathrm{pH} \gg 9$ run2 $* 3 \times \mathrm{pH} 6.5-8.5$ run1 $\bullet 3 \times \mathrm{pH} 6.5-8.5$ run2 $+3 x \mathrm{pH} 6.5-8.5$ run3

Calcium thiosulfate

Figure 27: Reaction rate constants for calcium thiosulfate at the two $\mathrm{pH}$ regimes. 


\subsubsection{Summary of Dechlorination Results}

Table 17 summarizes the results of the investigation of the impact of mixing and $\mathrm{pH}$ on the dechlorination rate of the seven dechlorination chemicals.

Table 17: Impact of mixing and solution $\mathrm{pH}$ on the dechlorination rate

\begin{tabular}{|c|c|c|c|}
\hline \multirow{2}{*}{ 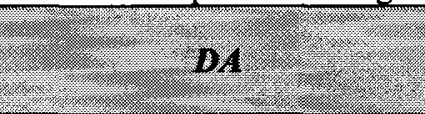 } & \multicolumn{2}{|c|}{ 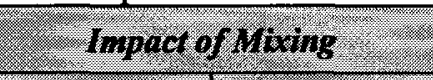 } & \multirow{2}{*}{$p$ II } \\
\hline & mombrist? & $\left.2 \log q_{4}\right)^{2}$ & \\
\hline Sodium Sulfite (SS) & $\mathrm{X}$ & $\checkmark$ & $\checkmark$ \\
\hline Sodium Bisulfite (SBS) & $\mathrm{X}$ & $X$ & $\mathrm{X}$ \\
\hline $\begin{array}{l}\text { Sodium Metabisulfite } \\
\text { (SMBS) }\end{array}$ & $\mathrm{X}$ & $\mathrm{X}$ & $\mathrm{X}$ \\
\hline Sodium Thiosulfate (STS) & $\mathrm{X}$ & $\mathrm{X}$ & $\mathrm{X}$ \\
\hline Calcium Thiosulfate (CTS) & $\checkmark$ & $\checkmark$ & $\checkmark$ \\
\hline Ascorbic Acid (AA) & $\mathrm{X}$ & $\checkmark$ & $\checkmark$ \\
\hline Hydrogen Peroxide (HP) & $\mathrm{X}$ & $\mathrm{X}$ & $\mathrm{X}$ \\
\hline
\end{tabular}

* frequency of mixing refers to periodic or continuous mixing

$\checkmark-$ indicates that the reaction rate increased as a result of the described treatment

$\mathrm{X}$ - indicates that the reaction rate had minimal or no significant increase

(numerically) as a result

of the described treatment

Inconclusive - need further studies

Table 18 summarizes the dechlorination results of this experimental study in comparison

to what has been reported in literature.

Table 18: Results summary for dechlorination experiments

\begin{tabular}{|c|c|c|}
\hline 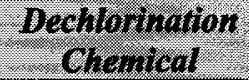 & Eqperinemm Fhohgs & Thorotire \\
\hline All & $\begin{array}{l}\text { - } 1 \mathrm{x} \text { stoichiometric dosages of } \mathrm{DA}: \mathrm{Cl}_{2} \\
\text { (mg/mg) is inadequate to achieve } \\
\text { complete dechlorination in less than } \\
60 \text { seconds } \\
\text { - SBS and AA showed zero order } \\
\text { reaction kinetics with respect to total } \\
\text { chlorine concentration in solution } \\
\text { - SS, SMBS, STS and HP had pseudo- } \\
\text { first order kinetics } \\
\text { - CTS had zero order kinetics at } 10 \mathrm{x} \\
\text { dosage and at lower dosages (1x, } 2 \mathrm{x} \text {, } \\
3 \mathrm{x} \text { ) the reaction was second order } \\
\text { overall }\end{array}$ & $\begin{array}{l}\text { - the typical weight ratio of dechlorination } \\
\text { agent added to chlorine is } 1: 1 \text { (USEPA, } \\
2000 \text { ) } \\
\text { - an excess of } 10 \% \text { above theoretical values } \\
\text { of the dechlorination agent is necessary to } \\
\text { achieve complete dechlorination (NMED, } \\
2003 \text { ) } \\
\text { - over-dosing is the best approach (GVRD, } \\
1997 \text { ) }\end{array}$ \\
\hline
\end{tabular}




\begin{tabular}{|c|c|c|}
\hline $\begin{array}{l}\text { Dechlorinotion } \\
\text { Chemical }\end{array}$ & - Experimental Fudings: & Literame \\
\hline $\begin{array}{l}\text { Sulfur Salts } \\
\text { Sodium Sulfite } \\
\text { Sodium Bisulfite } \\
\text { Sodium } \\
\text { Metabisulfite }\end{array}$ & $\begin{array}{l}-1 \times \text { stoichiometric dosages of } \mathrm{DA}: \mathrm{Cl}_{2} \\
\text { (mg/mg) is inadequate to achieve } \\
\text { complete dechlorination in less than } \\
60 \text { seconds } \\
\text { - dechlorination reactions are rapid but } \\
\text { not instantaneous } \\
\text { - dechlorination agents are needed } 2 \text { - } \\
3 \mathrm{x} \text { in excess of the stoichiometric } \\
\text { requirement to achieve dechlorination } \\
\text { in }<180 \text { seconds }\end{array}$ & $\begin{array}{l}\text { - } 50 \% \text { molar excess (relative to the initial } \\
\text { total residual chlorine) is currently used } \\
\text { (Helz \& Nweke, 1995) } \\
\text { - produce sulfur (IV) compounds that readily } \\
\text { reacts with free and combined chlorine } \\
\text { species (Ekkad \& Huber, 1996) } \\
\text { - reaction between free or combined } \\
\text { chlorine and the sulfur (IV) compounds will } \\
\text { occur in 15-20 seconds, especially at high } \\
\text { pH (Helz \& Nweke, 1995; NMED, 2003) } \\
\text { - all the dechlorination reactions are rapid at } \\
\text { low pH but slow at neutral pH (Ekkad and } \\
\text { Huber, 1996) } \\
\text { - dechlorination is rapid and complete } \\
\text { (USEPA, 2000; Ekkad \& Huber, 1996) } \\
\text { - only removes } 87 \text { - 98\% of free chlorine in } \\
\text { the effluent and the rest is reduced at a much } \\
\text { slower rate (Helz \& Nweke, 1995) } \\
\text { - sulfite only reduces } 67 \% \text { of residual } \\
\text { chlorine within the first } 2 \text { minutes (Bedner } \text { et } \\
\text { al., 2004) } \\
\text { - not as effective in reducing inorganic } \\
\text { chloramines, especially N-chloropeptides } \\
\text { (Bedner et al., 2004; Helz \& Nweke, 1995; } \\
\text { Jensen \& Helz, 1998; Jameel \& Helz, 1999; } \\
\text { MacCrehan et al., 1998) }\end{array}$ \\
\hline $\begin{array}{l}\text { Sodium Sulfite } \\
\text { (SS) } \\
\text { - sulfur salt }\end{array}$ & $\begin{array}{l}\text { - pseudo-first order kinetics wrt to } \\
\text { total chlorine concentration at } 10 \mathrm{x} \\
\text { dosage } \\
\text {-second order kinetics overall at } 4 \mathrm{x} \\
\text { dosage } \\
\text { - req'd reaction time at } 1 \mathrm{x} \text { dosage }> \\
\text { CTS but }<\text { STS } \\
\text { - at } 1,2,3 \mathrm{x} \text { dosages reaction } \\
\text { incomplete in }<180 \text { s } \\
\text { - } 4 \mathrm{x} \text { and } 10 \mathrm{x} \text { dosages req'd } 40-50 \mathrm{~s} \\
\text { - frequency of mixing did not have an } \\
\text { impact on the reaction rate } \\
\text { - intensity of mixing did have an } \\
\text { impact on the reaction rate } \\
\text { - reaction rate not effected at } \mathrm{pH}>9\end{array}$ & $\begin{array}{l}\text { - SS: Cl ratio of } 1.8: 1 \mathrm{mg} / \mathrm{mg} \text { should be used } \\
\text { (DEP, 2005) } \\
\text { - required reaction time << thiosulfates (EC, } \\
\text { 2003; US Army, 1988) } \\
\text { - dechlorination is not rapid and complete } \\
\text { (Bedner et al., 2004; Helz \& Nweke, 1995; } \\
\text { Jensen \& Helz, 1998; MacCrehan } \text { et al., } \\
\text { 1998) }\end{array}$ \\
\hline
\end{tabular}




\begin{tabular}{|c|c|c|}
\hline Dechlorination & Experinental Findings & Literature \\
\hline $\begin{array}{l}\text { Sodium Bisulfite } \\
\text { (SBS) } \\
\text { - sulfur salt }\end{array}$ & $\begin{array}{l}\text { - zero order kinetics wrt to total } \\
\text { chlorine concentration at } 10 \mathrm{x} \text { dosage } \\
\text {-second order kinetics overall at } 2-3 \mathrm{x} \\
\text { dosage } \\
\text { - } 1 \mathrm{x} \text { dosage req'd } \sim 70-80 \mathrm{~s} \text { to } \\
\text { complete } \\
\text { - } 2 \mathrm{x} \text { dosage req'd } 50-60 \mathrm{~s} \\
-2.5 \mathrm{x} \text { and } 3 \mathrm{x} \text { needed only } 30-40 \mathrm{~s} \\
-10 \mathrm{x} \text { dosage req'd } 30-40 \mathrm{~s} \\
\text { - frequency } \& \text { intensity of mixing did } \\
\text { not have an impact on reaction rate } \\
\text { - need more studies to determine } \\
\text { effects of pH change } \\
\text { - required reaction time at } 1 \mathrm{x} \text { dosage }> \\
\text { CTS but }<\text { STS }\end{array}$ & $\begin{array}{l}\text { - SBS: Cl ratio of } 1.5: 1 \mathrm{mg} / \mathrm{mg} \text { should be } \\
\text { used (DEP, 2005) } \\
\text { - required contact times for these reactions } \\
\text { are between one to five minutes } \\
\text { - required reaction time << thiosulfates (EC, } \\
\text { 2003; US Army, 1988) } \\
\text { - at high pH, reaction occur within } 15-20 \mathrm{~s} \\
\text { (Helz \& Nweke, 1995) } \\
\text { - dechlorination is not rapid and complete } \\
\text { (Bedner } \text { et al., 2004; Helz \& Nweke, 1995; } \\
\text { Jensen \& Helz, 1998; MacCrehan } \text { et al., } \\
\text { 1998) }\end{array}$ \\
\hline $\begin{array}{l}\text { Sodium } \\
\text { metabisulfite } \\
\text { (SMBS) }\end{array}$ & $\begin{array}{l}\text { - pseudo-first order kinetics wrt total } \\
\text { chlorine concentration at } 10 \mathrm{x} \text { dosage } \\
\text {-second order kinetics overall at } 2-4 \mathrm{x} \\
\text { dosage } \\
-1 \mathrm{x} \text { dosage req'd }>90 \text { s for completion } \\
-3 \mathrm{x} \text { and } 4 \mathrm{x} \text { dosages req'd } 50-60 \text { s to } \\
\text { achieve complete neutralization } \\
-10 \mathrm{x} \text { reaction complete in } \sim 40 \mathrm{~s} \\
\text {-frequency } \& \text { intensity of mixing did } \\
\text { not have an impact on reaction rate } \\
\text { - reaction rate not effected at pH }>9 \\
\text { - required reaction time at } 1 \mathrm{x} \text { dosage }> \\
\text { CTS but }<\text { STS } \\
\end{array}$ & $\begin{array}{l}\text { - SMBS: Cl ratio of } 1.5: 1 \mathrm{mg} / \mathrm{mg} \text { should be } \\
\text { used (DEP, 2005) } \\
\text { - produce sulfur (IV) compounds that readily } \\
\text { reacts with free and combined chlorine } \\
\text { species (Ekkad \& Huber, 1996) } \\
\text { - required reaction time << thiosulfates (EC, } \\
\text { 2003; US Army, 1988) } \\
\text { - dechlorination is not rapid and complete } \\
\text { (Bedner } \text { et al., 2004; Helz \& Nweke, 1995; } \\
\text { Jensen \& Helz, 1998; MacCrehan et al., } \\
\text { 1998) }\end{array}$ \\
\hline $\begin{array}{l}\text { Sodium } \\
\text { Thiosulfate } \\
\text { (STS) }\end{array}$ & $\begin{array}{l}\text { - pseudo first order kinetics wrt total } \\
\text { chlorine concentration at } 10 \mathrm{x} \text { dosage } \\
\text {-second order kinetics overall at } 2-4 \mathrm{x} \\
\text { dosage } \\
\text { - reaction incomplete at } 1 \mathrm{x} \text { dosage } \\
\text { - at } 2,3 \text {, and } 10 \mathrm{x} \text { dosage reactions } \\
\text { completed in } 40-60 \text { s } \\
\text { - frequency and intensity of mixing did } \\
\text { not have an impact on the reaction rate } \\
\text { - reaction rate not effected at } \mathrm{pH}>9 \\
\end{array}$ & 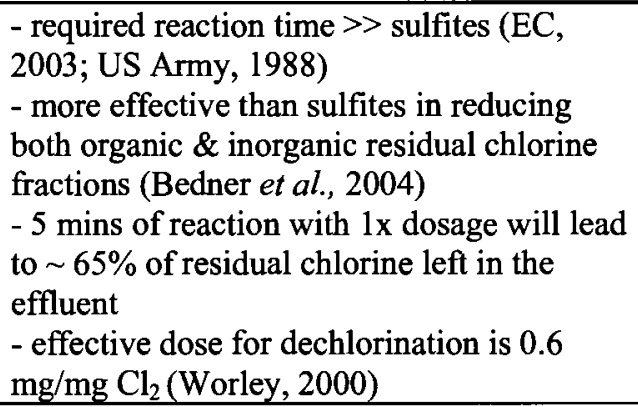 \\
\hline $\begin{array}{l}\text { Calcium } \\
\text { Thiosulfate } \\
\text { (CTS) }\end{array}$ & $\begin{array}{l}\text { - zero order kinetics wrt total chlorine } \\
\text { concentration at } 10 \mathrm{x} \text { dosage } \\
\text {-second order kinetics overall at } 2-4 \mathrm{x} \\
\text { dosage } \\
\text { - at } 1-3 \mathrm{x} \text { dosage first order reaction } \\
-1 \mathrm{x} \text { dosage needed } \sim 70 \text { s to achieve } \\
\text { complete neutralization } \\
-2 \text { and } 3 \mathrm{x} \text { had similar reaction rates } \\
\text { and took } \sim 50-60 \mathrm{~s} \text { to achieve complete } \\
\text { dechlorination } \\
-10 \mathrm{x} \text { reaction req'd } 30-40 \text { s for } \\
\text { completion } \\
\text { - intensity \& frequency of mixing did } \\
\text { have an impact on the reaction rate } \\
\text { - reaction rate not effected at } \mathrm{pH}>9\end{array}$ & $\begin{array}{l}\text { - more effective than sulfites in reducing } \\
\text { both organic and inorganic residual chlorine } \\
\text { fractions (Bedner } \text { et al., 2004) } \\
\text { - required reaction time }>>\text { sulfites (EC, } \\
\text { 2003; US Army, 1988) }\end{array}$ \\
\hline
\end{tabular}




\begin{tabular}{|c|c|c|}
\hline Dechlorination & Experimental Findings & Liferature \\
\hline Chenicar & 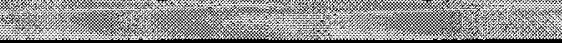 & 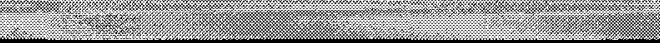 \\
\hline $\begin{array}{l}\text { Ascorbic acid } \\
\text { (AA) }\end{array}$ & $\begin{array}{l}\text { - zero order kinetics wrt total chlorine } \\
\text { concentration at } 10 \mathrm{x} \text { dosage } \\
\text {-second order kinetics overall at } 2-4 \mathrm{x} \\
\text { dosage } \\
\text { - did not reach completion in } 180 \text { s at } \\
1 \mathrm{x} \text { stoichiometric dosage } \\
-2,3 \text {, and } 10 \mathrm{x} \text { dosage req'd } 25-40 \text { s } \\
\text { - intensity of mixing did have an } \\
\text { impact on the reaction rate } \\
\text { - frequency of mixing did not have an } \\
\text { impact on the reaction rate } \\
\text { - pH }>9 \text { increased reaction rate }\end{array}$ & $\begin{array}{l}\text { - reacts with chlorine rapidly (EC, 2003) } \\
\text { - less effective than sulfites (Bedner } \text { et al., } \\
2004 \text { ) } \\
\text { - } 5 \text { mins of reaction with } 1 \times \text { dosage leave } ~ \\
7.5 \% \text { of residual chlorine in the effluent } \\
\text { - effective dose for dechlorination of } \\
\text { chlorine is } 3.0 \mathrm{mg} / \mathrm{mg} \text { as } \mathrm{Cl}_{2} \text { (Worley, 2000) }\end{array}$ \\
\hline $\begin{array}{l}\text { Hydrogen } \\
\text { peroxide (HP) }\end{array}$ & $\begin{array}{l}\text { - pseudo-first order kinetics wrt total } \\
\text { chlorine concentration at } 10 \mathrm{x} \text { dosage } \\
\text {-second order kinetics overall at } 2-4 \mathrm{x} \\
\text { dosage } \\
\text { - at the } 1 \mathrm{x} \text { dosage, req'd between } 20 \text { - } \\
30 \mathrm{~s} \text { for completion } \\
\text { - } 0.1 \mathrm{x} \text { dosage complete in } 50-60 \mathrm{~s} \\
\text { - } 0.5 \mathrm{x} \text { dosage complete in } 20-30 \mathrm{~s} \\
\text { - interferences with the DIC probes } \\
\text { and DPD measurements suspected } \\
\text { - frequency of mixing did not impact } \\
\text { reaction rate } \\
\text { - reaction rate not effected at pH>9 } \\
\text { - intensity \& frequency of mixing did } \\
\text { not have an impact on reaction rate }\end{array}$ & $\begin{array}{l}\text { - rapidly reacts with free chlorine, reaction } \\
\text { with combined chlorine is slow, require } \\
\text { longer contact times of } 10 \text { to } 15 \text { mins } \\
\text {-pseudo-first order reaction wrt } \mathrm{OCl}^{-} \text {(Shams } \\
\text { El Din \& Mohammed, } 1998 ; \mathrm{EC}, 2003 \text { ) } \\
\text { - } 5 \mathrm{mins} \text { of reaction with } 1 \mathrm{x} \text { dosage cause } ~ \\
2.5 \% \text { the residual chlorine to be left in the } \\
\text { effluent } \\
\text { - effective dose for the dechlorination of } \\
\text { chlorine is } 2.2 \mathrm{mg} / \mathrm{mg} \mathrm{Cl}_{2} \text { (Worley, 2000) } \\
\text { - interfere with DPD measurements (DPD } \\
\text { Method) }\end{array}$ \\
\hline
\end{tabular}

\subsection{Acute Toxicity Tests: Daphnia magna Experiments}

The following sections discuss the results of the 48-hour acute lethality tests undertaken to identify the least harmful chemical in terms of the percentage mortality of Daphnia magna at various concentrations of the dechlorination chemicals. A fixed number (5 or 10) of Daphnia magna of less than 24 hours (neonates) of age were put into each test chamber with a specific dechlorination agent concentration ranging from 0 to $200 \mathrm{mg} / \mathrm{L}$. The number of neonates that were alive in the test solutions were enumerated at the beginning $(t=0)$ and after 48 hours. Three replicates were tested for each concentration and the average mortality values were calculated as the $\%$ mortalities at each 
concentration, and the error bars indicate one standard deviation above and below the average values. The percentage survival and mortality at each concentration were calculated as follows:

$$
\begin{aligned}
\% \text { Survival for each replicate } r & =\frac{(\# \text { neonates alive after } 48 \mathrm{hrs})}{(\# \text { neonates alive at time }=0)} \times 100 \\
\% \text { Survival at a given concentration } & =\frac{\text { sumof } \% \text { survival of } 3 \text { replicates }}{3} \\
\% \text { Mortality } & =1-\% \text { survival }
\end{aligned}
$$

For all the chemicals tested, the 48 -hour $\mathrm{LC}_{50}$ values were calculated using the Graphical Method suggested by the USEPA (2002). Sodium thiosulfate (STS) and sodium sulfite (SS) were omitted from the $\mathrm{LC}_{50}$ calculation because of the reasons discussed in the methodology section. For SS and STS, the actual concentration of the dechlorination agent at which $50 \%$ of the Daphnia magna would be killed was calculated instead.

The Daphnia magna acute toxicity test results are discussed in three separate sections: sulfur salts, thiosulfates and other chemicals. SS, SBS and SMBS are discussed as part of sulfur salts, sodium and calcium thiosulfate are discussed as part of the thiosulfates category, while ascorbic acid and hydrogen peroxide are considered together under the other chemicals category. Dechlorination chemicals were categorized as non-toxic, directly toxic or indirectly toxic: Chemicals that caused no mortality at high (50-200 $\mathrm{mg} / \mathrm{L}$ ) concentrations tested were identified as non-toxic; chemicals that caused mortality by substantial $\mathrm{pH}$ or $\mathrm{DO}$ suppression were indentified as indirectly toxic; while chemicals that caused mortality by suppressing $\mathrm{DO}$ and/or $\mathrm{pH}$ of solution were indentified as directly toxic. 


\subsubsection{Toxicity of Sulfur Salts}

The percentage survival values obtained for Daphnia magna under different concentrations of the three sulfur salts tested are illustrated in Figure 28.

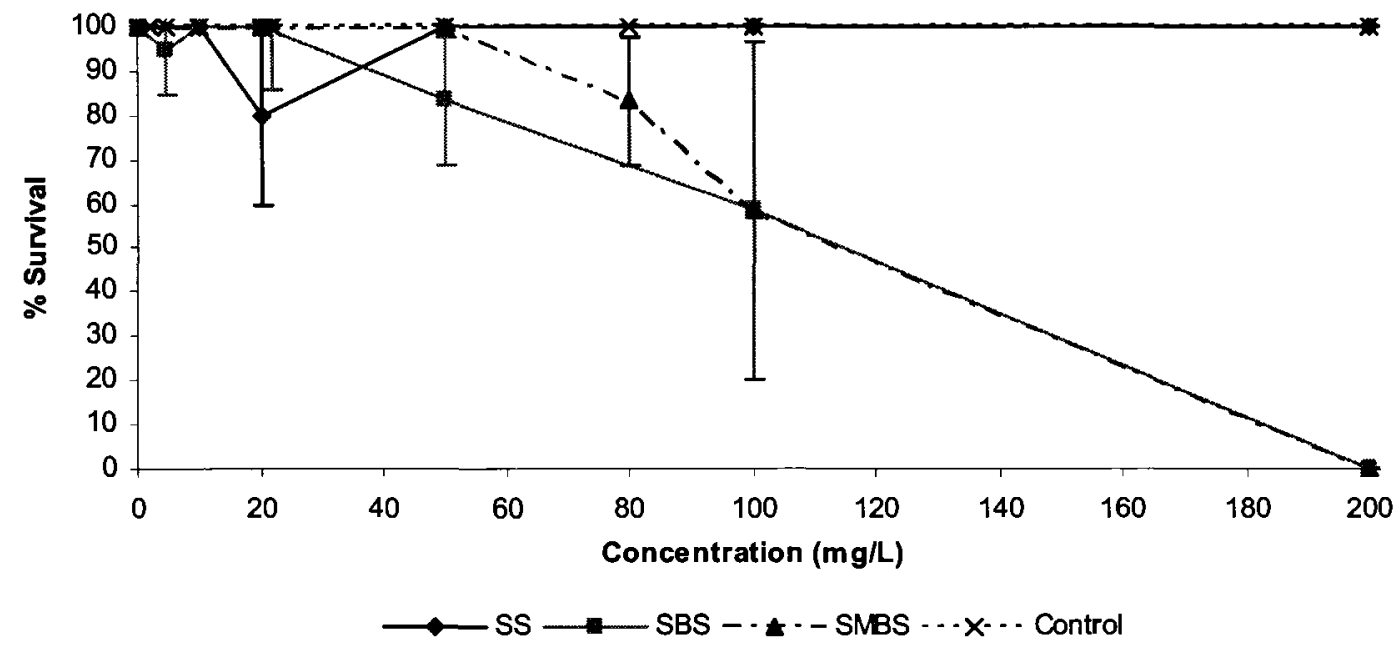

Figure 28: Percentage survival of Daphnia magna for various concentrations of sodium sulfite, bisulfite and metabisulfite.

From the Figure 28, it is evident that the least harmful sulfur salt is SS, which resulted in $100 \%$ survival of Daphnia magna at $200 \mathrm{mg} / \mathrm{L}$ concentrations. This result is consistent with previous findings for SS 48 hour $\mathrm{LC}_{50}$ value of $440 \mathrm{mg} / \mathrm{L}$ (Mallinckrodt Baker Inc., 2005) for Daphnia magna. The $20 \%$ mortality that occurred at the $20 \mathrm{mg} / \mathrm{L}$ of SS could be attributed to either the reduction in $\mathrm{pH}(0.8 \mathrm{pH}$ units) that was observed (see Table 19) and/or experimental error as indicated by the error bars. For SBS concentrations of 50 , $100,200 \mathrm{mg} / \mathrm{L}$, the decreases in $\mathrm{pH}$ observed were $0,0.1$ and 0.6 , respectively. However, following the addition of $20 \mathrm{mg} / \mathrm{L}$ of $\mathrm{SS}$ to the solution, the $\mathrm{pH}$ of the solution decreased by 0.8 units, which is unusual and may be attributed to experimental error, because for concentrations $>20 \mathrm{mg} / \mathrm{L}$ the $\mathrm{pH}$ suppression is not consistently higher as expected. Another possible source of error for the death of the $20 \%$ of the test population 
of neonates could have been stresses induced during transfer from the culture chamber into the test beakers. However, in the $20 \mathrm{mg} / \mathrm{L}$ of SS case, $100 \%$ of the test organisms in the control solution survived, which makes the overall SS test results acceptable under the USEPA (2002) test results acceptability criteria, which require that over $80 \%$ of the test organisms in the control solution survive. Thus, the SS test results for the $20 \mathrm{mg} / \mathrm{L}$ concentration were still included in the analysis.

Since SMBS dissociates into SBS when dissolved in water, both SBS and SMBS were expected to have similar toxicity profiles. However, from the survival plot Figure 28, SMBS seems to be less toxic than SBS between the concentrations of $20-100 \mathrm{mg} / \mathrm{L}$. A possible reason for the higher mortality with SBS could be the higher DO suppression caused by SBS in the solution compared to SMBS. The tabulated DO values in Table 19 show a larger change in the DO values of SMBS compared to SBS for the concentrations of 50,100 and $200 \mathrm{mg} / \mathrm{L}$. This result is in agreement with what has been previously reported in literature, where among the sulfur salts SMBS have the greatest impact on DO (Tikkanen et al., 2001). If a reduction in DO concentration was the reason for the difference in survival, then the percentage survival values would be expected to differ for all the subsequent concentrations of SBS and SMBS tested as well, but this was not the case. For concentrations below $20 \mathrm{mg} / \mathrm{L}$ and higher than $100 \mathrm{mg} / \mathrm{L}$, the survival rates are identical for SBS and SMBS. This finding led to the hypothesis that the reason for the discrepancy between SBS and SMBS might be a lethal combination of $\mathrm{pH}$ and DO suppression that occurred at SMBS concentrations over $50 \mathrm{mg} / \mathrm{L}$. But at $100 \mathrm{mg} / \mathrm{L}$, both 
chemicals may have reached their threshold of $\mathrm{DO}$ and $\mathrm{pH}$ suppression at which point the percentage survival values became identical.

The above noted hypothesis was refuted after examining the obtained $\mathrm{pH}$ and $\mathrm{DO}$ data that is tabulated in Table 19.

Table 19: The average dissolved oxygen (\%) and $\mathrm{pH}$ values for the three replicates with various concentrations of sodium sulfite, bisulfite and metabisulfite.

\begin{tabular}{|c|c|c|c|c|c|c|c|c|c|c|c|c|c|c|c|c|c|c|}
\hline 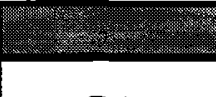 & 5 & $5 \mathrm{mg} / \mathrm{L}$ & & & $\mathrm{mg}$ & $\frac{18}{/ L}$ & $\frac{8}{2}$ & $\frac{89}{\mathrm{mg}}$ & I & $\frac{8}{5}$ & $\frac{\mathrm{mg}}{\mathrm{mg}}$ & $\frac{1}{/ L}$ & $\frac{10}{10}$ & $0 \mathrm{~m}$ & $\frac{1}{1 / \mathrm{L}}$ & 20 & 0 & $\frac{\mathrm{g} / \mathrm{L}}{\mathrm{s}}$ \\
\hline DA & ctrl & Avg & $\begin{array}{c}\text { Avg } \\
\Delta\end{array}$ & ctrl & Avg & Avg & ctrl & Avg & Avg & ctrl & Avg & Avg & ctrl & Avg & Avg & ctrl & Avg & Avg \\
\hline Sodium Sulfite & 97 & 94 & -3 & 97 & 94 & -2 & 96 & 94 & -2 & 93 & 83 & -10 & 94 & 78 & -16 & 83 & 64 & -19 \\
\hline $\begin{array}{l}\text { Sodium } \\
\text { Bisulfite }\end{array}$ & 97 & 95 & -2 & 97 & 96 & -1 & 96 & 95 & -1 & 93 & 89 & -5 & 94 & 90 & -4 & 83 & 74 & -9 \\
\hline $\begin{array}{l}\text { Sodium } \\
\text { Metabisulfite }\end{array}$ & 97 & 93 & -4 & 97 & 95 & -2 & 96 & 93 & -3 & 93 & 83 & -10 & 94 & 56 & -38 & 83 & 40 & -43 \\
\hline & & $\mathrm{mg} /$ & & & $\mathrm{mg}$ & & & $\mathrm{mg}$ & & & $\mathrm{mg}$ & & & $0 \mathrm{~m}$ & $\mathrm{~g} / \mathrm{L}$ & & $0 \mathrm{~m}$ & $\mathrm{~g} / \mathrm{L}$ \\
\hline DA & ctrl & Avg & $\begin{array}{c}\text { Avg } \\
\Delta\end{array}$ & ctrl & Avg & $\begin{array}{c}\text { Avg } \\
\end{array}$ & ctrl & Avg & Avg & ctrl & Avg & Avg & ctrl & Avg & Avg & $c t \pi l$ & Avg & Avg \\
\hline Sodium Sulfite & 6.8 & 6.6 & -0.2 & 6.8 & 6.5 & -0.3 & 7.7 & 6.9 & -0.8 & 6.8 & 6.9 & 0.0 & 7.7 & 7.6 & -0.1 & 6.8 & 7.4 & 0.6 \\
\hline $\begin{array}{l}\text { Sodium } \\
\text { Bisulfite }\end{array}$ & 6.8 & 6.6 & -0.2 & 7.7 & 7.5 & -0.2 & 7.7 & 7.1 & -0.6 & 6.8 & 6.6 & -0.2 & 6.8 & 6.5 & -0.3 & 6.8 & 6.5 & -0.3 \\
\hline $\begin{array}{l}\text { Sodium } \\
\text { Metabisulfite }\end{array}$ & 7.7 & 7.6 & -0.1 & 7.7 & 7.5 & -0.2 & 7.7 & 6.9 & -0.8 & 6.8 & 6.7 & -0.1 & 6.8 & 6.6 & -0.3 & 6.8 & 6.5 & -0.3 \\
\hline
\end{tabular}

* The average change $(\operatorname{Avg} \Delta)$ is indicated as positive $(+)$, if the $\mathrm{DO}$ or $\mathrm{pH}$ value increased following the addition of the dechlorination agent. If the $\mathrm{DO}$ or $\mathrm{pH}$ value decreased following the addition of the dechlorination agent, the value is indicated as negative (-).

* Ctrl corresponds to control solution - dilution water only, without the DA

For the 5 and $10 \mathrm{mg} / \mathrm{L}$ concentrations of SBS and SMBS, the reduction of $\mathrm{pH}$ observed in solution is between $0.1-0.2$. Although, the $\mathrm{pH}$ decreased by 0.6 and 0.8 for $20 \mathrm{mg} / \mathrm{L}$ concentration of the SBS and SMBS, respectively, no mortality was observed. In addition, for the 100 and $200 \mathrm{mg} / \mathrm{L}$ concentrations of SBS and SMBS, the reduction in $\mathrm{pH}$ observed was identical ( $0.3 \mathrm{pH}$ units), yet the DO change observed with SMBS is much higher than the DO suppression caused by SBS. If the reason for the observed mortality of SBS and SMBS at 100 and $200 \mathrm{mg} / \mathrm{L}$ is only the DO suppression, then 
SMBS would be expected to cause higher percentages of mortality than SBS, which is not the case. As shown in Figure 28, the observed mortalities for the both 100 and 200 $\mathrm{mg} / \mathrm{L}$ concentrations of SBS and SMBS are identical. Thus it is likely that the mortality values observed for SBS and SMBS are caused by a combination of inherent toxicity of the two chemicals and $\mathrm{DO}$ and $\mathrm{pH}$ suppression caused by those chemicals.

Another trend illustrated in Figure 28 is that both SBS and SMBS seem to have a threshold effect at which they cause mortality. For SBS and SMBS, there is no mortality observed until $>20 \mathrm{mg} / \mathrm{L}$ and $>50 \mathrm{mg} / \mathrm{L}$, respectively, which is identified as the toxic threshold that Daphnia magna can tolerate. These results are in agreement with previous reports which show that a reduction in DO, sufficient to cause a fish kill, is to be expected when the in-stream concentrations of sulfur salts are equal to or exceed $\sim 39$ $\mathrm{mg} / \mathrm{L}$ (Ryon et al., 2002). Both SBS and SMBS are reported to cause the indirect effect of $\mathrm{pH}$ depletion as well (Ryon et al., 2002), which might have contributed to the death of Daphnia magna. However, in this experimental study, large suppression in DO was observed only for SMBS at concentrations $>50 \mathrm{mg} / \mathrm{L}$, and the suppression in $\mathrm{pH}$ observed was less than $0.3 \mathrm{pH}$ units for both SMBS and SBS at all tested concentrations. Thus, inherent toxicity of these chemicals is suspected. Further studies are needed at constant $\mathrm{pH}$ and DO concentrations to investigate the inherent toxicity of SBS and SMBS, which is beyond the scope of this project. 


\subsubsection{Toxicity of Thiosulfates}

In the case of the two thiosulfates tested, the addition of STS did not cause any mortality at concentrations up to $200 \mathrm{mg} / \mathrm{L}$ (see Figure 29), while Daphnia magna experienced mortality starting at $4.6 \mathrm{mg} / \mathrm{L}$ of CTS.

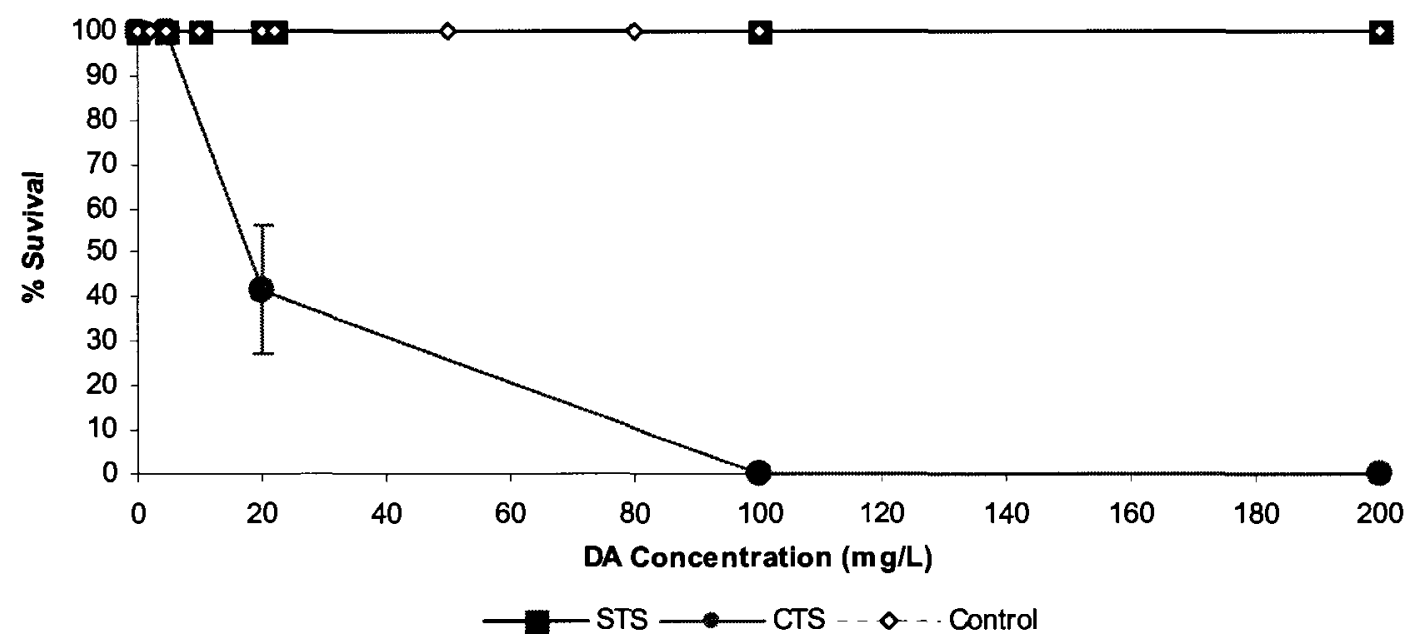

Figure 29: Percentage survival of Daphnia magna for various concentrations of the sodium thiosulfate and calcium thiosulfate.

Median Effect Concentration $\left(\mathrm{EC}_{50}\right)$; the STS concentration that produces a lethality effect in 50\% of test organisms in a given population (IUPAC, 1997) of Daphnia magna, have been previously reported (Oh et al., 2008) to be as high as $1334 \mathrm{mg} / \mathrm{L}$. Given such high reported $\mathrm{EC}_{50}$ values, it was not surprising that not mortality was observed at the STS range tested in this study. Also, $\mathrm{pH}$ and $\mathrm{DO}$ values tabulated in Table 20 shows that the addition of STS did not alter the solution $\mathrm{pH}$ or the DO concentration more than 0.3 units and $2 \%$, respectively. Thus, it is safe to conclude that STS does not have any direct or indirect lethality effects on Daphnia magna. 
Table 20: The average dissolved oxygen (\%) and $\mathrm{pH}$ values for the three replicates with various concentrations of sodium and calcium thiosulfate.

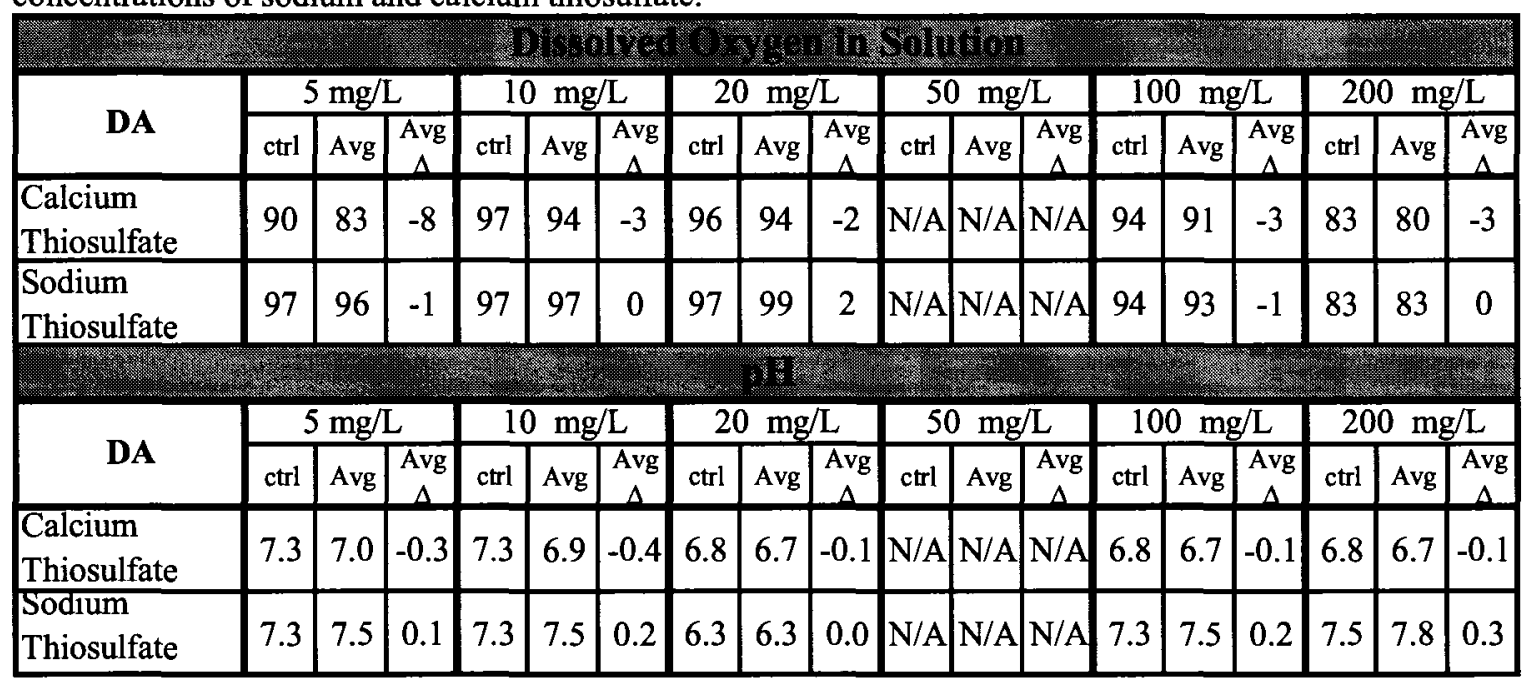

* The average change $(\operatorname{Avg} \Delta)$ is indicated as positive $(+)$, if the $\mathrm{DO}$ or $\mathrm{pH}$ value increased following the addition of the dechlorination agent. If the $\mathrm{DO}$ or $\mathrm{pH}$ value decreased following the addition of the dechlorination agent, the value is indicated as negative (-).

* concentrations at which tests were not undertaken are indicated as N/A

* Ctrl corresponds to control solution

For CTS on the other hand, mortality was observed beginning at concentrations as low as $20 \mathrm{mg} / \mathrm{L}$ and at 100 and $200 \mathrm{mg} / \mathrm{L}, 100 \%$ mortality rates were observed. In addition, CTS did not alter the solution $\mathrm{pH}$ or the DO concentration more than 0.4 units and $8 \%$, respectively. When the DO level was suppressed by $8 \%$ at $5 \mathrm{mg} / \mathrm{L}$ concentration of CTS, no mortality was observed. These results are consistent with what have been reported in literature that CTS is not an oxygen scavenger (Wang et al., 2006). Therefore, the observed mortality was likely due to the inherent toxicity of CTS itself in water because the $\mathrm{DO}$ and the $\mathrm{pH}$ of the solution did not change substantially (see

Table 20). 


\subsubsection{Toxicity of Hydrogen Peroxide and Ascorbic Acid}

Figure 30 shows the percentage survival values obtained for Daphnia magna under different tested concentrations of hydrogen peroxide (HP) and ascorbic acid (AA).

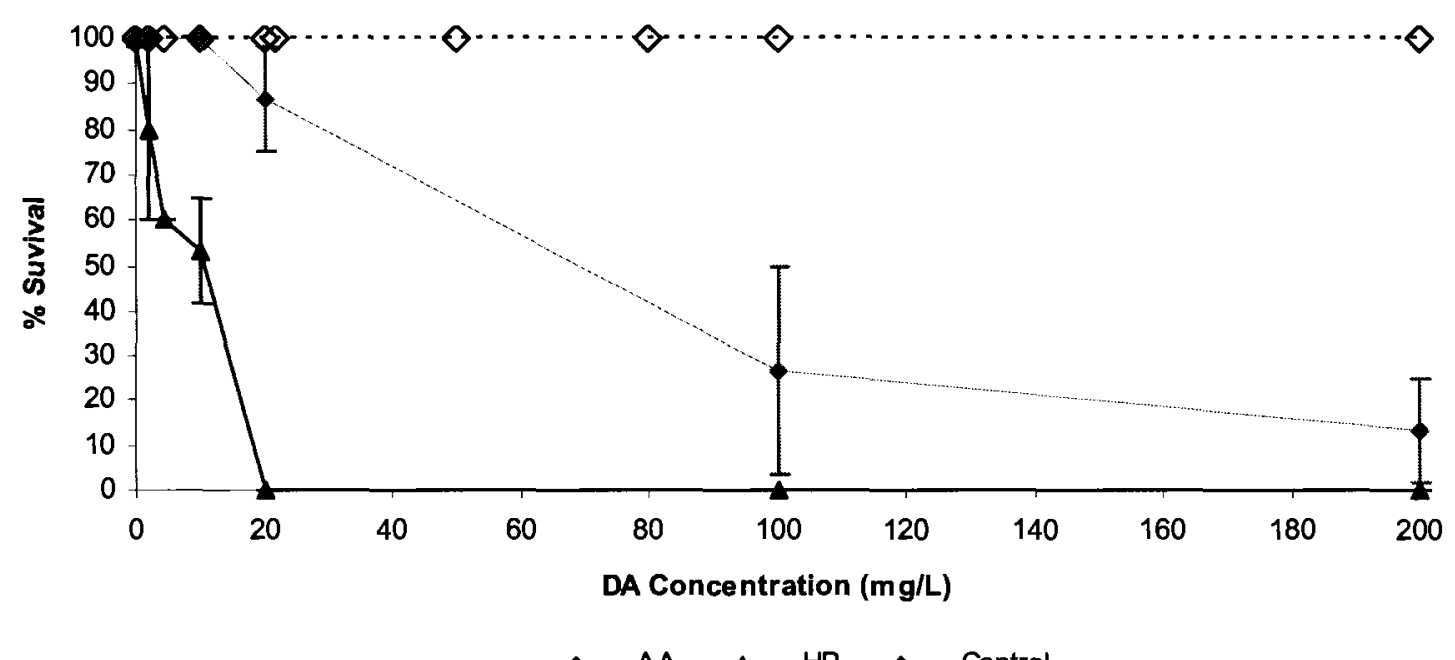

Figure 30: Percentage survival of Daphnia magna for various concentrations of hydrogen peroxide and ascorbic acid.

Between HP and AA, HP was the most toxic. Lethality effects of HP were observed beginning at concentrations as low as $2 \mathrm{mg} / \mathrm{L}$, and $20 \mathrm{mg} / \mathrm{L}$ of $\mathrm{HP}$ resulted in $100 \%$ mortality of the test organisms. These results are consistent with the $\mathrm{EC}_{50}$ values reported in the literature (Advanced Sterilization Products, 2005) of $7.7 \mathrm{mg} / \mathrm{L}$. In this study, the actual concentration of HP that caused $50 \%$ mortality was approximately 10 $\mathrm{mg} / \mathrm{L}$. These results are not surprising considering that HP is commonly used as a disinfectant as it is a stronger oxidant than chlorine.

Although not as toxic as HP, AA also caused a considerable percentage of mortality starting at concentrations as low as $20 \mathrm{mg} / \mathrm{L}$. The actual concentration that caused $50 \%$ mortality in this study was approximately $70 \mathrm{mg} / \mathrm{L}$. This result is surprising since it does 
not agree with what has been reported in the literature. For example, NICNAS (2003) reports that AA is non-toxic at concentrations as high as $200 \mathrm{mg} / \mathrm{L}$, and the 48 hour $\mathrm{EC}_{50}$ value for Daphnia magna based on measured concentrations, is given as $>190 \mathrm{mg} / \mathrm{L}$ by NICNAS (2003). The reason for this observed discrepancy in results may be that, even though not explicitly stated, NICNAS (2003) may have undertaken the toxicity tests under controlled $\mathrm{pH}$ conditions, which may have masked any indirect toxicity as a result of $\mathrm{pH}$ suppression.

Comparatively, AA had a greater impact on the $\mathrm{pH}$ of the solution than HP. For instance at 100 and $200 \mathrm{mg} / \mathrm{L}$ concentrations of $\mathrm{AA}$, the $\mathrm{pH}$ of the solution decreased by 0.5 and $1.2 \mathrm{pH}$ units, respectively (see Table 21 ).

Table 21: The average dissolved oxygen (\%) and $\mathrm{pH}$ values for the three replicates with various concentrations of ascorbic acid and hydrogen peroxide.

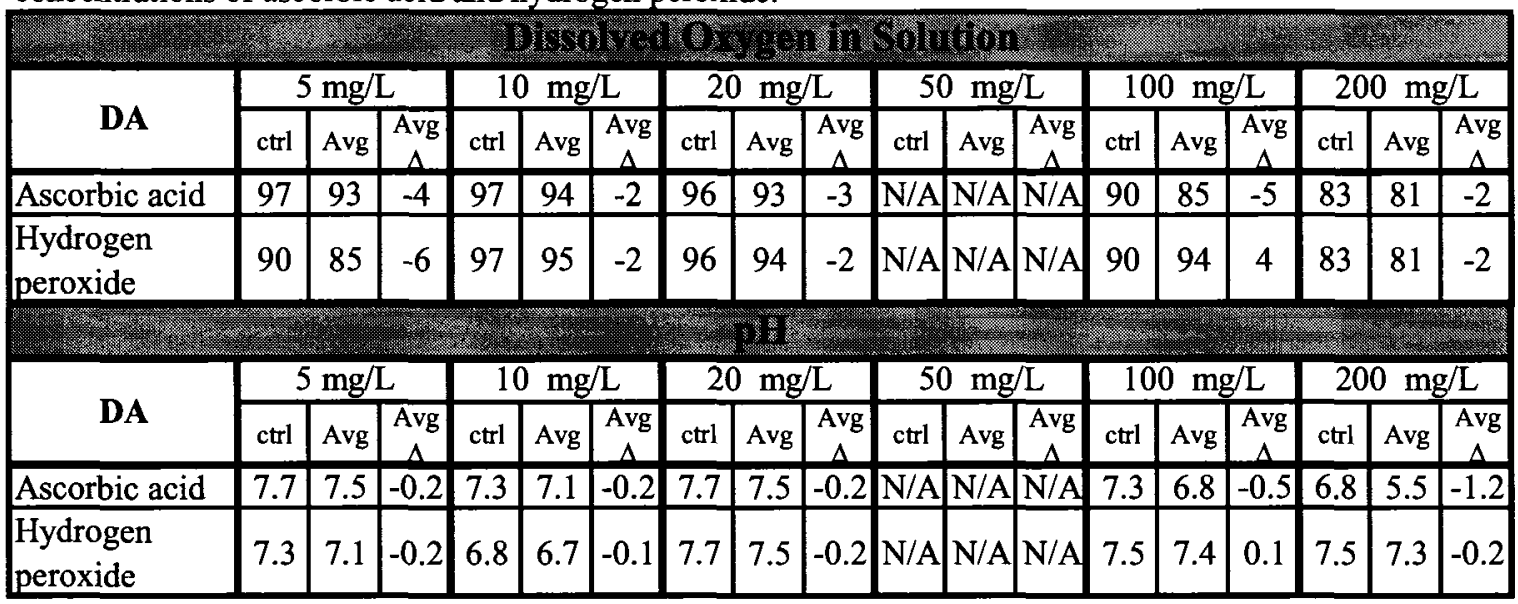

* The average change $(\operatorname{Avg} \Delta)$ is indicated as positive $(+)$, if the $\mathrm{DO}$ or $\mathrm{pH}$ value increased following the addition of the dechlorination agent. If the $\mathrm{DO}$ or $\mathrm{pH}$ value decreased following the addition of the dechlorination agent, the value is indicated as negative (-).

* concentrations at which tests were not undertaken are indicated as N/A

* Ctrl corresponds to control solution 
This observed $\mathrm{pH}$ reduction with $\mathrm{AA}$ is consistent with what has been reported in the literature (EC, 2003). The mortality observed for ascorbic acid concentrations 100 and $200 \mathrm{mg} / \mathrm{L}$ could be due to the $\mathrm{pH}$ suppression that is caused by AA in solution, and AA therefore indirectly causes toxicity to Daphnia magna. Also, the DO data (see Table 21) shows that neither AA nor $\mathrm{HP}$ is an oxygen scavenger. For HP, a substantial $\mathrm{pH}$ or DO reduction was not observed, possibly because the observed mortality was a consequence of inherent toxicity of HP itself.

\subsubsection{Comparison of the Acute Toxicity of the Dechlorination Agents}

Of all the dechlorination agents tested, STS had no toxicity effects on Daphnia magna over the concentration range tested $(0-200 \mathrm{mg} / \mathrm{L})$. SS and STS were very similar in that they both resulted in $100 \%$ survival for the concentration range rested; except that the 20 $\mathrm{mg} / \mathrm{L}$ concentration of SS resulted in $20 \%$ mortality due to $\mathrm{pH}$ suppression or possible experimental errors as previously discussed (see Section 4.2.1). Figure 31 below shows a comparison between the dechlorination chemicals that produced a lethality effect to Daphnia magna. Both SS and STS were omitted from Figure 31, because these chemicals did not cause any significant changes to the percentage survival for the concentrations tested over 48 hours. 


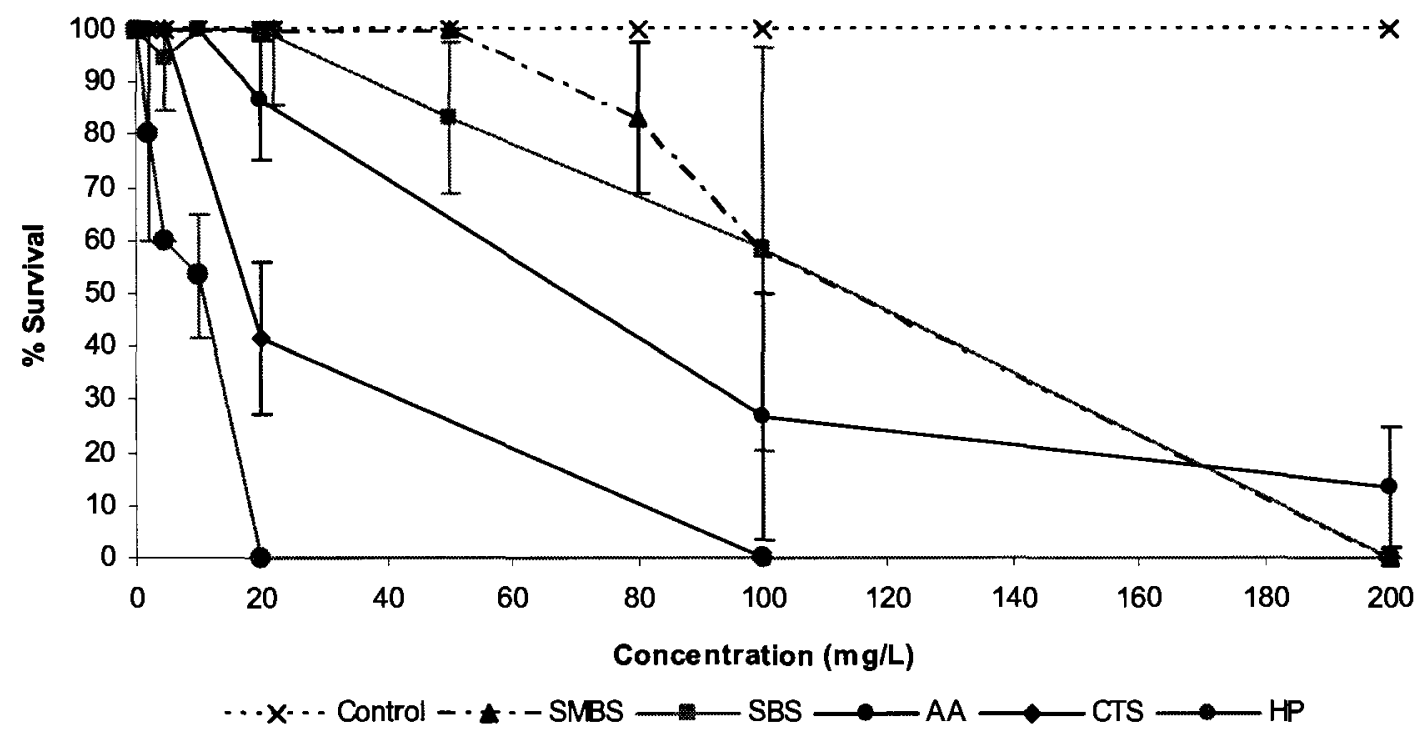

Figure 31: Percentage survival for the control, sodium bisulfite, metabisulfite, ascorbic acid, calcium thiosulfate and hydrogen peroxide. Sodium sulfite and sodium thiosulfate were omitted as these chemicals did not cause any significant changes to the percentage survival.

From examining the Daphnia magna survival plots as well as the $\mathrm{pH}$ and DO data, three types of toxicity criteria were identified for the seven dechlorination chemicals tested.

Based on these criteria the seven dechlorination agents were categorized as follows:

Table 22: Type of aquatic toxicity caused by the dechlorination chemicals.

\begin{tabular}{|c|c|c|}
\hline $\begin{array}{l}\text { Mpe of Aquatic } \\
\text { Toxicity }\end{array}$ & Criterif & Chemicals. \\
\hline Non- toxic & $\begin{array}{l}\text { - no mortality was observed for high }(50-200 \\
\text { mg/L) concentrations tested }\end{array}$ & $\begin{array}{l}\text { Sodium Sulfite } \\
\text { Sodium Thiosulfate }\end{array}$ \\
\hline Direct Toxicity & $\begin{array}{l}\text { - chemical is inherently toxic } \\
\text { - observed DO suppression } \leq 10 \% \\
\text { - observed pH suppression } \leq 0.3 \mathrm{pH} \text { units }\end{array}$ & $\begin{array}{l}\text { Hydrogen Peroxide } \\
\text { Calcium Thiosulfate }\end{array}$ \\
\hline Indirect Toxicity & $\begin{array}{l}\text { - chemical inherently non-toxic } \\
\text { - cause mortality by suppressing DO and/or pH of } \\
\text { solution }\end{array}$ & $\begin{array}{l}\text { Ascorbic Acid } \\
\text { Sodium } \\
\text { Metabisulfite } \\
\text { Sodium Bisulfite }\end{array}$ \\
\hline
\end{tabular}

SBS and SMBS have similar toxicity profiles, except it can be seen from Figure 31 that for concentrations between $20-50 \mathrm{mg} / \mathrm{L}$ SMBS deviates from the $\%$ mortality observed for SBS, even though SBS is produced following the addition of SMBS to the water. 
Ascorbic acid (AA) closely follows SMBS in the toxicity profile, yet mortality was consistently higher than for SMBS up to $100 \mathrm{mg} / \mathrm{L}$. For 20 and $200 \mathrm{mg} / \mathrm{L}$ of AA the observed percentage mortalities were $14 \%$ and $87 \%$, respectively, while for SMBS, they were $0 \%$ and $42 \%$. However, at $200 \mathrm{mg} / \mathrm{L}$, the $\%$ mortality observed for AA was $\sim 87 \%$, which is less than that of SMBS $(100 \%)$, for unknown reasons.

CTS and HP are the most toxic dechlorination agents tested in this study. Percentage survival under CTS and HP is significantly below all of the other chemicals tested (Figure 31). For both of these chemicals, the $\%$ survival values start decreasing at concentrations as low as $4.6 \mathrm{mg} / \mathrm{L}$ and the rate of decrease in percentage survival followed a similar trend until $20 \mathrm{mg} / \mathrm{L}$. At $20 \mathrm{mg} / \mathrm{L}, \mathrm{HP}$ caused $100 \%$ mortality in all the replicates tested while CTS was less toxic and resulted in only $40 \%$ survival on average. Since HP releases oxygen when added to water, it is not considered a DO suppressor. Also, HP has not been reported to decrease $\mathrm{pH}$ in the test solutions. Thus it seems that being a strong oxidant like chlorine, HP itself is directly toxic to Daphnia magna. The highly reactive and corrosive nature of hydrogen peroxide (Advanced Sterilization Products, 2005) seems to have caused the acute toxicity observed in Daphnia magna. CTS also, did not suppress the $\mathrm{pH}$ and the DO of solution, thus the observed mortality induced by CTS is attributed to its inherent toxicity.

Following the analysis of actual percentage lethality values under various concentrations of the dechlorination agents, the obtained mortality results were analyzed using the Graphical Method suggested by the USEPA (2002) to estimate the $\mathrm{LC}_{50}$ value for each of 
the seven dechlorination chemicals (refer to Appendix 4 for individual graphs). This Graphical Method is a mathematical procedure used to estimate the $\mathrm{LC}_{50}$ values by linear interpolation between points of a plot of observed $\%$ mortality versus the $\log _{10}$ of $\%$ effluent concentration. One short-coming of this method, however, is that it does not produce confidence intervals for the LC50 values. The LC50 values obtained from the Graphical Method are shown in Table 23. STS and SS could not be analyzed using the Graphical Method (USEPA, 2002), because this method is only valid for analyzing data when the obtained percentage mortalities bracket the $50 \%$ mortality mark.

Table 23: 48 hour $\mathrm{LC}_{50}$ values derived using the Graphical Method (USEPA, 2002).

\begin{tabular}{|l|c|}
\hline \multicolumn{1}{|c|}{ Dechlorination Agent } & $\begin{array}{c}\text { Calculated } 48 \mathrm{hr} \\
\text { LC }\end{array}$ \\
\hline Sodium Thiosulfate (ST) & $>200^{*}$ \\
\hline Sodium Sulfite (SS) & $>200^{*}$ \\
\hline Sodium Metabisulfite (SMBS) & 100 \\
\hline Sodium Bisulfite (SBS) & 68 \\
\hline Ascorbic acid (AA) & 55 \\
\hline Calcium Thiosulfate (CTS) & 22 \\
\hline Hydrogen peroxide (HP) & 4.7 \\
\hline
\end{tabular}

* observed mortality could not be analyzed using the graphical method since no mortality was observed over the tested concentration range of $0-200 \mathrm{mg} / \mathrm{L}$, thus actual concentrations at which $50 \%$ mortality observed are indicated.

Therefore, from the analysis of the actual percentage survival values, and the 48 hour $\mathrm{LC}_{50}$ values of Daphnia magna under varying concentrations of SS, SBS, SMBS, STS, CTS, AA and HP, it is apparent that HP has the highest acute toxicity values. CTS closely follows HP, and was observed to be more toxic than AA. The three sulfur salts were comparably safer than CTS, AA and HP. However, of the three sulfur salts tested, SBS and SMBS had similar toxicity profiles, and SS did not cause substantial acute toxicity. 
In conclusion, from the study of seven dechlorination chemicals, STS was identified as the chemical with the least or no acute toxicity over the concentration range tested $(0-$ $200 \mathrm{mg} / \mathrm{L}$ ). This result was similar to that of SS. Thus, STS and SS are the least toxic chemicals and as such would be the preferred chemicals for the dechlorination of municipal wastewater effluent prior to discharge into natural rivers and lakes, because these chemicals produce the least acute toxicity to the common indicator organism Daphnia magna.

Table 24 summarizes the experimental findings of this study and provides a comparison to the results reported in the literature regarding the acute toxicity of the seven dechlorination agents in consideration.

Table 24: Acute toxicity test results summary

\begin{tabular}{|c|c|c|}
\hline $\begin{array}{c}\text { Dechiorination } \\
\text { Chemical }\end{array}$ & Experimental Findings & Literature \\
\hline $\begin{array}{l}\text { Sodium Sulfite } \\
\text { (SS) }\end{array}$ & $-48 \mathrm{hr} \mathrm{LC}_{50}>200 \mathrm{mg} / \mathrm{L}$ & $\begin{array}{l}\text { - } 48 \text { hour } \mathrm{LC}_{50} \text { value of } 440 \mathrm{mg} / \mathrm{L} \\
\text { (Mallinckrodt Baker Inc., 2005) } \\
\text { - non-hazardous for aquatic species, } 96 \mathrm{hr} \\
\mathrm{LC}_{50} \text { is } 460 \mathrm{mg} / \mathrm{L} \text { for Western Mosquitofish } \\
\text { (Mallinckrodt Chemicals, 2007). } \\
\text { - use of stoichiometric concentrations can } \\
\text { suppress the DO by } 0.30 \mathrm{mg} / \mathrm{L} \text { (Tikkanen } \text { et } \\
\text { al., 2001) }\end{array}$ \\
\hline $\begin{array}{l}\text { Sodium Bisulfite } \\
\text { (SBS) }\end{array}$ & $\begin{array}{l}\text { - } 48 \mathrm{hr} \mathrm{LC}_{50} \text { is } 68 \mathrm{mg} / \mathrm{L} \\
\text { - more toxic than SMBS between the } \\
\text { concentrations of } 20 \text { to } 100 \mathrm{mg} / \mathrm{L} \\
\text { - chemical inherently non-toxic } \\
\text { - cause mortality by suppressing DO } \\
\text { and/or } \mathrm{pH} \text { of solution }\end{array}$ & $\begin{array}{l}\text { - } \mathrm{LC}_{50} \text { for Ceriodaphnia Dubia is } 245 \mathrm{mg} / \mathrm{L} \\
\text { - over dosing does not have any direct } \\
\text { aquatic impacts } \\
\text { - at higher dosages can suppress the } \mathrm{DO} \text { and } \\
\text { pH level in the receiving water (EC, } 2003 \text {; } \\
\text { Ryon } \text { et al., 2002) } \\
\text { - } 39 \mathrm{mg} / \mathrm{L} \text { concentration in receiving waters } \\
\text { can cause a fish kill event and can reduce the } \\
\text { DO level in the receiving waters by } \sim 6 \mathrm{mg} / \mathrm{L} \\
\text { (Ryon } \text { et al., } 2002 \text { ) } \\
\text { - sulfite ion ( } \mathrm{SO}_{3}^{-2} \text { ) concentrations of less } \\
\text { than } 10 \mathrm{mg} / \mathrm{L} \text { have no significant effect on } \\
\text { the aquatic environment (White, } 1999 \text { ) }\end{array}$ \\
\hline
\end{tabular}




\begin{tabular}{|c|c|c|}
\hline $\begin{array}{l}\text { Sodium } \\
\text { metabisulfite } \\
\text { (SMBS) }\end{array}$ & $\begin{array}{l}-48 \mathrm{hr} \mathrm{LC} \mathrm{C}_{50} \text { is } 100 \mathrm{mg} / \mathrm{L} \\
\text { - less toxic than } \mathrm{SBS} \text { between the } \\
\text { concentrations of } 20 \text { to } 100 \mathrm{mg} / \mathrm{L} \\
\text { - larger change in the DO compared } \\
\text { to } \mathrm{SBS} \text { for the concentrations of } 50, \\
100 \text { and } 200 \mathrm{mg} / \mathrm{L} \\
\text { - chemical inherently non-toxic } \\
\text { - cause mortality by suppressing DO } \\
\text { and/or } \mathrm{pH} \text { of solution }\end{array}$ & $\begin{array}{l}-96 \mathrm{hr} \mathrm{LC} \mathrm{L}_{50} \text { is } 100 \mathrm{mg} / \mathrm{L} \text { for fish, } 72 \mathrm{hr} \mathrm{EC}_{50} \\
\text { is } 48.1 \mathrm{mg} / \mathrm{L} \text { for algae, } 48 \mathrm{hr} \mathrm{EC}_{50} \text { is } 88.76 \\
\mathrm{mg} / \mathrm{L} \text { and } \mathrm{NOEC} \text { is }>10 \mathrm{mg} / \mathrm{L} \text { for daphnids } \\
\text { (USEPA, 2007) } \\
\text { - cause } \mathrm{pH} \text { and DO suppression (Tikkanen } \text { et } \\
\text { al., 2001) } \\
\text { - use of stoichiometric concentrations can } \\
\text { suppress DO by } 1.18 \mathrm{mg} / \mathrm{L} \text { (Tikkanen } \text { et al., } \\
\text { 2001) }\end{array}$ \\
\hline $\begin{array}{l}\text { Sodium } \\
\text { Thiosulfate } \\
\text { (STS) }\end{array}$ & $\begin{array}{l}\text { - } 48 \mathrm{hr} \mathrm{LC} \mathrm{L}_{50} \text { value }>200 \mathrm{mg} / \mathrm{L} \\
\text { - did not cause any mortality at } \\
\text { concentrations as high as } 200 \mathrm{mg} / \mathrm{L} \\
\text { - did not alter the solution } \mathrm{pH} \text { or the } \\
\text { DO concentration more than } 0.3 \text { units } \\
\text { and } 2 \% \text {, respectively }\end{array}$ & $\begin{array}{l}\text { - EC } 50 \text { is } 1334 \mathrm{mg} / \mathrm{L} \text { (Oh } \text { et al., 2008) } \\
\text { - non-toxic to aquatic species even at high } \\
\text { concentrations (Ryon } \text { et al., 2002; Tikkanen } \\
\text { et al., 2001) } \\
\text { - concentration of } 34-40 \mathrm{mg} / \mathrm{L} \text { of STS was } \\
\text { able to cause a fish kill if specific set of } \\
\text { conditions (Ryon et al., 2002) } \\
\text { - form biologically unavailable forms of } \\
\text { metal complexes with several cationic metals } \\
\text { (such as copper - Cu(II), cadmium - Cd(II), } \\
\text { nickel - Ni(II)), which could lead to over or } \\
\text { underestimation of the sample toxicity (Oh et } \\
\text { al., 2008) } \\
\text { - use of stoichiometric concentrations of STS } \\
\text { can suppress the DO in the water stream by } \\
0.55 \mathrm{mg} / \mathrm{L} \text { (Tikkanen } \text { et al., 2001) }\end{array}$ \\
\hline $\begin{array}{l}\text { Calcium } \\
\text { Thiosulfate } \\
\text { (CTS) }\end{array}$ & $\begin{array}{l}-48 \mathrm{hr} \mathrm{LC}_{50} \text { is } 22 \mathrm{mg} / \mathrm{L} \\
\text { - mortality was observed beginning at } \\
\text { concentrations as low as } 20 \mathrm{mg} / \mathrm{L} \text { and } \\
\text { at } 100 \text { and } 200 \mathrm{mg} / \mathrm{L}, 100 \% \text { mortality } \\
\text { rates were observed } \\
\text { - chemical is inherently toxic } \\
\text { - observed DO suppression } \leq 10 \% \\
\text { - observed pH suppression } \leq 0.3 \mathrm{pH} \\
\text { units }\end{array}$ & $\begin{array}{l}\text { - use of stoichiometric concentrations can } \\
\text { suppress DO in the stream by } 0.50 \mathrm{mg} / \mathrm{L} \\
\text { (Tikkanen } \text { et al., 2001) }\end{array}$ \\
\hline $\begin{array}{l}\text { Ascorbic acid } \\
\text { (AA) }\end{array}$ & $\begin{array}{l}-48 \mathrm{hr} \mathrm{LC} \mathrm{L}_{50} \text { is } 55 \mathrm{mg} / \mathrm{L} \\
\text { - AA also caused a considerable } \\
\text { percentage of mortality starting at } \\
\text { concentrations as low as } 20 \mathrm{mg} / \mathrm{L} \\
\text { - actual concentration that caused } \\
50 \% \text { mortality in this study was } \\
\text { approximately } 70 \mathrm{mg} / \mathrm{L} \\
-100 \text { and } 200 \mathrm{mg} / \mathrm{L} \text { concentrations of } \\
\text { AA, the } \mathrm{pH} \text { of the solution decreased } \\
\text { by } 0.5 \text { and } 1.2 \mathrm{pH} \text { units, respectively } \\
\text { - not a DO scavenger }\end{array}$ & $\begin{array}{l}\text { - AA is non-toxic at high concentrations ( } 200 \\
\text { mg/L) (NICNAS, 2003) } \\
-48 \text { hr EC50 value for D. Magna based on } \\
\text { measured concentrations is }>190 \mathrm{mg} / \mathrm{L} \\
\text { - } 96 \mathrm{hr} \text { LC50 value for fish is }>80 \mathrm{mg} / \mathrm{L} \\
\text { (NICNAS, 2003) } \\
\text { can deplete water pH (EC, 2003; Tikkanen } \\
\text { et al., 2001). }\end{array}$ \\
\hline
\end{tabular}




\begin{tabular}{|c|c|c|}
\hline $\begin{array}{l}\text { Hydrogen } \\
\text { peroxide (HP) }\end{array}$ & $\begin{array}{l}\text { - } 48 \mathrm{hr} \mathrm{LC} 50 \text { is } 4.7 \mathrm{mg} / \mathrm{L} \\
\text { - Lethality effects of } \mathrm{HP} \text { was } \\
\text { observed beginning at concentrations } \\
\text { as low as } 2 \mathrm{mg} / \mathrm{L} \text {, and } 20 \mathrm{mg} / \mathrm{L} \text { of } \mathrm{HP} \\
\text { resulted in } 100 \% \text { mortality of the test } \\
\text { organisms } \\
\text { - chemical is inherently toxic } \\
\text { - observed DO suppression } \leq 10 \% \\
\text { - observed pH suppression } \leq 0.3 \mathrm{pH} \\
\text { units } \\
\text { - the actual concentration of } \mathrm{HP} \text { that } \\
\text { caused } 50 \% \text { mortality was } \\
\text { approximately } 10 \mathrm{mg} / \mathrm{L}\end{array}$ & $\begin{array}{l}\text { - increase the DO in water (Tikkanen } \text { et al, } \\
2001 \text { ) } \\
\text { - highly reactive and corrosive nature can } \\
\text { cause adverse effects in the aquatic } \\
\text { environment } \\
\text { - } \mathrm{EC}_{50} \text { for Daphnia magna is } 7.7 \mathrm{mg} / \mathrm{L}, 48 \mathrm{hr} \\
\mathrm{LC}_{50} \text { for Daphnia pulex is } 2.4 \mathrm{mg} / \mathrm{L} \text {, fathead } \\
\text { minnow and catfish have } 96 \mathrm{hr} \mathrm{LC} 50 \text { values } \\
\text { of } 16.4 \text { and } 37.4 \mathrm{mg} / \mathrm{L} \text {, respectively } \\
\text { - pose a threat to the aquatic species at much } \\
\text { smaller concentrations (Advanced } \\
\text { Sterilization Products, 2005) }\end{array}$ \\
\hline
\end{tabular}

\subsection{Applications in Wastewater Treatment Plant Design}

Dechlorination of the disinfected wastewater effluent is an essential step prior to discharging it into natural lakes and rivers to avoid the toxic effects of residual chlorine. Findings of this experimental study can be applied to full-scale wastewater treatment plant design to determine the required dosage of the DA based on the required contact time and the aquatic health impacts. Also, the kinetic data and the required reaction time information can be used in practice to identify the dechlorination chemical application point. Experimental results obtained under variable mixing and $\mathrm{pH}$ conditions will assist the WWTP designers to determine the necessary $\mathrm{pH}$ and mixing conditions to achieve complete dechlorination within a desirable amount of time and with a minimum possible dechlorination agent dosage.

Kinetic analysis of the dechlorination reactions revealed that most reactions were pseudofirst order with respect to the total chlorine concentration in solution at $10 x$ stoichiometric. First order rate equations were deduced from the reaction rate constants (k) obtained from the experimental studies. The reaction rate equation is in the form of 


$$
[C]=[C]_{0} e^{k t}
$$

where $\mathrm{k}$ is the reaction rate constant. For example, for sodium sulfite, the pseudo-first order rate equation is $[C]=[C]_{0} e^{-0.142 t}$. The first order rate equations for each of the dechlorination chemicals could in turn be used to calculate the required contact time to achieve complete neutralization of a given residual concentration of chlorine in the effluent as follows.

$$
\begin{aligned}
& {[C]=[C]_{0} e^{k t}} \\
& \ln (C / C o)=e^{k t} \\
& t=\frac{1}{k} \ln \frac{C}{C o}
\end{aligned}
$$

For the chemicals with zero order reaction kinetics, the reaction rate is in the form of

$$
C_{A}-C_{A 0}=-k t
$$

and the required reaction time to achieve the neutralization of a given residual chlorine level is calculated using the following formula:

$$
\frac{1}{k}\left(C_{A 0}-C_{A}\right)=t
$$

Kinetic analysis of the dechlorination reactions at $2-4 \mathrm{x}$ stoichiometric dosage revealed that most reactions were second order overall and first order with respect to each of the reactants. Second order rate equations were deduced from the reaction rate constants $(\mathrm{k})$ obtained from the experimental studies. The reaction rate equation is in the form of

$$
r=k C_{A} C_{B}
$$

and the required reaction time to achieve the neutralization of a given residual chlorine level is calculated using the following formula:

$$
t=\frac{\ln \frac{M-X_{A}}{M\left(1-X_{A}\right)}}{C_{A 0}(M-1) k}
$$


In this case the plot of $\ln \frac{M-X_{A}}{M\left(1-X_{A}\right)}$ versus time gives a straight line and the slope of the trendline is divided $b \mathrm{C}_{\mathrm{A} 0}(\mathrm{M}-1) \mathrm{k}$ to obtain the $\mathrm{k}$ value, which represents the rate constant. Equation 13 was used to calculate the time required to neutralize a given chlorine residual in the effluent at $3 \mathrm{x}$ stoichiometric dosage of each of the dechlorination agent by substituting $C_{\mathrm{A} 0}=1,2$, or $3 \mathrm{mg} / \mathrm{L}$ and the obtained $\mathrm{k}$ values. For example, in the case of the $3 \mathrm{x}$ stoichiometric dosage of SMBS, the required reaction time for the neutralization of $1 \mathrm{mg} / \mathrm{L}$ of residual chlorine was calculated as follows:

$$
\begin{aligned}
& C_{A 0}=1 \mathrm{mg} / \mathrm{L}=0.014 \mathrm{~mol} / \mathrm{L} \\
& C_{A}=0.02 \mathrm{mg} / \mathrm{L}=0.000282 \mathrm{~mol} / \mathrm{L} \\
& X_{A}=1-\frac{0.000282}{0.014}=0.9798 \\
& M=3 \quad k=0.737 \mathrm{~L} / \mathrm{mol} . \mathrm{s} \\
& t=\frac{\ln \frac{M-X_{A}}{M\left(1-X_{A}\right)}}{C_{A 0}(M-1) k}=\frac{\ln \frac{3-0.9798}{3(1-0.9798)}}{0.014 x(3-1) \times 0.737 \mathrm{~L} / \mathrm{mol} . \mathrm{s}}=170 \mathrm{sec} \text { ond } \mathrm{s}
\end{aligned}
$$

This calculated 170 second reaction time does not agree with what was observed through the experimental studies. For example, during the experiments, with the $3 \mathrm{x}$ stoichiometric dosage of SMBS, $3.56 \mathrm{mg} / \mathrm{L}$ of chlorine was neutralized to $0.03 \mathrm{mg} / \mathrm{L}$ within 59 seconds. Therefore, $1 \mathrm{mg} / \mathrm{L}$ of chlorine in the effluent is expected to be completely neutralized within nearly 20 seconds. However, this is not what the above calculations reveal, suggesting that there might be some deficiencies in the data analysis. One possible reason for the discrepancy between the observed and the calculated reaction times is that there might have been significant reduction in the reactant concentrations during the first 20 seconds following the DA addition, which was unable to be measured due to the lag time in the analytical equipment. Further studies should be conducted with equipment which could detect chlorine levels in the solution instantaneously, thus eliminating the 
lag time. It is also possible to modify the data analysis, by assigning the $\mathrm{C}_{\mathrm{A} 0}$ value as the chlorine concentration at $\mathrm{t}=20$ seconds instead of $\mathrm{t}=0$ seconds, eliminate possible errors that might have arisen by ignoring the obtained data between $0-20$ seconds due to the lag time.

The calculated reaction times for the $10 \mathrm{x}$ stoichiometric dosage of the seven dechlorination chemicals are tabulated in Table 25 below.

Table 25: Calculated required reaction times for $10 \mathrm{x}$ stoichiometric dosages of DAs to achieve $0.02 \mathrm{mg} / \mathrm{L}$ residual with a 1,2 and $3 \mathrm{mg} / \mathrm{L}$ initial concentration of chlorine.

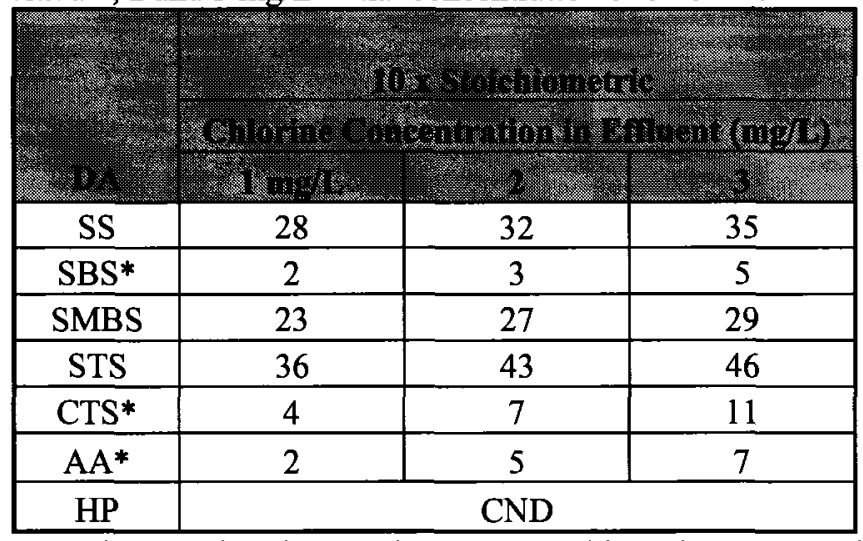

CND denotes that the reaction times could not be calculated since the reaction rate could not be determined from the obtained kinetic data

* at $10 \mathrm{x}$ stoichiometric dosage the reaction is zero order

Table 25 shows that in the case of the $10 \mathrm{x}$ stoichiometric dosage, all the chemicals, except HP, achieved desired residual levels in less than 60 seconds, with SBS, CTS and AA reactions going to completion in less than 11 seconds, probably because the reactions were zero order and thus the reaction rate was independent of the reactant concentrations. Further investigation is needed to determine which other factors effect the dechlorination rate of these reactions. In addition, at the $10 \mathrm{x}$ stoichiometric, SS, SMBS and STS required between $23-46$ seconds to achieve complete neutralization. 
The experimental data show that a $1 \mathrm{x}$ stoichiometric dosage of SS, STS and AA is insufficient to achieve complete dechlorination within a reasonable amount of time. The dosage required to achieve complete dechlorination within 60 seconds is approximately $3 \mathrm{x}$ in excess of the stoichiometric requirement. Dechlorination chemical dosages of $10 \mathrm{x}$ in excess of the stoichiometric requirement are not needed because ultimately the goal of dechlorination is to achieve neutralization of residual chlorine within a reasonable amount of time using the least amount of chemicals possible.

If the reaction times were able to be calculated for the $1 \mathrm{x}$ and the $3 \mathrm{x}$ dosage, those reaction times are not only useful in determining the necessary DA dosage, they could also assist the treatment plant operators in deducing the dechlorination application point to allow for the necessary contact time between the DA and the effluent prior to discharge. Based on the flow of the wastewater stream, the operators can determine the distance that is needed to allow for a given reaction time. Being able to address higher residual chlorine effluent levels by simply altering the DA application point could be a very economical choice for existing plants that are having difficulties achieving the desired residual chlorine levels.

Another important finding of this study is that the measuring probes used in detecting chlorine in the wastewater stream must be carefully chosen because some constituents of the wastewater can interfere with the functionality of these probes and produce erroneous results. The Dulcometer ${ }^{\circledR} 1 \mathrm{C}$ continuous residual chlorine and $\mathrm{pH}$ analyzer used in this study was determined to be unsuitable for real life treatment plant applications because 
the analyzer readings were effected by wastewater constituents such as amines. The Hach spectrophotometer was found to be more useful in determining the residual chlorine levels of the effluent for all the chemicals except in the case of HP. Even though it is easy to use, it has been reported that Hach measurements are not accurate for measuring chlorine residual below $0.10 \mathrm{mg} / \mathrm{L}(\mathrm{EC}, 2003)$.

In combination with the above finding that the dechlorination agents should be used in excess of the stoichiometric requirement, acute aquatic toxicity tests can be utilized to determine the aquatic health impacts of varying concentrations of the various dechlorination chemicals in the water. The 48-hour acute toxicity test data showed that all the dechlorination agents have no lethality effects at concentrations of $2 \mathrm{mg} / \mathrm{L}$ except for hydrogen peroxide as shown in Figure 32.

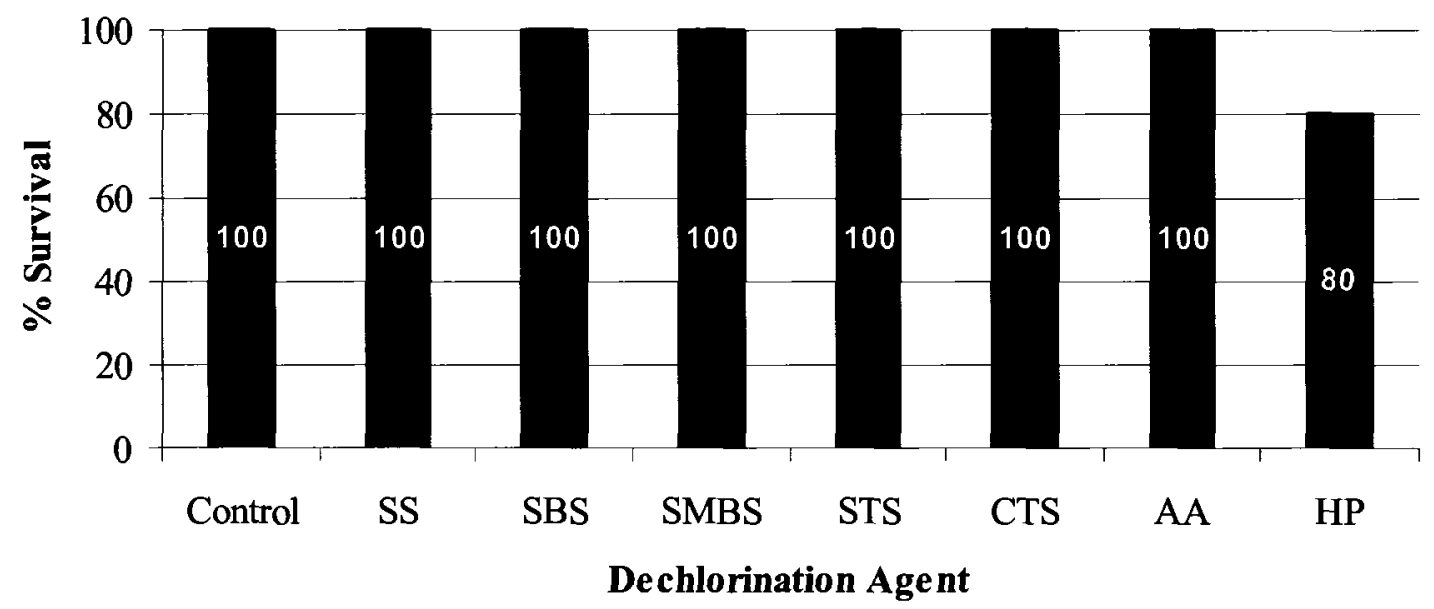

Figure 32: Percentage survival data for Daphnia magna for the $2 \mathrm{mg} / \mathrm{L}$ concentration of the seven dechlorination agents.

It is likely to find $2 \mathrm{mg} / \mathrm{L}$ of DA in the effluent if the dechlorination agent is used in approximately $2 \mathrm{x}$ in excess of the stoichiometric requirement, and it is encouraging to 
know that these doses do not have deleterious effects on Daphnia magna. On the other hand, if the dechlorination agents are used $10 \mathrm{x}$ in excess, the effluent DA concentrations could rise up to approximately $10-20 \mathrm{mg} / \mathrm{L}$. In this case, Daphnia magna start to die for SS, CTS, AA and HP as shown in Figure 33 . The $20 \%$ mortality observed for SS might be an experimental error or due to the drop in $\mathrm{pH}$ that was observed, as discussed in section 4.2.1.

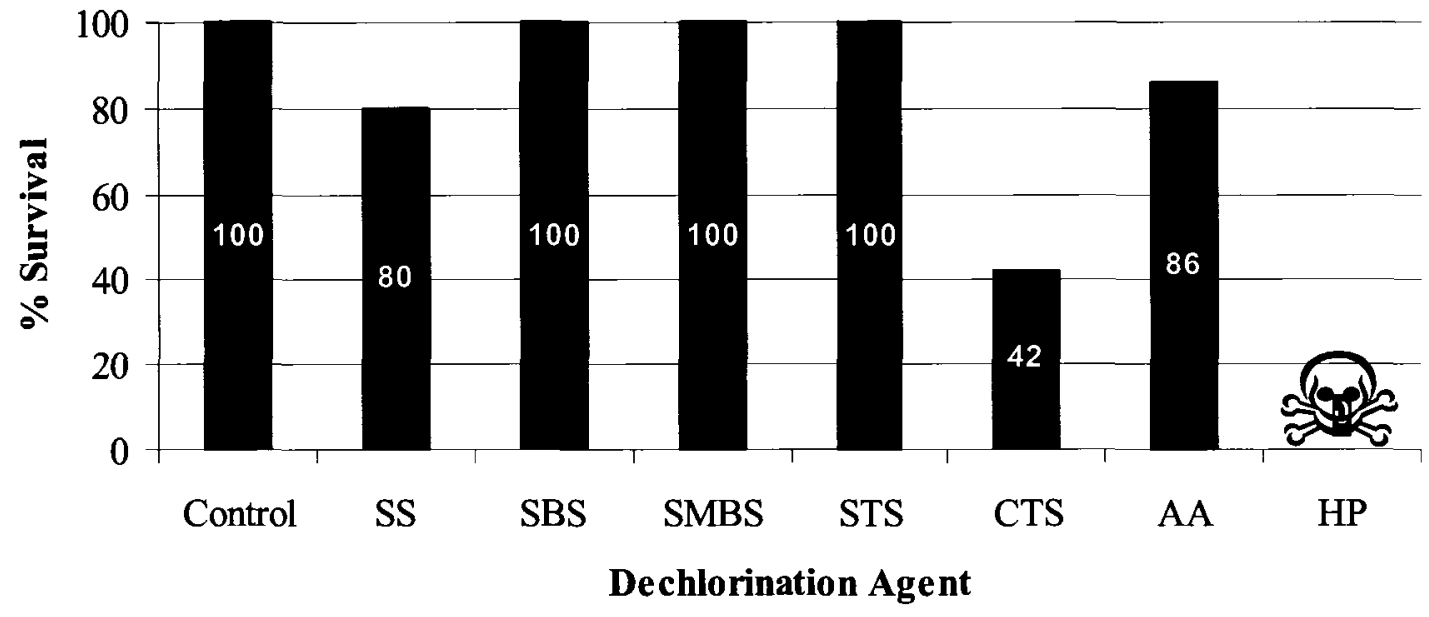

Figure 33: Percentage survival data for Daphnia magna for the $20 \mathrm{mg} / \mathrm{L}$ concentration of the seven dechlorination agents.

The

From Figure 33 it is apparent that SBS and SMBS, which are the commonly used dechlorination agents in North America, did not cause lethality. STS is also shown to be safe at concentrations as high as $20 \mathrm{mg} / \mathrm{L}$, where as the same concentration of CTS resulted in only $42 \%$ survival. HP, on the other hand, was the most lethal; it killed $100 \%$ of the Daphnia magna. These results indicate that it is advisable to avoid using DA concentrations slightly in excess of the stoichiometric requirement if it gives rise to concentrations of $20 \mathrm{mg} / \mathrm{L}$ or less in the effluent. 
Furthermore, 48-hour acute lethality tests were conducted using $200 \mathrm{mg} / \mathrm{L}$ of the dechlorination agents to simulate a scenario of a large discharge, which is likely to happen only in the case of an accidental spill or equipment malfunction. The obtained $\%$ survival data for Daphnia magna is plotted in Figure 34.

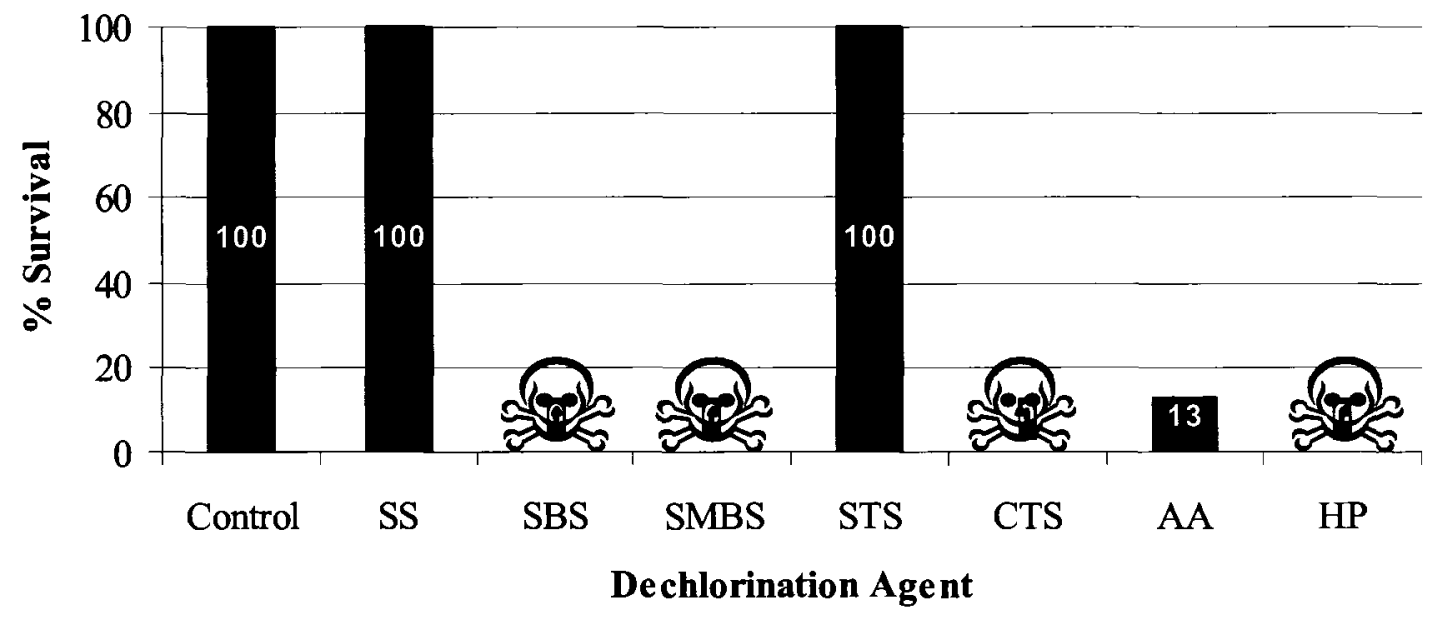

Figure 34 : Percentage survival data for Daphnia magna for the $200 \mathrm{mg} / \mathrm{L}$ concentration of the seven dechlorination agents.

The indicate $100 \%$ mortality.

From Figure 34 it can be seen that all the dechlorination agents appear to be toxic to Daphnia magna except for SS and STS. Thus it is important to realize that even dechlorination agents that are used to reduce the toxicity of chlorine to aquatic species can have deleterious effects at very high concentrations. As such, care should be taken to ensure that the minimum possible dosage is used to achieve a balance between the reasonable reaction time and the resulting residual DA concentration in the effluent. This result further substantiates that the use of dechlorination agents at 2-3x in excess of the stoichiometric dosage does not have appreciable mortality effects to daphnia magna, and will allow the effluent residual chlorine to be neutralized within 60 seconds. 


\section{Chapter 5}

\section{Conclusions and Future Work}

This chapter presents the overall conclusions for the dechlorination kinetic study and the acute toxicity testing conducted as a part of this research project. Section 5.1 includes the overall conclusions that emerged from this two phase study, and section 5.2 presents a list of recommendations for future work in the area of dechlorination.

\subsection{Conclusions}

As a part of this thesis project the dechlorination reaction kinetics of seven dechlorination chemicals were studied under varying dosages, mixing regimes and $\mathrm{pH}$ conditions. Dechlorination agent dosages ranging from $1 \mathrm{x}-10 \mathrm{x}$ stoichiometric were tested to identify the minimum dosage required to achieve near zero chlorine residual levels $(0.02$ $\mathrm{mg} / \mathrm{L}$ ) in the effluent. In order to assess the affects of mixing frequency and intensity on the dechlorination rate of these chemicals, samples were periodically and continuously mixed at two different intensities - 130 and 275 RPM. Lastly, two different pH ranges 
were tested $(6.5-8.5$ and $\mathrm{pH}>9)$ to assess the effects of variable $\mathrm{pH}$ on the dechlorination rate of these chemicals. Acute toxicity tests were also undertaken using a common aquatic indicator species - Daphnia magna - to identify the least harmful dechlorination chemical in terms of the percentage mortality. The following is a list of conclusions that emerged from this experimental study.

1. Dechlorination reactions at $1 \times$ stoichiometric dosage $\left(\mathrm{mg} \mathrm{DA} / \mathrm{mg} \mathrm{Cl}_{2}\right.$ ) of the DAs were rapid in most cases but not instantaneous. Dechlorination using a $1 \mathrm{x}$ stoichiometric dosage of sodium bisulfite, metabisulfite, calcium thiosulfate and hydrogen peroxide was rapid but not instantaneous, the fastest reaction occurred with hydrogen peroxide. Sodium sulfite, thiosulfate and ascorbic acid were not able to achieve near-zero residual levels with $1 \mathrm{x}$ stoichiometric dosage. In these cases, dechlorination agents were need more than the stoichiometric dosage to ensure a near zero residual $(0.02 \mathrm{mg} / \mathrm{L}$ total residual chlorine, as required by CEPA (1999)).

2. Dechlorination reactions were either zero order or pseudo-first order with respect to the total chlorine concentration in solution when the dechlorination agent was present well in excess of the stoichiometric dosage (i.e. 10x stoichiometric). Dechlorination reactions of sodium bisulfite, calcium thiosulfate and ascorbic acid were zero order and for sodium sulfite, sodium metabisulfite, sodium thiosulfate and hydrogen peroxide were pseudo-first order with respect to the total chlorine concentration in solution. The obtained rate constants can be used to calculate the 
required reaction time to achieve complete neutralization of a given residual chlorine concentration in the effluent.

3. Dechlorination reactions were second order overall when the dechlorination agent was present $2-4 \mathrm{x}$ in excess of the stoichiometric dosage (i.e. 10x stoichiometric). Dechlorination reactions of sodium bisulfite, calcium thiosulfate and ascorbic acid were second order overall. But for sodium sulfite, sodium metabisulfite and sodium thiosulfate the reactions were first order with respect to the total chlorine and the DA concentration in solution. The obtained rate constants can be used to calculate the required reaction time to achieve complete neutralization of a given residual chlorine concentration in the effluent.

4. Except in the case of ascorbic acid and calcium thiosulfate, using the dechlorination agents in excess of the stoichiometric requirement was found to pose no significant threat to Daphnia magna. Mortality levels at dosages of 2 $\mathrm{mg} / \mathrm{L}, 20 \mathrm{mg} / \mathrm{L}$ and $200 \mathrm{mg} / \mathrm{L}$ were analyzed to get an idea of aquatic toxicity of low, medium and high effluent concentrations of DAs, respectively. The 48-hour acute (short-term) toxicity tests conducted with varying concentrations of the dechlorination agents revealed that sodium sulfite and sodium thiosulfate had the least aquatic impacts while hydrogen peroxide and calcium thiosulfate had the most deleterious effects on Daphnia magna. 
5. Dechlorination agents were either directly toxic or indirectly toxic to Daphnia magna. Hydrogen peroxide and calcium thiosulfate were identified as directly toxic to Daphnia magna because those chemicals showed inherent toxicity without suppressing the DO or reducing the $\mathrm{pH}$ of the solution. Ascorbic acid, sodium metabisulfite and sodium bisulfite on the other hand caused mortality indirectly by suppressing the $\mathrm{DO}$ and the $\mathrm{pH}$ of the solution.

6. The mixing intensity and the frequency had no or minimal impact on the dechlorination reaction rate of sodium bisulfite, sodium thiosulfate, and sodium metabisulfite. For sodium sulfite and ascorbic acid, only the intensity of mixing had an impact on the dechlorination rate but the frequency had no impact. The reaction rate of calcium thiosulfate reaction on the other hand was increased by both the mixing intensity and the frequency.

7. Increasing the $\mathrm{pH}$ of the reaction solution from $6.5-8.5$ to $>9$ had minimal or no impact on the dechlorination reaction rate of SS, SBS, SMBS, STS, and CTS. The effect of $\mathrm{pH}$ on the reaction rate of SBS was inconclusive from the experimental evidence. For $\mathrm{AA}$ on the other hand, increase in $\mathrm{pH}$ of the experimental solution caused a decrease in the reaction rate.

The conclusions from this dechlorination kinetic and aquatic toxicity study was then used to formulate a set of recommendations for the wastewater facility managers, designers and policy makers to assist with making accurate decisions regarding the most suitable dechlorination chemical. 


\section{List of Recommendations}

The following list is a set of recommendations formulated for wastewater facility operators, managers, and designers in complying with the regulated effluent total residual chlorine levels. Some recommendations stemming from the acute toxicity studies can also assist policy makers with making accurate decisions regarding the most suitable dechlorination chemical.

- If $1 \mathrm{x}$ stoichiometric dosages of the dechlorination agents are used for economical or other reasons, calcium thiosulfate or hydrogen peroxide should be the dechlorination agent of choice.

- Using this required contact time data in combination with the flow rate of the wastewater stream at a treatment plant, the dechlorination agent application point could be determined to ensure effluent residual chlorine levels are in compliance.

- If SMBS and STS are the dechlorination agent of choice, then the $1 \mathrm{x}$ stoichiometric dosage on a weight basis ( $\mathrm{mg} \mathrm{Cl}_{2} / \mathrm{mg} \mathrm{DA}$ ) is insufficient to achieve near zero residual levels, thus SMBS and STS should be used in excess of the stoichiometric requirement to achieve complete neutralization within a reasonable time.

- From an aquatic toxicity perspective, SS and STS should be the dechlorination agent of choice, while HP and CTS should be avoided. It is safe to use the dechlorination agents $2-3 \mathrm{x}$ in excess of the stoichiometric requirement, except 
for HP and AA. CTS, HP and AA should be avoided as dechlorination agents if possible.

- If CTS or AA is the dechlorination agent of choice, the reaction mixture should be continuously mixed at high intensity (G-value $\left.=349 \mathrm{~s}^{-1}\right)$ to maximize the reaction rate. For SMBS, mixing the reaction continuously at low intensity (G-value $=$ $507 \mathrm{~s}^{-1}$ ) is sufficient to achieve complete neutralization within a reasonable amount of time. If SS, SBS, or STS is used, periodic mixing is adequate to achieve a homogenous reactant mixture.

- If AA is the dechlorination agent of choice, care should be taken to ensure that the solution $\mathrm{pH}$ does not exceed $\mathrm{pH}$ 9. At $\mathrm{pH}>9$, the rate of the reaction between AA and chlorine is reduced, which would lead to higher than expected residual chlorine levels. 


\subsection{Future Work}

In order to further expand the knowledge of dechlorination kinetics and aquatic toxicity of the dechlorination chemicals and build on the findings of this research study, the following focus areas are suggested for future work:

- Further dechlorination kinetic analysis could be conducted using chlorinated wastewater to better understand the dechlorination kinetics of these dechlorination chemicals in full-scale when both organic and inorganic forms of chlorinated species are present.

- Since the concentration/composition dependent term of the rate equation was derived from this experimental study by holding the temperature constant, a set of experiments could be undertaken to investigate the temperature dependent term of the rate equation.

$$
-r_{A}=f[\underbrace{\text { concentration dependent term }}_{\text {Found in this study }}, \underbrace{\text { temperature dependent term }}_{\text {Need Investigation }}]
$$

- Hydrogen peroxide should be further studied to investigate the possible reasons for the reaction to reach completion with less than stoichiometric dosages.

- Further studies could be conducted at higher mixing intensities (e.g. G-values between $1000-1500 \mathrm{~s}^{-1}$ ) to understand the effects of very high intensity mixing on the dechlorination rate. 
- Lower $\mathrm{pH}$ ranges $(<6.5)$ could also be tested to investigate the effects of lower $\mathrm{pH}$ levels on the dechlorination rate of these chemicals.

- Aquatic toxicity tests could be conducted using dechlorinated wastewater to assess the completeness of dechlorination by these dechlorination chemicals.

- Further aquatic tests could be conducted at higher dosages of SS and STS to determine the $\mathrm{LC}_{50}$ values of these chemicals.

- In order to investigate the inherent toxicity of the dechlorination chemicals, aquatic toxicity tests should be conducted under constant dissolved oxygen (DO) and $\mathrm{pH}$ conditions. 


\section{References}

Advanced Sterilization Products. 2005. Hydrogen Peroxide Material Safety Data Sheet (MSDS). MSDS NUMBER: 09461-0-001. Irvine, CA. URL: http://www.sterrad.com/customer_support/user_resources/msds/h2o2_msds.pdf. Accessed on April 23, 2008.

Alberta Environment. 1996. Northern River Basins Study Final Report. URL: http://www3.gov.ab.ca/env/water/nrbs/index.html Accessed on February 21st, 2008.

Bedner, M., MacCrehan, W.A., \& Helz, G. R. 2004. Making chlorine greener: investigation of alternatives to sulfite for dechlorination. Water Research, 38, 2505-2514.

Canada Colors Limited. 2008. Email Communication on May $20^{\text {th }} 2008$.

CSTEE (Scientific Committee on Toxicity, Ecotoxicity and the Environment). 2001. Opinion on the results of the Risk Assessment of: Hydrogen Peroxide Human Health Effects. CAS No.: 7722-84-1, EINECS No.: 231-765-0.

Department of Environmental Protection (DEP). Bureau of Land \& Water Quality. 2005. Dechlorination Design Standards for Maine Wastewater Facilities. URL: http://www.state.me.us/dep/blwg/ddds.htm Accessed on June 29, 2008.

Ekkad, N. V., \& Huber, C. O. 1996. Residual sulfite after dechlorination of water. Water, Air, \& Soil Pollution, 90(1-2): 195-300.

Environment Canada. 2003. Review of Municipal Effluent Chlorination/Dechlorination Principles, Technologies and Practices. Prepared by Associated Engineering (B.C.)

Ltd.

URL:http://www.pyr.ec.gc.ca/GeorgiaBasin/resources/publications/SciTechRepor ts/SciTech06 e.htm Accessed on January 23, 2008. Report Number: C2003980317-1

Environment Canada. 2001a. The State of Municipal Wastewater Effluents in Canada. Municipal wastewater effluents: What they are and what they contain. URL: http://www.ec.gc.ca/soer-ree/English/soer/MWWE1.cfm. Accessed on October 29, 2007. Report Number: C2001-980074-6.

Environment Canada. 2001b. Threats to Sources of Drinking Water and Aquatic Ecosystem Health in Canada, Chapter 9 - Municipal Wastewater Effluents. URL : http://www.nwri.ca/threats/chapter09-e.html. Accessed on January 10, 2008. Report Number: C2001-980362-1 
Environment Canada (EC), 1990 (with 1996 amendments). Biological Test Method: Acute Lethality Test Using Daphnia spp. Ottawa, Ontario. Report Number: C90098684-0.

EPA Victoria. 2002. Disinfection of Treated Wastewater. Guidelines for Environmental Management. Publication \# 730. Victoria, Australia.

ESSECO USA. 2007. Catalyzed sodium sulfite with sodium metabisulfite Material Safety Data Sheet (MSDS). MSDS Number: EUSA-165. New Jersey.

Francy, D.S., Hart, T.L., Virosteck, C.M. 1996. Effects of Receiving-Water Quality and Wastewater Treatment on Injury, Survival, and Regrowth of Fecal-Indicator Bacteria and Implications for Assessment of Recreational Water Quality. U.S. Geological Survey Water-Resources Investigations Report, 96-4199. Columbus, Ohio.

GE Infrastructure Water \& Process Technologies (GE). 2004. ProMinent Dulcometer ${ }^{\mathrm{TM}}$ D1C / DMTa Chlorine Analyzer and Controller Total and Free Chlorine Control. Fact Sheet. Trevose, PA.

Greater Vancouver Regional District (GVRD). 1997. Chlorine Monitoring and Dechlorination Techniques Handbook prepared by ENKON Environmental Limited and Norecol, Dames \& Moore, Inc. URL: http://www.gvrd.bc.ca/water/chlorin/handbk2.pdf Access on January 26th, 2008.

Helz, G.R., \& Nweke, A.C. 1995. Incompleteness of Wastewater Dechlorination. Environmental Science and Toxicology, 29, 1018-1022.

IUPAC. 1997. IUPAC Compendium of Chemical Terminology, $2^{\text {nd }}$ Edition compiled by Alan D. McNaught and Andrew Wilkinson (Royal Society of Chemistry, Cambridge, UK).

Jameel, R.H. \& Helz, G.R. 1999. Organic Chloramines in Disinfected Wastewaters: Rates of

Reduction by Sulfite and Toxicity. Environmental Toxicology and Chemistry, 18(9): 1899-1904.

Jensen, J. S., Helz, G. R. 1998. Rates of reduction of n-chlorinated peptides by sulfite: Relevance to incomplete dechlorination of wastewaters. Environmental Science \& Technology, 32, 516-522.

Levenspiel, O. 1999. Chemical Reaction Engineering $3^{\text {rd }}$ Edition. John Wiley \& Sons, New Jersey, USA.

Liu, W., Andrews, S. A., Stefan, M.I., Bolton, J.R. 2003. Optimal methods for quenching $\mathrm{H}_{2} \mathrm{O}_{2}$ residuals prior to UFC testing. Water Research, 37(15): 36973703. 
Loge, F.J., Emerick, R.W., Thompson, D.E., Nelson, D.C., Darby, J.L. 1999. Factors Influencing Ultraviolet Disinfection Performance Part I: Light Penetration to Wastewater Particles. Water Environment Research, 71(3): 377-381.

Macauley, J.J., Qiang, Z., Adams, C.D., Surampalli, R., \& Mormile, M.R. 2006. Disinfection of swine wastewater using chlorine, ultraviolet light and ozone. Water Research, 40(10): 2017-2026.

MacCrehan, W.A. Jensen, J.S., \& Helz, G.R. 1998. Detection of sewage organic chlorination products that are resistant to dechlorination with sulfite. Environmental Science and Technology, 32, 3640-3645.

Mitchell, S.E., Read, A.F., \& Little, T.J. 2004. The effect of a pathogen epidemic on the genetic structure and reproductive strategy of the crustacean Daphnia magna. Ecological Letters. 7:848-858.

Mallinckrodt Chemicals. 2005. Sodium Sulfite MSDS, Phillisburn, New Jersey. URL: http://www.jtbaker.com/msds/englishhtml/s5066.htm Accessed on March 20, 2008.

MDL Information Systems, Inc. 2002. Sodium Thiosulfate Material Safety Data Sheet. http://www.deq.state.mi.us/documents/deq-ess-lab-SodiumThiosulfate.pdf Accessed on

New Mexico Environment Department (NMED). 2003. Recommended Standards for Wastewater Facilities; Policies for the design, review, and approval of plans and specifications for wastewater collection and treatment facilities. Santa Fe, NM.

National Industrial Chemicals Notification and Assessment Scheme (NICNAS). 2003.

Public Report, 2-O--D-glucopyranosyl-L-ascorbic acid, File Number STD/1056. Australia.

Oh, S.R., Kim, J.K., Lee, M.J., and Choi, K. 2008. Dechlorination with Sodium Thiosulfate Affects the Toxicity of Wastewater Contaminated with Copper, Cadmium, Nickel, or Zinc. Environmental Toxicology. 9999(9999), NA.

Oxford University. 2005. The Physical and Theoretical Chemistry Laboratory. Safety data for hydrogen peroxide, $30 \%$ solution. URL: http://ptcl.chem.ox.ac.uk/MSDS/HY/hydrogen_peroxide 30pc.html Accessed on February, 15th 2007.

Parker, J.A., and Darby, J.L. 1995. Particle-Associated Coliform in Secondary Effluents: Shielding from Ultraviolet Light Disinfection. Water Environment Research, 67:1065-1075. 
Peterka, G.A. 1998. Solution That's Easy to Swallow: Vitamin C - A Promising Dechlorination Reagent. Opflow, 24:12(1), 4-5.

Ryon, M.G., Stewart, A.J., Kszos, L.A., \& Phipps, T.L. 2002. Impacts on Streams from the use of sulfur-based compounds for dechlorinating industrial effluents. Water, Air, and Soil Pollution, 136, 255-268.

Sciencelab.com, Inc. 2005a. Ascorbic Acid MSDS. Houston, Texas. URL: http://www.sciencelab.com/xMSDS-Ascorbic_acid-9922972. Accessed on June 29, Accessed April 27, 2008.

Sciencelab.com, Inc. 2005b. Sodium metabisulfite MSDS. Houston, Texas. URL: http:/www.sciencelab.com/xMSDS-Sodium_metabisulfite-9927597, Accessed April 28, 2008.

Shams El Din, A.M., Mohammed, R.A.1998. Kinetics of the reaction between hydrogen peroxide and hypochlorite. Desalination, 115, 145-153.

Society of Environmental Toxicology and Chemistry (SETAC). 2004. Whole Effluent Toxicity Testing, SETACTIP, technical issue paper. Pensacola, Florida.

Satterfield, Z. 2004. What does ppm or ppb mean? On Top. National Environmental Services Center, West Virginia University, Morgantown, WV.

Tchobanoglous, G., Burton, F. L., \& Stensel, H. D. 2003. Wastewater engineering treatment and reuse. McGraw-Hill series in civil and environmental engineering. Boston: McGraw-Hill. pp1261 - 1263.

Tikkanen, M.W., Schroeter, J.H., Lawrence, P.E., Leong,Y.C., Ganesh, R. 2001. Guidance Manual for the Disposal of Chlorinated Water. AWWARF, Denver, CO.

Tramfloc Inc. 2002. Calcium Thiosulfate MSDS. Tempe, AZ.

United States Department of Army (US Army). 1988. Domestic Wastewater Treatment. Publication Number: TM 5-814-3. URL: http://www.usace.army.mil/publications/ armytm/tm5-814-3/ Accessed on January $26^{\text {th }}, 2008$.

United States Environmental Protection Agency (USEPA), 2007a. Reregistration Eligibility Decision - Inorganic Sulfites. Arlington, VA. URL: http://www.epa.gov/pesticides/reregistration/REDs/inorganicsulfites.pdf Accessed on February, 3rd 
USEPA, 2007b. TRI Forms \& Instructions Document: Appendix B. Section 7A. On-site Waste Treatment Methods and Efficiency. Water treatment. URL: http://www.epa.gov/tri/TWebHelp/WebHelp/trilib.htm\#4 2 21 water treatment.ht m Accessed on April 2, 2008

USEPA. 2003. Sodium thiosulfate; Notice of Filing a Pesticide Petition to Amend a Tolerance for a Certain Pesticide Chemical in or on Food. Federal Register, 68(228): 66416-66421. URL: http://www.epa.gov/EPAPEST/2003/November/Day-26/p29320.htm Accessed on February 17th, 2008.

USEPA. 2002. Short-term Methods for Estimating the Chronic Toxicity of Effluents and Receiving Waters to Freshwater Organisms, $4^{\text {th }}$ Ed. Section 13 - Test Method Daphnid, Ceriodaphnia Dubia, Survival and Reproduction Test Method 1002.0. $141-196$.

USEPA. 2000. Wastewater Technology Fact Sheet, Dechlorination. URL: http://www.epa.gov/owmitnet/mtb/dechlorination.pdf Accessed on January 11th, 2008 .

USEPA. 1998. Sewer and Tank Sediment Flushing: Case Studies. Chapter 4. EPA\# EPA/600/R-98/157.

Utilities Kingston. 2004. Ravensview WPCP Secondary treatment and capacity upgrade Class EA update. Technical Memo \#6 - Disinfection Process. Prepared by J.L. Richards \& Associates Limited.

Wang, L.K., Hung, Y., and Shammas, $\mathbf{N}$ (Editors). 2006. Advanced Physicochemical Treatment Processes (Handbook of Environmental Engineering Volume 4). Humana Press, New Jersey, USA.

Weerasinghe, B.N., and Basu, O.D. 2008. Dechlorination Kinetics of Municipal Wastewater Effluent. Conference Proceedings of the $37^{\text {th }}$ Annual WEAO Technical Symposium and OPCEA Exhibition, Collingwood, Ontario.

Water Environment Federation (WEF) and American Society of Civil Engineers (ASCE). 1998. Design of Municipal Wastewater Treatment Plants - MOP 8, 4th Edition, VA, USA.

White, G.C. 1999. Handbook of Chlorination and Alternative Disinfectants. John Wiley and Sons, Inc., New York (4th ed).

Wiseman, K.C. 1997. Use of Ascorbic Acid to Remove Chloramine from Dialysate Water. American Nephrology Nurses' Association Journal, 24(1), 67-68. 
Worley, J.L. 2000. Evaluation of Dechlorinating Agents and Disposable Containers for Odor Testing of Drinking Water. Masters Thesis. Virginia Polytechnic Institute and State University.

Wu, Y., Lin, C., \& Yuan, L. 2007. Characteristics of six cladocerans in relation to ecotoxicity testing. Ecological Indicators. 7:768-775.

Yonkos, L.T., Fisher, D.J., Burton, D.T., Whitekettle, W.K., \& Petrille, J.C. 2001. Effectiveness of the sulfur (IV) compound, sodium bisulfite, in reducing chlorine, chlorine dioxide, and chlorite toxicity to Daphnia magna in well water and pond water. Environmental Toxicology and Chemistry, 20(3), 530-536.

Zumdahl, S.S. 1998. Chemical Principles, $3^{\text {rd }}$ Edition. Houghton Mifflin Company. Boston, USA. 


\section{Appendices \\ Appendix 1: NFPA Hazard Chart}

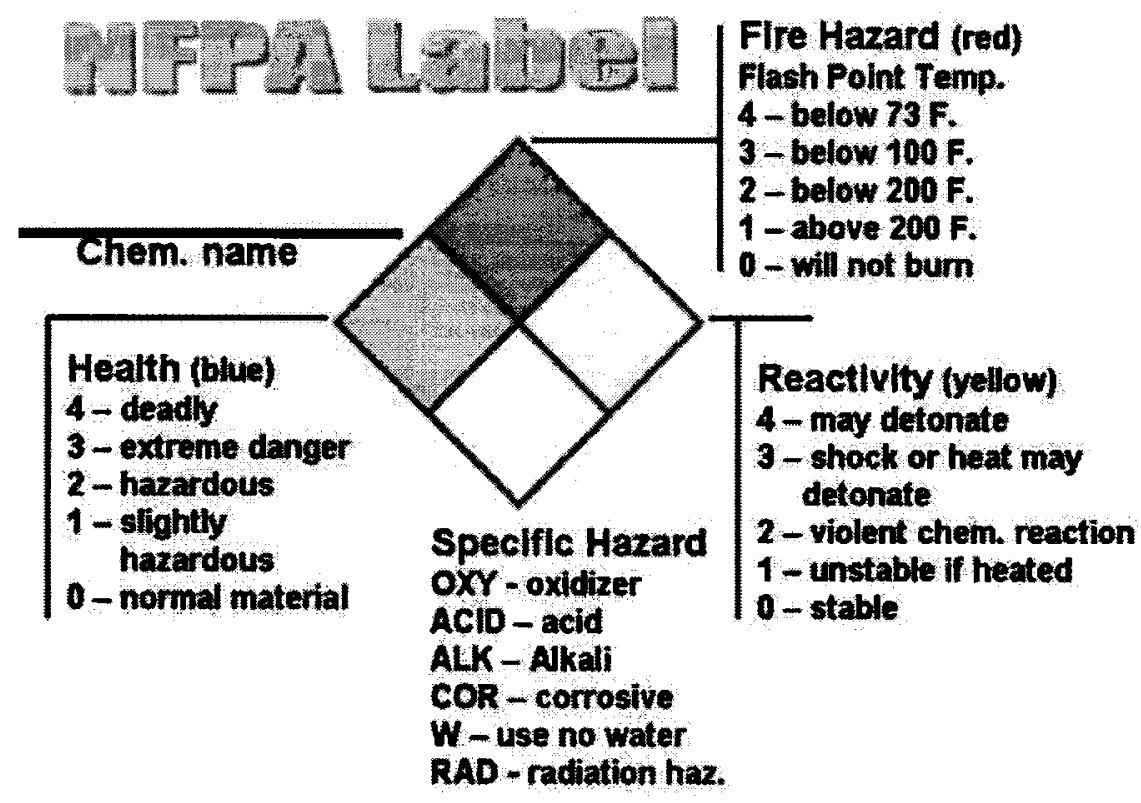

Figure A 1: NFPA Hazard rating chart.

Adapted from: http://www.nmsu.edu/ safety/images/signs/label_NFPA1.jpg 


\section{Appendix 2: Dechlorination Agent Dosage and Cost Calculations}

\section{Sodium Sulfite}

$$
\begin{aligned}
& \mathrm{Cl}_{2}+\mathrm{H}_{2} \mathrm{O} \rightarrow \mathrm{HOCl}+\mathrm{H}^{+}+\mathrm{Cl}^{-} \\
& \underset{\text { Sodium sulfite }}{\mathrm{Na}_{2} \mathrm{SO}_{3}}+\underset{\text { Hypochlorous acid }}{\mathrm{HOCl}} \rightarrow \underset{\text { Sodium sulfate }}{\mathrm{Na}_{2} \mathrm{SO}_{4}}+\underset{\text { Hydrochloric acid }}{\mathrm{HCl}}
\end{aligned}
$$

Stoich. dosage for $\mathrm{SS}=$

$\frac{126 \mathrm{mg} \mathrm{Na}_{2} \mathrm{SO}_{3}}{1 \mathrm{~mol} \mathrm{Na}_{2} \mathrm{SO}_{3}} \times \frac{1 \mathrm{~mol} \mathrm{Na}_{2} \mathrm{SO}_{3}}{1 \mathrm{~mol} \mathrm{HOCl}} \times \frac{1 \mathrm{~mol} \mathrm{HOCl}}{70.9 \mathrm{mgCl}_{2}}=1.78 \mathrm{mg} \mathrm{SS} / \mathrm{mg} \mathrm{Cl}_{2}$

Oxygen Scavenging: $\underset{\text { Sodium sulfite }}{2 \mathrm{Na}_{2} \mathrm{SO}_{3}}+\mathrm{O}_{2} \rightarrow \underset{\text { Sodium sulfate }}{2 \mathrm{Na}_{2} \mathrm{SO}_{4}}$

Oxygen $(\mathrm{mg})$ scavenged by $1 \mathrm{mg}$ of sodium sulfite $=\frac{\left(32 \mathrm{~g} / \mathrm{mol} \mathrm{O}_{2}\right)}{2\left(126 \mathrm{~g} / \mathrm{mol} \mathrm{Na}_{2} \mathrm{SO}_{4}\right)}=0.127$

Sample Calculation For SS :

Stoichiometric Dosage $=1.78 \mathrm{Kg} / \mathrm{Kg} \mathrm{Cl}_{2}$

Delivery Concentration $=96 \%$

Cost $/ \mathrm{Kg}$ of chemical $=\$ 1.22$

Cost $/ \mathrm{Kg}$ of $\operatorname{Re}$ sidual $=\frac{\$ 1.22}{\mathrm{Kg} \operatorname{Re} \text { sidual }} \times \frac{1.78 \mathrm{Kg}}{\mathrm{Kg} \mathrm{Cl}_{2}} \times \frac{100}{96}=\$ 2.26 / \mathrm{Kg}$ of $\operatorname{Re}$ sidual

\section{Sodium Bisulfite}

$$
\underset{\text { Sodium bisulfite }}{\mathrm{NaHSO}_{3}}+\underset{\text { Hypochlorous acid }}{\mathrm{HOCl}} \rightarrow \underset{\text { Sodium bisulfate }}{\mathrm{NaHSO}_{4}}+\underset{\text { Hydrochloric acid }}{\mathrm{HCl}}
$$

Stoich. dosage for SBS =

$\frac{104.1 \mathrm{mg} \mathrm{NaHSO}}{1 \mathrm{~mol} \mathrm{NaHSO}_{3}} \times \frac{1 \mathrm{~mol} \mathrm{NaHSO}_{3}}{1 \mathrm{~mol} \mathrm{HOCl}} \times \frac{1 \mathrm{~mol} \mathrm{HOCl}}{70.9 \mathrm{mg} \mathrm{Cl}}=1.47 \mathrm{mg} \mathrm{SS} / \mathrm{mg} \mathrm{Cl}_{2}$

Sample Calculation For SBS :

Stoichiometric Dosage $=1.47 \mathrm{Kg} / \mathrm{Kg} \mathrm{Cl}_{2}$

Delivery Concentration $=38 \%$

Cost $/$ Kg of Chemical $=\$ 0.45$

Cost $/ \mathrm{Kg}$ of $\operatorname{Re}$ sidual $=\frac{\$ 0.45}{\mathrm{Kg} \operatorname{Re} \text { sidual }} \times \frac{1.47 \mathrm{Kg}}{\mathrm{Kg} \mathrm{Cl}_{2}} \times \frac{100}{38}=\$ 1.74 / \mathrm{Kg}$ of $\operatorname{Re}$ sidual 


\section{Sodium Metabisulfite}

$$
\underset{\text { Sodium metabisulffite }}{\mathrm{Na}_{2} \mathrm{~S}_{2} \mathrm{O}_{5}}+2 \mathrm{Cl}_{2}+3 \mathrm{H}_{2} \mathrm{O} \rightarrow \underset{\text { Sodium bisulfite }}{2 \mathrm{NaHSO}_{4}}+\underset{\text { Hydrochloric acid }}{4 \mathrm{HCl}}
$$

Stoich. dosage for SMBS =

$\frac{190.1 \mathrm{mg} \mathrm{Na}_{2} \mathrm{~S}_{2} \mathrm{O}_{5}}{1 \mathrm{~mol} \mathrm{Na}_{2} \mathrm{~S}_{2} \mathrm{O}_{5}} \times \frac{1 \mathrm{~mol} \mathrm{Na}_{2} \mathrm{~S}_{2} \mathrm{O}_{5}}{2 \mathrm{~mol} \mathrm{Cl}_{2}} \times \frac{2 \mathrm{~mol} \mathrm{Cl}_{2}}{141.8 \mathrm{mg} \mathrm{Cl} l_{2}}=1.34 \mathrm{mg} \mathrm{SMBS} / \mathrm{mg} \mathrm{Cl}{ }_{2}$

Sample Calculation For SMBS :

Stoichiometric Dosage $=1.34 \mathrm{Kg} / \mathrm{Kg} \mathrm{Cl}$

Delivery Concentration $=97 \%$

Cost $/$ Kg of Chemical $=\$ 0.94$

Cost $/ \mathrm{Kg}$ of $\operatorname{Re}$ sidual $=\frac{\$ 0.94}{\mathrm{Kg} \operatorname{Re} \text { sidual }} \times \frac{1.34 \mathrm{Kg}}{\mathrm{KgCl}_{2}} \times \frac{100}{97}=\$ 1.30 / \mathrm{Kg}$ of $\mathrm{Re}$ sidual

\section{Sodium Thiosulfate}

$$
\underset{\text { Sodium thiosulfate }}{\mathrm{Na}_{2} \mathrm{~S}_{2} \mathrm{O}_{3}}+\mathrm{Cl}_{2}+5 \mathrm{H}_{2} \mathrm{O} \rightarrow \underset{\text { Sodium bisulfate }}{2 \mathrm{NaHSO}_{4}}+8 \mathrm{HCl}
$$

Stoich. dosage for STS =

$\frac{158.1 \mathrm{mg} \mathrm{Na}_{2} \mathrm{~S}_{2} \mathrm{O}_{3}}{1 \mathrm{~mol} \mathrm{Na}_{2} \mathrm{~S}_{2} \mathrm{O}_{3}} \times \frac{1 \mathrm{~mol} \mathrm{Na}_{2} \mathrm{~S}_{2} \mathrm{O}_{3}}{1 \mathrm{~mol} \mathrm{Cl}_{2}} \times \frac{1 \mathrm{~mol} \mathrm{Cl}_{2}}{70.9 \mathrm{mgCl}_{2}}=2.23 \mathrm{mg} \mathrm{SMBS} / \mathrm{mgCl} l_{2}$

Sample Calculation for STS@pH6.5 :

Stoichiometric Dosage $=2.23 \mathrm{Kg} / \mathrm{Kg} \mathrm{Cl}_{2}$

Delivery Concentration $=97 \%$

Cost $/$ Kg of Chemical $=\$ 1.70$

Cost $/ \mathrm{Kg}$ of $\operatorname{Re}$ sidual $=\frac{\$ 1.70}{\mathrm{Kg} \operatorname{Re} \text { sidual }} \times \frac{2.23 \mathrm{Kg}}{\mathrm{Kg} \mathrm{Cl}_{2}} \times \frac{100}{97}=\$ 3.90 / \mathrm{Kg}$ of $\mathrm{Re}$ sidual

\section{Calcium Thiosulfate}

$$
\underset{\text { Calcium thiosulfate }}{\mathrm{CaS}_{2} \mathrm{O}_{3}}+\underset{\text { Hypochlorus Acid }}{4 \mathrm{HOCl}}+\mathrm{H}_{2} \mathrm{O} \rightarrow \underset{\text { Calciumsulfate }}{\mathrm{CaSO}_{4}}+\underset{\text { Hydrochloric Acid }}{4 \mathrm{HCl}}+\underset{\text { Sulfuric Acid }}{\mathrm{H}_{2} \mathrm{SO}_{2}}
$$

Stoich. dosage for CTS =

$\frac{152.2 \mathrm{mg} \mathrm{CaS}_{2} \mathrm{O}_{3}}{1 \mathrm{~mol} \mathrm{CaS}_{2} \mathrm{O}_{3}} \times \frac{1 \mathrm{~mol} \mathrm{CaS}_{2} \mathrm{O}_{3}}{4 \mathrm{~mol} \mathrm{HOCl}} \times \frac{1 \mathrm{~mol} \mathrm{HOCl}}{70.9 \mathrm{mg} \mathrm{Cl}}=0.54 \mathrm{mg} \mathrm{CTS} / \mathrm{mg} \mathrm{Cl}_{2}$ 
Sample Calculation for CTS@pH11:

Stoichiometric Dosage $=0.45 \mathrm{Kg} / \mathrm{Kg} \mathrm{Cl}_{2}$

Delivery Concentration $=30 \%$

Cost $/ \mathrm{Kg}$ of Chemical $=\$ 1.95$

Cost $/ \mathrm{Kg}$ of $\operatorname{Re}$ sidual $=\frac{\$ 1.95}{\mathrm{Kg} \operatorname{Re} \text { sidual }} \times \frac{0.45 \mathrm{Kg}}{\mathrm{Kg} \mathrm{Cl}_{2}} \times \frac{100}{30}=\$ 2.93 / \mathrm{Kg}$ of $\operatorname{Re}$ sidual

\section{Ascorbic Acid}

$\mathrm{C}_{5} \mathrm{H}_{5} \mathrm{O}_{5} \mathrm{CH}_{2} \mathrm{OH} \mathrm{OH}+\underset{\text { Hypochloric Acid Acid }}{\mathrm{HOCl}} \rightarrow \underset{\text { Dehydroascorbic Acid }}{\mathrm{C}_{5} \mathrm{H}_{3} \mathrm{O}_{5} \mathrm{CH}_{2} \mathrm{OH}}+\underset{\text { Hydrochloric Acid }}{\mathrm{HCl}}+\mathrm{H}_{2} \mathrm{O}$

Stoich. dosage for AA =

$\frac{176.1 \mathrm{mg} \mathrm{C}_{6} \mathrm{H}_{8} \mathrm{O}_{6}}{1 \mathrm{~mol} \mathrm{C}_{6} \mathrm{H}_{8} \mathrm{O}_{6}} \times \frac{1 \mathrm{~mol} \mathrm{C}_{6} \mathrm{H}_{8} \mathrm{O}_{6}}{1 \mathrm{~mol} \mathrm{HOCl}} \times \frac{1 \mathrm{~mol} \mathrm{HOCl}}{70.9 \mathrm{mgCl}}=2.48 \mathrm{mg} \mathrm{AA} / \mathrm{mg} \mathrm{Cl}_{2}$

Sample Calculation for $A A$ :

Stoichiometric Dosage $=2.5 \mathrm{Kg} / \mathrm{Kg} \mathrm{Cl}_{2}$

Delivery Concentration $=99 \%$

Cost $/$ Kg of Chemical $=\$ 9.95$

Cost $/ \mathrm{Kg}$ of $\operatorname{Re}$ sidual $=\frac{\$ 9.95}{\mathrm{Kg} \operatorname{Re} \text { sidual }} \times \frac{2.5 \mathrm{Kg}}{\mathrm{Kg} \mathrm{Cl}_{2}} \times \frac{100}{99}=\$ 25.13 / \mathrm{Kg}$ of $\operatorname{Re}$ sidual

\section{Hydrogen Peroxide}

$$
\mathrm{Cl}_{2}+\mathrm{H}_{2} \mathrm{O}_{2} \rightarrow 2 \mathrm{HCl}+\mathrm{O}_{2}
$$

Stoich. dosage for $\mathrm{HP}=$

$$
\frac{34 \mathrm{mg} \mathrm{H}_{2} \mathrm{O}_{2}}{1 \mathrm{~mol} \mathrm{H}_{2} \mathrm{O}_{2}} \times \frac{1 \mathrm{~mol} \mathrm{H}_{2} \mathrm{O}_{2}}{1 \mathrm{~mol} \mathrm{HOCl}^{2}} \times \frac{1 \mathrm{~mol} \mathrm{HOCl}}{70.9 \mathrm{mgCl}_{2}}=0.48 \mathrm{mg} \mathrm{HP} / \mathrm{mg} \mathrm{Cl}_{2}
$$

Sample Calculation for HP :

Stoichiometric Dosage $=0.48 \mathrm{Kg} / \mathrm{Kg} \mathrm{Cl}_{2}$

Delivery Concentration $=35 \%$

Cost $/ \mathrm{Kg}$ of Chemical $=\$ 1.37$

Cost $/ \mathrm{Kg}$ of $\operatorname{Re}$ sidual $=\frac{\$ 1.37}{\mathrm{Kg} \operatorname{Re} \text { sidual }} \times \frac{0.48 \mathrm{Kg}}{\mathrm{Kg} \mathrm{Cl}_{2}} \times \frac{100}{35}=\$ 1.88 / \mathrm{Kg}$ of $\operatorname{Re}$ sidual 


\section{Appendix 3: Plots for Reaction Order Determination}
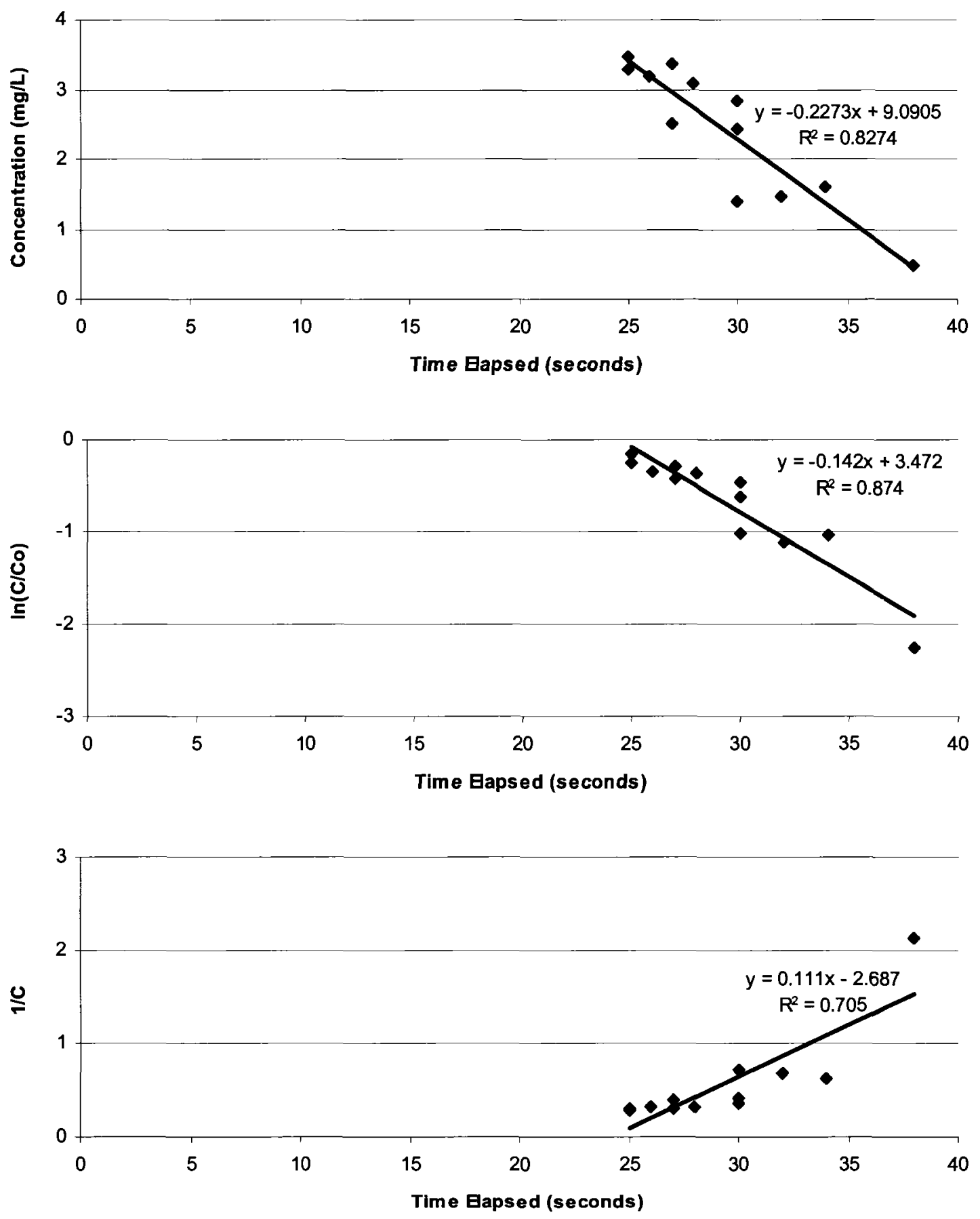

Figure A 2: Test undertaken to determine the order of the reaction of sodium sulfite with respect to the total chlorine concentration in solution. Dosages of SS in excess of $10 \mathrm{x}$ stoichiometric dosage at continuous low intensity mixing and $\mathrm{pH} 6.5-8.5$ data was used to determine the pseudo-order of the reactions. 

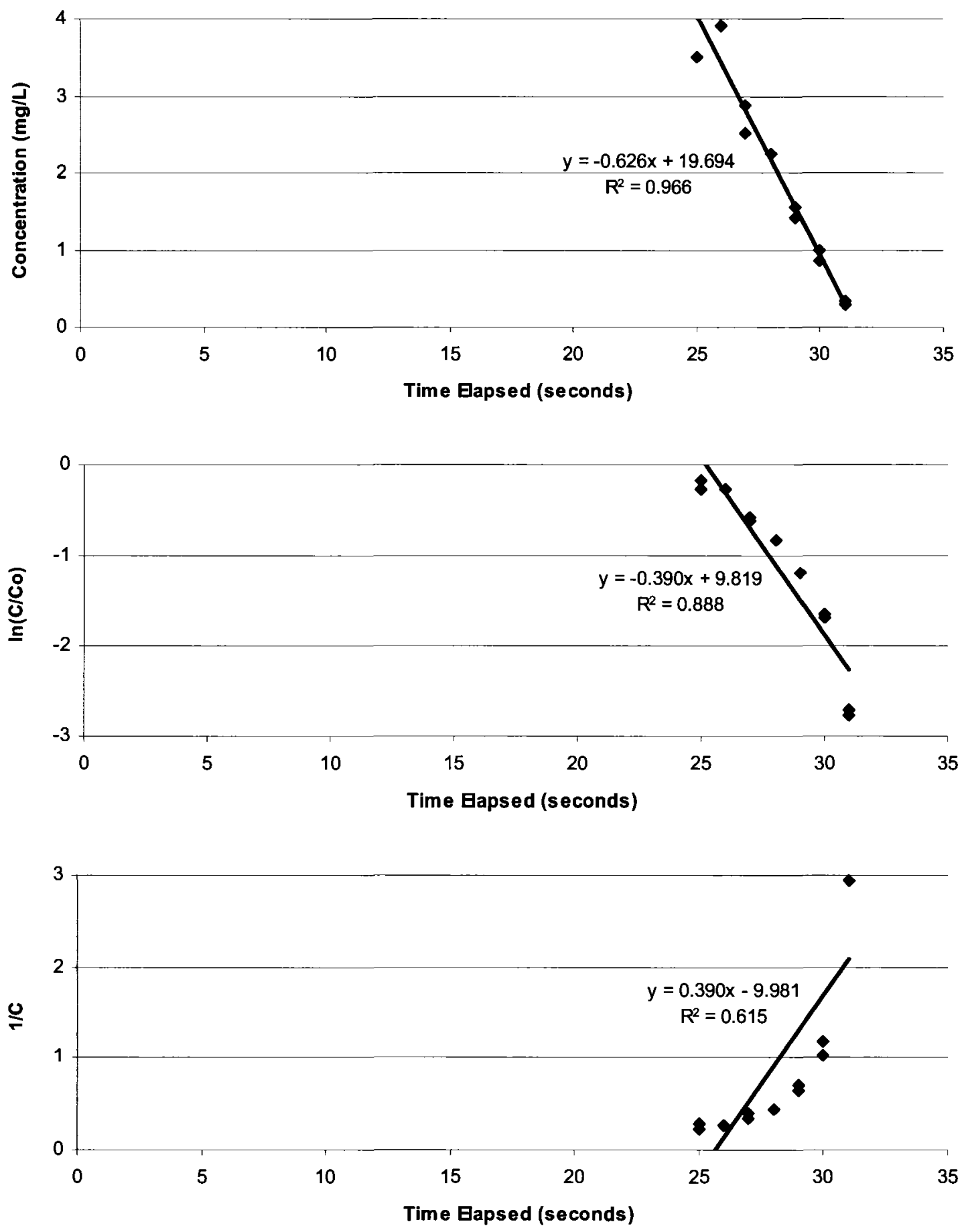

Figure A 3: Test undertaken to determine the order of the reaction of sodium bisulfite with respect to the total chlorine concentration in solution. Dosages of SBS in excess of $10 \mathrm{x}$ stoichiometric dosage at continuous low intensity mixing and $\mathrm{pH} 6.5-8.5$ data was used to determine the pseudo-order of the reactions. 

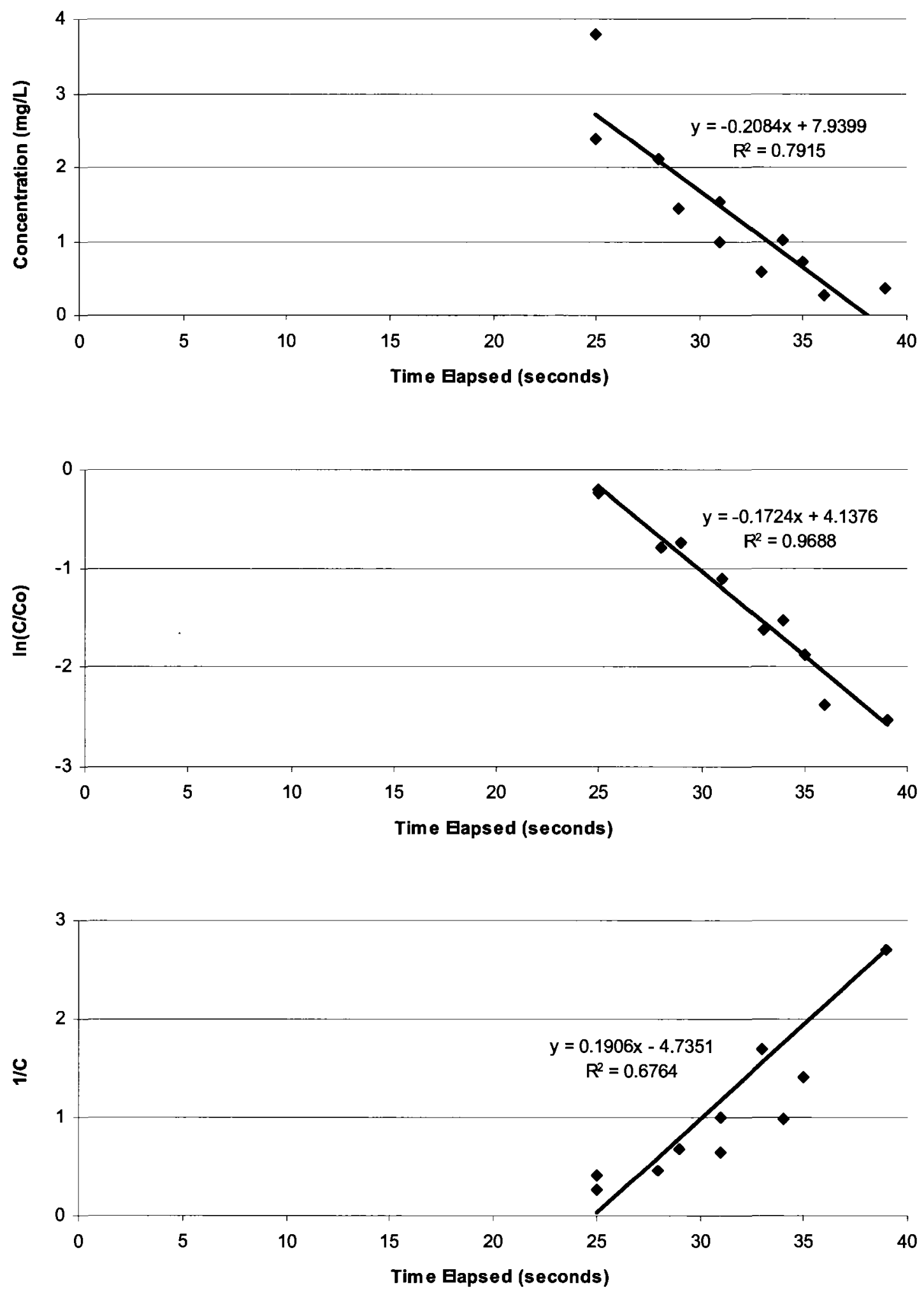

Figure A 4: Test undertaken to determine the order of the reaction of sodium metabisulfite with respect to the total chlorine concentration. Dosages of SMBS in excess of $10 \mathrm{x}$ stoichiometric dosage at continuous low intensity mixing and $\mathrm{pH} 6.5-8.5$ data was used to determine the pseudo-order of the reactions. 

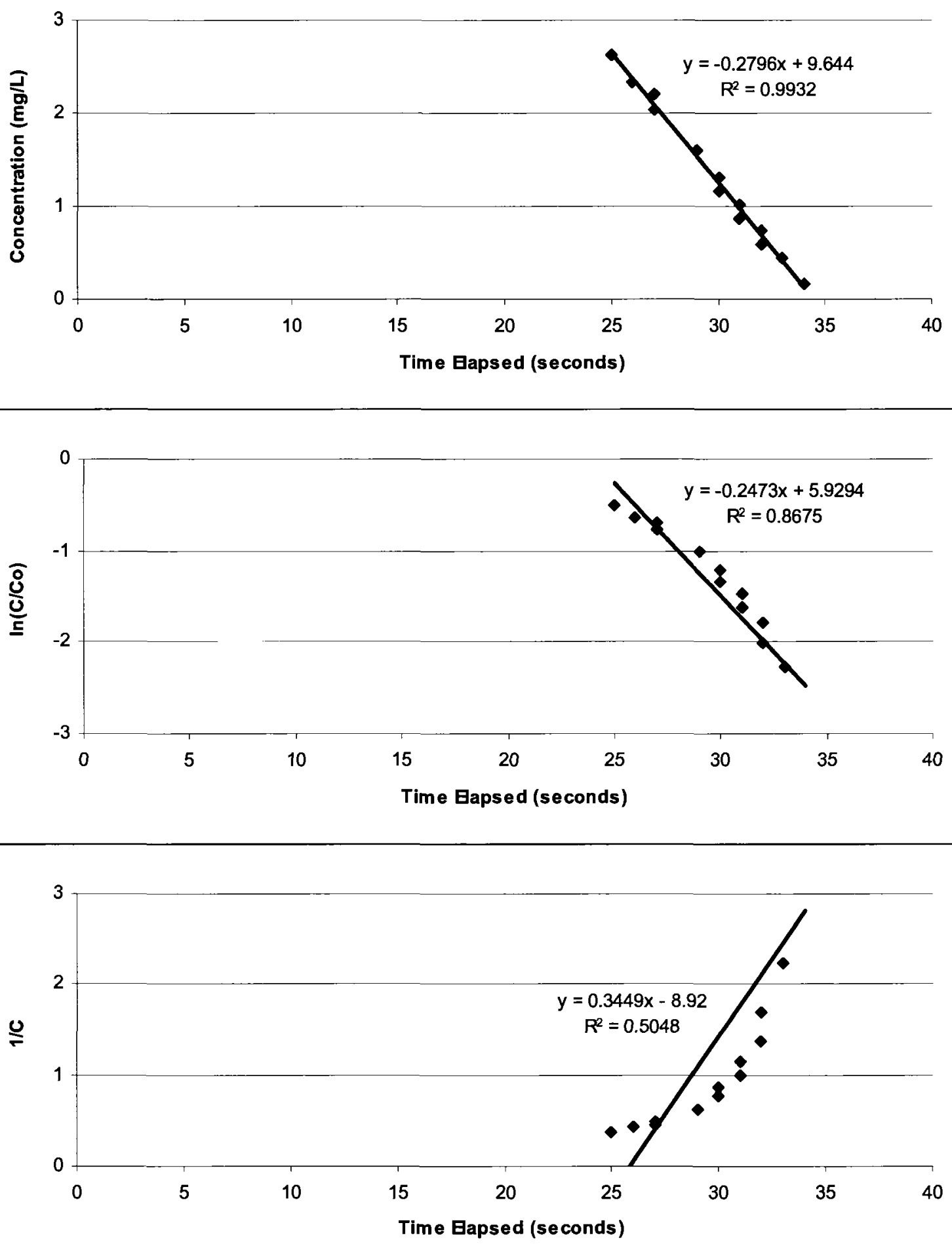

Figure A 5: Test undertaken to determine the order of the reaction of calcium thiosulfate with respect to the total and free chlorine concentration in solution. Dosages of CTS in excess of $10 \mathrm{x}$ stoichiometric dosage at continuous low intensity mixing and $\mathrm{pH} 6.5-8.5$ data was used to determine the pseudo-order of the reactions. 

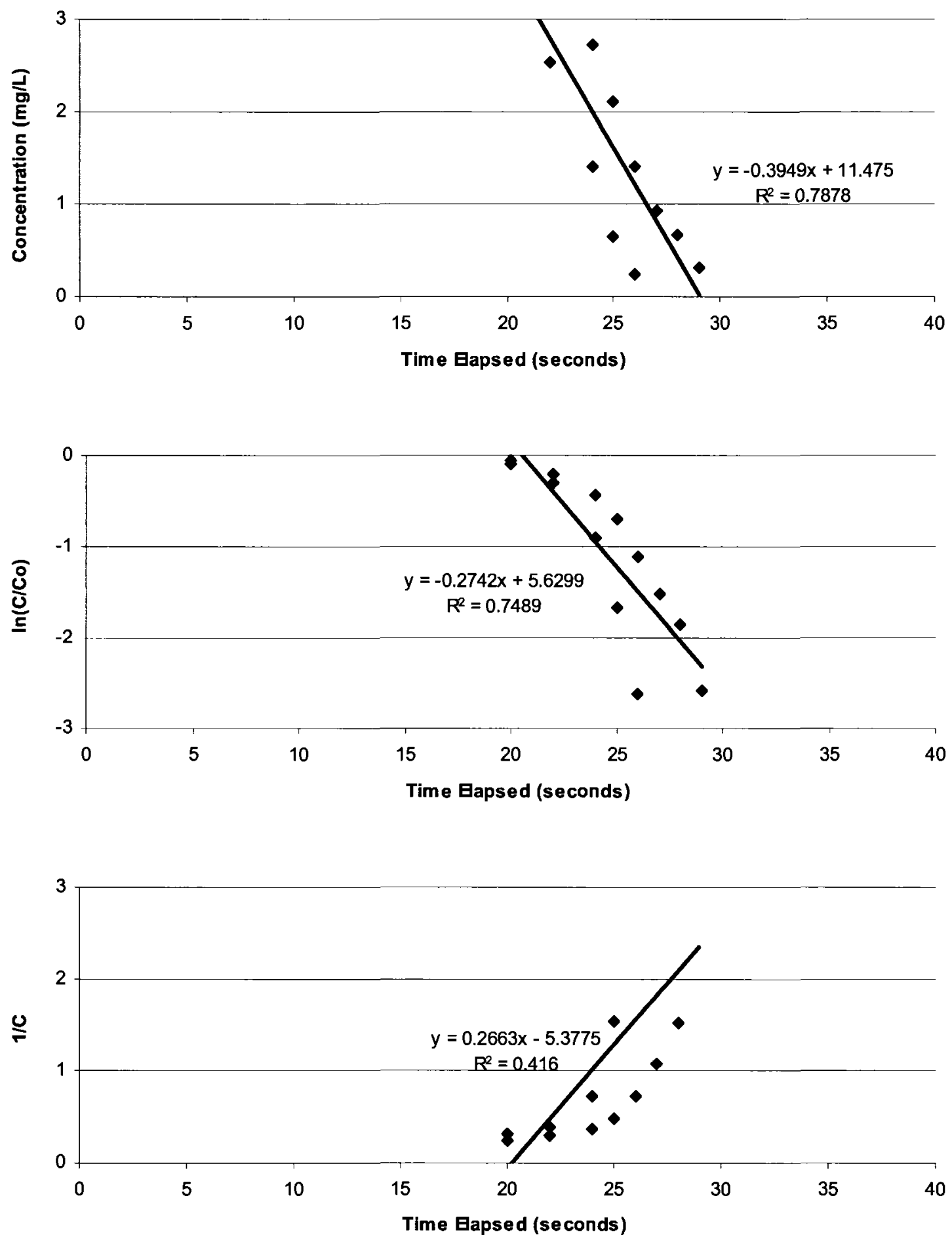

Figure A 6: Test undertaken to determine the order of the reaction of ascorbic acid with respect to the total and free chlorine concentration in solution. Dosages of AA in excess of $10 \mathrm{x}$ stoichiometric dosage at continuous low intensity mixing and $\mathrm{pH} 6.5-8.5$ data was used to determine the pseudo-order of the reactions. 

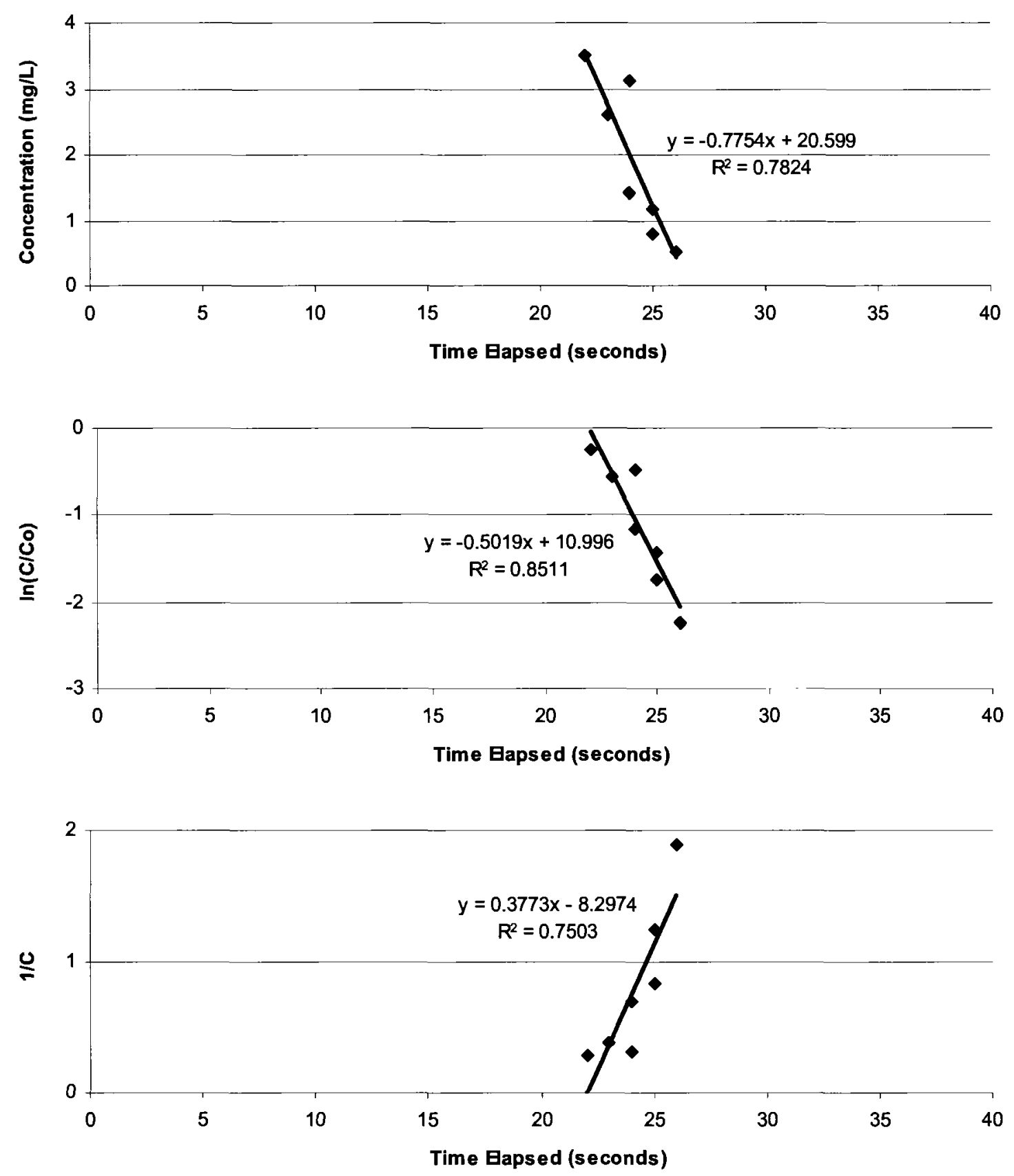

Figure A 7: Test undertaken to determine the order of the reaction of hydrogen peroxide with respect to the total chlorine concentration in solution. Dosages of HP in excess of $10 \mathrm{x}$ stoichiometric dosage at continuous low intensity mixing and $\mathrm{pH} 6.5-8.5$ data was used to determine the pseudo-order of the reactions. 


\section{Appendix 4: Plots for LC50 Determination}

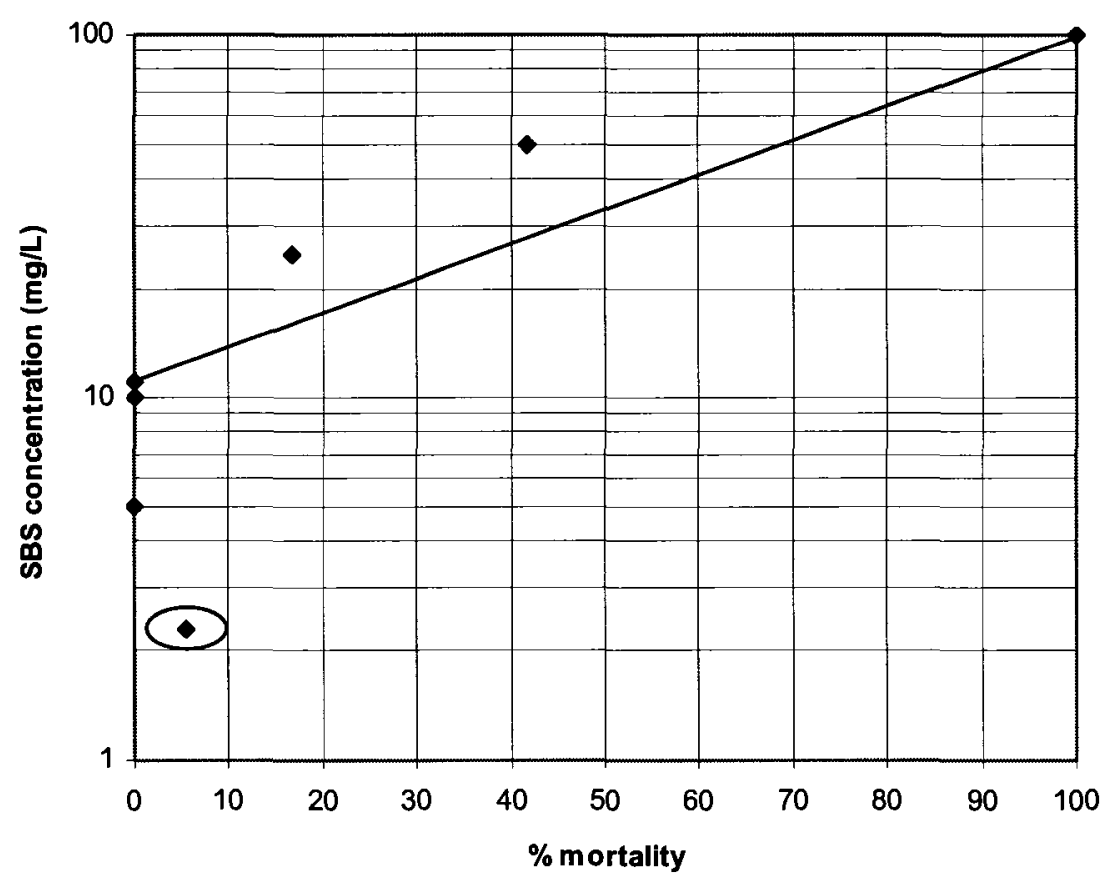

Figure A 8: Plot of percentage mortality at different dosages of Sodium Bisulfite (SBS) used to determine the LC50 value. One outlier was identified in the data (circled), which was omitted in the data analysis.

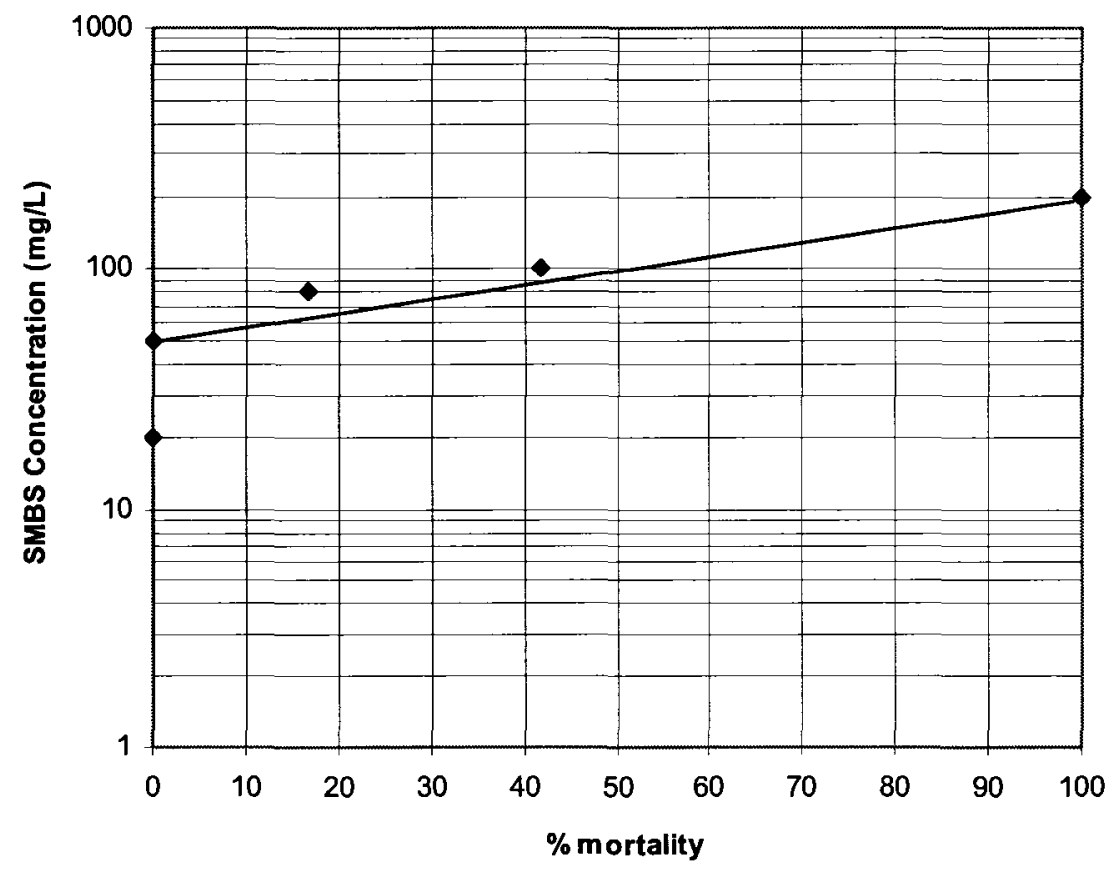

Figure A 9: Plot of percentage mortality at different dosages of Sodium Metabisulfite (SMBS) used to determine the LC50 value. 


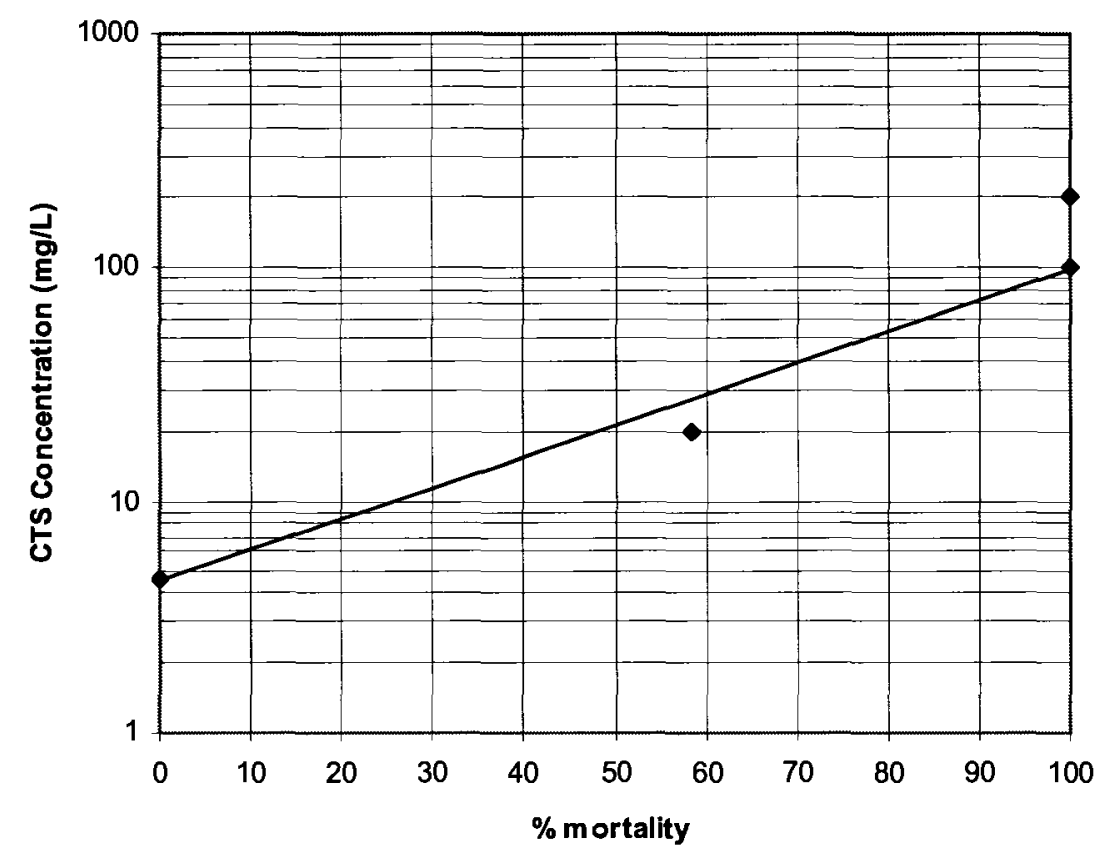

Figure A 10: Plot of percentage mortality at different dosages of Calcium Thiosulfate (CTS) used to determine the LC50 value.

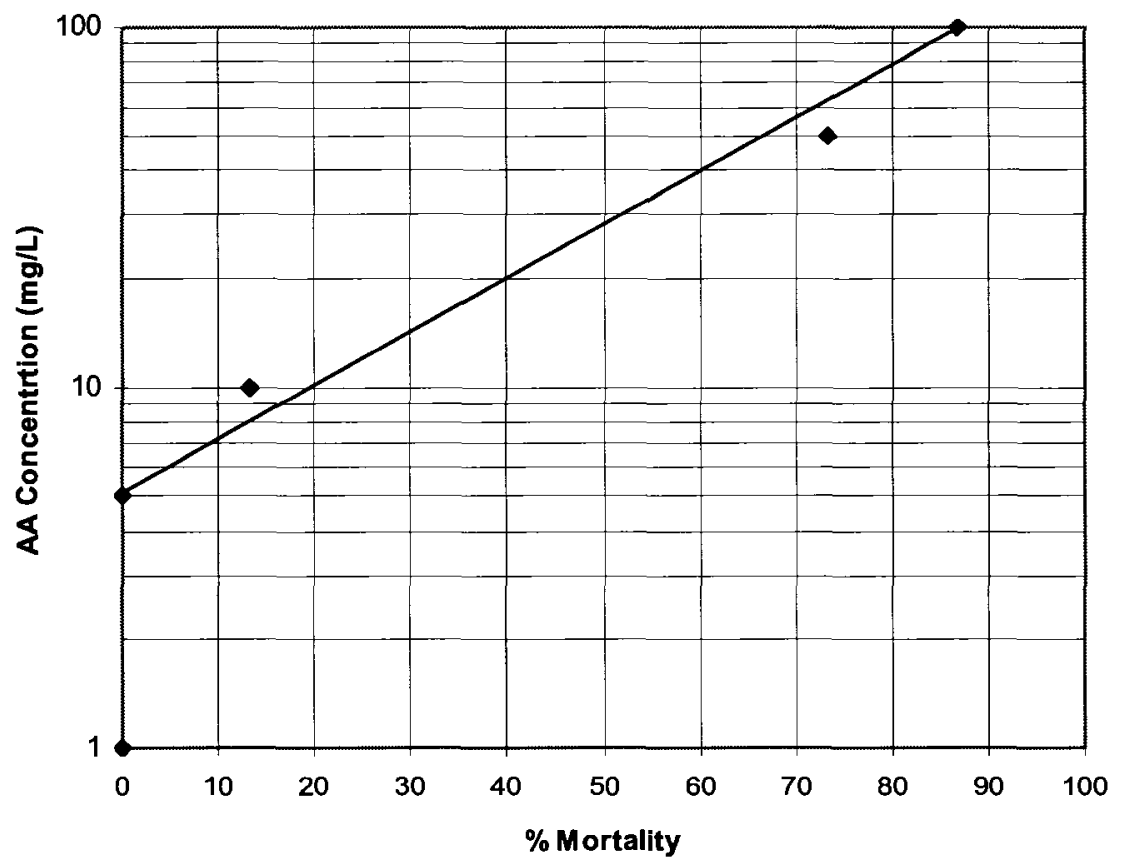

Figure A 11: Plot of percentage mortality at different dosages of Ascorbic Acid (AA) used to determine the LC50 value. 


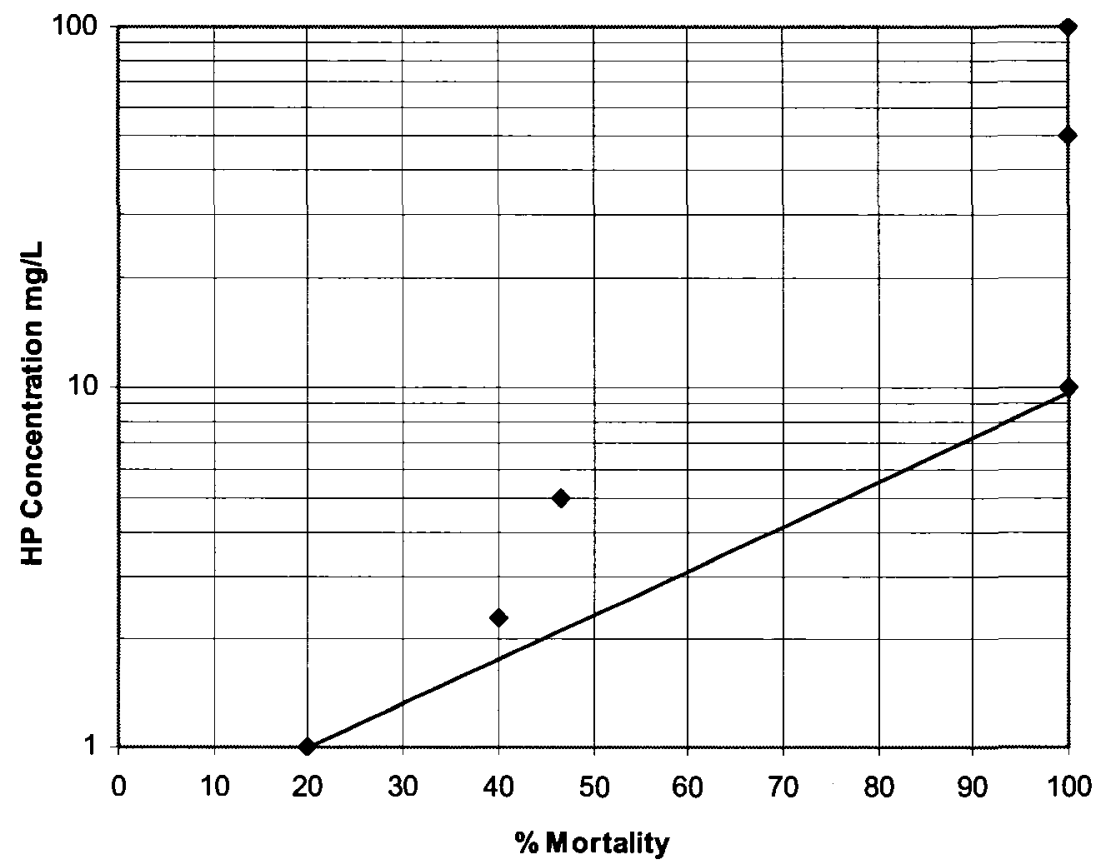

Figure A 12: Plot of percentage mortality at different dosages of Hydrogen Peroxide (HP) used to determine the LC50 value. 